\title{
ESTABILIDADE E ADAPTABILIDADE FENOTÍPICA ATRAVÉS DA REAMOSTRAGEM "BOOTSTRAP" NO MODELO AMMI
}

\section{OSMIR JOSÉ LAVORANTI}

Tese apresentada à Escola Superior de Agricultura "Luiz de Queiroz", Universidade de São Paulo, para obtenção do título de Doutor em Agronomia, Área de Concentração: Estatística e Experimentação Agronômica.

\section{PIRACICABA}

Estado de São Paulo - Brasil

Julho - 2003 


\section{ESTABILIDADE E ADAPTABILIDADE FENOTÍPICA ATRAVÉS DA REAMOSTRAGEM "BOOTSTRAP" NO MODELO AMMI}

\section{OSMIR JOSÉ LAVORANTI}

Bacharel em Estatística

Orientador: Prof. Dr. CARLOS TADEU DOS SANTOS DIAS

Tese apresentada à Escola Superior de Agricultura "Luiz de Queiroz", Universidade de São Paulo, para obtenção do título de Doutor em Agronomia, Área de Concentração: Estatística e Experimentação Agronômica.

PIRACICABA

Estado de São Paulo - Brasil

Julho - 2003 
Dados Internacionais de Catalogação na Publicação (CIP)

DIVISÃO DE BIBLIOTECA E DOCUMENTAÇÃO - ESALQ/USP

\section{Lavora nti, Osmir J osé}

Esta bilida de e a daptabilidade fenotípica a través da reamostragem "bootstrap" no modelo AMMI / OsmirJ osé Lavoranti. - - Piracicaba, 2003. $166 \mathrm{p}$.

Tese (doutorado) - Escola Superior de Agricultura Luiz de Queiroz, 2003. Bibliografia.

1. Boostrap jacknife re-amostra gem 2. Estabilidade fenotípica 3.

Eucalipto 4. Interação genótipo-ambiente 5. Melhoramento genético vegetal I. Título

CDD 634.9734

"Permitida a cópia total ou parcial deste documento, desde que citada a fonte - O autor" 


\title{
DEDICATÓRIA
}

\author{
A \\ DEUS \\ e a MÃE RAINHA, \\ razão da fé à vida eterna.
}

Aos meus pais,

Orides José Lavoranti e

Helena Felipe Lavoranti,

pela luta incansável na formação de seus filhos.

À minha esposa Silvana,

por se manter sempre compreensiva, paciente e, principalmente, por

ser essa mulher maravilhosa e dedicada. Com todo amor e gratidão.

Às minhas filhas,

Maria Isabel e

Natália,

por proporcionarem-me a felicidade diária. 


\section{AGRADECIMENTOS}

À Embrapa Florestas, o afastamento concedido.

À Escola Superior de Agricultura "Luiz de Queiroz" (ESALQ/USP), a excelente estrutura física e humana, perfeita para o desenvolvimento acadêmico.

Ao professor Dr. Carlos Tadeu dos Santos Dias, a convivência, a amizade e a confiança, além do excelente exemplo de vida, responsável, dedicado, honesto e seguro, e, finalmente, a orientação, calma e com firmeza de propósito, transferindo tranquilidade, aos seus orientados, nas horas mais difíceis.

Aos pesquisadores Dr. Carlos Alberto Ferreira, ex-chefe da Embrapa Florestas, e Dr. Helton Damin da Silva, ex-chefe adjunto de Pesquisa e Desenvolvimento, da Embrapa Florestas, a confiança em seder-me o material para o desenvolvimento deste trabalho.

Aos pesquisadores Dr. Vitor Afonso Hoeflich, chefe da Embrapa Florestas, e Dr. Moacir Sales Medrado, chefe adjunto de Pesquisa e Desenvolvimento, da Embrapa Florestas, a credibilidade depositada.

Ao pesquisador Dr. Edilson Batista de Oliveira, o aconselhamento e prontidão, nos atendimentos das normas internas da Embrapa.

Ao professor Dr. Antonio Galvez, a orientação durante o período de mestrado no Instituto de Matemática e Estatística de São Paulo (IME/USP).

À coordenadora do Programa de Pós-Graduação em Estatística e Experimentação Agronômica prof ${ }^{\mathrm{a}}$ Dr ${ }^{\mathrm{a}}$ Clarice Garcia Borges Demétrio, a presteza e dedicação as solicitações encaminhadas.

Aos professores Dr. Décio Barbin e Dr $\stackrel{a}{a}$ Roseli Aparecida Leandro o atendimento e confiança. 
À professora Dra ${ }^{\mathrm{a}}$ Maria Cristina Stolf Nogueira, ex-coordenadora do Programa de Pós-Graduação em Estatística e Experimentação Agronômica, o atendimento e amizade.

Aos professores do Departamento de ciências Exatas da ESALQ/USP, Dr. Antônio Francisco Iemma, Dr. César Gonçalves de Lima (FZEA/USP), Dr. José Eduardo Corrente, Dr. Silvio Sandoval Zocchi e Dra $\underline{a}$ Sônia Maria de Stefano Piedade, a amizade e contribuição à minha formação.

Aos professores do Departamento de Genética da ESALQ/USP, Dr. Antonio Augusto Franco Garcia e Dr. Roland Vencovsky, os valiosos comentários científicos, que muito contribuiram para o desenvolvimento deste trabalho.

Ao professor Dr. Wojtek J. Krzanowski, School of Mathematical Sciences - University of Exeter/UK, as valiosas sugestões.

Aos colegas de estudo, Antonio Carlos, André, Andréia, Cristiano, Denise, Ezequiel, Flávia, Glaucy, Genevile, Janaína, João Maurício, Juliana, Mariana, Maria Cristina, Moita, Ramiro, Renato, Suely, Telde, e, em especial, aos amigos, Adriano Ferreti Borgatto e Silvano Cesar da Costa, o apoio.

À Rosa Maria Alves, a revisão deste texto. À Luciane Brajão e Solange de Assis Paes Sabadin, a compreensão e auxílio permanentes. Ao técnico em informática, Jorge Alexandre Wiendl, o apoio.

Às minhas irmãs Neide e Magali, e ao meu irmão André, o carinho e amor compartilhados. Aos meus cunhados Inácio e Milton Sérgio, a amizade.

Aos meus sogros José Dirceu Thomazine e Elza Bendassoli Thomazine, e meus cunhados José Sidynei Thomazine e Marta Regina Thomazine, a acolhida e espaço cedido.

Um agradecimento especial eu reservo aos meus grandes amigos Waldemar Stival, sua esposa, Carmen Lúcia Cassilha Stival, e suas filhas Carolina e Mariana, a força, estímulo, disponibilidade e convivência.

Meu muito obrigado a todos que, de forma direta ou indireta, contribuíram para a realização deste trabalho. Que a paz de Cristo esteja com todos. 


\section{SUMÁRIO}

Página

LISTA DE FIGURAS . . . . . . . . . . . . . . . . . . viii

LISTA DE TABELAS . . . . . . . . . . . . . . . . . . xi

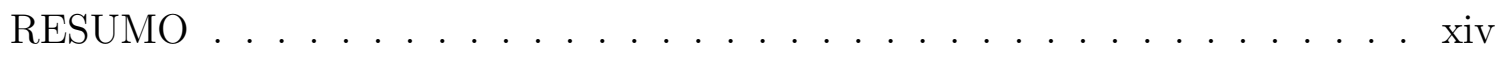

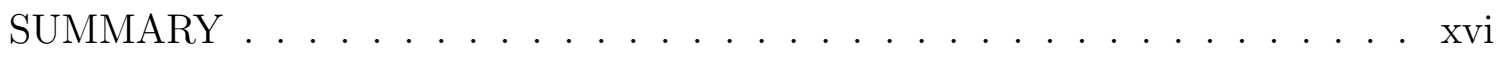

1 INTRODUÇÃOO . . . . . . . . . . . . . . . . . . . . . . . 1

2 REVISÃO DE LITERATURA . . . . . . . . . . . . . . . . . . . . 4

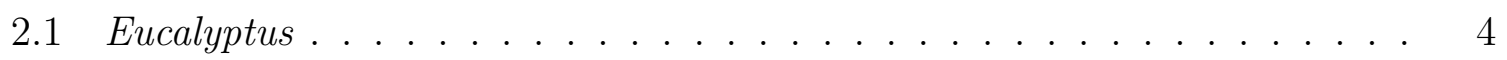

2.2 Eucalipto no Brasil . . . . . . . . . . . . . . . . . . 5

2.3 Melhoramento florestal . . . . . . . . . . . . . . . . . . . . 8

2.4 Interação genótipo $\times$ ambiente $\ldots \ldots \ldots \ldots$

2.4.1 Estratificação de ambientes . . . . . . . . . . . . . . . . 18

2.5 Estabilidade e adaptabilidade fenotípica . . . . . . . . . . . . . . 24

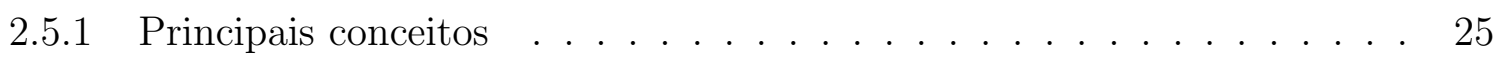

2.5.2 Metodologias univariadas ...................... 28

2.5.3 Metodologias multivariadas . . . . . . . . . . . . . . . 53

2.5.4 Comparações de metodologias . . . . . . . . . . . . . . 63

2.5.5 Reamostragem jackknife e bootstrap . . . . . . . . . . . . . . 64

3 MATERIAL E MÉTODOS . . . . . . . . . . . . . . . . . 75

3.1 Estabilidade e adaptabilidade fenotípica via método AMMI . . . . . . . . 81

3.2 Estabilidade e adaptabilidade fenotípica via método "bootstrap" AMMI 83

4 RESUltados E DiSCUSSÃO . . . . . . . . . . . . . . . . . 90 
4.1 Análises AMMI . . . . . . . . . . . . . . . . . . . . . . . . . . . . . . . . . . . 99

4.1.1 Procedência, 12 km S. of Ravenshoe-Mt Pandanus-QLD . . . . . . . . 99

4.1.2 Procedência, Baldy State Forest 194-Atherton-QLD. . . . . . . . . . . 106

4.1.3 Procedência, Bellthorpe St. Forest-QLD. . . . . . . . . . . . . . . . 111

4.1.4 Considerações sobre as análises AMMI . . . . . . . . . . . . . 116

4.2 Análises "bootstrap" AMMI . . . . . . . . . . . . . . . . . . . . . . . 118

4.2.1 Procedência, 12 km S. of Ravenshoe-Mt Pandanus-QLD ...... . 119

4.2.2 Procedência, Baldy State Forest 194-Atherton-QLD . . . . . . . . . . . 127

4.2.3 Procedência, Bellthorpe St. Forest-QLD. . . . . . . . . . . . . . . . 134

4.2.4 Considerações sobre as análises "bootstrap" AMMI . . . . . . . . . . . 141

5 CONCLUSÕES . . . . . . . . . . . . . . . . . . . . . 149

REFERÊNCIAS BIBLIOGRÁFICAS . . . . . . . . . . . . . 150 


\section{LISTA DE FIGURAS}

Página

1 Padrões de respostas convexo e côncavo dos genótipos $Y(\mu)$ às variações na qualidade ambiental $\mu \ldots \ldots$. . . . . . . . . . . . . . . 47

2 Diagrama da distribuição "bootstrap" da estatística $T_{n}(\mathbf{x}, F)$. . . . . . 71

3 Regiões de confiança de 90\% (linha cheia) e de 99\% (linha pontilhada) segundo os escores de genótipos (acima) e de ambientes (abaixo) sobre o modelo $\mathrm{AMMI}_{2}$, para dados de altura, em metros, de E. grandis aos 5 anos. Procedência, 12 km S. of Ravenshoe-Mt Pandanus-QLD (14.420) 102

4 Intervalos de confiança de 90\% (linha cheia) e de 99\% (linha pontilhada) segundo os escores de genótipos (acima) e de ambientes (abaixo) sobre o modelo $\mathrm{AMMI}_{1}$, para dados de altura, em metros, de E. grandis aos 5 anos. Procedência, Baldy State Forest 194-Atherton-QLD (14.423) . . 108

5 Intervalos de confiança de 90\% (linha cheia) e de 99\% (linha pontilhada) segundo os escores de genótipos (acima) e de ambientes (abaixo) sobre o modelo $\mathrm{AMMI}_{1}$, para dados de altura, em metros, de E. grandis aos 5 anos. Procedência, Bellthorpe St. Forest-QLD (14.431) . . . . . . . . . . 113

6 Regiões de confiança de $99 \%$ para os escores de genótipos, para dados de altura, em metros, de E. grandis aos 5 anos. Procedência, $12 \mathrm{~km} \mathrm{S.} \mathrm{of}$ Ravenshoe-Mt Pandanus-QLD (14.420) . . . . . . . . . . . . . . . . . . 122

7 Regiões de confiança de $99 \%$ para os escores de ambientes, para dados de altura, em metros, de E. grandis aos 5 anos. Procedência, $12 \mathrm{~km} \mathrm{S.} \mathrm{of}$ Ravenshoe-Mt Pandanus-QLD (14.420) . . . . . . . . . . . . . . 123 
8 Regiões de confiança de $99 \%$ para os escores de genótipos, para dados de altura, em metros, de E. grandis aos 5 anos. Procedência, Baldy State Forest 194-Atherton-QLD (14.423) ． . . . . . . . . . . . . . 130

9 Regiões de confiança de $99 \%$ para os escores de ambientes, para dados de altura, em metros, de E. grandis aos 5 anos. Procedência, Baldy State Forest 194-Atherton-QLD (14.423) . . . . . . . . . . . . . . . 131

10 Biplot $\mathrm{AMMI}_{2}$, para genótipos e ambientes, dos dados de altura, em metros, de E. grandis aos 5 anos. Procedência, Baldy State Forest 194Atherton-QLD (14.423) f . . . . . . . . . . . . . . . . 131

11 Regiões de confiança de $99 \%$ para os escores de genótipos, para dados de altura, em metros, de E. grandis aos 5 anos. Procedência, Bellthorpe St. Forest-QLD $(14.431) \ldots \ldots \ldots$

12 Regiões de confiança de $99 \%$ para os escores de ambientes, para dados de altura, em metros, de E. grandis aos 5 anos. Procedência, Bellthorpe St. Forest-QLD (14.431) . . . . . . . . . . . . . . . . . . . 139

13 Biplot $\mathrm{AMMI}_{2}$, para genótipos e ambientes, dos dados de altura, em metros, de E. grandis aos 5 anos. Procedência, Bellthorpe St. ForestQLD (14.431) . . . . . . . . . . . . . . . . . 139

14 Gráficos de dispersão dos escores "bootstrap" de genótipos, para dados de altura, em metros, de E. grandis aos 5 anos. Procedência, $12 \mathrm{~km} \mathrm{S.} \mathrm{of}$ Ravenshoe-Mt Pandanus-QLD (14.420) . . . . . . . . . . . . . . . . . . . 143

15 Gráficos de dispersão dos escores "bootstrap" de genótipos, para dados de altura, em metros, de E. grandis aos 5 anos. Procedência, Baldy State Forest 194-Atherton-QLD (14.423) . . . . . . . . . . . . . . . 144

16 Gráficos de dispersão dos escores "bootstrap" de genótipos, para dados de altura, em metros, de E. grandis aos 5 anos. Procedência, Bellthorpe St. Forest-QLD (14.431) . . . . . . . . . . . . . . . . . . . 145 
17 Gráficos de dispersão dos escores "bootstrap" de ambientes, para dados de altura, em metros, de E. grandis aos 5 anos. Procedência, $12 \mathrm{~km} \mathrm{S.} \mathrm{of}$ Ravenshoe-Mt Pandanus-QLD (14.420) . . . . . . . . . . . . . . . . . 146

18 Gráficos de dispersão dos escores "bootstrap" de ambientes, para dados de altura, em metros, de E. grandis aos 5 anos. Procedência, Baldy State Forest 194-Atherton-QLD (14.423) . . . . . . . . . . . . . . . . . 146

19 Gráficos de dispersão dos escores "bootstrap" de ambientes, para dados de altura, em metros, de E. grandis aos 5 anos. Procedência, Bellthorpe St. Forest-QLD (14.431) . . . . . . . . . . . . . . . 147 


\section{LISTA DE TABELAS}

Página

1 Disposição dos dados em linhas (progênies) e colunas (ambientes) . . . . 10

2 Estrutura da análise de variância conjunta, envolvendo os diferentes

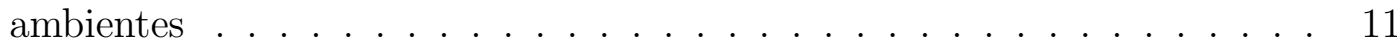

3 Estimativas das somas de quadrados da interação entre genótipos e pares de ambientes . . . . . . . . . . . . . . . . . . . . 19

4 Categorias de sensibilidade de respostas, para classificação de genótipos, segundo Verma et al. (1978) . . . . . . . . . . . . . . . . . . . 38

5 Critério de enquadramento dos genótipos e significado prático, conforme Toler $(1990) \ldots \ldots \ldots \ldots$. . . . . . . . . . . . . . . 50

6 Localização das procedências de Eucalyptus grandis coletadas na Austrália 75

7 Localização dos testes de procedências e progênies de Eucalyptus grandis implantados no Brasil . . . . . . . . . . . . . . . . . . 76

8 Esquema da análise de variânia para cada local . . . . . . . . . . . . . 77

9 Condições climáticas das regiões experimentais . . . . . . . . . . . . . 78

10 Condições ambientais dos locais de ensaios, preparos e adubações dos solos, pelas empresas . . . . . . . . . . . . . . . . . . 79

11 Análise completa de variância, a partir de médias, usando os procedimentos de Gollob (1968) e Cornelius et al.(1992) . . . . . . . . . . . . . . . . 80

12 Médias de alturas, em metros, das progênies (Prog.) de E. grandis aos 5 anos. Procedência, 12 km S. of Ravenshoe-Mt Pandanus-QLD (14.420) 91

13 Médias de alturas, em metros, das progênies (Prog.) de E. grandis aos 5 anos. Procedência, Baldy State Forest 194-Atherton-QLD (14.423) . . 92 
14 Médias de alturas, em metros, das progênies (Prog.) de E. grandis aos 5 anos. Procedência, Bellthorpe St. Forest-QLD (14.431) . . . . . . . . . . 93

15 Autovalor $\left(\lambda_{k}^{2}\right)$ e porcentagem da soma de quadrados acumulada (PA) por eixo singular . Análise conjunta da variância, incluíndo o desdobramento da interação $\mathrm{G} \times \mathrm{E}$ para dados de altura, em metros, de Eucalyptus grandis aos 5 anos. Procedência, 12 km S. of Ravenshoe-Mt Pandanus-QLD (14.420) 94

16 Autovalor $\left(\lambda_{k}^{2}\right)$ e porcentagem da soma de quadrados acumulada (PA) por eixo singular . Análise conjunta da variância, incluíndo o desdobramento da interação $\mathrm{G} \times \mathrm{E}$ para dados de altura, em metros, de Eucalyptus grandis aos 5 anos. Procedência, Baldy State Forest 194-Atherton-QLD (14.423)

17 Autovalor $\left(\lambda_{k}^{2}\right)$ e porcentagem da soma de quadrados acumulada (PA) por eixo singular . Análise conjunta da variância, incluíndo o desdobramento da interação $\mathrm{G} \times \mathrm{E}$ para dados de altura, em metros, de Eucalyptus grandis aos 5 anos. Procedência, Bellthorpe St. Forest-QLD (14.431) . . . . . . . 96

18 Médias e escores de genótipos e de ambientes para dados de altura, em metros, de E. grandis aos 5 anos. Procedência, $12 \mathrm{~km} \mathrm{S.} \mathrm{of} \mathrm{Ravenshoe-Mt}$ Pandanus-QLD (14.420) . . . . . . . . . . . . . . . . 101

19 Respostas médias esperadas para dados de altura, em metros, de E. grandis aos 5 anos. Procedência, $12 \mathrm{~km} \mathrm{S.} \mathrm{of} \mathrm{Ravenshoe-Mt} \mathrm{Pandanus-QLD}$

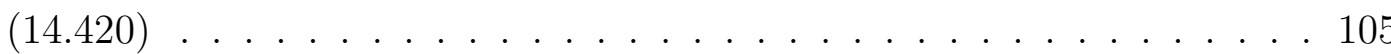

20 Médias e escores de genótipos e de ambientes para dados de altura, em metros, de E. grandis aos 5 anos. Procedência, Baldy State Forest 194Atherton-QLD (14.423) . . . . . . . . . . . . . . . 107

21 Respostas médias esperadas para dados de altura, em metros, de E. grandis aos 5 anos. Procedência, Baldy State Forest 194-Atherton-QLD (14.423)110

22 Médias e escores de genótipos e de ambientes para dados de altura, em metros, de E. grandis aos 5 anos. Procedência, Bellthorpe St. Forest-QLD $(14.431)$ 
23 Respostas médias esperadas para dados de altura, em metros, de E. grandis aos 5 anos. Procedência, Bellthorpe St. Forest-QLD (14.431) . . . . . 115

24 Alturas médias, em metros, de E. grandis aos 5 anos, estimadas pelo modelo $\mathrm{AMMI}_{3}$. Procedência, 12 km S. of Ravenshoe-Mt Pandanus-QLD $(14.420)$

25 Classificações das estabilidades, para dados de altura, em metros, de $E$. grandis aos 5 anos. Procedência, 12 km S. of Ravenshoe-Mt Pandanus-

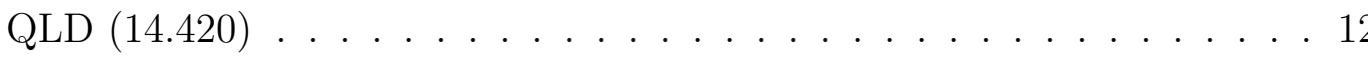

26 Alturas médias, em metros, de E. grandis aos 5 anos, estimadas pelo modelo $\mathrm{AMMI}_{3}$. Procedência, Baldy State Forest 194-Atherton-QLD (14.423)127

27 Classificações das estabilidades, para dados de altura, em metros, de $E$. grandis aos 5 anos. Procedência, Baldy State Forest 194-Atherton-QLD

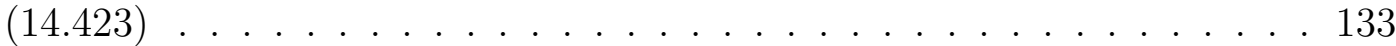

28 Alturas médias, em metros, de E. grandis aos 5 anos, estimadas pelo modelo $\mathrm{AMMI}_{2}$. Procedência, Bellthorpe St. Forest-QLD (14.431) . . . . 135

29 Classificações das estabilidades, para dados de altura, em metros, de $E$. grandis aos 5 anos. Procedência, Bellthorpe St. Forest-QLD (14.431) . 140 


\section{ESTABILIDADE E ADAPTABILIDADE FENOTÍPICA ATRAVÉS DA REAMOSTRAGEM "BOOTSTRAP" NO MODELO AMMI}

Autor: OSMIR JOSÉ LAVORANTI

Orientador: Prof. Dr. CARLOS TADEU DOS SANTOS DIAS

\section{RESUMO}

As posições críticas dos estatísticos, que atuam em programas de melhoramento genético, referem-se à falta de uma análise criteriosa da estrutura da interação do genótipo com o ambiente $(\mathrm{G} \times \mathrm{E})$ como um dos principais problemas para a recomendação de cultivares. Tradicionalmente, a análise dessa estrutura é superficial não detalhando os efeitos da complexidade da interação. Com isso, os ganhos genéticos podem ser diminutos, pela não seleção de genótipos superiores melhores indicados a um ambiente específico. A busca constante por novos métodos e algoritmos, visando eliminar ou minimizar esse problema, tem proporcionado uma inegável evolução científica, com a geração de tecnologias de ponta que envolvem grande capacidade de processamento computacional. Atualmente, a metodologia AMMI (additive main effects and multiplicative interaction analysis) propõe ser mais eficiente que as análises usuais na interpretação e compreensão da interação 
$\mathrm{G} \times$ E. Entretanto, os principais pontos negativos dessa metodologia dizem respeito à dificuldade de se interpretar a interação quando há baixa explicação do primeiro componente principal; à dificuldade de se quantificar os escores como baixos, considerando estável os genótipos e/ou ambientes, além de não apresentar o padrão de resposta do genótipo, o que caracteriza os padrões de adaptabilidade. Nesse contexto, essa metodologia apresenta alguns inconvenientes de ordem estatística, fazendo com que suas interpretações sejam vistas com ressalvas. Assim, o objetivo desta tese foi o desenvolvimento de procedimentos estatísticos que minimizem esses problemas, tornando a metodologia AMMI mais precisa e confiável na caracterização da estabilidade e adaptabilidade fenotípica de plantas. Nesse sentido, foi desenvolvido uma metodologia via reamostragem "bootstrap", no modelo AMMI, que possibilitou as análises gráficas e numéricas, das estabilidades e adaptabilidades fenotípicas de 75 progênies de Eucalyptus grandis, procedentes de três localidades australianas, e implantadas em sete testes de procedências e progênies nas regiões Sul e Sudeste do Brasil. Os resultados indicaram comportamentos diferenciados dos genótipos e dos ambientes, sendo a interação $\mathrm{G} \times \mathrm{E}$ significativa ao nível de $1 \%$ de probabilidade. As interpretações das estabilidades e adaptabilidades fenotípicas foram melhores compreendidas com a realização da reamostragem "bootstrap". A metodologia "bootstrap" AMMI, eliminou as dúvidas relacionadas à quantificação dos escores como baixos, tornando a metodologia AMMI mais precisa e confiável, na predição da estabilidade fenotípica de genótipos e de ambientes. O coeficiente "bootstrap" de estabilidade (CBE), baseado na distância quadrada de Mahalanobis, sobre o modelo $\mathrm{AMMI}_{2}$, obtidos através da região de predição para o vetor nulo, permitiu classificar os genótipos e ambientes em cinco escalas de estabilidade, e, conjuntamente com as representações gráficas das regiões de confiança para a estabilidade e gráficos de dispersões dos escores "bootstrap", em biplot $\mathrm{AMMI}_{2}$, apresentaram melhores qualidades para predições das estabilidades fenotípicas, do que o método tradicional AMMI, com representação gráfica em biplot. 


\title{
PHENOTYPIC STABILITY AND ADAPTABILITY VIA AMMI MODEL WITH BOOTSTRAP RE-SAMPLING
}

\author{
Author: OSMIR JOSÉ LAVORANTI \\ Adviser: Prof. Dr. CARLOS TADEU DOS SANTOS DIAS
}

\section{SUMMARY}

Reliable evaluation of the stability of genotypes and environment is of prime concern to plant breeders, who have Undertaken much research into the development of methods for studying in detail the structure of genotype-environment interaction. The lack of a comprehensive analysis of the structure of the GEI interaction has been a stumbling block to the recommendation of cultivars. Traditionally, the analysis of that structure was superficial and stopped short of detailing the effects of the complexity of the interaction. However, recent advances in computer science have allowed the development of interactive systems of data processing with fast and precise algorithms. Consequently, statistical methods are being developed to study in detail the structure and stability of GEI interaction. At the moment, the Additive Main Effects and Multiplicative Interaction (AMMI) Model promises to be more efficient than the usual analyses in the interpretation and understanding of the 
GEI interaction. The main drawbacks of the AMMI methodology are the difficulty of interpreting the interaction when there is a poor explanation of the first principal component; the difficulty of determining low scores, which relates to the statistical stability of the genotypes and/or environments; and the lack of presentation of the pattern of response of the genotype, which characterizes the adaptability patterns of the groups formed through significant parameters. Thus care needs to be exercised in the interpretation. The present contribution proposes the use of bootstrap re-sampling in the AMMI Model, and applies it to obtain both a graphical and a numerical analysis of the phenotypic stability and adaptability of 75 progenies of Eucalyptus grandis from Australia that were planted in seven environments in the South and Southeast regions of Brazil. The results show differential behavior of genotypes and environments, the genotype $\times$ environment interaction being significant ( $\mathrm{p}$ value $<0.01$ ). The interpretation of the phenotypic stability through graphical analysis of the AMMI biplot is better understood with the aid of the bootstrap. The bootstrap coefficient of stability based on the squared Mahalanobis distance of the scores bootstrap, shows that genotypes and environments can be differentiated in terms of their stabilities. The AMMI bootstrap proposal thus provides better and more precise predictions of phenotypic stability and adaptability of the genotypes than the traditional AMMI analysis, and eliminates the doubts related to the identification of the low scores. 


\section{INTRODUÇÃO}

Os ganhos em produtividade e qualidade dos materiais genéticos são resultados dos acúmulos de conhecimentos científicos, originados dos diversos programas de melhoramento genético. Dentre esses valiosos conhecimentos, destacam-se os trabalhos sobre estabilidade fenotípica e adaptabilidade de plantas, assim como as técnicas evolutivas utilizadas nessas análises.

Essa inegável evolução científica, deve-se a uso frequente de tecnologias de ponta, geradas pela qrande quantidade de trabalhos científicos, destinados a essa área. Evidencia-se também, o esforço dos pesquisadores na busca por novos métodos e algoritmos, que melhorem o entendimento sobre estabilidade e adaptabilidade fenotípica, permitindo um aumento dos ganhos genéticos, propiciados pela alocação otimizada de genótipos, nos vários ambientes.

Como o principal objetivo de um programa de melhoramento é selecionar genótipos de consistente e elevada produtividade, nos mais diversos ambientes, a baixa eficiência na análise da interação genótipo com ambiente $(\mathrm{G} \times \mathrm{E})$ pode representar um problema aos melhoristas, por reduzir a precisão de seleção de um ambiente para outro. A presença da interação $\mathrm{G} \times \mathrm{E}$ provoca um aumento do desvio padrão fenotípico, reduz a herdabilidade ao longo de ambientes e, consequentemente, diminui os ganhos genéticos potenciais (Matheson \& Raymond, 1986).

As posições críticas dos estatísticos que atuam em programas de melhoramento genético, referem-se à falta de uma análise criteriosa da estrutura da interação $\mathrm{G} \times \mathrm{E}$ como um dos principais problemas para a recomendação de cultivares. Tradicionalmente, a análise dessa estrutura é superficial, não detalhando os efeitos da complexidade da interação. Com isso, os ganhos genéticos podem ser diminutos, 
pela não seleção de genótipos superiores melhores indicados a um ambiente específico (Comstock \& Moll, 1963).

Também teve evolução acentuada a ciência da computação e, conseqüentemente, o desenvolvimento de sistemas sofisticados de processamento de dados, com algoritmos rápidos e precisos.

Baseando-se nesses fatos, muitos estatísticos, matemáticos e melhoristas estão trabalhando no desenvolvimento do modelo AMMI - Additive Main effects and Multiplicative Interaction model, com a finalidade de estudar detalhadamente a estrutura do efeito da interação $\mathrm{G} \times \mathrm{E}$. Busca-se também, com base nesse modelo, obter uma nova metodologia que possibilite a análise da estabilidade e adaptabilidade fenotípica de plantas.

O modelo AMMI, proposto inicialmente por Mandel (1971), permite um detalhamento maior da soma de quadrados da interação, e conseqüentemente, traz vantagens na seleção de genótipos, quando comparados a outros métodos tradicionais de análise (Zobel et al., 1988). Outra vantagem, é a possibilidade da representação gráfica simultânea dos escores dos efeitos da interação para cada genótipo e para cada ambiente, obtidos por análise multivariada, podendo dessa forma, a interpretação ser feita através da análise da magnitude e do sinal dos escores, sendo considerados estáveis aqueles genótipos ou ambiente cujos escores são baixos (Duarte \& Vencovsky, 1999).

A utilização dessa teoria parece ser uma alternativa eficiente para os programas de melhoramento, pois permite combinar em um único modelo estatístico, componentes aditivos para os efeitos principais, como genótipos e ambientes, e componentes multiplicativos para os efeitos da interação.

Como principais pontos negativos dessa metodologia, podemos relacionar: a dificuldade na interpretação dessa interação quando há baixa explicação do primeiro componente principal (Crossa 1990); a dificuldade na quantificação dos escores como baixos (Lavoranti \& Dias, 1999), e a não apresentação de um padrão de resposta do genótipo em cada ambiente (Rosse, 1999). Nesse contexto, essa 
metodologia apresenta algumas dificuldades na interpretação prática dos resultados estatísticos, fazendo com que seja vista com ressalva.

Assim, a presente tese propõe uma sistemática para o estudo e a interpretação da estabilidade e adaptabilidade fenotípica de progênies de Eucalyptus grandis, através da técnica de reamostragem "bootstrap" na matriz de resíduo, estimada via metodologia AMMI. Os principais objetivos foram o desenvolvimento de procedimentos estatísticos, visando solucionar ou minimizar os problemas relacionados, principalmente ao associado à quantificação dos escores como baixo, tornando a metodologia AMMI mais precisa e confiável, de forma a contribuir para uma melhor caracterização e seleção de populações para programas de melhoramento genético. 


\section{REVISÃO DE LITERATURA}

\section{$2.1 \quad$ Eucalyptus}

O gênero Eucalyptus pertence à família Myrtaceae, subgênero Symphyomirtus e é composto por cerca de 600 espécies, 24 subespécies, 24 variedades e muitos híbridos não quantificados. É de origem australiana e arredores (Timor, Indonésia, Papua Guiné, Molucas, Irian Jayas, e sul das Filipinas), presentes em uma faixa abrangente de $9^{\circ} \mathrm{N}$ a $45^{\circ} \mathrm{S}$ (Eldridge et al., 1993).

O Eucalyptus possui destaque internacional por representar a maior área de árvores plantadas nas regiões de clima tropical e subtropical. Pode ser encontrado desde a forma arbustiva até árvores de grande porte, com distribuição predominante entre as latitudes $40^{\circ} \mathrm{N}$ e $45^{\circ} \mathrm{S}$, e altitudes que variam de 30 a 1000 metros. Possui espécies adaptadas a diversas condições de clima e solo (Cresswell et al., 1985).

Com uma área cultivada de aproximadamente três milhões de hectares, o Brasil é o maior produtor mundial de eucalipto, seguido pela Índia, África do Sul, Portugal, Angola, Espanha, e China (SBS Silvicultura, 2000).

Com produtividade média de $45 \mathrm{~m}^{3}$ / ha por ano (em plantios clonais) e alta qualidade de fibras e polpa de madeira, o Eucalyptus tornou-se a atração principal dos reflorestamentos comerciais no mundo. A rotação pode ser reduzida para 5 anos de idade, num regime que permite até três rotações sucessivas e econômicas (Ho et al., 1998).

Devido à importância econômica das plantações comerciais, houve um considerado aumento no interesse pelo melhoramento genético do eucalipto. Isso 
proporcionou o desenvolvimento de programas próprios para atender às necessidades de cada região. E, por méritos dos trabalhos realizados nas últimas décadas, o Brasil possui hoje um dos mais importantes bancos de germoplasma do gênero Eucalyptus, com alta produtividade e adaptabilidade às suas regiões produtoras.

No Brasil, o Eucalyptus grandis é a espécie mais cultivada, devido às suas características silviculturais, propriedades tecnológicas de sua madeira e importância econômica. Essa espécie já vem sendo melhorada há algum tempo, e tem se destacado dentro do gênero, como a melhor em desenvolvimento, nos plantios comerciais para as regiões subtropicais (Moraes, 1987).

Na Austrália, a faixa de maior ocorrência de Eucalyptus grandis varia de $25^{\circ} \mathrm{S}$ a $33^{\circ} \mathrm{S}$, ocorrendo pequenas populações no centro de Queensland $\left(21^{\circ} \mathrm{S}\right)$, e em faixas desde o noroeste de Ownsville, até o norte de Queensland ( entre $16^{\circ} \mathrm{S}$ a $19^{\circ} \mathrm{S}$ ) (Boland et al., 1993).

\subsection{Eucalipto no Brasil}

Os primeiros plantios de eucaliptos foram instalados no Rio Grande do Sul em 1868 por Assis Brasil, o primeiro brasileiro a interessar-se pelo gênero. E os primeiros estudos científicos com eucalipto no Brasil foram iniciados em 1904 por Edmundo Navarro de Andrade (Loefgren, 1906), da ex-Cia. Paulista de Estradas de Ferro, que convidou Carlos Arnaldo Krug, chefe da Secção de Genética do Instituto Agronômico de Campinas, para elaborar um programa de melhoramento genético de eucaliptos.

Com o programa de melhoramento genético de eucaliptos de Carlos Arnaldo Krug, considerado um dos mais avançados de sua época, foram conduzidos, no período de 1940 a 1950, programas intensivos de seleção de árvores superiores. Essa seleção de árvores superiores abrangeu todos os plantios da ex-Cia. Paulista de Estrada de Ferro, dando origem a um arquivo de "árvores Plus", também denominadas "brasões", que recebiam todos os cuidados para a sua preservação. Elas também foram utilizadas na formação de um pomar de sementes clonal experimental 
(Krug \& Alves, 1949; Andrade, 1961).

As pesquisas sobre seleção de árvores superiores de eucaliptos, no Brasil, consolidaram-se e expandiram-se após a Segunda Conferência Mundial de Eucalipto, realizada em 1960. Em 1964, o Instituto Florestal de São Paulo estabeleceu intenso programa de seleção de árvores superiores e iniciou um programa de certificação de sementes melhoradas.

O período de 1969 a 1975, foi considerado como marco inicial de pesquisas aplicadas (Perego \& Garlipp, 1983). As entidades EMBRAPA, IPEF, IFSP e empresas privadas intensificaram seus estudos no melhoramento genético florestal, visando atender a crescente demanda de sementes melhoradas. Nesse período, uma das principais atividades foi a seleção intensiva de árvores superiores para a instalação de testes de progênies, pomares de sementes e bancos clonais. O melhoramento genético florestal foi caracterizado pela instalação de Pomares Clonais para a produção de sementes melhoradas, provenientes de árvores superiores, selecionadas em raças locais ou de novas procedências. A seleção de espécies/procedências das sementes/árvores superiores deixaram de ser baseadas em parâmetros silviculturais, e passam a ser estudadas mais tecnicamente, por métodos genético-estatísticos (Ferreira \& Santos, 1997).

Com as intensas geadas ocorridas nas regiões sul e sudeste do Brasil, em 1975, a maioria das plantações de Eucalyptus grandis, sofreram perdas significativas. Entretanto, os estudos realizados após a ocorrência das geadas, mostraram a possibilidade de selecionar árvores superiores tolerantes a geadas.

Em 1978, a Embrapa assumiu a responsabilidade de desenvolver e coordenar pesquisas com espécies florestais no Brasil, e cadastrou 601 projetos de melhoramento florestal, sendo que 408 eram ensaios de introdução de espécies e procedências. Desses, 60 projetos caracterizavam-se como testes de progênies para seleção de árvores superiores de eucaliptos (Embrapa, 1987).

Em 1979, a Aracruz Florestal realizou a primeira plantação clonal comercial com árvores superiores de eucaliptos no Brasil. A área instalada foi de 1000 
ha, em Aracruz, Estado do Espírito Santo (Ikemori,1990).

Em 1983, a Embrapa Florestas, através de um convênio estabelecido com a CSIRO (Commonwealth Scientific and Industrial Research Organization) e sob o patrocínio do Banco Mundial - BIRD coletou, na Austrália, 148 Kg de sementes de eucaliptos, pertencentes a 55 procedências australianas (raças geográficas), envolvendo 12 principais espécies para o Brasil (Ferreira, 1989). Com essas sementes foram instalados 172 testes de progênies, visando a conservação da variabilidade genética e a produção de sementes melhoradas pela seleção de árvores superiores, baseadas nos valores genéticos individuais (Higa et al., 1997).

No terceiro levantamento de pesquisa florestal em andamento no Brasil, em 1987, foram cadastrados 2043 projetos de pesquisa (Embrapa, 1987). A maioria desses projetos eram de teste de novos materiais genéticos.

Entre 1980 e 1990, as pesquisas básicas em melhoramento genético e introdução de espécies e procedências, deixaram de ser prioridade. A prioridade passou a ser a árvore superior para propagação clonal. O novo ambiente para pesquisa foi caracterizado pela busca da árvore/clone, que apresentasse a maior produtividade no menor espaço de tempo, e que não interagisse significativamente com o ambiente (Ferreira \& Santos, 1997).

Atualmente, as empresas concentram seus esforços na seleção de um número reduzido de clones que passam a ser imediatamente incluídos no plantio clonal massal (Ferreira \& Santos, 1997). O uso de clones altamente produtivos em povoamentos florestais é justificado como parte do processo de intensificação, sofrido pelo manejo florestal, na busca crescente do aumento da produtividade.

Entretanto, tem-se observado que as principais dificuldades práticas do melhoramento florestal são devidas ao tempo necessário para completar um ciclo de seleção e recombinação de indivíduos, para melhorar as características quantitativas que se expressam somente em idades mais avançadas, e à dificuldade de selecionar de forma eficiente em níveis de progênies e de indivíduo. Mais especificamente, os programas de melhoramento genético florestal requerem muito tempo para que se- 
jam obtidos resultados e dessa forma, verifica-se a necessidade constante de técnicas plausíveis de seleção, de materiais estáveis e adaptados, visando o aumento da produtividade das florestas plantadas.

\subsection{Melhoramento florestal}

De acordo com Vencovsky (1986), estudos de melhoramento vegetais vêm sendo desenvolvidos desde antes da doutrina de Gregor J. Mendel (1822-1884), porém, naquela época não era fundamentada pelos cálculos genético-estatísticos, como hoje, mas baseavam-se essencialmente no bom senso e desvelo.

Atualmente, nos estudos de melhoramento florestal, para se obterem árvores superiores, de grande importância econômica, são necessários muitos cálculos estatísticos para descriminar materiais mais promissores sob vários contextos, e verificar se os indivíduos selecionados trazem em sua bagagem os atributos de superioridade, principalmente, o genético e o evolutivo.

Normalmente, os atributos de superioridade são quantitativos e de difícil seleção (Cruz, 1990). A dificuldade de seleção é devida à complexidade da base genética do material experimental, e à influência sofrida pelo efeito ambiental.

Dessa forma, a adaptabilidade do material genético, isto é, a capacidade de o indivíduo sobreviver, crescer e se reproduzir nas condições ambientais do local de introdução é ponto básico a ser considerado em estudos de melhoramento genético de plantas. A eficiência de adaptação das espécies, quando introduzidas em locais que não os da origem, depende de uma série muito grande de influências bióticas e de interações edafoclimáticas (López \& Fornés, 1997). A estabilidade, por outro lado, seria a capacidade de um genótipo exibir um desempenho, o mais constante possível, em função de variações na qualidade ambiental. Assim, as respostas diferenciadas dos genótipos às diferentes condições do ambiente, reforçam a importância de estudos dessa natureza, que aliados à necessidade de alta produtividade e à qualidade dos materiais genéticos nos vários ambientes, tornam-se os principais motivadores dos programas de melhoramento florestais. 


\subsection{Interação genótipo $\times$ ambiente}

Devido aos motivos anteriormente citados, a seleção de genótipos superiores são efetuadas com base em observações obtidas a partir do fenótipo e, portanto, extremamente dependentes da composição do valor fenotípico em relação ao caráter sob seleção (Mauro, 1991; Carneiro, 1998). O fenótipo é o resultado dos efeitos genéticos e daqueles devidos aos ambientes, aos quais o genótipo foi exposto durante o seu desenvolvimento.

A resposta diferenciada dos genótipos nos vários ambientes, conhecida como interação de genótipos com ambientes - G×E (Eberhart \& Russel, 1966) é um fenômeno natural que faz parte da evolução das espécies. Seus efeitos permitem o aparecimento de genótipos estáveis e aptos a um ambiente específico, assim como, de comportamento geral, aptos a vários ambientes.

Segundo Vencovsky \& Barriga (1992), a interação G×E é de natureza genética, mas não no sentido usual, e sim em decorrência de instabilidades das manifestações genotípicas entre ambientes. Dessa forma, o comportamento dos genótipos em relação ao ambiente, tem merecido especial atenção por parte dos melhoristas, pois interfere nos processos de seleção. Por essa razão, torna-se importante o conhecimento preciso dessas estimativas, bem como sua utilização na determinação da estabilidade fenotípica das diferentes variedades.

O fenômeno da interação $\mathrm{G} \times \mathrm{E}$ é de extrema importância nos programas de melhoramento. A partir dele é possível executar uma seleção de genótipos com adaptação ampla ou específica, escolher locais de seleção, identificar o nível de estresse nos ambientes escolhidos, para as fases iniciais da seleção, e determinar o número ideal de ambientes e de genótipos a serem avaliados em cada fase da seleção (Fox et al., 1997).

O processo tradicional de investigar as interações $\mathrm{G} \times \mathrm{E}$ é a análise conjunta de variância, com grupos de experimentos, que pode ser visto em Pimentel Gomes (1990). Pode-se verificar a interação através de uma tabela de dupla entrada (Tabela 1), em que se tem nas linhas, os genótipos, e nas colunas, os ambientes em 
que os ensaios foram instalados.

Tabela 1. Disposição dos dados em linhas (progênies) e colunas (ambientes)

\begin{tabular}{cccccccc}
\hline & \multicolumn{7}{c}{ Ambientes } \\
\cline { 2 - 6 } Genótipos & 1 & 2 & 3 & $\cdots$ & e & Média \\
\hline 1 & $Y_{11}$ & $Y_{12}$ & $Y_{13}$ & $\cdots$ & $Y_{1 e}$ & $\bar{Y}_{1 .}$ \\
2 & $Y_{21}$ & $Y_{22}$ & $Y_{23}$ & $\cdots$ & $Y_{2 e}$ & $\bar{Y}_{2 .}$ \\
3 & $Y_{31}$ & $Y_{32}$ & $Y_{33}$ & $\cdots$ & $Y_{3 e}$ & $\bar{Y}_{3 .}$ \\
$\vdots$ & $\vdots$ & $\vdots$ & $\vdots$ & $\ddots$ & $\vdots$ & $\vdots$ \\
g & $Y_{g 1}$ & $Y_{g 2}$ & $Y_{g 3}$ & $\cdots$ & $Y_{g e}$ & $\bar{Y}_{g .}$ \\
Médias & $\bar{Y}_{.1}$ & $\bar{Y}_{.2}$ & $\bar{Y}_{.3}$ & $\cdots$ & $\bar{Y}_{. e}$ & $\bar{Y}_{. .}$ \\
\hline
\end{tabular}

Nessa tabela de dupla entrada, de dimensão g $\times$ e, associada aos genótipos $G_{i}$ colocados nas linhas $(\mathrm{i}=1,2, \ldots, \mathrm{g})$ e nos ambientes $E_{j}$ nas colunas $(\mathrm{j}=1,2, \ldots, \mathrm{e})$, assume-se que as n observações fenótípicas de uma variável $Y_{i j}$ seguem o modelo matemático:

$$
\bar{Y}_{i j}=\mu+\hat{G}_{i}+\hat{E}_{j}+(\widehat{G E})_{i j}+\bar{\epsilon}_{i j}
$$

em que:

$\bar{Y}_{i j}$ : observação fenotípica do genótipo i no ambiente j, podendo representar a média de $\mathrm{r}$ repetições;

$\mu$ : média geral;

$\hat{G}_{i}=\bar{Y}_{i .}-\bar{Y}_{. .} \quad$ (efeito do genótipo i);

$\hat{E}_{j}=\bar{Y}_{. j}-\bar{Y}_{. .} \quad($ efeito do ambiente $\mathrm{j}) ;$

$(\widehat{G E})_{i j}=Y_{i j}-\bar{Y}_{i .}-\bar{Y}_{. j}+\bar{Y}_{. .} \quad($ efeito da interação $G \times E) ;$

$\bar{\epsilon}_{i j}$ : é o erro assumindo ser normal e identicamente distribuído $\left(0, \frac{\sigma^{2}}{n}\right)$ e, $\sigma^{2}$ é a variância do erro dentro de ambiente, assumida como constante. 
A estrutura da análise da variância (Tabela 2), permite a estimação da interação $\mathrm{G} \times \mathrm{E}$ que estaria confundida com a variância devida a genótipos na análise individual (por ambiente). Se os ambientes abrangidos pelos ensaios, representam, de fato, uma zona ecológica adequada à espécie, a variância genética devida a genótipos, sem a devida interação com ambientes, seria mais indicada para expressar de fato a variação disponível ao melhoramento.

Tabela 2. Estrutura da análise de variância conjunta, envolvendo os diferentes ambientes

\begin{tabular}{lllll}
\hline Causa de variação & GL & QM & $\mathrm{E}[Q M]$ & $\mathrm{F}$ \\
\hline Blocos/ambientes & $\mathrm{e}(\mathrm{r}-1)$ & $\mathrm{QMB}$ & $\sigma^{2}+g \sigma_{B / E}^{2}$ & \\
Ambientes (E) & $\mathrm{e}-1$ & $\mathrm{QME}$ & $\sigma^{2}+g \sigma_{B / E}^{2}+g r \sigma_{E}^{2}$ & $\mathrm{QME} / \mathrm{QMB}$ \\
Genótipos (G) & $\mathrm{g}-1$ & $\mathrm{QMG}$ & $\sigma^{2}+r \ell \sigma_{G E}^{2}+e r \Phi_{G}$ & $\mathrm{QMG} / \mathrm{QMGE}$ \\
$\mathrm{G} \times \mathrm{E}$ & $(\mathrm{g}-1)(\mathrm{e}-1)$ & $\mathrm{QMGE}$ & $\sigma^{2}+r \ell \sigma_{G E}^{2}$ & $\mathrm{QMGE} / \mathrm{QMR}$ \\
Resíduo & $\mathrm{e}(\mathrm{r}-1)(\mathrm{g}-1)$ & $\mathrm{QMR}$ & $\sigma^{2}$ & \\
\hline$\ell=g /(g-1)$ & $\mathrm{e}$ & $\Phi_{G}=\sum_{i}^{g} G_{i}^{2} /(g-1)$ & &
\end{tabular}

A análise consiste em verificar três possibilidades: ausência de interação, interação simples e interação complexa.

A interação simples e a ausência de interação não trazem qualquer preocupação ao melhorista, porque não alteram a classificação dos genótipos nos ambientes. Porém, a interação complexa é um problema sério, por alterar o ordenamento dos genótipos nos ambientes, e dessa forma, haver falta de sensibilidade para a seleção e recomendação desse material, comercialmente. Esses fenômenos interferem na classificação relativa dos genótipos, dificultando sua avaliação e fazendo com que as interpretações das estimativas fenotípicas não possam ser estendidas a programas de melhoramento de outras regiões (Robertson, 1959; Crossa, 1990; Ramalho et al., 1993). 
A significância dessas interações deve ser interpretada, a princípio, como uma indicação de que existem genótipos particularmente adaptados a determinados ambientes (adaptação específica) e outros que sejam menos influenciados pelas variações ambientais, podendo ser explorados em vários outros ambientes (adaptação geral). Essa última apresenta, como inconveniente, o fato de estar normalmente associada a uma baixa produtividade o que impede a recomendação desses cultivares de maneira generalizada, acarretando maiores dificuldades e, exigindo a adoção de medidas que controlem ou minimizem os efeitos dessa interação, para que seja possível, assim, proceder uma recomendação mais segura.

As variações ambientais, que podem contribuir para a interação, são agrupadas em previsíveis e imprevisíveis. No primeiro caso, estão incluídos os fatores permanentes do ambiente, como tipo de solo e aqueles nos quais o homem atua de forma direta, como época de plantio, tipo de adubação, métodos de colheita, etc. No segundo estão aquelas que ocorrem com as flutuações climáticas atípicas, e com a ocorrência de pragas e doenças (Allard \& Bradshaw, 1964).

A interação pode ser usada vantajosamente quando se procura maximizar ou capitalizar os ganhos genéticos dos materiais, em um ambiente específico (interação complexa), como ocorre nos programas de melhoramentos florestal (Owino,1977; Mori et al., 1986; Barnes, 1987; Gonçalves, 1990; Davide, 1992). Entretanto, se o experimento é instalado em apenas um ambiente, pode acarretar uma superestimação dos ganhos genéticos e, se a interação for do tipo complexa, a recomendação de materiais genéticos para ambientes diferentes daqueles onde eles foram selecionados poderá contribuir para a redução expressiva do ganho com a seleção (Crossa, 1990; Rocha \& Vello, 1999).

Em termos biométricos, a variância da interação $\mathrm{G} \times \mathrm{E}$ pode ser dividida em duas partes. A primeira ocorre devido às diferenças na variabilidade genética, que ocorre dentro de ambientes (parte simples da interação), e a segunda advém da falta de uma correlação linear perfeita entre os genótipos, de um ambiente para o outro (parte complexa da interação). 
O problema da interação genótipos por ambientes é extremamente complexo porque, em geral, existem muitos ambientes envolvidos, nos quais há possibilidades de serem introduzidas culturas produtivas e economicamente viáveis. O importante é que cada melhorista decida qual deverá ser o ambiente a receber os genótipos selecionados. Essa decisão pode ser tomada de modo mais consciente quando os melhoristas conhecem a natureza da interação (Carneiro, 1998).

Os primeiros relatos de exploração da interação $\mathrm{G} \times \mathrm{E}$ significativa, ocorreram com Yates \& Cochran (1938). Esses autores desdobraram essa fonte de variação para cada genótipo, determinando uma regressão linear da produtividade em relação à média de todos eles, em cada ambiente.

Assumindo-se uma relação linear entre $(\widehat{G E})_{i j}$ e os efeitos dos ambientes $\left(\hat{E}_{j}\right)$, ou seja:

$$
(\widehat{G E})_{i j}=\beta_{i} \hat{E}_{j}+\delta_{i j}
$$

em que, $\delta_{i j}$ são os desvios da regressão, e combinando-se (1) e (2) tem-se:

$$
\begin{aligned}
\bar{Y}_{i j} & =\mu+\hat{G}_{i}+\hat{E}_{j}+\beta_{i} \hat{E}_{j}+\delta_{i j}+\bar{\epsilon}_{i j} \\
& =\mu+\hat{G}_{i}+\left(1+\beta_{i}\right) \hat{E}_{j}+\delta_{i j}+\bar{\epsilon}_{i j}
\end{aligned}
$$

O termo $\left(1+\beta_{i}\right)$ da expressão (3) corresponde ao parâmetro $b_{i}$ da regressão de valores de $Y_{i j}$, com as respectivas médias (Finlay \& Wilkinson, 1963) ou os efeitos dos ambientes (Eberhat \& Russel, 1966). O valor de $\beta_{i}$ representa também o coeficiente de regressão dos valores de $Y_{i j}$ com os efeitos da interação $\mathrm{G} \times \mathrm{E}$, representados por $(G E)_{i j}$ (Lin et al., 1986).

Assumindo-se em (3), uma relação linear entre $\hat{G}_{i}$ e $\beta_{i}\left(\beta_{i}=\alpha \hat{G}_{i}\right)$, temos:

$$
\bar{Y}_{i j}=\mu+\hat{G}_{i}+\left(1+\alpha \hat{G}_{i}\right) \hat{E}_{j}+\delta_{i j}+\bar{\epsilon}_{i j}
$$

A expressão (4) representa a generalização do modelo de interação linear $\times$ linear de Yates (1972). A hipótese nula $H_{o}: \alpha=0$, contra a hipótese alternativa $H_{a}=\alpha \neq 0$, pode ser realizada pelo teste de não-aditividade de Tukey 
de um grau de liberdade (Tukey, 1949). Na hipótese de não rejeição de $H_{o}$ o modelo (4) é simplificado em:

$$
\bar{Y}_{i j}=\mu+\hat{G}_{i}+\hat{E}_{j}+\bar{\epsilon}_{i j}
$$

em que: $\bar{\epsilon}_{i j}=\delta_{i j}=(\widehat{G E})_{i j}$ da expressão $(1)$.

Pelo teste de não-aditividade de Tukey, pode-se detectar se há ou não correlação entre os valores de $b_{i} \quad\left(b_{i}=1+\beta_{i}\right)$ com os valores de $\bar{Y}_{i \text {. }}$. A parcela residual da interação $\mathrm{G} \times \mathrm{E}$ representada pelos desvios da regressão $\left(\delta_{i j}\right)$, deve ser investigada para a avaliação de sua magnitude e conseqüentemente, da existência da interação $\mathrm{G} \times \mathrm{E}$.

A rejeição de $H_{o}: \alpha=0$, pelo teste de Tukey, implica na aceitação do modelo (4) ou seja, que há um efeito não linear de $\mathrm{G} \times \mathrm{E}$. Implica também, em que as curvas de regressão para cada genótipo, determinadas pelas metodologias de Finlay \& Wilkinson (1963) ou Eberhart \& Russel (1966) tenham um ponto de concorrência (PC) comum, onde o efeito do local seja dado por $\hat{E}_{. j}=Y_{c}-\bar{Y}_{. .}=\frac{-1}{\alpha}$ (Mandel, 1961). Assim, quando $H_{o}: \alpha=0$ é rejeitada, PC passa por:

$$
Y_{c}=\bar{Y}_{. .}-\frac{1}{\alpha}
$$

Existindo a concorrência, todos os genótipos, nesse ponto, possuem o mesmo valor $Y_{c}$ para a variável em análise. Por conseguinte, a média dos genótipos (ordenada) que define a média do suposto ambiente, atribui o mesmo valor $Y_{c}$ à abscissa $\mathrm{X}$ (ambientes). Conseqüentemente, $\mathrm{PC}$ tem as coordenadas $\left(Y_{c}, Y_{c}\right)$, estando localizado na reta que passa pela origem, com inclinação de $45^{\circ}\left(b_{i}=1,0\right)$. Trata-se, portanto, da bissetriz dos quadrantes um e três do gráfico cartesiano X (ambientes) $\times$ Y (genótipos).

Geralmente a variável $Y_{i j}$, estudada no melhoramento genético, assume apenas valores positivos (altura, diâmetro, produtividade, etc.) e, dessa forma, quando houver um ponto de concorrência (PC), conforme (6), esse estará situado no quadrante principal do gráfico cartesiano ambiente $(\mathrm{X}) \times$ genótipo $(\mathrm{Y})$. A localização do PC poderia estar, a princípio, em três posições possíveis: abaixo, acima 
ou dentro da faixa compreendida entre os valores médios, mínimos e máximos dos ambientes em estudo.

Se o PC estiver situado abaixo da faixa, então os genótipos de maior performance média exibirão também maior adaptabilidade, porque a rejeição de $H_{0}: \alpha=0$ demonstra a existência da correlação direta entre os valores de $b_{i}$ versus $Y_{i}$ (Hardwick, 1981). As diferenças entre genótipos são mínimas nos ambientes desfavoráveis, mas, aumentam com a melhoria do ambiente. Essa condição é freqüentemente referida como interação dependente de nível (Snee, 1982). Como $\operatorname{Var}\left[G_{i}\right]=\left(1+\beta_{i}\right)^{2} \sigma_{g i}^{2}$ (Chaves et al., 1989) e $b_{i}=1+\beta_{i}$, têm-se que, quanto maior o valor de $b_{i}$ de um determinado genótipo, maior será sua variância e, menor será sua estabilidade.

Se o PC estiver situado acima do ambiente com maior produtividade, o que é um caso pouco provável de ocorrer, já que contraria a hipótese de $\beta_{i}$ ser proporcional ao efeito genotípico $\left(\beta_{i}=\alpha G_{i}\right)$, o genótipo de maior performance seria aquele que, consistentemente, respondesse menos à melhoria ambiental, na maioria dos ambientes em teste. Representaria também, uma situação contrária às condições naturais, pois a performance de alguns genótipos melhoraria com o aumento das condições adversas ou dos fatores limitantes à produção.

Finalmente, no caso de o PC estar situado dentro da faixa de performance dos ambientes, isso indicaria uma fraca correlação entre os valores de $b_{i} \operatorname{com} Y_{i}$, já que à esquerda do $\mathrm{PC}$, os genótipos com valores $b_{i}<1,0$ teriam performance superior aos com valores $b_{i}>1,0$ e, essa situação seria invertida nos ambientes a direita do PC. Nessas condições a interpretação seria a usualmente utilizada: os genótipos de adaptabilidade elevada $\left(b_{i}>1,0\right)$ seriam recomendados para os ambientes favoráveis (acima do PC), enquanto que, aqueles com valores $b_{i}<1,0$ seriam indicados para ambientes desfavoráveis (abaixo de PC).

A heterogeneidade dos coeficientes de regressão entre os diversos genótipos pode ser detectada pelo método de Mandel (1961) e Snee (1982). Um teste de comparação quanto a adaptabilidade entre genótipos, dois a dois, pode 
ser realizado pelo teste t de Student. Esse mesmo teste servirá para agrupar os genótipos na classificação de adaptabilidade baixa $\left(b_{i}<1,0\right)$, média $\left(b_{i}=1,0\right)$ e elevada $\left(b_{i}>1,0\right)$, conforme sugerido por Finlay \& Wilkinson (1963).

Se for confirmado que $\alpha>0$, a condição necessária e suficiente para evidenciar a existência de concorrência, segundo Mandel (1961), é que o teste da soma de quadrados dos desvios da regressão seja não significativo. Caso contrário, justifica-se plotar os valores de $b_{i}$ contra os $Y_{i}$ para verificar a existência de algum ponto influente na análise de regressão. Após a confirmação de que o modelo é multiplicativo, o ponto de convergência das regressões deve ser determinado, para um estudo detalhado da adaptabilidade dos genótipos nos diferentes ambientes. Quando constatado que os desvios da regressão são significativos, mas o teste de aditividade é insignificante, isso indica que nem o modelo (4), nem o (5), serviriam para analisar os dados. Alternativamente, é indicado o uso de modelos não lineares como propostos por Mandel (1971); Snee (1982); Chaves et.al. (1989) ou transformar os dados originais a fim de normalizar sua distribuição e homogeneizar sua variância.

Ressalta-se, também, que a presença da interação significativa pode ser devida a outros fatores e, não necessariamente, à diferença na adaptabilidade dos materiais genéticos. Nesse contexto, menciona-se, entre esses fatores, a falta de ajuste do conjunto de dados, ao modelo estatístico adotado (Chaves et al., 1989).

Entre as aspirações dos melhoristas está a busca de materiais genéticos que, ao serem avaliados nos vários ambientes, não mostrem alterações significativas, conferindo, assim, uma maior segurança na recomendação de cultivares. No entanto, somente uma pequena porção da interação pode ser atribuída a determinantes ambientais conhecidos, sendo a maior parte inexplicável na análise estatística.

Do ponto de vista do melhoramento, a interação $\mathrm{G} \times \mathrm{E}$ significativa não é desejável. Assim, existem na literatura várias opções para atenuar os efeitos significativos dessa interação:

a) identificar genótipos específicos para cada ambiente; 
b) realizar zoneamento ecológico, ou seja, promover a subdivisão de uma área heterogênea em sub-regiões mais uniformes, de modo que dentro delas os genótipos não interajam significativamente com os ambientes e,

c) identificar genótipos com maior estabilidade fenotípica.

Essa última opção é a que tem sido mais utilizada, por poder ser aplicada nas mais variadas situações, requerendo estudos sobre a performance genotípica, com base nos parâmetros adaptabilidade e estabilidade, pelos quais torna-se possível a identificação de cultivares de comportamento previsível e que sejam responsivos às variações ambientais, em condições específicas ou amplas (Vencovsky \& Barriga, 1992; Ramalho et al., 1993; Cruz \& Regazzi, 1994).

Já a primeira opção, embora teoricamente possível, é limitada pela infinidade de ambientes encontrados nos países de clima tropical, o que onera e dificulta as etapas de produção de sementes e manutenção dos inúmeros genótipos necessários. Além disso, segundo Ramalho et al. (1993), o ambiente pode ser muito restrito e quaisquer variações imprevistas nessas condições, podem fazer com que o material genético indicado não mais o seja. Na opinião desses autores, essa é uma solução altamente dispendiosa para as instituições de pesquisa, pois exige um trabalho de conscientização agrícola que inviabiliza a sua adoção. Entretanto, segundo Gauch \& Zobel (1996), genótipos com adaptações específicas podem diferenciar uma variedade como boa ou excelente, possibilitando rendimentos diferenciados nas etapas finais de um programa de seleção.

A estratificação de ambientes é de grande importância quando se quer verificar se, entre os ambientes da rede experimental, há padrões de similaridade da resposta dos cultivares avaliados. Isso possibilita avaliar o grau de representatividade dos ensaios na faixa de adaptação da cultura, agrupar ambientes em que a interação $\mathrm{G} \times \mathrm{E}$ seja não significativa para o conjunto de genótipos avaliados, e decidir, seja por problemas técnicos, ou escassez de recursos, sobre o descarte de ambientes (Magari \& Kang, 1997; Carneiro, 1998). 


\subsubsection{Estratificação de ambientes}

A estratificação de ambientes pode ser feita através das estimativas do quadrado médio para a interação entre genótipos e pares de ambientes, com o agrupamento daqueles ambientes cuja interação for não-significativa (Lin, 1982). O método prossegue com a estimação da interação para grupos de três ambientes, sendo empregado o Teste F (5\%), para avaliar a possibilidade da formação de cada grupo.

A soma de quadrados da interação $\mathrm{G} \times \mathrm{E}$, para cada par de ambiente, pode ser obtida por:

$$
\begin{aligned}
S Q(G \times E)_{j j^{\prime}} & =\frac{1}{2}\left[d_{j j^{\prime}}^{2}-\frac{1}{g}\left(Y_{. j}-Y_{. j^{\prime}}\right)^{2}\right] \quad \text { em que: } \\
d_{j j^{\prime}}^{2} & =\sum_{j}\left(Y_{. j}-Y_{. j^{\prime}}\right)^{2}
\end{aligned}
$$

sendo que esse expressa o quadrado da distância euclidiana entre os ambientes j e j', com base no comportamento médio de "g" genótipos.

A distância euclidiana também foi utilizada por Mungomery et al. (1974), no agrupamento de ambientes semelhantes, com a finalidade de dividir uma macro-região em sub-regiões, ou de permitir a eliminação de ambientes com características afins.

Essa estratificação ambiental é usada efetivamente para reduzir os efeitos da interação. Entretanto, apresenta o inconveniente de o agrupamento ser feito com base em diferenças macro-ambientais, tornando-as vulneráveis às variações imperceptíveis que possam ocorrer no ambiente (Eberhart \& Russel, 1966). Além disso, a interação genótipos por anos, na maioria das vezes, ainda permanece elevada (Tai, 1971). Visando minimizar esse problema e, avaliar a semelhança ente locais, Liang et al. (1966), basearam-se na comparação dos valores das interações genótipos por locais e por anos.

Cruz \& Regazzi (1994), com base no algoritmo de Lin (1982), descreveram uma metodologia de estratificação ambiental, em função da discriminação genotípica, que permite agrupar os ambientes em que os genótipos se comportam de modo semelhante e, entre os quais, em consequência, a interação é não significativa. 
Nesse método, a estratificação também pode ser realizada mediante as similaridades de respostas dos genótipos, nos diferentes ambientes, mesmo que os ambientes nos quais os genótipos dão respostas similares não sejam semelhantes entre si.

Para isso, calculam-se as somas de quadrados da interação entre genótipos para todos os possíveis pares de ambientes. O grupo inicial é formado pelo par de ambientes que apresentar a menor soma de quadrados, cuja interação é não significativa. Para testar a significância da interação é utilizado o teste F (8).

Para a inclusão de um novo ambiente nesse grupo, calculam-se as somas de quadrados de todas as possíveis combinações do grupo inicial (um par de ambientes), com cada um dos ambientes restantes. Aquele grupo, agora de três ambientes, que apresentar menor soma de quadrados, será formado, ou seja, o novo ambiente é incluído se, pelo teste $\mathrm{F}$, a $\mathrm{G} \times \mathrm{E}$ for não significativa. Procede-se do mesmo modo até que o novo grupo de ambientes formado apresente interação significativa, impossibilitando, assim, a formação do referido grupo.

Para um melhor entendimento desse processo metodológico de estratificação, considere as estimativas das somas de quadrados da interação entre genótipos e pares de ambiente (Tabela 3).

Tabela 3. Estimativas das somas de quadrados da interação entre genótipos e pares de ambientes

\begin{tabular}{ccccccc}
\hline Ambientes & 1 & 2 & 3 & 4 & $\cdots$ & e- 1 \\
\hline 1 & - & $\theta_{12}$ & $\theta_{13}$ & $\theta_{14}$ & $\cdots$ & $\theta_{1(e-1)}$ \\
2 & & - & $\theta_{23}$ & $\theta_{24}$ & $\cdots$ & $\theta_{2(e-1)}$ \\
3 & & & - & $\theta_{34}$ & $\cdots$ & $\theta_{3(e-1)}$ \\
$\vdots$ & & & & - & $\vdots$ & $\vdots$ \\
$\mathrm{e}$ & & & & & & $\theta_{e(e-1)}$ \\
\hline
\end{tabular}

O par de ambientes que proporcionar menor $\theta_{j j^{\prime}}$ formará um grupo se 
o quadrado médio da interação for não significativo. A estatística adequada para o teste é:

$$
\begin{aligned}
F= & \frac{Q M(G \times E)_{j j^{\prime}}}{Q M R} \text { em que: } \\
Q M R: \quad & \text { quadrado médio do resíduo da análise conjunta; com } F_{\alpha,(g-1), m} \\
& (\text { m: graus de liberdade do resíduo da análise conjunta); } \\
Q M(G \times E)_{j j^{\prime}}= & \frac{\theta_{j j^{\prime}}}{(g-1)(e-1)} ; \\
\theta_{j j^{\prime}}= & S Q(G \times E)_{j j^{\prime}} ; \\
g: \quad & \text { número de genótipos e } \\
e: \quad & \text { número de ambientes (inicialmente, e }=2) .
\end{aligned}
$$

Realiza-se o teste F com o resíduo da análise de variância conjunta, uma vez que essa análise é feita pressupondo homogeneidade das variâncias do resíduo das análises individuais, além de ter maior número de graus de liberdade associado.

Para a inclusão de um novo ambiente nesse grupo, calculam-se as somas de quadrados da interação, considerando todas as possíveis combinações do grupo formado inicialmente (um par de ambientes), com cada um dos ambientes restantes.

Sendo $S Q(G \times E)_{\left(j j^{\prime}\right) k}$ a soma de quadrados da interação calculada, considerando-se os ambientes j, j’ e k, a estatística para avaliar a inclusão do ambiente k, ao grupo formado pelos ambientes homogêneos j e j' é:

$$
\begin{aligned}
F & =\frac{Q M(G \times E)_{\left(j j^{\prime}\right) k}}{Q M R} \text { com, } \quad F_{\alpha,(g-1)(e-1), m} \\
Q M(G \times E)_{\left(j j^{\prime}\right) k} & =\frac{S Q(G \times E)_{\left(j j^{\prime}\right) k}}{(g-1)(e-1)} \quad(e=3)
\end{aligned}
$$

Esse processo de cálculo torna-se inviável quando o número de genótipos e de ambientes é relativamente grande. Por essa razão, Cruz \& Regazzi (1994) apresentaram o cálculo das somas de quadrados com base na distância euclidiana: 


$$
\begin{aligned}
S Q_{\text {Ambiente }} & =S Q E=\frac{r}{g}\left[\sum_{j} Y_{. j}^{2}-\frac{1}{e} Y_{. .}^{2}\right] \\
S Q_{\text {Genótipo }} & =S Q G=\frac{r}{e}\left[\sum_{i} Y_{i .}^{2}-\frac{1}{g} Y_{. .}^{2}\right] ; \\
S Q(G, E) & =r\left[\sum_{i} \sum_{j} Y_{i j}^{2}-\frac{1}{g e} Y_{. .}^{2}\right] \mathrm{e} \\
S Q(G \times E) & =S Q(G, E)-S Q E+S Q G \text { tem se: } \\
S Q(G \times E)_{j j^{\prime}} & =\sum_{i} \sum_{j} Y_{i j}^{2}-\frac{1}{e} \sum_{i} Y_{i .}^{2}-\frac{1}{g} \sum_{j} Y_{. j}^{2}+\frac{Y_{. .}^{2}}{g e}
\end{aligned}
$$

Considerando dois ambientes, e de acordo com a Tabela 3, e (10):

$$
S Q(G \times E)_{12}=\theta_{12}=\sum_{i}\left(Y_{i 1}^{2}+Y_{i 2}^{2}\right)-\frac{1}{2} \sum_{i} Y_{i .}^{2}-\frac{1}{g}\left(Y_{.1}^{2}+Y_{.2}^{2}\right)+\frac{\left(Y_{.1}+Y_{.2}\right)^{2}}{2 g}
$$

Considerando os dois primeiros termos de (11):

$$
\begin{aligned}
\sum_{i}\left[Y_{i 1}^{2}+Y_{i 2}^{2}-\frac{1}{2}\left(Y_{i 1}+Y_{i 2}\right)^{2}\right] & =\sum_{i}\left[Y_{i 1}^{2}+Y_{i 2}^{2}-\frac{1}{2} Y_{i 1}^{2}-Y_{i 1} Y_{i 2}-\frac{1}{2} Y_{i 2}^{2}\right] \\
& =\sum_{i}\left[\frac{1}{2} Y_{i 1}^{2}+\frac{1}{2} Y_{i 2}^{2}-Y_{i 1} Y_{i 2}\right] \\
& =\left[\frac{1}{2} \sum_{i}\left(Y_{i 1}-Y_{i 2}\right)^{2}\right] \\
& =\frac{1}{2} d_{12}^{2}
\end{aligned}
$$

que conforme equação (7), corresponde ao quadrado da distância euclidiana entre os ambientes 1 e 2 .

Considerando agora, os dois termos finais de (11):

$$
\begin{aligned}
-\frac{1}{g}\left(Y_{.1}^{2}+Y_{.2}^{2}\right)+\frac{\left(Y_{.1}+Y_{.2}\right)^{2}}{2 g} & =-\frac{1}{g}\left[Y_{.1}^{2}+Y_{.2}^{2}-Y_{.1} Y_{.2}-\frac{Y_{.1}^{2}}{2}-\frac{Y_{.2}^{2}}{2}\right] \\
& =-\frac{1}{g}\left[\frac{Y_{.1}^{2}}{2}+\frac{Y_{.2}^{2}}{2}-Y_{.1} Y_{.2}\right] \\
& =-\frac{1}{2 g}\left[Y_{.1}^{2}+Y_{.2}^{2}-2 Y_{.1} Y_{.2}\right] \\
& =-\frac{1}{2 g}\left[Y_{.1}-Y_{.2}\right]^{2}
\end{aligned}
$$


$\log 0$

$$
S Q(G \times E)_{12}=\frac{1}{2}\left[d_{12}^{2}-\frac{1}{g}\left(Y_{.1}-Y_{.2}\right)^{2}\right]
$$

que corresponde a expressão (7), proposta por Lin (1982).

Quando são incluídos mais ambientes ao grupo, por exemplo, 3 ambientes, tem-se:

$$
S Q(G \times E)_{j j^{\prime} k}=\theta_{j j^{\prime} k}=\frac{2}{n}\left(\theta_{j j^{\prime}}+\theta_{j k}+\theta_{j^{\prime} k}\right) \quad \text { em que, } \mathrm{n}=3 .
$$

Denotando $\theta_{j j^{\prime}}+\theta_{j k}+\theta_{j^{\prime} k}=S_{j j^{\prime}}$ ao incluir-se o quarto ambiente ao grupo, tem-se:

$$
S Q(G \times E)_{j j^{\prime} k l}=\frac{2}{n}\left(S_{j j^{\prime}}+\theta_{j l}+\theta_{j^{\prime} l}+\theta_{k l}\right) \quad \text { em que, } \mathrm{n}=4 .
$$

Esse procedimento deve ser adotado, sucessivamente, para verificar se outro ambiente é incluído ao grupo.

O coeficiente de correlação entre as produções médias num local, e as produções médias em cada um dos outros locais, também foram utilizados para determinar as similaridades entre ambientes (Campbell \& Lafever, 1977).

Atlin et al. (2000) propuseram um modelo para estratificação de grandes regiões, baseado na resposta correlacionada com a seleção, com base na eficácia para aumento de ganho genético. Assim, a resposta correlacionada na subregião com seleção indireta na região, relativa à resposta direta com a seleção dentro da sub-região, foi expressa como uma função da herdabilidade na região e na subregião, bem como da correlação genotípica entre médias da região e sub-região.

Gauch \& Zobel (1997) utilizaram o modelo AMMI com o auxílio da análise gráfica em biplot para alocar locais em mega-ambientes. Esses, representam porções amplas, não necessariamente contíguas de uma cultura, desenvolvida em uma região que apresenta ambientes bastantes homogêneos e que produzem genótipos similares quanto à produtividade. Romagosa \& Fox (1993), reportaram que a análise AMMI é mais apropriada do que a análise de componentes principais (ACP), para estudos sobre a interação $\mathrm{G} \times \mathrm{E}$, no que diz respeito ao agrupamento de ambientes. 
O estudo da avaliação dos ambientes (estratificação ambiental), nos ensaios de competição de cultivares são de grande importância, pois, a escolha da rede de ambientes para tais avaliações, em cada estado, é subjetiva, ou, muitas vezes, influenciada por fatores que não são relacionados com aspectos da cultura (Vencovsky et al., 1990).

Outro problema devido à interação $\mathrm{G} \times \mathrm{E}$ significativa, é identificar em quais dos ambientes a seleção deve ser processada. Seria nos ambientes favoráveis, que proporcionam as maiores produtividades, fornecem uma maior discriminação entre os ambientes e permitem as maiores manifestações da variabilidade genotípica ou, ambientes menos favoráveis?

Para Francis \& Kannenberg (1978), Brennan \& Byth (1979), Brakke et al. (1983), Soares (1987) e Furtado et al. (1990), os ambientes favoráveis, são os mais apropriados. Entretanto, Hinson \& Hanson (1962) e Lin \& Wu (1974) discordaram alegando que os ambientes favoráveis não correspondem às condições predominantes na maioria das lavouras comerciais, e que, por isso, a seleção deve ser realizada em ambientes o mais semelhante possível da realidade dos agricultores, ou seja, em ambientes menos favoráveis.

Dentro desse enfoque, Freeman (1973) afirmou que, em termos práticos, é desejável estimar a interação $\mathrm{G} \times \mathrm{E}$ para apontar os ambientes em que são maximizados os efeitos genotípicos de interesse.

Visando melhorar a eficiência dos métodos de melhoramento, Burton (1997), procurou desenvolver métodos para manejar a interação $\mathrm{G} \times \mathrm{E}$, de forma que as herdabilidades para produtividade fossem aumentadas. Toledo et al. (2000) também enfatizaram que a baixa herdabilidade do caráter e os consideráveis níveis de interação $\mathrm{G} \times \mathrm{E}$ exigem que a avaliação da produtividade seja criteriosamente realizada para haver progresso genético por seleção.

Entretanto, o fato de a interação $\mathrm{G} \times \mathrm{E}$ mostrar-se significativa, não diz muito, e força o melhorista a descobrir seus efeitos, o que pode ser feito pela decomposição de sua variância em dois componentes: o primeiro, pela função do contraste 
da variabilidade genética dentro dos ambientes, o que corresponde à interação simples; o segundo, aparece devido à falta de correlação genética entre os genótipos nos ambientes, o que corresponde à interação complexa.

Diante dos fatos abordados, vê-se que a interação $\mathrm{G} \times \mathrm{E}$ não deve ser encarada como um problema, ou um fator indesejável, cujos efeitos devem ser minimizados em um programa de melhoramento, mas como um fenômeno biológico natural, cumprindo-nos conhecê-la bem, para melhor aproveitá-la no processo de seleção (Chaves 2001). Assim, como já relatado anteriormente, genótipos que interagem positivamente com ambientes, podem fazer a diferença entre um bom e um ótimo cultivar, além de que, a obtenção de genótipos ideais é importante para uma melhor caracterização das variedades aos produtores, assim como na escolha de testemunha para experimentos comparativos e de genitores para cruzamento, em programas de melhoramentos (Gauch \& Zobel, 1996; Duarte \& Vencovsky, 1999). Esse enfoque passa a ter maior importância no caso de espécies onde o investimento é muito alto e demorado, como é o caso do melhoramento florestal.

Entretanto, apesar de serem de grande importância para o melhoramento, uma simples análise da interação $\mathrm{G} \times \mathrm{E}$, não proporciona informações precisas sobre o comportamento de cada genótipo frente às variações ambientais. Para tal objetivo, realizam-se análises de estabilidade e adaptabilidade fenotípica, pelas quais torna-se possível a identificação de cultivares com comportamento previsível e que sejam responsivos às variações ambientais, em condições especificas ou amplas (Cruz \& Regazzi. 1994).

\subsection{Estabilidade e adaptabilidade fenotípica}

As metodologias para as análises da estabilidade e adaptabilidade fenotípica destinam-se à avaliação de um grupo de genótipos testados em vários ambientes. Tais metodologias são fundamentadas na existência da interação genótipo com ambiente $(\mathrm{G} \times \mathrm{E})$. Assim, esses procedimentos são complementares ao da análise de variância individual e conjunta, com dados experimentais resultantes de ensaios 
realizados em uma série de ambientes.

Segundo Vencovsky \& Barriga (1992), a adaptação e a estabilidade, embora sejam fenômenos relacionados, não devem ser considerados como um só. Nesse sentido, vários métodos genético-estatísticos foram propostos para medir a estabilidade e a adaptabilidade fenotípica. Suas diferenças provêm dos vários conceitos empregados e dos diferentes procedimentos estatísticos utilizados para suas determinações.

\subsubsection{Principais conceitos}

Lewis (1954) relatou a estabilidade fenotípica como a capacidade de um indivíduo ou de uma população, de produzir variações mínimas de fenótipos em diferentes ambientes.

Finlay \& Wilkinson (1963) definiram estabilidade média de uma forma dinâmica, para caracterizar uma variedade cuja produção varia, de acordo com a capacidade dos ambientes, em proporcionar altas ou baixas produtividades.

Allard \& Brasdshaw (1964) apresentaram como variável estável, aquela que apresenta potencial para ajustar o seu estado genotípico e fenotípico às flutuações ambientais.

Para Eberhart \& Russel (1966) e Mariotti et al. (1976), a adaptabilidade refere-se à capacidade de os genótipos aproveitarem vantajosamente os estímulos do ambiente. Cruz \& Regazzi (1994) conceituaram adaptabilidade da mesma forma e comentaram que estabilidade refere-se à capacidade de os genótipos mostrarem um comportamento altamente previsível, em função do estímulo ambiental.

Heinrich et al. (1983), descreveram estabilidade de produção, como a capacidade de um genótipo de evitar flutuações substanciais na produção sobre vários ambientes.

Lin et al. (1986), sugeriram três conceitos: a) na estabilidade do tipo 1, o cultivar será considerado estável se sua variância entre ambientes for pequena; b) na do tipo 2, o cultivar será estável se sua resposta aos ambientes for paralela ao 
desempenho médio de todos os cultivares avaliados nos experimentos, e c) na do tipo 3, será estável o cultivar que apresentar o quadrado médio do desvio de regressão baixo, próximo a zero, ou seja, alta confiabilidade na resposta estimada.

Becker \& Léon (1988) dividem estabilidade em dois tipo: estática, associando aqueles genótipos que apresentam performance constante com as variações ambientais. Esse tipo de estabilidade é desejável quando se quer preservar determinada característica genética; e dinâmico, associando os genótipos que apresentam um comportamento previsível dentro das variações ambientais. Tanto para o tipo 3 de Lin et al. (1986), como para o tipo dinâmico de Becker \& Léon (1988), utiliza-se a análise estatística por regressão para fazer a previsibilidade da variação.

Yue et al. (1997), denotaram estabilidade como sendo a consistência no ranqueamento relativo de outros cultivares, num dado grupo de ambientes.

Lin et al (1986), identificaram quatro grupos de parâmetros estatísticos necessários para a avaliação da estabilidade, sendo: Grupo A - estimativas a partir dos efeitos genotípicos; Grupo B - estimativas baseadas na variância da interação genótipo com ambiente $(\mathrm{G} \times \mathrm{E})$; Grupo $\mathrm{C}$ - baseado nos coeficientes de regressão; e Grupo D - baseado nos desvios de regressão.

$\mathrm{Na}$ interpretação desses conceitos, as estimativas dos grupos A e B avaliam a estabilidade do tipo biológica, refletindo a uniformidade de produção entre os diversos ambientes, característica que, logicamente, será desejável em genótipos com boa produtividade. As estimativas do grupo C explicam o comportamento do genótipo, em termos do nível de resposta ao ambiente, indicando o tipo de adaptação, geral ou específica. As estimativas do grupo D expressam a confiabilidade no nível de resposta ao ambiente do genótipo, ou estabilidade do tipo agronômica.

Os autores apresentaram uma proposta de conceituação para a estabilidade fenotípica em função dos diversos parâmetros de avaliação: Tipo 1, o genótipo é considerado estável se a variância entre ambientes é pequena, e estão associadas ao conceito de estabilidade no sentido biológico ou estático, que são altamente dependentes do grupo de ambientes escolhidos. Apresentam como restrição, o fato 
de terem pouca utilidade para conjuntos de muitos ambientes, embora possam ser úteis em áreas geográficas mais restritas. Esse tipo de estabilidade está associado a respostas relativamente pobres, em ambientes de baixas produtividades, e, baixas produtividades em ambientes altamente produtivos. No Tipo 2, o genótipo é considerado estável se, sua resposta aos ambientes é paralela à resposta média de todos os genótipos do experimento. Está ligado ao conceito de estabilidade agronômica e depende do grupo de genótipos avaliados. No Tipo 3, o genótipo é considerado estável se, a relação entre o quadrado médio do resíduo da regressão, pelo índice ambiental, é pequena. As estatísticas mostram o quanto os dados se ajustam bem à regressão, mas não estabelecem relação direta com a estabilidade dos genótipos.

Vencovsky \& Torres (1988) apontaram dois tipos de estabilidade: a estabilidade espacial e a estabilidade temporal, enfatizando que a estabilidade espacial é sinônimo de adaptabilidade. Espera-se boa produtividade sem que haja interações com as flutuações climáticas existentes entre anos. Fox et al. (1997), seguiram essa mesma linha de conceito e usaram os termos adaptabilidade e estabilidade para referirem-se às dimensões, espacial e temporal, respectivamente.

Vencovsky \& Barriga (1992) chamaram a atenção para a existência de grupos de pesquisadores que preferiam utilizar o termo estabilidade para referirem-se à maior habilidade apresentada por certos genótipos, para adaptarem-se às flutuações climáticas ao longo de anos agrícolas, dentro de uma localidade. O termo adaptabilidade seria, nesse caso, empregado para designar a adaptação ecológica a diferentes ambientes, tais como locais ou outras condições geográficas.

Como relatado, existem na literatura muitos conceitos de estabilidade. Porém, os autores têm utilizado as terminologias de Finlay \& Wilkinson (1963) e de Eberhart \& Russel (1966) ou variações das mesmas. Alguns deles mostram uma certa concordância entre si, ou seja, genótipo estável seria aquele que, quando cultivado em vários ambientes, apresentasse pouca oscilação para o caráter avaliado.

Nesse sentido, o conceito de estabilidade é muito importante para os melhoristas de plantas, cujo interesse está na obtenção de variedades que se com- 
portem bem, não apenas em um ambiente particular, mas também em amplas faixas de cultivo, onde ocorrem diferentes condições ambientais. O ambiente em questão pode ter várias interpretações, como locais (solo, clima, etc.), anos, épocas, sistemas de plantio e colheita, técnicas de cultivo, etc.

É importante ressaltar que, os parâmetros que determinam a estabilidade, são específicos para os materiais genéticos avaliados, bem como para os ambientes analisados, sendo errôneo inferir esses resultados para outros materiais e ambientes (Yates \& Cochran, 1938).

\subsubsection{Metodologias univariadas}

Dentre os métodos propostos para estudar a estabilidade e a adaptabilidade fenotípica, destacam-se: os procedimentos baseados na variância da interação G×E (Plaisted \& Peterson, 1959; Wricke, 1962; Tai, 1971; Shukla, 1972; Wricke \& Weber, 1986 e Magari \& Kang, 1997); regressão linear simples (Yates \& Cochran , 1938, Finlay \& Wilkinson, 1963; Eberhart \& Russell, 1966 e Perkins \& Jinks, 1968) e regressão múltipla (Verma et al, 1978; Silva \& Barreto, 1986; Cruz et al., 1989 e Storck \& Vencovsky, 1994); regressão quadrática (Brasil \& Chaves, 1994); modelos não lineares (Chaves et al. 1989; Toler \& Burrows, 1998; Silva, 1998 e Rosse \& Vencovsky, 2000) e não paramétricos, como a ordem de classificação genotípica (Huehn, 1996); métodos multivariados, com a ACP (Crossa, 1990), análise de agrupamento (Hanson, 1994), análise fatorial de correspondências (Hill, 1974) e análise de coordenadas principais (Westcott, 1987); e métodos que integram a análise comum de variância (método univariado) com a análise de componentes principais (método multivariado), como é o caso da análise AMMI sugerido por Gauch \& Zobel (1996). As diferenças entre eles originam-se nos diferentes conceitos e procedimentos matemáticos utilizados para medir a interação $(\mathrm{G} \times \mathrm{E})$ e suas conseqüências nos programas de melhoramentos.

A medida mais simples de estabilidade fenotípica de um genótipo é dada pela variância de sua performance entre os diversos ambientes. Esse tipo de 
estabilidade é considerado como estabilidade no sentido biológico. Entretanto, normalmente, a baixa variância esta associada a genótipos de baixa produtividade e vice-versa (Becker \& Léon, 1988). Assim, essa estatística não contempla, perfeitamente, as aspirações dos melhoristas.

Pode ser creditada à Roemer ${ }^{1}$, citado por Duarte \& Zimmermann (1995), uma das primeiras metodologias propostas para avaliar a estabilidade fenotípica, baseada na interação $(\mathrm{G} \times \mathrm{E})$.

Roemer utilizou a variabilidade da média de um determinado genótipo, nos diversos ambientes, para caracterizar a estabilidade fenotípica das variedades. Tal estimativa foi calculada por:

$$
\operatorname{Ro\sigma }_{i}^{2}=\frac{\left[\sum_{j} Y_{i j}^{2}-\frac{\left(Y_{i .}\right)^{2}}{\ell}\right]}{\ell-1}
$$

em que, $\ell$ é o número de locais ou ambientes de avaliação; $Y_{i j}$ é a observação do genótipo i no ambiente $\mathrm{j}(\mathrm{i}=1,2, \cdots, \mathrm{g}$ e $\mathrm{j}=1,2, \cdots, \mathrm{e})$.

Quanto menor $R o \sigma_{i}^{2}$, maior a estabilidade do genótipo.

Plaisted \& Peterson (1959) verificaram que, quando são testados genótipos em vários locais, uma proporção da variância é devida à $\mathrm{G} \times \mathrm{E}$, e que, dessa variância, cada genótipo contribui com uma determinada fração. O parâmetro de estabilidade é obtido pela média aritmética dos componentes de variância da interação $\mathrm{G} \times \mathrm{E}$, que envolve um genótipo particular:

$$
\begin{aligned}
p p_{i} & =\frac{\sum_{i^{\prime}} \hat{\sigma}_{g e_{i i^{\prime}}}^{2}}{g-1} \text { em que: } \\
\hat{\sigma}_{g e_{i i^{\prime}}}^{2} & =\frac{Q M(G \times E)_{i i^{\prime}}-Q M R}{b}
\end{aligned}
$$

e b representa o número de blocos ou repetições.

${ }^{1}$ ROEMER, T. Sind die ertragsreichen Sorten ertragssicherer? Mitt. DLG., v.32, n.1, p.87-89, 1917. 
Os genótipos mais estáveis serão aqueles que apresentarem as menores estimativas de $p p_{i}$ e, consequentemente, contribuem menos para a interação $\mathrm{G} \times \mathrm{E}$.

Wricke (1962), através de uma análise de variância, calculou a contribuição individual dos genótipos para a interação, e denominou essa estatística de "ecovalência" e, sua estimativa consiste na decomposição da $\mathrm{SQ}(\mathrm{G} \times \mathrm{E})$, nas partes devidas a genótipos isolados.

As vantagens e desvantagens dessa metodologia são, em sua maioria, as mesmas apresentadas pela metodologia de Plaisted e Peterson, visto que os parâmetros de estabilidade são obtidos pela decomposição da variância devida à interação genótipos por ambientes. Assim, o parâmetro estimado por esse método, também refere-se apenas à estabilidade fenotípica. A partição da $\mathrm{SQ}(\mathrm{G} \times \mathrm{E})$ é dada por:

$$
w_{i}=\sum_{j}(\widehat{G E})_{i j}^{2}
$$

em que $(\widehat{G E})_{i j}$ é definido conforme equação (1).

Segundo Wricke, os genótipos mais estáveis estão associados às menores estimativas de $w_{i}$.

Tai (1971), ao referir-se à análise de estabilidade, procura estudar a relação:

$$
G E_{i j}=b_{i} E_{j}+\delta_{i j}
$$

Entretanto, como as estimativas de mínimos quadrados, para $G E_{i j}$ e $E_{j}$, estão sujeitas a erros, propõe a correção:

$$
\hat{b}_{i}^{*}=\frac{\widehat{\operatorname{Cov}}\left(\widehat{G E}_{i j}, E_{j}\right)}{\hat{\sigma}_{e}^{2}},
$$

em que, $\hat{\sigma}_{e}^{2}$ é a estimativa do erro associado ao efeito da interação $G \times E$.

Outros métodos de avaliação da estabilidade fenotípica que merecem destaques são os de parâmetros $\hat{\sigma}_{i}^{2}$ e $S_{i}^{2}$ propostos por Shukla (1972), derivados da ecovalência, e o teste estatístico (teste-F), proposto por Kang \& Miller (1984), 
para $w^{2}$ através do cálculo da ecovalência média de cada genótipo, usando como denominador um "pool" de variâncias ambientais e o método tradicional.

O método tradicional, consiste em se fazer uma análise conjunta dos experimentos, ou seja, analisar os diversos genótipos nos vários ambientes e, posteriormente, fazer a decomposição da soma de quadrados (SQ) devida aos ambientes, adicionada à $\mathrm{SQ}$ da interação $\mathrm{G} \times \mathrm{E}$, nas somas de quadrados de ambientes dentro de cada genótipo $(\mathrm{SQE} / \mathrm{G})$. A variação de ambientes dentro de cada genótipo é usada como estimador da estabilidade, de modo que o genótipo que apresentar menor quadrado médio, ou seja, menor variância, será considerado o mais estável (Cruz \& Regazzi, 1994). As somas de quadrados de ambientes dentro de genótipos pode ser obtida por:

$$
\begin{aligned}
S Q E / G & =S Q E+S Q(G \times E), \text { ou ainda, } \\
S Q E / G_{i} & =b \frac{\left[\sum_{j} Y_{i j}^{2}-\frac{\left(Y_{i .}\right)^{2}}{\ell}\right]}{\ell-1},
\end{aligned}
$$

em que, $\ell$ é o número de locais ou ambientes de avaliação, e b o número de blocos ou repetições.

A metodologia de Plaisted \& Peterson (1959) é eficiente para indicar os genótipos mais estáveis, em relação à metodologia tradicional, por trabalhar com componentes de variância da interação $\mathrm{G} \times \mathrm{E}$ e não com o quadrado médio de ambiente dentro de genótipo, cuja estimativa envolve também o componente do erro associado a cada genótipo que pode não ser homogêneo. Admitindo que os genótipos que mais contribuem para a interação $\mathrm{G} \times \mathrm{E}$ são aqueles que apresentam adaptações específicas a determinados tipos de ambientes, pode-se verificar que, o parâmetro estimado por esse método é o mesmo do método tradicional, ou seja, estabilidade fenotípica. Entretanto, a metodologia de Plaisted \& Peterson (1959) apresenta como desvantagem a imprecisão do parâmetro de estabilidade, relativo a qualquer componente de variância (Cruz \& Regazzi, 1994).

Fica evidenciado por esses métodos, que a variância mínima apresenta- 
da pelos genótipos expressa apenas a estabilidade fenotípica, ou seja, não há nenhuma estimativa da adaptabilidade dos cultivares nem do direcionamento de suas respostas aos diferentes tipos de ambientes. Essa é a principal desvantagem desses métodos, pois, em geral, os genótipos que apresentam um comportamento regular, entre os ambientes, são pouco produtivos. Além disso, segundo Monelli (1996), o parâmetro de estabilidade é pouco preciso. Contudo, esses métodos forneceram as bases para muitos autores desenvolverem outros métodos que, além de avaliar os efeitos genéticos, ambientais e suas interações, passaram a obter estimativas de parâmetros de estabilidade fenotípica, através da análise de regressão.

Becker \& Léon (1988) citam que Stringfleld \& Salter ${ }^{2}$, devem ter sido, provavelmente, os primeiros a calcular o coeficiente de regressão linear para caracterizar a resposta específica de genótipos às variações ambientais.

Yates \& Cochran (1938) sugeriram a decomposição da interação variedades $\times$ ambientes, determinando para cada variedade, uma regressão linear da produtividade, em relação à média da produtividade de todas as variedades em cada ambiente. Uma equação de regressão é ajustada para cada variedade que, representada em um gráfico de eixos cartesianos, mostra o comportamento individual de cada variedade, sob o efeito dos diferentes ambientes.

Os primeiros pesquisadores a trabalharem com índice ambiental foram Finlay \& Wilkinson (1963). Esses autores estimaram esse parâmetro como sendo a média de rendimento de todos os genótipos em cada ambiente. Sugeriram que a variável produtividade fosse submetida à transformação logarítmica, com a finalidade de aumentar a linearidade na regressão, e proporcionar maior homogeneidade das variâncias residuais dos experimentos. O modelo de regressão é dado por:

$$
y_{i j}=\beta_{0 i}+\beta_{1 i} x_{j}+\delta_{i j}+\bar{\epsilon}_{i j}
$$

${ }^{2}$ STRINGFLELD, G.H.; SALTER, R.M. Differential response of com varrieties to fertility levels and to seasons. Journal Agricultural Research., v.49, n.5, p.991-1000, 1939. 
em que:

$y_{i j} \quad$ : média do genótipo i no ambiente $\mathrm{j}$;

$\beta_{0 i} \quad$ : intercepto;

$\beta_{1 i}:$ coeficiente angular;

$x_{j}=\frac{1}{g} \sum_{i} y_{i j}, \quad$ definido como índice ambiental;

$\delta_{i j} \quad$ : desvio da regressão;

$\bar{\epsilon}_{i j} \quad$ : $\quad$ erro experimental médio.

Para facilitar as interpretações, utiliza-se o índice ambiental centrado, definido por:

$$
I_{j}=\frac{1}{g} \sum_{i} y_{i j}-\frac{1}{e g} y_{. .}
$$

Dessa forma, obtém-se ambientes favoráveis e desfavoráveis para os índices positivos e negativos, respectivamente. O estimador BLUE (Best Linear Unbiased Estimator) é obtido por:

$$
\hat{\beta}=\left(\mathbf{X}^{\prime} \mathbf{X}\right)^{-1} \mathbf{X}^{\prime} \mathbf{y}
$$

em que:

$$
y=\left[\begin{array}{c}
y_{i 1} \\
y_{i 2} \\
\vdots \\
y_{i e}
\end{array}\right] \quad e \quad X=\left[\begin{array}{cc}
1 & I_{1} \\
1 & I_{2} \\
\vdots & \vdots \\
1 & I_{e}
\end{array}\right]
$$

Logo,

$X^{\prime} X=\left[\begin{array}{cc}e & 0 \\ 0 & \sum_{j} I_{j}^{2}\end{array}\right] ; \quad\left(X^{\prime} X\right)^{-1}=\frac{1}{e \sum_{j} I_{j}^{2}}\left[\begin{array}{cc}\sum_{j} I_{j}^{2} & 0 \\ 0 & e\end{array}\right] \quad e \quad X^{\prime} y=\left[\begin{array}{c}\bar{y}_{i .} \\ \sum_{j} y_{i j} I_{j}\end{array}\right]$, portanto,

$$
\hat{\beta}=\left[\begin{array}{c}
\hat{\beta}_{0 i} \\
\hat{\beta}_{1 i}
\end{array}\right]=\left[\begin{array}{c}
\bar{y}_{i .} \\
\frac{\sum_{j} y_{i j} I_{j}}{\sum_{j} I_{j}^{2}}
\end{array}\right] .
$$


Por esse método, um genótipo ideal é aquele que apresenta produtividade média alta, coeficiente de regressão igual a um, e desvio de regressão próximo de zero, ou seja, seria um genótipo responsivo à melhoria das condições ambientais e de comportamento altamente previsível. Nesse caso, o teste estatístico recomendado para verificar a hipótese nula $H_{0}: \beta_{1 i}=1$ é dado por:

em que:

$$
t=\frac{\hat{\beta}_{1 i}-1}{\sqrt{\hat{V}\left(\hat{\beta}_{1 i}\right)}},
$$

$$
\begin{aligned}
\hat{V}\left(\hat{\beta}_{1 i}\right) & =\frac{1}{\sum_{j} I_{j}^{2}} \hat{\sigma}_{\epsilon}^{2} ; \\
\hat{V}\left(\hat{\beta}_{0 i}\right) & =\frac{1}{e} \hat{\sigma}_{\epsilon}^{2} \mathrm{e} \\
\hat{\sigma}_{\epsilon}^{2} & =\frac{Q M_{\text {res }}}{r} .
\end{aligned}
$$

Eberhart \& Russel (1966) com base na proposta de Finlay \& Wilkinson (1963), sugeriram a não transformação dos dados e a estimação dos desvios da regressão. Para eles, os desvios da regressão são indicativos do grau de confiabilidade da resposta linear estimada, o que caracteriza a previsibilidade do genótipo. O modelo sugerido é dado por:

$$
Y_{i j}=\beta_{0 i}+\beta_{1 i} I_{j}+\delta_{i j}+\bar{\varepsilon}_{i j}
$$

em que:

$y_{i j}:$ média do genótipo i no ambiente $\mathrm{j}$;

$\beta_{0 i}$ : intercepto; média geral do genótipo i $(\mathrm{i}=1,2, \cdots, \mathrm{g})$;

$\beta_{1 i}$ : coeficiente angular; resposta linear do genótipo i à variação ambiental;

$I_{j}:$ índice ambiental codificado $(13)$, tal que $\sum_{j} I_{j}=0$ para $\mathrm{j}=1,2, \cdots$, e;

$\delta_{i j}:$ desvio da regressão e

$\bar{\varepsilon}_{i j} \quad: \quad$ erro experimental médio. 
As estimativas dos parâmetros $\beta_{0 i}$ e $\beta_{1 i}$ são estimados de forma análoga ao método de Finlay \& Wilkinson (1963), e, a medida da estabilidade $\left(s^{2} d_{i}\right)$, e, previsibilidade do comportamento linear $\left(r_{i}^{2}\right)$, são dados por:

$$
s^{2} d_{i}=\frac{\left(\sum_{j} Y_{i j}^{2}-\frac{Y_{i .}^{2}}{m}\right)-\frac{\left(\sum_{j} Y_{i j} I_{j}\right)^{2}}{\sum_{j} I_{j}^{2}}}{m-2} \mathrm{e}
$$

em que, m é o número de graus de liberdade do resíduo, $s_{I_{j}}^{2}=\sum_{j} I_{j}^{2} /(m-1)$ e $S Q E / G_{i}$, conforme equação (12).

Essa metodologia permite que se faça desdobramento das somas de quadrados da interação $\mathrm{G} \times \mathrm{E}$ em duas partes, uma devida à regressão linear e a outra aos desvios da regressão. A estabilidade fenotípica e a adaptabilidade de genótipos são obtidas em função do coeficiente de regressão $\beta_{1 i}$ e de sua produtividade média $\bar{Y}_{i .}$, respectivamente. Assim, quando os genótipos apresentam coeficientes de regressão próximos a um, os autores consideram-nos de estabilidade média (sentido agronômico). Quando estão associados à produtividade alta, são de adaptabilidade geral, caso contrário são considerados pouco adaptados. Genótipos com coeficientes de regressão maiores do que um, apresentam estabilidade abaixo da média, sendo especificamente adaptados para ambientes mais produtivos (ambientes favoráveis), ao passo que, com coeficientes de regressão menores do que um, são especificamente adaptados para os ambientes de baixa produtividade (ambientes desfavoráveis). Aqueles com $\beta_{1 i}$ próximo de zero são definidos como sendo de estabilidade absoluta (estabilidade no sentido biológico) e, se estiverem associados a alta produtividade, caracterizarão o genótipo ideal (Bilbro \& Ray, 1976).

Segundo Becker \& Léon, 1988 e Romagosa \& Fox, 1993, a grande maioria dos melhoristas utiliza-se da análise de regressão para estudar a estabilidade fenotípica. Entretanto, o uso da regressão linear simples, como proposto por Eberhart \& Russel (1966), têm sido amplamente discutidos, principalmente, pelo 
fato de que os índices ambientais, tal como foram tomados, não são independentes das variedades testadas (o índice ambiental é obtido a partir dos próprios dados) e isso sofre algumas críticas de cunho estatístico (Lin et al., 1986; Crossa, 1990; Storck \& Vencovsky, 1994).

Segundo Crossa (1990), entre as principais limitações do uso da regressão linear simples como metodologia para se estimar estabilidade fenotípica de cultivares, está a dependência que existe entre a variável que mede o índice ambiental $\left(I_{j}\right)$ e a produtividade média do cultivar $\bar{Y}_{i}$, já que a primeira é obtida em função de $\bar{Y}_{i j}$. Isso viola um dos princípios da análise de regressão que é a independência entre as variáveis dependentes e independentes. Storck \& Vencovsky (1994), concluíram que a variância associada à variável independente (índice ambiental) é função do número de ambientes, de repetições dentro de ambientes e de tratamentos envolvidos, além também, de erro experimental e da variância de blocos dentro dos ambientes. Assim, quando o erro dessa estimativa for de alta magnitude, pode-se inferir que a estimativa desse parâmetro está viesada. É oportuno salientar que a variância é maior quando o número de cultivares presentes no estudo é pequeno (g < 15, Rosse, (1999)). Entretanto, tanto a independência quanto a variância não seria problema se, no experimento, estiver incluído um número razoável de genótipos, e a amplitude de ambientes for tal que o quadrado médio deles seja significativamente maior que o quadrado médio do erro.

Outro problema da aplicação dessa metodologia ocorre quando o número de ambientes é pequeno e os genótipos têm desempenho muito diferentes. Nesse caso, a adaptação de um dado genótipo pode ser devida, principalmente, ao desempenho naqueles ambientes extremos, o que provavelmente mascararia os resultados (Crossa, 1990).

Por fim, Crossa (1990) comenta que, a obtenção de parâmetros via análise de regressão linear, é bastante usada por melhoristas de plantas, por ser uma técnica matematicamente simples e biologicamente interpretável. No entanto, apresenta algumas desvantagens: 
a) não é informativa quando a linearidade falha;

b) é altamente dependente do grupo de genótipos e ambientes incluídos na análise;

c) tende a simplificar padrões de resposta diferentes, por explicar a variação da interação $\mathrm{G} \times \mathrm{E}$ em apenas uma dimensão (coeficiente de regressão), quando na realidade ela pode ser altamente complexa.

Lin et al. (1986) questionam o uso dos desvios da regressão como parâmetro de estabilidade. Segundo esses autores, essa estimativa não é a mais correta para avaliar a estabilidade do genótipo, servindo apenas como indicativo do ajustamento dos dados à linha de regressão. Se esse componente for significativo, não se deve interpretá-lo como sendo conseqüência de uma não adequação do modelo de regressão ao conjunto de dados analisados, mas sim, devido à extrema diversidade dos genótipos envolvidos. Desse modo, a utilização da técnica de regressão linear, bem como a interpretação de seus parâmetros, principalmente a variância dos desvios da regressão, devem ser feitas com ressalvas (Rosse,1999). Outra crítica feita por Cruz \& Regazzi, 1994, relaciona os riscos em descartar bons genótipos quando eles apresentarem altos valores de desvios de regressão e também, se forem avaliados por um único coeficiente de regressão.

Diante desses problemas, Verma et al. (1978), propuseram uma técnica alternativa de regressão, que consiste no ajuste de duas regressões lineares separadamente, argumentando que, em quase todas as espécies cultivadas, há genótipos apropriados para ambientes pobres (desfavoráveis) e ricos (favoráveis). Envolveram, também, nesse modelo, o menor índice ambiental negativo em valor absoluto, visando manter a continuidade de regressão. Justificaram o uso dessa metodologia argumentando que o ajustamento de dois ou mais segmentos de reta podem explicar melhor a resposta daqueles genótipos, cujos desvios de regressão linear simples se mostrassem elevados.

Verma et al. (1978) classificaram, conforme o padrão de resposta dos genótipos frente aos ambientes favoráveis e desfavoráveis, em nove categorias de 
sensibilidade de resposta (Tabela 4).

Tabela 4. Categorias de sensibilidade de respostas, para classificação de genótipos, segundo Verma et al. (1978)

\begin{tabular}{ccc}
\hline Categorias & Ambientes desfavoráveis & Ambientes favoráveis \\
\hline 1 & $\beta_{1}<1$ & $\beta_{2}<1$ \\
2 & $\beta_{1}<1$ & $\beta_{2}=1$ \\
3 & $\beta_{1}<1$ & $\beta_{2}>1$ \\
4 & $\beta_{1}=1$ & $\beta_{2}<1$ \\
5 & $\beta_{1}=1$ & $\beta_{2}=1$ \\
6 & $\beta_{1}=1$ & $\beta_{2}>1$ \\
7 & $\beta_{1}>1$ & $\beta_{2}<1$ \\
8 & $\beta_{1}>1$ & $\beta_{2}=1$ \\
9 & $\beta_{1}>1$ & $\beta_{2}>1$ \\
\hline
\end{tabular}

Pelo método proposto por Verma et al. (1978), o genótipo mais estável seria escolhido com base na análise conjunta dos coeficientes de regressão, para os ambientes favoráveis e desfavoráveis. A referida metodologia fundamenta-se no princípio de que, um genótipo teoricamente ideal é aquele com rendimento relativamente elevado e constante, em ambientes considerados desfavoráveis $\left(\hat{\beta}_{1 i} \cong 0\right)$, mas com capacidade para responder a ambientes favoráveis $\left(\hat{\beta}_{2 i} \geq 1\right)$, isto é, à melhoria do ambiente. A categoria 3 é a que contempla o genótipo de desempenho ideal, por ser responsivo a ambientes melhorados, ou favoráveis, e manter a produtividade em níveis razoáveis, em ambientes adversos.

O método proposto por Silva \& Barreto (1985), surgiu como alternativa para contornar os inconvenientes da técnica proposta por Verma et al. (1978). Nesse método, o ajustamento para cada genótipo, é obtido de uma única equação de regressão, constituída de dois segmentos de reta, com união no ponto correspondente ao valor zero do índice de ambiente. No primeiro segmento, que abrange os 
ambientes desfavoráveis $\left(I_{J} \leq 0\right)$, a estabilidade é dada pela estimativa do coeficiente de regressão $\hat{\beta}_{1 i}$. Para o segundo segmento, que considera os ambientes favoráveis $\left(I_{j}>0\right)$, a estabilidade é dada por $\left(\hat{\beta}_{1 i}+\hat{\beta}_{2 i}\right)$, e vice-versa, sem que isso seja devido a causas genéticas. Os índices ambientais utilizados nessa metodologia são os mesmos da equação (13). O modelo de regressão linear segmentado é definido pela equação:

$$
Y_{i j}=\beta_{0 i}+\beta_{1 i} I_{j}+\beta_{2 i} T\left(I_{j}\right)+\delta_{i j}+\bar{\varepsilon}_{i j}
$$

em que:

$$
\begin{aligned}
& T\left(I_{j}\right)=0 \quad \text { se } I_{j} \leq 0 \\
& T\left(I_{j}\right)=I_{j} \quad \text { se } I_{j}>0
\end{aligned}
$$

Os estimadores das soma de quadrados e dos parâmetros de estabilidade, além dos testes de significância, são semelhantes aos empregados nas metodologias de Finlay \& Wilkinson (1963) e Eberhart \& Russel (1966).

Uma das desvantagens desse método surge quando o número de ambientes é reduzido, de modo que a análise torna-se de pouca precisão (número reduzido de graus de liberdade para cada linha de regressão), além de provocar também, a não independência entre as linhas de regressão, o que torna os testes estatísticos questionáveis.

Cruz et al. (1989) propuseram uma alteração na metodologia proposta por Silva \& Barreto (1985), e implantaram um modelo de regressão descontínuo, com estimativas não correlacionadas dos coeficientes de regressão. O objetivo era facilitar a estimação dos parâmetros e melhorar a precisão das estimativas. O modelo matemático proposto é o mesmo que apresentado na equação 14, entretando, o índice de ambiente foi codificado por:

$$
\begin{aligned}
& T\left(I_{j}\right)=0 \quad \text { se } I_{j} \leq 0 \\
& T\left(I_{j}\right)=I_{j}-\bar{I}_{+} \quad \text { se } I_{j}>0
\end{aligned}
$$

sendo $\bar{I}_{+}$a média dos índice $I_{j}$ positivos. 
Os estimadores de mínimos quadrados para a constante e para os coeficientes de regressão são dados por:

$$
\begin{aligned}
\hat{\beta}_{0 i} & =\bar{Y}_{i .,} \\
\hat{\beta}_{1 i} & =\frac{\sum_{j} Y_{i j}-\sum_{j} Y_{i j} T\left(I_{j}\right)}{\sum_{j} I_{j}^{2}-\sum_{j} T^{2}\left(I_{j}\right)}, \\
\hat{\beta}_{2 i} & =\frac{\sum_{j} I_{j}^{2} \sum_{j} Y_{i j} T\left(I_{j}\right)-\sum_{j} T^{2}\left(I_{j}\right) \sum_{j} Y_{i j} I_{j}}{\sum_{j} T^{2}\left(I_{j}\right)\left[\sum_{j} I_{j}^{2}-T^{2}\left(I_{j}\right)\right]} .
\end{aligned}
$$

A esses estimadores estão associadas as seguintes variâncias:

$$
\begin{aligned}
V\left(\widehat{\beta}_{0 i}\right) & =\frac{\hat{\sigma}^{2}}{e r}, \\
V\left(\widehat{(\beta}_{1 i}\right) & =\frac{\hat{\sigma}^{2}}{r \sum_{j} I_{j}^{2}-\sum_{j} T^{2}\left(I_{j}\right)} \mathrm{e} \\
V\left(\widehat{\beta}_{2 i}\right) & =\frac{\hat{\sigma}^{2} \sum_{j} I_{j}^{2}}{r \sum_{j} T^{2}\left(I_{j}\right)\left[\sum_{j} I_{j}^{2}-T^{2}\left(I_{j}\right)\right]},
\end{aligned}
$$

em que:

$\hat{\sigma}^{2}$ : quadrado médio do resíduo da análise de variância conjunta (QMR);

$r$ : número de repetições que deram origem ás médias.

Em função da equação 15, que impede que as linhas de regressão se toquem no ponto onde o índice ambiental é nulo, permite a independência dos dois segmentos de reta, ou seja, na descontinuidade. Assim, caso ocorra correlação entre os coeficientes de regressão, ela é decorrente apenas das propriedades dos materiais genéticos (Carneiro, 1998). Desse modo, um genótipo desejável, por essa metodologia, seria aquele que apresentasse média alta, e baixo $\hat{\beta}_{1 i}$ (próximo de zero) nos ambientes desfavoráveis, e que fosse responsivo à melhoria do ambiente, com $\hat{\beta}_{1 i}+$ $\hat{\beta}_{2 i}$ o maior possível, e, preferencialmente, com comportamento altamente previsível. 
A estabilidade é avaliada por dois parâmetros: pelo desvio da regressão de cada genótipo, em função das variações ambientais, e pelo coeficiente de determinação.

Um dos inconvenientes que surgem com relação ao emprego do coeficiente de determinação, como medida de previsibilidade dos genótipos, é que, esse parâmetro dependente da magnitude do coeficiente de regressão $\left(\hat{\beta}_{1 i}\right)$, o que provoca uma certa tendenciosidade nas conclusões (Duarte \& Zimmermann, 1995). Segundo esses autores, o desvio da regressão apresenta uma menor associação com o coeficiente de regressão, devendo ser, por isso, preferível para inferir sobre a previsibilidade dos genótipos.

Posteriormente, Storck (1989) estendeu o método de Cruz et al. (1989), com a finalidade de aprimorar a metodologia, incluindo mais um parâmetro de descontinuidade $\left(\beta_{3 i}\right)$, no ponto médio do índice ambiental, de modo a manter a independência entre os ângulos dos dois segmentos. Denominando de modelo bissegmentado descontínuo, procurou associar a interpretação das estimativas dos parâmetros do modelo sob a forma de curva exponencial de crescimento, dando um sentido mais agronômico às interpretações. Considerou, como cultivares desejáveis, os que se identificam com a fase inicial da curva de crescimento (ângulo do primeiro segmento menor do que 1, ângulo do segundo segmento maior do que o do primeiro e descontinuidade positiva), possuem média alta em ambientes inferiores e apresentam pequena variação dos desvios da regressão. Em tal modelo deve-se preferir um número de repetições que permita uma boa estimativa da média, com o maior número possível de ambientes, sendo que os valores ambientais devem ser equidistantes e com maior amplitude de variação possível.

Outra proposta de modelo segmentado para avaliação de estabilidade fenotípica, foi apresentada por Brasil (1990). Esse modelo utiliza-se de três parâmetros para se mensurar a estabilidade:

1) coeficiente de primeiro grau que mede a estabilidade do cultivar no ambiente médio; 
2) coeficiente de regressão quadrático que mede a concavidade da curva de regressão, dando uma idéia da mudança de resposta dos cultivares com o aumento do índice ambiental, e

3) coeficiente de determinação do modelo quadrático.

Segundo esse autor, o cultivar de comportamento ideal é aquele que apresenta média elevada, coeficiente de regressão de primeiro grau unitário e positivo, coeficiente de regressão quadrático positivo e significativamente diferente de zero e coeficiente de determinação do modelo tendendo a um, no modelo:

$$
Y_{i j}=\beta_{0 i}+\beta_{1 i} I_{j}+\beta_{2 i} I_{j}^{2}+\delta_{i j}+\bar{\varepsilon}_{i j}
$$

em que:

$\beta_{0 i}$ : média geral do genótipo i $(\mathrm{i}=1,2, \cdots, \mathrm{g})$;

$\beta_{1 i}$ : resposta linear do genótipo i à variação ambiental;

$\beta_{2 i}$ : resposta quadrática do genótipo i à variação ambiental;

$I_{j}$ : índice ambiental (13) para o local $\mathrm{j}(\mathrm{j}=1,2, \cdots, \mathrm{e})$;

$\delta_{i j}:$ desvio da regressão e

$\bar{\varepsilon}_{i j}:$ erro experimental médio.

Lin \& Binns (1988) definiram como medida de estabilidade, o quadrado médio da distância entre a média do cultivar e a resposta média máxima para todos os locais. Desde que a resposta máxima esteja no limite superior em cada local, o quadrado médio menor indicará uma superioridade geral do cultivar em questão. Essa medida de superioridade é dada por:

$$
P_{i}=\frac{\sum_{j=1}^{n}\left(Y_{i j}-Y_{M(j)}\right)^{2}}{2 e},
$$

em que:

$P_{i}$ : a estimativa do parâmetro estabilidade do cultivar i, denominada de Me- 
dida de Adaptabilidade e Estabilidade de Comportamento (MAEC);

$Y_{i j}:$ a produtividade do i-ésimo cultivar no j-ésimo local;

$Y_{M(j)}$ : a resposta máxima observada entre todos os cultivares no local j;

$e$ : o número de locais.

Quanto menor a distância entre a resposta do genótipo e a produtividade máxima, ou seja, quanto menor $P_{i}$, mais estável é o genótipo. Esse método é similar ao método de Plaisted \& Peterson (1959), exceto que o parâmetro de estabilidade é baseado nos efeitos médios de genótipo e da interação $\mathrm{G} \times \mathrm{E}$, e que cada genótipo é comparado somente com a produtividade máxima em cada ambiente. Segundo Carneiro (1998), a avaliação da performance genotípica nesse método é relativa a um cultivar hipotético de adaptabilidade geral, cujo coeficiente de regressão da produtividade em função dos índices ambientais, é igual à unidade, ou seja, a estatística $P_{i}$ considera o conceito de adaptabilidade geral definido por Finlay \& Wilkinson (1963). Uma vantagem dessa metodologia é que ela tenta aliar estabilidade com adaptabilidade.

Hernandes et al. (1993), propuseram o cálculo da área sob a curva de regressão da produtividade dos cultivares, em função dos índices ambientais. Para estimação dessa área, os autores usaram a integral da equação de regressão para cada cultivar avaliado. Quanto maior a área sob a curva de regressão, mais adaptado será o cultivar em estudo.

Percebe-se que o referido método não leva em consideração a adaptabilidade dos cultivares, definida como resposta dos cultivares às variações ambientais, e nem a estabilidade fenotípica ou de comportamento, uma vez que a estimativa da área é independente da magnitude do coeficiente de regressão e do seu ajuste, determinado pelo desvio da regressão, uma vez que as áreas dos trapézios são calculadas com base nas médias ajustadas (Carneiro, 1998).

Entretanto, seria interessante incorporar nessa metodologia os princípios de adaptabilidade e estabilidade de comportamento, contemplados na 
metodologia de Lin \& Binns (1988). Assim, uma medida de adaptabilidade, relativa a um cultivar de comportamento ideal, conforme definido por Verma et al. (1978), pode, então, ser dada pela diferença das áreas entre os trapézios do i-ésimo cultivar e do genótipo hipotético ideal, formados pelos valores da variável em questão e dos índices ambientais (Carneiro, 1998).

A área do trapézio (A), formada pelos valores observados para o i-ésimo cultivar e pelos índices ambientais para dois ambientes é dada por:

$$
\begin{aligned}
A & =\left(\frac{Y_{i 2}+Y_{i 1}}{2}\right)\left[\left(\bar{Y}_{.2}-\bar{Y}_{. .}\right)-\left(\bar{Y}_{.1}-\bar{Y}_{. .}\right)\right] \\
& =\left(\frac{Y_{i 2}+Y_{i 1}}{2}\right)\left(\bar{Y}_{.2}-\bar{Y}_{.1}\right) .
\end{aligned}
$$

Então, o somatório das áreas dos trapézios formados pelos pares de ambientes é dado por:

$$
A=\sum_{j=1}^{n}\left(\frac{Y_{i(j+1)}+Y_{i j}}{2}\right)\left(\bar{Y}_{.(j+1)}-\bar{Y}_{. j}\right),
$$

em que, n é o número de ambientes.

Para o genótipo ideal, tem-se:

$$
\sum_{j=1}^{n}\left(\frac{Y_{g(j+1)}+Y_{g j}}{2}\right)\left(\bar{Y}_{.(j+1)}-\bar{Y}_{. j}\right) .
$$

Portanto, o somatório das diferenças das áreas dos trapézios entre o cultivar i e o genótipo hipotético ideal é dado por:

$$
P_{i}=\sum_{j=1}^{n}\left[\left(\frac{Y_{g(j+1)}+Y_{g j}}{2}\right)-\left(\frac{Y_{i(j+1)}+Y_{i j}}{2}\right)\right]\left(\bar{Y}_{.(j+1)}-\bar{Y}_{. j}\right) .
$$

Verifica-se que essa metodologia não leva em consideração a variação genotípica ao longo dos ambientes, ou seja, ela não tem a propriedade de variância. Dessa forma, deve-se fazer a correção pela expressão:

$$
P_{i}=\sum_{j=1}^{n}\left[\left(\frac{Y_{g(j+1)}+Y_{g j}}{2}\right)-\left(\frac{Y_{i(j+1)}+Y_{i j}}{2}\right)\right]^{2}\left(\bar{Y}_{.(j+1)}-\bar{Y}_{. j}\right) .
$$

O primeiro termo da expressão, elevado ao quadrado, tem propriedade de variância, e é equivalente à estatística do método de Lin \& Binns (1988). Dessa 
forma, a estatística acima pode ser denominada de MAEC, com vantagem de ponderar pela amplitude dos índices ambientais, ou seja, considera a dissimilaridade entre os locais de teste dos cultivares (Carneiro, 1998).

Com base na equação 16, o método das diferenças de áreas de trapézio quadrático pode ser usado para a estimação do parâmetro MAEC - multivariado. Para tanto, é necessária a padronização dos $P_{i^{\prime} s}$ e a ponderação pelos pesos para cada variável, como apresentado a seguir:

$$
P_{m i}=\sum_{k=1}^{v}\left[P_{i k} \frac{1}{\hat{\sigma}_{p k}}\right] .
$$

em que:

$P_{m i}:$ estimador do parâmetro MAEC - multivariado para o cultivar i;

$P_{i k}$ : estimador do parâmetro MAEC, para o cultivar i relativo a k-ésima variável; $\hat{\sigma}_{p k}$ : desvio padrão dos $P_{i^{\prime} s}$ para a k-ésima variável.

De uso mais restrito, outras propostas metodológicas para estudar a estabilidade fenotípica têm-se baseado em modelos não-lineares.

O parâmetro $\hat{\lambda}_{i}$ proposto por Tai (1971), usa regressão linear para determinar as respostas linear e não-linear de genótipos com os ambientes e leva em consideração a magnitude da variância experimental, tornando sua determinação e interpretação mais complexas. O parâmetro de estabilidade é dado por:

$$
\hat{\lambda}_{i}=\frac{\hat{\sigma}_{\delta_{i}}^{2}+\hat{\sigma}_{e}^{2}}{\hat{\sigma}_{e}^{2}},
$$

em que:

$\hat{\sigma}_{\delta_{i}}^{2}$ : estimativa do desvio da resposta linear do genótipo as variações do ambiente; $\hat{\sigma}_{e}^{2}:$ estimativa do erro associado ao efeito da interação $\mathrm{G} \times \mathrm{E}$.

O modelo de regressão não-linear nos parâmetros apresentados por Digby (1979), é muito parecido com o modelo de Eberhart \& Russell (1966), diferindo apenas pelo parâmetro $\mu_{i}$ que avalia o efeito ambiental. 
O modelo proposto é:

$$
Y_{i j}=\alpha_{i}+\beta_{i} \mu_{j}+\bar{\varepsilon}_{i j}
$$

em que:

$\alpha_{i}$ : parâmetro que informa sobre a performance média do genótipo i, em todos os ambientes;

$\beta_{i}$ : parâmetro que informa sobre a sensibilidade de resposta do genótipo i; $\bar{\varepsilon}_{i j}:$ erro experimental médio.

O parâmetro $\mu_{j}$ é estimado juntamente com os demais , $\alpha_{i}$ e $\beta_{i}$ sujeito às restrições $\sum_{i}^{g} \beta_{i}=g$ e $\sum_{j}^{e} \mu_{j}=0$. Isso assegura que a performance média dos genótipos $\left(\alpha_{i}\right)$ ocorra com $\mu_{j}=0$, numa escala de efeitos ambientais $\mu_{j}$, e que a resposta de sensibilidade média dos genótipos seja igual à unidade $\left(\beta_{i}=1\right)$.

Sob a suposição de normalidade e independência dos erros $\left(\varepsilon_{i j}\right)$, as distribuições amostrais conjuntas de $\alpha_{i}, \beta_{i}$ e $\mu_{j}$ convergem para uma distribuição normal multivariada. Essa convergência é garantida pelas propriedades dos estimadores de máxima verossimilhança para amostras grandes (Toler \& Burrows, 1998).

Assim, através da técnica de ajustamento de quadrados mínimos nãolineares, obtém-se:

$$
\begin{aligned}
\hat{\alpha}_{i} & =\bar{Y}_{i .,}, \\
\hat{\mu}_{j} & =\frac{\sum_{i=1}^{g} \hat{\beta}_{i}\left(Y_{i j}-\bar{Y}_{i .}\right)}{\sum_{i=1}^{g} \hat{\beta}_{i}^{2}}, \\
\hat{\beta}_{i} & =\frac{1+\sum_{j=1}^{e} \hat{\mu}_{j}\left(Y_{i j}-\hat{Y}_{i .}-\hat{Y}_{. j}+\hat{Y}_{. .}\right)}{\sum_{j=1}^{e} \hat{\mu}_{j}^{2}} .
\end{aligned}
$$

Observa-se que $\hat{\mu}_{j}$ é estimado pelo desvio entre o valor observado do genótipo i, no ambiente $\mathrm{j}\left(Y_{i j}\right)$ e a média desse genótipo em todos os ambientes $\left(\bar{Y}_{i .}\right)$, 
ponderado pela sua sensibilidade de resposta $\left(\hat{\beta}_{i}\right)$, que por sua vez é ponderada por $\hat{\mu}_{j}$. Portanto, para estimar os parâmetros $\mu_{j}$ e $\beta_{i}$ deve-se fazer o uso de processos interativos. Pode-se usar como valor inicial para $\hat{\mu}_{j}$ o $I_{j}$ dado pela equação 13.

Obtidas as estimativas desses parâmetros, faz-se o teste de hipótese $\left(H_{0}: \beta_{i}=1\right)$ contra $\left(H_{a}: \beta_{i} \neq 1\right)$ para a classificação dos genótipos. Se a hipótese $H_{0}$ for rejeitada, pode-se inferir que o genótipo é mais responsivo quando $\beta_{i}>1$ ou menos responsivo se $\beta_{i}<1$, ao aumento ou não do nível da qualidade ambiental, respectivamente. Caso contrário, $\beta_{i}=1$, o genótipo não desvia da resposta média do ambiente (Digby, 1979).

Toler (1990) discutiu que um dado genótipo, quando avaliado em vários ambientes, pode mostrar dois padrões de resposta, denominando-os de padrões convexo e côncavo.

Com base na metodologia proposta por Digby (1979), o padrão convexo ocorre quando o genótipo apresenta performance consistente em ambientes desfavoráveis $\left(\mu_{j}<0\right)$, e consegue explorar satisfatoriamente as condições ambientais favoráveis $\left(\mu_{j}>0\right)$, sendo considerado duplamente desejável, ou seja, de perfomance consistente em ambientes desfavoráveis e que explorem positivamente condições ambientais favoráveis. Por outro lado, duplamente desfavoráveis são aqueles que exibem sensibilidade nos ambientes abaixo da média geral, mas que não respondem às condições ambientais favoráveis. Esse padrão associa-se a uma resposta côncava (Figura 1).

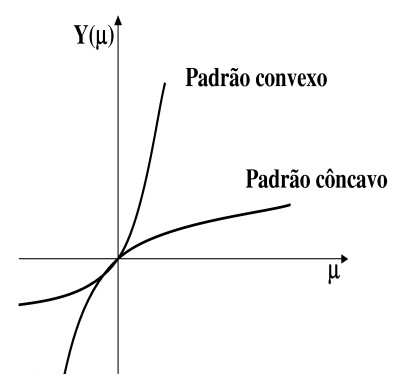

Figura 1 - Padrões de respostas convexo e côncavo dos genótipos $Y(\mu)$ às variações na qualidade ambiental $\mu$ 
O modelo proposto por Toler (1990), considera os ambientes acima e abaixo da média de todos os ambientes, com união entre eles no ponto $\mu_{j}=0$.

Assumindo, para os ambientes abaixo da média, $\mathrm{k}=1$, e, para os ambientes acima da média, $\mathrm{k}=2$, tem-se o seguinte modelo:

$$
Y_{k}(\mu)=\alpha_{K}+\beta_{K} \mu \quad \text { para } \mathrm{k}=1,2
$$

A condição de igualdade $Y_{1}(0)=Y_{2}(0)$, que implica na continuidade dos dois segmentos de reta é dada por $\mu_{j}=0$. Portanto, a função segmentada com ponto de união em $\mu_{j}=0$, e na condição imposta de que $\alpha_{1}=\alpha_{2}=\alpha$, de modo que o intercepto fica $Y(0)=\alpha$ é dada por:

$$
\begin{aligned}
& Y_{k}(\mu)=\alpha+\beta_{1} \mu \quad \text { se } \mu_{j} \leq 0 \quad \text { e } \\
& Y_{k}(\mu)=\alpha+\beta_{2} \mu \quad \text { se } \mu_{j} \geq 0 .
\end{aligned}
$$

Desse modo o modelo de regressão não-linear nos parâmetros para avaliar a estabilidade fenotípica dos genótipos fica:

$$
Y_{i j}=\alpha_{i}+\left[Z_{j} \beta_{1 i}+\left(1-Z_{j}\right) \beta_{2 i}\right] \mu_{j}+\bar{\varepsilon}_{i j}
$$

em que:

$Y_{i j} \quad$ : resposta média do genótipo i no ambiente j;

$\alpha_{i} \quad$ : parâmetro que reflete o valor da resposta do genótipo i no intercepto $\operatorname{com} \mu=0$;

$\beta_{1 i}$ : parâmetro que reflete a sensibilidade de resposta do genótipo i, no ambiente de baixa produtividade;

$\beta_{2 i}$ : parâmetro que reflete a sensibilidade de resposta do genótipo i, no ambiente de alta produtividade;

$\mu_{j}:$ parâmetro que reflete o efeito do ambiente $\mathrm{j}$;

$\bar{\varepsilon}_{i j} \quad: \quad$ erro experimental médio;

$Z_{j}= \begin{cases}1 & \text { se } \mu_{j} \leq 0 \\ 0 & \text { se } \mu_{j}>0\end{cases}$ 
As restrições paramétricas desse modelo $\left(\sum_{i=1}^{g} \beta_{1 i}=\sum_{i=1}^{g} \beta_{2 i}=g \quad \mathrm{e}\right.$ $\left.\sum_{j=1}^{e} \mu_{j}=0\right)$ asseguram que a performance média dos genótipos $\left(\alpha_{i}\right)$ ocorra com $\mu=0$, na escala de efeitos ambientais $\mu_{j}$, e que a resposta da sensibilidade média dos genótipos seja igual a um. Nesse modelo, o ambiente j será caracterizado por $\mu_{j}$ e a resposta do genótipo i passa a ser caracterizada pelos parâmetros $\alpha_{i}, \beta_{1 i}, \beta_{2 i}$.

Pelo emprego da técnica de quadrados mínimos não-lineares $\left(\alpha_{i}=Y_{i}\right)$, quando $\beta_{1 i}=\beta_{2 i}=\beta_{i}$, para todo $\mathrm{i}=1,2, \cdots$, g, a equação 17 pode ser reduzida à:

$$
\begin{aligned}
\beta_{1 i} & =\beta_{2 i}=\beta, \\
Y_{i j} & =\alpha_{i}+\left[Z_{j} \beta_{1 i}+\left(1-Z_{j}\right) \beta_{2 i}\right] \mu_{j}+\bar{\varepsilon}_{i j}, \\
Y_{i j} & =\alpha_{i}+\left[Z_{j} \beta+\left(1-Z_{j}\right) \beta\right] \mu_{j}+\bar{\varepsilon}_{i j}, \\
Y_{i j} & =\alpha_{i}+\beta \mu_{j}\left[Z_{j}+\left(1-Z_{j}\right)\right]+\bar{\varepsilon}_{i j} .
\end{aligned}
$$

Entretanto, se $\beta_{1 i} \neq \beta_{2 i}, \hat{\alpha}_{i}$ não pode ser formulado como uma simples função linear das observações $y_{i j}$. Assim Toler (1990) mostrou que, através das técnicas de quadrados mínimos não-lineares, $\hat{\alpha}_{i}$ passa a ser expresso pela seguinte equação:

$$
\hat{\alpha}_{i}=\bar{Y}_{i .}+\left(\hat{\beta}_{2 i}-\hat{\beta}_{1 i}\right)\left[\frac{1}{e} \sum_{j=1}^{e} \hat{Z}_{j} \hat{\mu}_{j}\right]
$$

Verifica-se que o parâmetro $\alpha_{i}$ é função da diferença entre as respostas da sensibilidade nos ambientes abaixo e acima da média ambiental $\left(\beta_{1 i}\right.$ e $\left.\beta_{2 i}\right)$, respectivamente, e da magnitude do componente $\frac{1}{e} \sum_{j=1}^{e} \hat{Z}_{j} \hat{\mu}_{j}$. Quando $Z_{j}=0$ temse $\hat{\alpha}_{i}=\bar{Y}_{i}$ e, para $Z_{j}=1$ a expressão $\sum_{j=1}^{e} \hat{Z}_{j} \hat{\mu}_{j}$ terá um resultado negativo por considerar apenas os ambientes inferiores.

Portanto, $\hat{\alpha}_{i}$ é dado pelo desvio, para mais ou para menos, de $\hat{Y}_{i}$. dependendo dos valores de $\beta_{1 i}$ e $\beta_{2 i}$. Pode-se testar a hipótese nula $H_{0}: \beta_{1 i}=\beta_{2 i}$ para veificar se uma única linha de regressão com inclinação $\beta_{i}$ é adequada para representar a performance média do genótipo i. Caso esta hipótese seja rejeitada temos duas situações: se $\beta_{2 i}>\beta_{1 i}$, então $\hat{\alpha}_{i}$ terá um valor menor que $\hat{Y}_{i \text {. e assumirá }}$ 
um padrão convexo. Por outro lado, se $\beta_{2 i}<\beta_{1 i}$, então $\hat{\alpha}_{i}$ terá um valor maior que $\hat{Y}_{i}$. e assumirá um padrão côncavo.

Através do modelo 17 é possível classificar os genótipos com base nos seus padrões de respostas, em cinco categorias, das nove apresentadas na Tabela 4, que são: 1, 3, 5, 7 e 9. O critério de enquadramento dos genótipos nos distintos grupos e o significado prático de cada um desses grupos, conforme Toler (1990), são dados em função dos testes da hipótese nula $H_{0}: \beta_{1}=\beta_{2}$ e $H_{0}: \beta=1$ (Tabela 5).

Tabela 5. Critério de enquadramento dos genótipos e significado prático, conforme Toler (1990)

\begin{tabular}{lll}
\hline Grupos & \multicolumn{1}{c}{ Critério } & \multicolumn{1}{c}{ Significado prático } \\
\hline A & Rejeita-se $H_{0}: \beta_{1}=\beta_{2}$ e aceita-se & Resposta convexa e duplo de- \\
& $\beta_{1}<1<\beta_{2}$ & sejável \\
B & Não se rejeita $H_{0}: \beta_{1}=\beta_{2}$ e & Resposta linear simples e de- \\
& rejeita-se $H_{0}: \beta=1$, sendo o co- & sejável só em ambientes de alta \\
& mum $\beta>1$ & qualidade \\
C & Não se rejeita $H_{0}: \beta_{1}=\beta_{2}$ e não & Resposta linear simples não des- \\
& se rejeita $H_{0}: \beta=1$ & viando da resposta média \\
D & Não se rejeita $H_{0}: \beta_{1}=\beta_{2}$ e & Resposta linear simples e de- \\
& rejeita-se $H_{0}: \beta=1$, sendo o co- & sejável só em ambientes de pobre \\
& mum $\beta<1$ & qualidade \\
& Rejeita-se $H_{0}: \beta_{1}=\beta_{2}$ e aceita-se & Resposta côncava e duplo inde- \\
& $\beta_{1}>1>\beta_{2}$ & sejável \\
\hline
\end{tabular}

Comparando as categorias apresentadas por Verma et al. (1978), e os grupos definidos por Toler (1990), observa-se que a categoria 1 corresponde ao grupo D, a categoria 3 ao grupo A, a categoria 5 ao grupo C, a categoria 7 ao grupo E e a categoria 9 corresponde ao grupo B. Nos grupos B, C e D, a resposta média do genótipo i $\left(\hat{\alpha}_{i}\right)$ no intercepto coincide com a performance média do genótipo i em 
todos os ambientes, ou seja, $\hat{\alpha}_{i}=\bar{Y}_{i}$. Nos grupos A e E, esse comportamento não ocorre $\left(\hat{\alpha}_{i} \neq \bar{Y}_{i}\right)$.

É conveniente mencionar que, o emprego de quadrados mínimos (como é feito nos modelos lineares), não admite soluções algébricas para as equações normais dos modelos não-lineares. Soluções, nesse caso, são obtidas através de processos iterativos de quadrados mínimos não-lineares , empregando-se, para a estimação dos parâmetros, o método de Gauss-Newton modificado (Gallant, 1987). O teste de hipótese é efetuado diretamente pela aplicação do princípio do erro condicional, que é, precisamente, equivalente ao critério da razão da máxima verossimilhança e, portanto, herda as propriedades de natureza assintomática. A execução do princípio do erro condicional requer uso repetitivo da estimação não-linear, para fornecer a soma de quadrados do erro condicional (SQRC), que é condição paramétrica implícita na hipótese assumida pelo modelo ajustado. A soma de quadrados da hipótese (SQH) é obtida pela diferença entre a SQRC e a SQR incondicional. Essa última é obtida pelo ajuste dos parâmetros do modelo por quadrados mínimos lineares, o qual está sujeito às restriçõos anteriormente apresentadas $\left(\sum_{i=1}^{g} \beta_{1 i}=\sum_{i=1}^{g} \beta_{2 i}=g\right.$ e $\left.\sum_{j=1}^{e} \mu_{j}=0\right)$. O teste é completado pela razão dos quadrados médios $(\mathrm{SQH} / \mathrm{r}) /$ (SQR/e), que apresenta uma distribuição F central, sendo r o número de graus de liberdade associados à $\mathrm{SQH}$ e o número de graus de liberdade associados à SQR.

Toler \& Burrows (1998), propuseram um método baseado em regressão não-linear que permite estimar conjuntamente os parâmetros de adaptação e estabilidade $\left(\beta_{1 i}, \beta_{2 i}\right.$ e $\left.R_{i}^{2}\right)$, e o índice ambiental $\left(\mu_{j}\right)$. Paralelamente, apresentaram os conceitos de padrão côncavo e padrão convexo de resposta, para a interpretação adaptativa dos genótipos.

Várias outras metodologias foram propostas para verificar a estabilidade fenotípica. Francis \& Kannenberg (1978), fizeram um estudo comparativo entre métodos de classificação de genótipos por estabilidade e propuseram um método alternativo, com base no coeficiente de variação (cv). O objetivo seria agrupar 
genótipos pelo cv determinando os seguintes grupos:

I) alta produção média e baixo cv;

II) alta produção média e alto cv;

III) baixa produção média e baixo cv e

IV) baixa produção média e alto cv

Francis \& Kannenberg (1978), justificaram que, cultivares que se encontram no grupo I são os mais desejáveis. Entretanto, o grupo mais estável seria o III, indicando estabilidade acima da média.

Para finalizar esse item de revisão, temos ainda os métodos que utilizam estatísticas não-paramétricas. Nesse tipo de análise há tendência de expressar em um ou poucos parâmetros, o desempenho e o comportamento de um genótipo em termos de rendimento, capacidade de resposta às variações ambientais e suas flutuações. Assim, compreende-se conceitos de adaptabilidade, de estabilidade de comportamento, ou fenotípica, dependendo do método em questão.

HUEHN (1990), apresentou algumas vantagens dessas metodologias, em relação aos que apresentam estatísticas paramétricas:

a) a tendenciosidade, causada por pontos completamente fora da equação de regressão ajustada é reduzida ou, às vezes, eliminada;

b) não é necessário assumir qualquer hipótese sobre a distribuição dos valores fenotípicos;

c) os parâmetros estimados, que apresentam classificações, são de fácil uso e interpretação;

d) a adição ou retirada de um ou poucos genótipos, não seria causa de grandes variações nas estimativas, como poderia ser para métodos paramétricos, e 
e) uso em outras aplicações, como, por exemplo, seleção em programas de melhoramento em que é de fundamental importância, a posição relativa ou classificação dos genótipos.

Muito embora sejam bastante difundidas na literatura, essas metodologias univariadas apresentaram pelo menos um problema de abordagem biológica ou estatística, fazendo com que suas interpretações sejam vistas com ressalvas. Zobel et al. (1988) e Crossa (1990), questionaram o uso desses procedimentos como detector de efeitos interativos de fatores. Para eles, os dados dos experimentos envolvendo estudos de $\mathrm{G} \times \mathrm{E}$, têm origem em multiambientes, e, dessa forma, deveriam ser abordados com técnicas estatísticas de análise multivariada.

\subsubsection{Metodologias multivariadas}

A análise multivariada apresenta três objetivos principais (Johnson \& Wichern, 1998):

a) eliminar os ruídos presentes nos dados;

b) sumarizar os dados; e

c) revelar a estrutura dos dados.

Segundo Crossa (1990), os dados obtidos de experimentos realizados em multiambientes apresentam três aspectos fundamentais:

a) padrão estrutural;

b) ruídos não estruturais; e

c) relações entre genótipos, ambientes e interação $\mathrm{G} \times \mathrm{E}$.

O padrão implica em que, um número de genótipos responde a determinados ambientes de forma sistemática, significante e interpretável, enquanto que ruído sugere que as respostas são imprevisíveis e não interpretáveis, sendo parte integrante da variabilidade estranha contido nos dados (Crossa, 1990). Assim, nesse 
tipo de abordagem, não se parte da premissa de que os desvios de atividade, decorrentes do ajuste dos efeitos principais, sejam inteiramente resultantes da interação $\mathrm{G} \times \mathrm{E}$. Com efeito, tais desvios podem conter ruídos. O descarte desses ruídos, permitirá caracterizar melhor os fatores genéticos e ambientais realmente envolvidos na interação genótipo com ambiente $(\mathrm{G} \times \mathrm{E})$ (Duarte, 2001).

Visando minimizar esses possíveis erros de estimação e garantir uma maior precisão e eficiência à análise de interação $\mathrm{G} \times \mathrm{E}$, Zobel et al. (1988), Crossa (1990), Gauch \& Zobel (1996) e De Cauwr \& Ortiz (1998) sugiram a introdução de procedimentos multivariados, como a análise de componentes principais, a análise de agrupamentos e o método AMMI.

Muitas pesquisas têm empregado técnicas multivariadas que abordam tal assunto sob esse enfoque. Essas técnicas são estatisticamente mais complexas, além de necessitarem, muitas vezes, de softwares específicos para o seu desenvolvimento, ou mesmo uma programação computacional. Por outro lado, os resultados gerados permitem que as interpretações mostrem-se mais coerentes com a realidade do material experimental. O uso mais frequente dessa técnica é em função de sua eficiência e acurácia comprovada, assim como do desenvolvimento de equipamentos eletrônicos mais capacitados para trabalhar com grande volume de dados.

A tendência atual é o uso de métodos multivariados, ou aqueles que integram métodos univariados com multivariados. Alguns desses métodos, como a análise de componentes principais (ACP) e análise de agrupamentos, não apresentam as limitações decorrentes da análise de regressão linear, e, portanto, têm sido usados para elucidar a estrutura interna da interação $\mathrm{G} \times \mathrm{E}$. Duas técnicas têm sido mais comumente utilizadas:

a) técnicas de ordenação, tais como a ACP, análise de coordenadas principais e análise de fatores;

b) técnicas de classificação, tais como análise de agrupamento e análise discriminante. 
Dessas, a ACP é a mais freqüentemente usada (Flores et al. 1996). O objetivo principal dessa técnica é transformar os dados a partir de um grupo de eixos de coordenadas, em outro grupo, que preserve a configuração original do grupo de pontos e concentre a maior parte da estrutura dos dados nos primeiros eixos da ACP. Assim, a resposta de um dado genótipo $G$ em $E$ ambientes pode ser conceituada como um padrão no espaço N dimensional (Crossa, 1990).

Uma das metodologias que vem ganhando espaço em uso, tem sido a análise AMMI. O objetivo principal da análise AMMI é selecionar modelos que expliquem o padrão relacionado à interação $\left(S Q_{G \times E}\right.$ Padrão), descartando os ruídos presentes nos dados e sem interesse agronômico ( $S Q_{G \times E}$ Ruídos).

Proposto inicialmente por Mandel (1971), o modelo baseia-se na decomposição das fontes de variação em efeitos aditivos de genótipos e ambientes de modo tradicional e, posteriormente, em efeitos multiplicativos para a interação $\mathrm{G} \times \mathrm{E}$ pela análise de componentes principais, o que permite um detalhamento maior da soma de quadrados da interação (Zobel et.al., 1988).

Segundo Zobel et.al. 1988, o modelo AMMI é dado por:

$$
Y_{i j}=\mu+g_{i}+e_{j}+\sum_{k=1}^{p} \lambda_{k} \gamma_{\mathbf{i k}} \alpha_{\mathbf{j k}}+\rho_{i j}+\bar{\varepsilon}_{i j},
$$

em que:

$Y_{i j}:$ resposta média de um genótipo i num ambiente j;

$\mu$ : média geral;

$g_{i} \quad:$ efeitos dos genótipos i;

$e_{j}:$ efeitos dos ambientes $\mathrm{j}$;

$\lambda_{k}:$ raiz quadrada do k-ésimo autovalor das matrizes $(\mathbf{G E})(\mathbf{G E})^{\prime}$ e $(\mathbf{G E})^{\prime}(\mathbf{G E})$, de iguais autovalores não nulos $\left(\lambda_{k}^{2}\right.$ é o k-ésimo autovalor; $\mathbf{G E}=\left[\hat{g} e_{i j}\right]$ matriz de interações obtida como resíduo do ajuste aos efeitos principais, por análise de variância, aplicada à matriz de médias (equação 1);

$\gamma_{\mathbf{i k}}$ : i-ésimo vetor (relacionado ao genótipo i) do k-ésimo autovetor de 
$(\mathbf{G E})(\mathbf{G E})^{\prime}$, associado a $\lambda_{k}^{2}$;

$\alpha_{\mathbf{j k}}:$ j-ésimo vetor (relacionado o ambiente $\mathbf{j}$ ) do k-ésimo autovetor de $(\mathrm{GE})^{\prime}(\mathrm{GE})$, associado a $\lambda_{k}^{2}$;

$\rho_{i j} \quad$ : ruídos presentes nos dados;

$\bar{\varepsilon}_{i j} \quad$ : erro experimental médio;

$i$ : variações de genótipos, $\mathrm{i}=(1,2, \cdots, \mathrm{g})$;

$j$ : variações de ambientes, $\mathrm{j}=(1,2, \cdots, \mathrm{e})$;

$p$ : raízes características não nulas, $\quad p=(1,2, \cdots, \min (g-1, e-1))$.

A matriz de interação $\mathbf{G E}$ é modelada por $\sum_{k=1}^{p} \lambda_{k} \gamma_{\mathbf{i k}} \alpha_{\mathbf{j k}}+\rho_{i j}$, sob as restrições de identificabilidade $\sum_{i=1}^{g} g_{i}=\sum_{j=1}^{e} e_{j}=\sum_{i=1}^{g}(g e)_{i j}=\sum_{j=1}^{e}(g e)_{i j}=0$.

O termo GE (interação no modelo tradicional), na metodologia AMMI é representado pela soma de p parcelas, cada uma resultante da multiplicação de $\lambda_{k}$, expresso na mesma unidade de $Y_{i j}$, por um efeito genotípico $\left(\gamma_{\mathbf{i k}}\right)$ e um efeito ambiental $\left(\alpha_{\mathbf{j k}}\right)$, ambos adimensionais, ou seja, $\sum_{k=1}^{n} \lambda_{k} \gamma_{\mathbf{i k}} \alpha_{\mathbf{j k}}$ (n: termos da interação). O termo $\lambda_{k}$ traz uma informação relativa a k-ésima parcela da interação $\mathrm{G} \times \mathrm{E}$, e os efeitos $\gamma_{\mathbf{i k}}$ e $\alpha_{\mathbf{j k}}$ representam os pesos do genótipo i e do ambiente j, naquela parcela da interação.

O número de eixos ou componentes da $\mathrm{ACP}$, retidos para a maioria das aplicações, é o menor possível (dois ou três no máximo), com o qual se pretende reduzir a dimensão do sistema e fornecer uma descrição mais parcimoniosa à cerca da estrutura da interação. Duarte \& Vencovsky (1999) mencionam que um dos procedimentos usuais adotados para a definição do número de eixos a serem retidos, de maneira a explicar o padrão relacionado à interação, consiste em determinar graus de liberdade associados à parcela da $S Q_{G \times E}$ relacionada a cada membro da família AMMI. Obtém-se, então, o quadrado médio (QM) correspondente a cada parcela (ou modelo). Em seguida é obtido um teste F, avaliando-se a significância

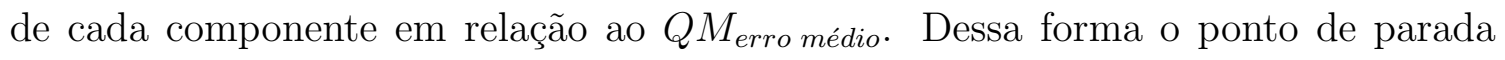


que determina a seleção do modelo $\left(A M M I_{0}, A M M I_{1}, \cdots\right.$ ou $\left.A M M I_{n}\right)$ baseia-se na significância do teste $\mathrm{F}$ para os sucessivos eixos da interação. O resíduo AMMI, reunindo os eixos descartados da interação, também pode ser testado de maneira a assegurar o seu caráter desprezível.

A análise AMMI pode auxiliar tanto na identificação de genótipos com alta produtividade e amplamente adaptados, como na realização do zoneamento agronômico com a finalidade de recomendação regionalizada e seleção de locais de teste (Gauch \& Zobel, 1996). O método ainda permite a obtenção de estimativas mais precisas das respostas genotípicas, e possibilita uma fácil interpretação gráfica dos resultados da análise estatística, através do procedimento biplot (Zobel et al., 1988). E também é uma ferramenta apropriada para diagnóstico em situações em que a interação significativa é acompanhada por não significância dos efeitos aditivos principais de genótipos e ambientes, ou, quando a estrutura da interação é influenciada por "outliers" (Shafii \& Price, 1998).

A representação gráfica em biplot, é uma técnica bastante útil na análise de componentes principais pois, o gráfico usado para representar simultaneamente as linhas e colunas, referentes a uma matriz de dados, pode indicar a existência de agrupamentos entre as observações, assim como, mostrar as variâncias e correlações entre as variáveis. Essa técnica foi introduzida por Gabriel (1971), e é baseada no fato de que, uma matriz de ordem maior do que dois pode ser aproximada por uma matriz de ordem dois, sendo que cada elemento da matriz é representado pelo produto interno dos vetores correspondentes à sua linha e coluna. Dessa forma, qualquer matriz de n observações e p variáveis pode ser representada por um biplot. Ou seja, toda matriz $\mathbf{Y}(\mathrm{n} \times \mathrm{p})$ de ordem $\mathrm{r}$ pode ser fatorada como $\mathbf{Y}=\mathbf{G H}$, em que $\mathbf{G}$ é uma matriz $(\mathrm{n} \times \mathrm{r})$ e $\mathbf{H}$ uma matriz $(\mathrm{p} \times \mathrm{r})$, ambas necessariamente de ordem r (Rao, 1965).

Uma maneira de fatorar $\mathbf{Y}$ é escolher $\mathrm{r}$ colunas de $\mathbf{G}$, como uma base ortogonal do espaço coluna de $\mathbf{Y}$, e calcular $\mathbf{H}$ como $\mathbf{Y}^{\prime} \mathbf{G}\left(\mathbf{G}\right.$ ortogonal $\Longrightarrow \mathbf{G}^{\prime}=$ $\left.\mathrm{G}^{-1} \Longrightarrow \mathbf{Y}^{\prime}=\mathbf{H G}^{\prime} \Longrightarrow \mathbf{Y}^{\prime} \mathrm{G}^{\prime-1} \Longrightarrow \mathbf{Y}^{\prime} \mathbf{G}^{\prime}=\mathbf{H}\right)$. 
Dessa forma, a fatoração pode ser escrita como $Y_{i j}=\mathbf{g}_{\mathbf{i}} \mathbf{h}_{\mathbf{j}}$ para cada i, j, em que i $=1,2, \cdots, \mathrm{g}$ (g: é o número de genótipos); j $=1,2, \cdots$, e (e: é o númerro de ambientes); $y_{i j}$ é o elemento na i-ésima coluna de $\mathbf{Y}, \mathbf{g}_{\mathbf{i}}^{\prime}$ é a i-ésima linha de $\mathbf{G}$ e $\mathbf{h}_{\mathbf{j}}$ é a j-ésima coluna de $\mathbf{H}$. Ou seja, a fatoração associa cada um dos vetores $\mathbf{g}_{\mathbf{1}}, \mathbf{g}_{\mathbf{2}}, \cdots, \mathbf{g}_{\mathbf{g}}$, a cada uma das $\mathrm{n}$ linhas de $\mathbf{Y}$, e os vetores $\mathbf{h}_{\mathbf{1}}, \mathbf{h}_{\mathbf{2}}, \cdots, \mathbf{h}_{\mathbf{e}}$ a cada uma das colunas de $\mathbf{Y}$. Cada um dos vetores tem ordem $r$ e fornece a representação de $\mathbf{Y}$ através de $(\mathbf{g}+\mathbf{e})$ vetores no espaço r-dimensional. Os vetores $\mathbf{g}_{\mathbf{1}}, \mathbf{g}_{\mathbf{2}}, \cdots, \mathbf{g}_{\mathrm{g}}$ podem ser considerados como efeito de linha e os vetores $\mathbf{h}_{\mathbf{1}}, \mathbf{h}_{\mathbf{2}}, \cdots, \mathbf{h}_{\mathbf{e}}$ os efeitos de coluna.

Outra vantagem apresentada pelo modelo AMMI, diz respeito à representação gráfica, onde são plotados os escores dos efeitos da interação, para cada genótipo e para cada ambiente, simultaneamente. A interpretação é feita observando a magnitude e o sinal dos escores de genótipos e ambientes para o eixo de componentes principais. Escores baixos indicam genótipos e/ou ambientes que contribuem pouco ou quase nada para a interação $\mathrm{G} \times \mathrm{E}$, sendo, portanto, estáveis. Tais genótipos podem ser recomendados amplamente desde que tenham médias elevadas. Em ambientes estáveis, o ordenamento dos genótipos deve ser mais consistente. Esse tipo de informação permite aos melhoristas selecionar também locais de testes, conforme seus interesses. Portanto, esse gráfico fornece informações sobre a estabilidade de genótipos e também de ambientes, além de permitir a realização de zoneamentos ecológicos, com a seleção de locais chaves (Duarte \& Vencovsky, 1999).

Esse fato é vantajoso na seleção de genótipos, quando comparado com os modelos tradicionais de estabilidade (Zobel et al., 1988). Nos métodos usuais de regressão linear, estudam-se os efeitos ambientais dentro dos genótipos, o que auxilia no processo de recomendação de cultivares, mas, certamente, não deixa explícito a identificação de relações importantes no discernimento das causas da interação (Duarte \& Vencovsky, 1999).

Por esses motivos, o método AMMI vem ganhando grande aplicabilidade, nos últimos anos, na análise de dados de experimentos, principalmente, em estudos da interação $\mathrm{G} \times \mathrm{E}$. Esse método, atualmente, tem recebido grandes elogios 
por parte de pesquisadores da área agronômica (Gauch, 1988, 1990 e 1992; Gauch \& Zobel, 1996; Zobel et al, 1988; Crossa, 1990; Crossa et al., 1991; Piepho, 1995; De Cauwr \& Ortiz, 1998; Duarte \& Vencovsky, 1999; Thallainathan \& Fernandez, 2001; Yan et al., 2001; Vargas et al. 2001; Lavoranti et al., 2001a e 2001b; Rocha, 2002; Lavoranti et al., 2002 e Oliveira et al., 2003).

Entretanto, os principais pontos negativos dessa metodologia relacionam a dificuldade na interpretação da interação, quando há baixa explicação do primeiro componente principal; a dificuldade para quantificar os escores como baixos, considerando estável os genótipos e/ou ambientes, além de não apresentar o padrão de resposta do genótipo, o que caracteriza os padrões de adaptabilidade dos grupos formados através de parâmetros significativos. Nesse contexto, essa metodologia apresenta alguns inconvenientes de ordem estatística, fazendo com que suas interpretações sejam vistas com ressalvas. A atribuição dos graus de liberdade, associados à parcela da $S Q_{G \times E}$, relacionada a cada membro da família AMMI, também é vista com ressalvas e merece um estudo mais detalhado.

Os dois sistemas mais comumente utilizados para atribuir os graus de liberdade ao modelo AMMI são os sistemas de Gollob (1968) e Mandel (1971). Segundo Gauch (1992), a proposta de Gollob é fundamentada na definição clássica de graus de liberdade, porque de acordo com o modelo AMMI apresentado na equação 18, cada eixo de interação tem "um" valor singular $\lambda_{k}$, "g" elementos para o vetor $\gamma_{\mathbf{k}}$ e "e" elementos para o vetor $\alpha_{\mathbf{k}}$ o que totaliza $(\mathrm{g}+\mathrm{e}+1)$ parâmetros a serem estimados. Entretanto, para a estimação dos parâmetros, os autovetores associados a $\gamma_{\mathbf{k}}$ e $\alpha_{\mathbf{k}}$ ficam sujeitos às restrições $\sum_{i} \gamma_{i k}=0, \sum_{j} \alpha_{j k}=0, \sum_{i} \gamma_{i k}^{2}=1, \sum_{j} \alpha_{j k}^{2}=1$ (comprimento unitário) e para a ortogonalidade dos eixos quando $\mathrm{n}>1$ temos mais $2(\mathrm{n}-1)$ restrições $\left(\sum_{i} \gamma_{i} \gamma_{i k}=0, \sum_{j} \alpha_{j} \alpha_{j k}=0\right)$ para $\mathrm{k}=1,2, \cdots, \mathrm{n}-1$. Assim, chega-se à proposta de Gollob, para os graus de liberdade dos eixos $\left(G L_{I P C A_{k}}\right)$ dada por:

$$
\begin{aligned}
G L_{I P C A} \mathrm{k}= & g+e+1-2-2-2(\mathrm{k}-1)=g+e-1-2 \mathrm{k} \\
& \mathrm{k}=1,2, \cdots, \mathrm{n}-1 \quad \text { e } \mathrm{n}=\operatorname{mínimo}(g, e) .
\end{aligned}
$$


O ponto de parada para seleção do modelo é o n-ésimo componente principal da interação que for significativo pelo teste F de Gollob (1968).

Para Mandel 1971, não há uma fórmula simples para se encontrar os graus de liberdade associados a cada parcela $\lambda_{k}^{2}$, porque, apesar de serem ligítimos componetes aditivos de $\sum_{i j}(\widehat{g e})_{i j}^{2}$, quando aplicados a $S Q_{(G \times E)}$, não têm distribuição $\chi^{2}$, e, dessa forma, o autor faz uma advertência àqueles que impulsivamente são tentados a aplicar o teste $\mathrm{F}$.

A distribuição dos graus de liberdade, associada a cada parcela $\lambda_{k}^{2}$, segundo Mandel (1971), é dado por:

$$
G L_{\mathrm{k}}=\frac{E\left[\lambda_{\mathrm{k}}^{2}\right]}{\sigma^{2}} \quad \text { para } \mathrm{k}=1,2, \cdots, \mathrm{n}-1 .
$$

em que, $\sigma^{2}$ é a variância aleatória populacional.

Dessa expressão e da suposição de normalidade, são feitas simulações que resultam em tabelas para obtenção dos graus de liberdade.

Testes para a validação do modelo $A M M I_{k}$ também têm sido apresentado por Gauch, 1992 (razão de sinal para o ruído), Cornelius et al., 1992, Cornelius, 1993 (testes $F_{G H 1}$ e $F_{G H 2}$ ), Piepho, 1994 e 1995 (teste $F_{R}$ ).

Algumas comparações entre esses testes revelaram que o teste $\mathrm{F}$ de Gollob tende a selecionar mais eixos do que o verdadeiro modelo contempla, enquanto que, os testes $F_{G H 1}$ e $F_{G H 2}$, foram mais liberais do que o teste $F_{R}$. O teste $F_{R}$ apresentou resultados semelhantes ao teste da razão de sinal para o ruído (Cornelius, 1993; Piepho, 1995 e Annicchiarico, 1997a, 1997b). De acordo com Piepho (1995), o teste $F_{R}$, com os graus de liberdades proposto por Cornelius et al. (1992), mostrouse como o mais robusto para a escolha do modelo AMMI. Observa-se que o teste $F_{R}$ é o que mais se aproxima dos resultados obtidos pela validação cruzada (Dias \& Krzanowski, 2003).

A estatística $F_{R}$, sob a hipótese nula de que não haja mais do que $\mathrm{n}$ termos determinando a interação, tem uma distribuição $\mathrm{F}$ aproximada com $f_{2}$ graus 
de liberdade e $G L_{\text {erro médio: }}$

$$
F_{R}=\frac{S Q_{(G \times E)}-\sum_{k=1}^{n} \lambda_{k}^{2}}{f_{2} Q M_{\text {erro médio }}}
$$

em que, $f_{2}=(g-1-n)(e-1-n)$ com $\mathrm{n}$ o número de termos multiplicativos incluídos no modelo.

Outra alternativa para a seleção de modelos AMMI é a técnica de avaliação "preditiva" do modelo, ou seja, feita a "priori", com os dados originais, via procedimentos jackknife, bootstrap e validação cruzada (Gauch, 1988). Essa abordagem só pode ser usada quando se tem mais de duas repetições por experimento (Ortiz et al., 2001). Assim, é possível estimar a diferença preditiva média (DPM) para cada modelo da família AMMI. O menor valor de DPM é indicativo de modelo mais preditivo e, portanto, será o selecionado.

No método proposto por Gauch (1988), as repetições para cada combinação de genótipo e ambiente são divididas aleatoriamente em dois grupos: um para a estimação do modelo AMMI e outro para a validação dos resultados. A menor soma de quadrados da diferença entre os valores estimados e os dados de validação, indicam o melhor modelo AMMI. Crossa et al. (1991) estimou a raiz quadrada dessa diferença, denominando de RMSPD, e sugeriu que esse procedimento fosse repetido por pelo menos dez vez, e que a menor média da RMSPD fosse o indicativo do melhor modelo.

Piepho (1994) sugeriu que a média da RMSPD fosse obtida de 1000 amostras aleatorizadas, quando o modelo experimental for de blocos aleatorizados.

Gauch \& Zobel (1996), sugeriram que o cunjunto de dados para a validação deve contivesse dados de todos os tratamentos.

Cornelius \& Crossa (1999), estudando o truncamento dos efeitos multiplicativos por validação cruzada e pelo melhor estimdor não-viesado (BLUP), encontraram um número máximo de 64 e mínimo de 39 para o conjunto de dados para a validação cruzada. 
Gabriel (2002) propôs um algoritmo para a validação cruzada utilizando-se de uma partição na matriz de dados, via decomposição por valores singulares (DVS). O algoritmo desenvolve-se a partir da submatriz $\mathbf{X}_{\backslash \mathbf{1 1}}$ dada por:

$$
\mathbf{X}_{g \times e}=\left[\begin{array}{cc}
x_{11} & \mathbf{x}_{1 .}^{\mathbf{T}} \\
\mathbf{X}_{.1} & \mathbf{X}_{\backslash \mathbf{1 1}}
\end{array}\right]
$$

em que:

$$
\mathbf{X}_{\backslash \mathbf{1 1}}=\sum_{k=1}^{r} \mathbf{u}_{(k)} \mathbf{d}_{k} \mathbf{v}_{(k)}^{T}=\mathbf{U D V}^{\mathbf{T}},
$$

sendo $\mathrm{r}$ o número de componentes multiplicativo em análise, $\mathbf{U}=\left[u_{1}, u_{2}, \ldots, u_{r}\right]$, $\mathbf{V}=\left[v_{1}, v_{2}, \ldots, v_{r}\right]$ e $\mathbf{D}=\left[d_{1}, d_{2}, \ldots, d_{r}\right]$.

O valor predito para $x_{11}$ é dado por:

$$
\hat{x}_{11}=\mathbf{x}_{1}^{\mathbf{T}} \mathbf{V D}^{-1} \mathbf{U}^{\mathbf{T}} \mathbf{x}_{.1}
$$

O resíduo da validação cruzada é obtido por:

$$
e_{11}=x_{11}-\hat{x}_{11}
$$

De forma similar, calculam-se todos os $\hat{x}_{i j} \quad$ e $\quad e_{i j}=x_{i j}-\hat{x}_{i j}$. Os resíduos são sumarizados por:

$$
\text { PRESS } r=\frac{1}{g e} \sum_{i=1}^{g} \sum_{j=1}^{e} e_{i j}^{2} .
$$

Para Gabriel (2002), o número de fatores multiplicativos correspondem ao r que proporcionar o menor PRESS.

De forma similar, Dias \& Krzanowski (2003), propuseram a estimação do elemento $\hat{x}_{i j}^{r}$ da matriz $\mathbf{X}$, por:

$$
\hat{x}_{i j}=\sum_{t=1}^{r}\left(\tilde{u}_{i t} \sqrt{\tilde{d}_{t}}\right)\left(\bar{v}_{t j} \sqrt{\bar{d}_{t}}\right)
$$

em que:

$$
\begin{aligned}
& \mathbf{X}^{(-\mathbf{i})}=\overline{\mathbf{U}} \overline{\mathbf{D}} \overline{\mathbf{V}}^{\mathbf{T}} \quad \text { com } \quad \overline{\mathbf{U}}=\left(\bar{u}_{s t}\right), \overline{\mathbf{D}}=\operatorname{diag}\left(\bar{d}_{1}, \bar{d}_{2}, \ldots, \bar{d}_{p}\right), \overline{\mathbf{V}}=\left(\bar{v}_{s t}\right), \\
& \mathbf{X}_{(-\mathbf{j})}=\tilde{\mathbf{U}} \tilde{\mathbf{D}} \tilde{\mathbf{V}}^{\mathbf{T}} \quad \operatorname{com} \quad \tilde{\mathbf{U}}=\left(\tilde{u}_{s t}\right), \tilde{\mathbf{D}}=\operatorname{diag}\left(\tilde{d}_{1}, \tilde{d}_{2}, \ldots, \tilde{d}_{p}\right), \tilde{\mathbf{V}}=\left(\tilde{v}_{s t}\right)
\end{aligned}
$$


e calcular $P R E S S_{r}$ por:

$$
\operatorname{PRES} S_{r}=\sum_{i=1}^{g} \sum_{j=1}^{e}\left(\hat{x}_{i j}^{r}-x_{i j}\right)^{2} .
$$

Outras informações relevantes sobre variáveis ambientais, tais como dados meteorológicos ou informações de solo, podem ser correlacionadas ou regredidas sobre escores ambientais, estimados pelo modelo AMMI. No entanto, informações ambientais externas não podem ser usadas diretamente no modelo AMMI. Assim, quando informações adicionais, sobre variáveis externas do cultivar, estão disponíveis (fisiologia, maturidade, reação a doenças, marcadores moleculares, etc.), outros modelos estatísticos, incluindo modelos bi-lineares como a regressão fatorial e a regressão parcial de mínimos quadrados, são úteis em reduzir variáveis e indicar quais as variáveis relacionadas aos genótipos ou ambientes influenciam mais a interação $\mathrm{G} \times \mathrm{E}$ (Vargas et al., 2001).

Outras abordagens multivariadas para estudos da interação $\mathrm{G} \times \mathrm{E}$ têm sido observadas na literatura. Yan et al. (2001) propuseram um método para avaliar a adaptabilidade e a estabilidade fenotípica, baseado na análise gráfica denominada de biplot GGE (efeitos principais de genótipos e da interação $\mathrm{G} \times \mathrm{E}$ ). O biplot GGE é construído plotando os dois primeiros componentes principais de uma ACP, utilizando-se modelos de regressão de locais. O objetivo principal é identificar genótipos superiores para recomendação aos agricultores e locais que melhor representem ambientes específicos ou mega-ambientes.

\subsubsection{Comparações de metodologias}

As propostas elaboradas para comparar as metodologias, em sua grande maioria, são feitas através da correlação entre os parâmetros que medem a estabilidade e adaptabilidade fenotípica. A correlação mais usada é a de Spearman. Essa abordagem tem como principal objetivo verificar similaridades ou divergências quanto ao ordenamento dos genótipos com os ambientes.

De acordo com Steel \& Torrie (1980), a fórmula mais conveniente para 
calcular o coeficiente $r_{S}$ de Spearman é:

$$
r_{S}=1-\frac{6 \sum_{i=1}^{n} d_{i}^{2}}{n^{3}-n},
$$

em que, $d_{i}^{2}$ é a diferença entre o ranqueamento dos genótipos e n o número de genótipos envolvidos na análise.

Para verificar a hipótese de nulidade, $\left(H_{0}: r_{S}=0\right)$, é aplicado o teste t:

$$
t=r_{S} \sqrt{\frac{n-2}{1-r_{S}^{2}}},
$$

e comparando-o com o teste t de Student, com n-2 graus de liberdade. A rejeição de $H_{0}$ implica que existe alguma associação entre as metodologias, e, quanto maior for essa correlação, maior a associação.

\subsubsection{Reamostragem jackknife e bootstrap}

As metodologias para análise estatística conhecidas como computacionalmente intensivas, vêm sendo cada vez mais utilizadas, devido à atual capacidade de processamento das máquinas ( "hardware"), e pelo desenvolvimento de programas de computadores ("software") capazes de processar e armazenar grandes conjuntos de dados, com qualidade, precisão e alta velocidade. Dentre essas metodologias, podem-se destacar o "jackknife" e o "bootstrap", apresentados por Efron (1979).

O "jackknife" surgiu da técnica desenvolvida por Quenouille (1949), que visava reduzir o vício de um estimador de correlação, com base na divisão da amostra original em duas semi-amostras. Alguns anos depois, esse estudo foi completado com a generalização do método (Quenouille , 1956). Assim, a amostra original de tamanho $n$ passa a ser dividida em $g$ sub-amostras de tamanho $h$, de modo que tem-se $n=g h$. O tamanho $h$ fixo em um, faz com que a amostra original passe a ser dividida em $n$ grupos com uma unidade observacional.

Para um melhor entendimento da técnica, propõe-se a seguinte situação clássica de análise de dados: seja $\left[x_{1}, x_{2}, \cdots, x_{n}\right]$ uma amostra de variáveis aleatórias 
independentes e identicamente distribuídas (i.i.d.). Seja $\mathrm{p}(\mathbf{X}, \theta)$ a função de verossimilhança dessa amostra aleatória (a.a.), com dependência do parâmetro $\theta$. Supondo-se que o estimador de $\theta$ seja a estatística $\hat{\theta}=T_{n}(\mathbf{x})$ e que $\hat{\theta}_{i}=T_{n-1}(\mathbf{x})$, seja o estimador baseado na amostra de tamanho n-1 obtida retirando-se o i-ésimo ponto amostral. Com esses valores constrói-se os pseudos-valores (Tukey, 1958):

$$
\tilde{\theta}_{i}=n \hat{\theta}-(n-1) \hat{\theta}_{i} \quad \mathrm{i}=1,2, \cdots, \mathrm{n} .
$$

A média aritimética dos n pseudo-valores $\tilde{\theta}_{i}$ dada por:

$$
\tilde{\theta}=\frac{1}{n} \sum_{i=1}^{n} \tilde{\theta}_{i}
$$

é chamado de estimador "jackknife" do parâmetro $\theta$.

De uma forma geral, o erro-padrão "jackknife" para a estatística $\hat{\theta}$ é dado por Tukey (1958):

$$
\widehat{S D}=\left[\frac{1}{n(n-1)} \sum_{i=1}^{n}\left(\tilde{\theta}_{i}-\tilde{\theta}\right)^{2}\right]^{\frac{1}{2}} .
$$

É importante observar que, dada a a.a., $\left[\left(x_{1}, y_{1}\right),\left(x_{2}, y_{2}\right), \cdots\left(x_{n}, y_{n}\right)\right]$ da distribuição bivariada de probabilidade F, é possível calcular uma estimativa da esperança do vetor aleatório bivariado e, além disso pode-se avaliar sua precisão. Para isso basta calcular a expressão do vetor média amostral $[\bar{x}, \bar{y}]$ e a matriz de covariância amostral

$$
\left[\begin{array}{cc}
\hat{\sigma}_{x}^{2} & \hat{\sigma}_{x y} \\
\hat{\sigma}_{x y} & \hat{\sigma}_{y}^{2}
\end{array}\right] .
$$

Contudo, quando se deseja avaliar a precisão de outros estimadores, como por exemplo a correlação amostral $\hat{\rho}_{X Y}=\frac{\hat{\sigma}_{x y}}{\hat{\sigma}_{x} \hat{\sigma}_{y}}$, não é posível fazê-lo sem o conhecimento de F. A solução, então, seria usar resultados assintóticos.

No caso da variância do estimador de $\mathrm{E}[\mathrm{X}], \bar{X}$, não existe problema para a sua estimação. Conhecendo-se ou não a distribuição da v.a., tem-se acesso à precisão da estatística $\bar{X}$. Dada a a.a. $\left[x_{1}, x_{2}, \cdots, x_{n}\right]$, da v.a. X, com distribuição desconhecida $\mathrm{F}$, o estimador do parâmetro $\mu=\mathrm{E}[\mathrm{X}]$ é dado por:

$$
\bar{X}=\frac{1}{n} \sum_{i=1}^{n} x_{i}
$$


Para o cálculo dos pseudo-valores de $\tilde{\theta}_{i}$ precisa-se de $\hat{\theta}_{(i)}$ dado por:

$$
\hat{\theta}_{(i)}=\bar{X}_{(i)}=\frac{n \bar{X}-X_{i}}{n-1} \quad \mathrm{i}=1,2, \cdots, \mathrm{n},
$$

e, assim, tem-se os pseudo-valores

$$
\tilde{\theta}_{(i)}=n \bar{X}-(n-1) \bar{X}_{(i)} \quad(\mathrm{i}=1,2, \cdots, \mathrm{n})
$$

que produzem o estimador "jackknife" de E[X],

$$
\tilde{\theta}=\frac{1}{n} \sum_{i=1}^{n} \tilde{\theta}_{(i)}=n \bar{X}-(n-1) \frac{1}{n} \sum_{i=1}^{n} \bar{X}_{(i)} .
$$

Pode-se mostrar por (21) e (23) que, nesse caso, $\tilde{\theta}=\bar{X}$ :

$$
\begin{aligned}
\tilde{\theta} & =n \bar{X}-(n-1) \frac{1}{n}\left[\frac{n \bar{X}-X_{1}}{n-1}+\frac{n \bar{X}-X_{2 i}}{n-1}+\cdots+\frac{n \bar{X}-X_{n}}{n-1}\right] \\
& =n \bar{X}-(n-1) \frac{1}{n(n-1)}\left[n n \bar{X}-\sum_{i=1}^{n} X_{i}\right] \\
& =\frac{1}{n} \sum_{i=1}^{n} X_{i}=\bar{X}
\end{aligned}
$$

e ainda, por 22 e 24 temos: $\tilde{\theta}_{(i)}-\tilde{\theta}=X_{i}-\bar{X} \quad$ pois,

$$
\begin{aligned}
\tilde{\theta}_{(i)}-\tilde{\theta} & =n \bar{X}-(n-1) \bar{X}_{(i)}-\bar{X}=(n-1) \bar{X}-(n-1) \bar{X}_{(i)}-\bar{X} \\
& =(n-1)\left(\bar{X}-\bar{X}_{(i)}\right)=(n-1)\left[\bar{X}-\frac{n \bar{X}-X_{i}}{n-1}\right] \\
& =X_{i}-\bar{X}
\end{aligned}
$$

Logo, $\mathrm{V}[\bar{X}]$ será dada por:

$V[\bar{X}]=\left[\frac{1}{n(n-1)} \sum_{i=1}^{n}\left(\tilde{\theta}_{(i)}-\tilde{\theta}\right)^{2}\right]=\left[\frac{1}{n(n-1} \sum_{i=1}^{n}\left(X_{i}-\bar{X}\right)^{2}\right]=\frac{s^{2}}{n}$.

Portanto, seja $\tilde{\theta}=\frac{1}{n} \sum_{i=1}^{n} \tilde{\theta}_{i}$ o estimador "jackknife" correspondente a um estimador viciado do parâmetro $\theta, \quad \hat{\theta}=T_{n}(\mathbf{x})$. Então $\tilde{\theta}$ elimina o termo de ordem $\frac{1}{n}$ do vício de $\hat{\theta}$. 
Segundo Tukey (1958), os n pseudo-valores poderiam ser tratados como v.a's aproximadamente i.i.d. e, dessa forma, poderia-se construir a quantidade pivotal:

$$
\frac{\tilde{\theta}-\theta}{\left[\frac{1}{n(n-1)}\left[\frac{\sum_{i=1}^{n}\left(\tilde{\theta}_{i}-\tilde{\theta}\right)^{2}}{n-1}\right]\right]^{\frac{1}{2}}}
$$

que tem aproximadamente distribuição $t_{n-1}$, e pode ser usada como pivô na estimação por intervalo do parâmetro $\theta$.

Bickel \& Freedman (1981), citam o vício como um dos fatores importantes para a escolha de um estimador. Esse exprime a quantidade de erro sistemático que ocorre na estimação do parâmetro, e portanto, é preferível, que tenham valor nulo e baixa variância (alta precisão). Contudo, isso nem sempre é possível, e dessa forma, o conhecimento do vício é importante para avaliar a precisão das estimativas.

Dada a a.a. $\mathbf{X}=\left[x_{1}, x_{2}, \cdots, x_{n}\right]$ da distribuição de probabilidade desconhecida F, é comum estimar-se o parâmetro de interesse, $\theta$, usando-se um estimador natural $\hat{\theta}=T_{n}(\mathbf{X})$. Caso o estimador seja viciado, uma aplicação de destaque do "jackknife" é o estimador do vício, b $(\theta, \hat{\theta})$, de um estimador $\hat{\theta}$. Dessa forma, tem-se:

$$
\begin{aligned}
E(\hat{\theta}) & =\theta+b(\theta, \hat{\theta}) \\
& =\theta+\frac{a_{1}(F)}{n}+\frac{a_{2}(F)}{n^{2}}+\frac{a_{3}(F)}{n^{3}}+\cdots,
\end{aligned}
$$

como, $\hat{\theta}_{.}=\frac{1}{n} \sum_{i=1}^{n} \hat{\theta}_{i}$ e $\quad \hat{\theta}=\frac{1}{n} \sum_{i=1}^{n} X_{i}=\bar{X}$, pela equação 21 , tem-se:

$$
\hat{\theta}_{.}=\frac{1}{n} \sum_{i=1}^{n} \hat{\theta}_{i}=\sum_{i=1}^{n}\left[\frac{n \bar{X}-X_{i}}{n-1}\right]=\frac{1}{n}\left[\frac{n^{2} \bar{X}-n \bar{X}}{n-1}\right]=\frac{n(n-1) \bar{X}}{n(n-1)}=\bar{X}
$$

portanto, $\hat{b}(\theta, \bar{X})=(n-1)(\bar{X}-\bar{X})=0$.

Para a estimação "jackknife" do vício do estimador de máxima verossimilhança $T_{n}(\mathbf{X})=\hat{\sigma}^{2}=\frac{1}{n} \sum_{i=1}^{n}\left(X_{i}-\bar{X}\right)^{2}$, da variância $\sigma^{2}$, da distribuição 
F, conhecida ou não, tem-se que:

$$
E\left[\hat{\sigma}^{2}\right]=E\left[\frac{1}{n} \sum_{i=1}^{n}\left(X_{i}-\bar{X}\right)^{2}\right]=\frac{1}{n}(n-1) \sigma^{2}=\sigma^{2}-\frac{\sigma^{2}}{n} .
$$

Logo, $b\left(\sigma^{2}, \hat{\sigma}^{2}\right)=\frac{-\sigma^{2}}{n}$, e da equação (27) vê-se que a aproximação vai somente até o termo de ordem $\frac{1}{n}$, sendo os demais nulos. E, como o estimador "jackknife" elimina esse termo da aproximação de $E\left[\hat{\sigma}^{2}\right]$, conclui-se que $\tilde{\theta}$ é não-viciado para $\sigma^{2}$. A estimativa do vício é dada por:

$$
\begin{aligned}
b\left(\sigma^{2}, \hat{\sigma}^{2}\right) & =\hat{\theta}-\tilde{\theta}=\frac{1}{n} \sum_{i=1}^{n}\left(X_{i}-\bar{X}\right)^{2}-\frac{1}{n-1} \sum_{i=1}^{n}\left(X_{i}-\bar{X}\right)^{2} \\
& =\frac{1}{n(n-1)} \sum_{i=1}^{n}\left(X_{i}-\bar{X}\right)^{2},
\end{aligned}
$$

que, em alguns casos, são exatamente iguais aos da teoria clássica.

É importante destacar que, no caso da estimação do vício de $\sigma^{2}$, obtémse uma estatística cuja esperança é $\frac{-\sigma^{2}}{n}$ :

$$
E\left[b\left(\sigma^{2}, \hat{\sigma}^{2}\right)\right]=\frac{-1}{n(n-1)} E\left[\sum_{i=1}^{n}\left(X_{i}-\bar{X}\right)^{2}\right]=\frac{-1}{n(n-1)} \sigma^{2}(n-1)=\frac{-\sigma^{2}}{n} .
$$

Portanto, o "jackknife" fornece um estimador não-viciado para o vício de $\hat{\sigma}^{2}$.

Segundo Efron \& Stein (1981), esse resultado ocorre sempre que a estatística for uma função quadrática.

O "bootstrap" é uma técnica estatística computacionalmente intensiva que permite a avaliação da variabilidade de estatísticas, com base nos dados de uma única amostra existente. Essa técnica foi introduzida por Efron (1979), e, desde então, tem merecido profundo estudo por parte dos estatísticos, não só na parte teórica, como também na aplicada.

O termo "bootstrap" surgiu da frase "to pull oneself up one's bootstrap" retirada de "Adventures of Baron Munchausem " de Rudolph Erich Raspe, século XVII: "The Barom had fallen to the of a deep lake. Just whem it looked like allwas lost, he thought to pick himself up by his own bootstraps." Esse texto relata uma situação em que o Barão esta afundando em um lago e vendo que 
tudo estava perdido, pensa que conseguirá emergir puxando os cadarços dos próprios sapatos (Efron \& Tibshirani, 1993). O sentido estatístico do termo é passar a idéia de que, em situações difíceis, deve-se tentar as mais variadas soluções possíveis.

Na estatística, as situações difíceis podem ser vistas como os problemas de soluções analíticas complexas, e, as variadas soluções possíveis, seriam a utilização de uma metodologia com grande quantidade de cálculos, para analisar um pequeno conjunto de dados. A solução para esses casos, com o uso de métodos computacionalmente intensivos, é obtida substituindo-se o poder analítico das expressões teóricas pelo poder de processamento dos computadores.

A idéia chave do método é a amostra "boostrap", que é retirada da amostra original com reposição. Dessa forma, todo resultado "bootstrap" depende diretamente da amostra original observada, isto é, os resultados "bootstrap" são robustos para a amostra original. Algumas considerações de regularidade sob as quais esse método é consistente foram discutidas por Bickel \& Freedman (1981). Os conceitos básicos, propriedades teóricas e aplicações podem ser encontrados em Efron \& Tibishirani (1993).

O "bootstrap" pode ser implementado tanto na estatística nãoparmétrica quanto na paramétrica, dependendo apenas do conhecimento do problema. No caso não-paramétrico, o método "bootstrap" reamostra os dados com reposição, de acordo com uma distribuição empírica estimada, tendo em vista que, em geral, não se conhece a distribuição subjacente aos dados. No caso paramétrico, quando se tem informação suficiente sobre a forma da distribuição dos dados, a amostra "bootstrap" é formada realizando-se a amostragem diretamente nessa distribuição com os parâmetros desconhecidos substituídos por estimativas paramétricas. A distribuição da estatística de interesse aplicada aos valores da amostra "bootstrap", condicional aos dados observados, é definida como a distribuição "bootstrap" dessa estatística.

Operacionalmente, o procedimento "bootstrap" consiste na reamostragem de mesmo tamanho e com reposição dos dados da amostra original, e 
cálculo da estatística de interesse para cada reamostra "bootstrap" (pseudo-dados).

Esquematicamente, sejam o parâmetro $\theta$ e o seu estimador a estatística $T_{n}(\mathbf{X}, F)$, em que $\mathbf{X}=\left[x_{1}, x_{2}, \cdots, x_{n}\right]$ é a a.a. disponível da v.a. com função distribuição desconhecida $\mathrm{F}\left(X_{i} \sim\right.$ i.i.d. $\left.F\right)$, e

$$
\hat{F}_{(n)}(x)=\frac{\left[\sum_{i=1}^{n} I\left(X_{i} \leq x\right)\right]}{n},
$$

em que:

$\hat{F}_{(n)}(x)$ : o estimador não-paramétrico de máxima verossimilhança de $\mathrm{F}$;

$I\left(X_{i} \leq x\right)$ : função indicadora.

Assim essa distribuição empírica é construída colocando-se massa probabilística $\frac{1}{n}$ em cada ponto amostral.

De $\hat{F}_{n}(x)(28)$ toma-se B amostras "bootstrap" de mesmo tamanho n,

$$
\begin{aligned}
& \mathbf{X}_{1}^{*}=\left[x_{11}^{*}, x_{12}^{*}, \cdots, x_{1 n}^{*}\right] \quad x_{1 i}^{*} \sim \text { i.i.d } \hat{F}_{n} \\
& \mathbf{X}_{2}^{*}=\left[x_{21}^{*}, x_{22}^{*}, \cdots, x_{2 n}^{*}\right] \quad x_{2 i}^{*} \sim \text { i.i.d } \hat{F}_{n} \\
& \mathbf{X}_{B}^{*}=\left[x_{B 1}^{*}, x_{B 2}^{*}, \cdots, x_{B n}^{*}\right] \quad x_{B i}^{*} \sim \text { i.i.d } \quad \hat{F}_{n}
\end{aligned}
$$

calcula-se as B estatísticas "bootstrap" $T_{n}^{*}\left(\mathbf{X}_{\ell}^{*}\right) \quad(\ell=1,2, \cdots, B)$, correspondentes às B amostras "bootstrap", e forma-se o conjunto:

$$
\left\{T_{n}\left(\mathbf{x}_{\ell}^{*}\right) ; \quad \ell=1,2, \cdots, B\right\}
$$

que é uma simulação da verdadeira distribuição amostral da estatística $T_{n}(\mathbf{x}, F)$.

Com o conjunto (29) pode-se obter a medida da variabilidade de $T_{n}(\mathbf{x}, F)$, como o erro-padrão "bootstrap" $\left(\hat{\theta}^{*}=s\left(x^{*}\right)\right)$. A estimativa do vício da estatística $T_{n}(\mathbf{X}, F)$ é dada por:

$$
b\left[\theta, T_{n}(\mathbf{x}, F)\right]=T_{n}(\mathbf{x}, F)-T_{n}^{*},
$$


em que,

$$
T_{n}^{*}=\frac{\sum_{\ell=1}^{B} T_{n}\left(\mathbf{x}_{\ell}^{*}\right)}{B},
$$

que corresponde à estimativa "bootstrap" do parâmetro de interesse.

A Figura 2, traz um diagrama esquemático ilustrando a construção da distribuição "bootstrap".

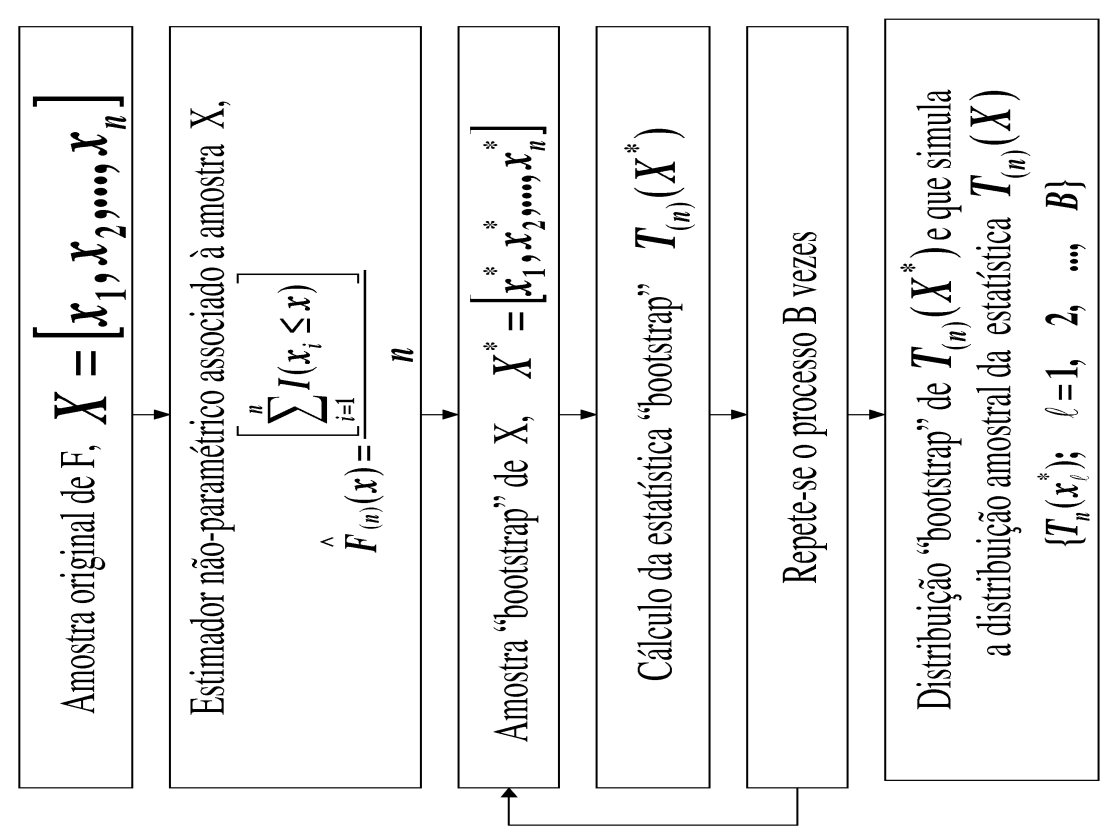

Figura 2 - Diagrama da distribuição "bootstrap" da estatística $T_{n}(\mathbf{x}, F)$

Na prática constroi-se a distribuição "bootstrap", (28), de $T_{n}(\mathbf{x}, F)$ por Monte-Carlo com um número de repetições, B, suficientemente grande. Um indicador do tamanho adequado de $\mathrm{B}$, independente do custo computacional, é a qualidade da convergência da estimativa "bootstrap" do parâmetro para a estimativa natural do parâmetro $T_{n}^{*}(B \rightarrow \infty) \longmapsto T_{n}(\mathbf{x}, F)$. A construção do algorítmo Monte-Carlo para obtenção da distribuição "bootstrap" das estatísticas usuais é em geral simples. Sua convergência está garantida pela lei dos Grandes Números, pois 
$T_{n}^{*}\left(\mathbf{X}_{1}^{*}\right), T_{n}^{*}\left(\mathbf{X}_{2}^{*}\right), \cdots, T_{n}^{*}\left(\mathbf{X}_{B}^{*}\right)$ nada mais são do que uma amostra de v.a's i.i.d. com distribuição condicional de $T_{n}^{*}(\mathbf{X}, \hat{F}) \mid \mathbf{X}=\mathbf{x}$.

Assim, quando B tende a infinito, a média amostral $T_{n}^{*}(30)$ aproximase de $E\left[T_{n}(\mathbf{X}, \hat{F}) \mid \mathbf{X}=\mathbf{x}\right]$. Efron (1979) sugeriu que a distribuição condicional "bootstrap" de $T_{n}(\mathbf{X}, \hat{F}) \mid \mathbf{X}=\mathbf{x}$ pode ser usada como a distibuição de $T_{n}(\mathbf{X}, F) \mid \mathbf{X}=\mathbf{x}$. Como se vê, no procedimento "bootstrap", os pontos da amostra original $\left[x_{1}, x_{2}, \cdots, x_{n}\right]$ são consideradas como uma população com função distribuição $\hat{F}$ e média $\bar{x}$. A estatística "bootstrap" $T_{n}^{*}=T_{n}^{*}(\mathbf{x}, \hat{F})$ é considerada como um estimador de $T_{n}(\mathbf{x}, F)$.

A distribuição de $T_{n}\left(\mathbf{x}^{*}, \hat{F}\right)$ pode ser usada para aproximar a distribuição amostal desconhecida de $T_{n}(\mathbf{x}, F)$, assim como, a distribuição de $\sqrt{n}\left(t_{n}^{*}-T_{n}\right)$ pode ser usada para aproximar a distribuição amostral de $\sqrt{n}\left(T_{n}-\theta\right)$ (Bickel \& Freedman, 1981; Efron \& Tibishirani, 1993). A normalidade assintótica de $\sqrt{n}\left(T_{n}^{*}-T_{n}\right)$, e a convergência em probabilidade da variância "bootstrap" (31) foram demostradas por Bickel \& Freedman (1981).

$$
\left.s^{* 2}=\frac{1}{B-1} \sum_{\ell=1}^{B}\left[T_{n}\left(\mathbf{x}_{\ell}^{*}\right)-T_{n}^{*}\right)\right]^{2} .
$$

O número de vezes em que o ponto amostal $x_{i}$ é selecionado no procedimento "bootstrap" $\left(\mathbf{X}^{*}=\mathbf{x}^{*}\right)$ é representado por:

$$
N_{i}^{*}=\#\left\{X_{i}^{*}=x_{i}\right\}
$$

consequentemente $\sum_{i}^{n} N_{i}^{*}=n$ e o vetor $\mathbf{N}^{*}=\left[N_{1}^{*}, N_{2}^{*}, \cdots, N_{n}^{*}\right]$ tem distribuição multinominal. Vê-se que $N_{i}^{*} \sim b\left(n, \frac{1}{n}\right)$ e, em correspondência a esses números existe uma distribuição de frequências relativas $f_{i}=\frac{N_{i}^{*}}{n}$, sendo que $f_{i}$ assume valores no conjunto $\left\{o, \frac{1}{n}, \frac{2}{n}, \cdots, \frac{n}{n}\right\}$. A v.a. $f_{i}$ possui média e variância dadas por:

$$
N_{i}^{*} \sim b\left(n, \frac{1}{n}\right) \longrightarrow\left\{\begin{array}{l}
E\left[f_{i}\right]=E\left[\frac{N_{i}^{*}}{n}\right]=\frac{1}{n} E\left[N_{i}^{*}\right]=\frac{1}{n} \\
V\left[f_{i}\right]=V\left[\frac{N_{i}^{*}}{n}\right]=\frac{1}{n^{2}} V\left[N_{i}^{*}\right]=\frac{n-1}{n^{3}}
\end{array}\right.
$$

Intervalos de confiança para parâmetros podem ser construídos com base em estatísticas "bootstrap". O mais simples dos intervalos "bootstrap" é aquele 
em que se substitui a estimativa usual do erro padrão, pela estimativa "bootstrap". Efron \& Tibshirani (1986) propõem um procedimento para estabelecer um intervalo de confiança, com base em uma função monôtona crescente f, tal que para $\varphi=f(\theta)$, $\hat{\varphi}=f(\hat{\theta})$ e $\hat{\varphi}^{*}=f\left(\hat{\theta}^{*}\right)$ tem-se as quantidades pivotais Gaussianas $\hat{\varphi}-\varphi$ e $\hat{\varphi}^{*}-\hat{\varphi}$, ou seja:

$$
\hat{\varphi}^{*}-\hat{\varphi} \sim N\left(-z_{0} \sigma, \sigma^{2}\right) \quad e \quad \hat{\varphi}-\varphi \sim N\left(-z_{0} \sigma, \sigma^{2}\right)
$$

para as constantes $z_{0}$ e $\sigma$. Portanto, $\hat{\varphi}-\varphi$ é uma quantidade pivotal Gaussiana sob $\mathrm{F}$ e $\hat{F}$. Dessa forma, se $\hat{\theta}=\theta(\hat{F})$ então $\hat{\varphi}=f(\hat{\theta})=f(\theta(\hat{F}))$. Sendo assim, o intervalo de confiança de nível $(1-\alpha)$ para $\varphi$, com base no pivo (32) é:

$$
P\left[\frac{\left|\hat{\varphi}-\varphi-\left(-z_{0} \sigma\right)\right|}{\sigma} \leq z_{\frac{\alpha}{2}}\right]=1-\alpha .
$$

O método mais simples para estimar intervalos de confiança por "bootstrap" é o método percentil. Esse método consiste em encontrar a distribuição $\hat{F}$ "bootstrap" (28) e calcular os percentis da distribuição $\hat{F}^{-1}\left(\frac{\alpha}{2}\right)$ e $\hat{F}^{-1}\left(1-\frac{\alpha}{2}\right)$, que correspondem aos limites inferiores $\left(L_{I}\right)$ e superiores $\left(L_{S}\right)$, respectivamente, do intervalo de confiaça $(1-\alpha) 100 \%$ (Efron \& Tibshirani, 1993). Na prática, esses intervalos $\left(L_{I}\right)$ e $\left(L_{S}\right)$ podem ser obtidos pelos valores relativos à parte inteira de $B \frac{\alpha}{2}$ e $B\left(1-\frac{\alpha}{2}\right)+1$, respectivamente, do ranqueamento das estatísticas "bootstrap" $T_{n}\left(X^{*}\right)$ obtidas em $(29)$.

Uma versão melhorada desse método, denominada $B C_{a}$ ("biascorrected and accelerated") (Efron \& Tibshirani, 1993), apresenta alta precisão na estimação dos intervalos de confiança para dados obtidos da distribuição "bootstrap" (Diciccio \& Efron, 1996). Esse método fixa os limites de confiança para $\theta$ em função dos percentis obtidos dos histograms gerados pelas amostras "bootstrap". Os percentis são dados por:

$$
\hat{\theta}_{B C_{a}}[\alpha]=\hat{G}^{-1} \Phi\left(z_{0}+\frac{z_{0}+z^{\alpha}}{1-a\left(z_{0}+z^{\alpha}\right)}\right) ;
$$

em que, $\hat{G}^{-1}$ é a inversa da função distribuição acumulada; $\Phi$ é a distribuição normal padronizada e $z^{\alpha}=\Phi^{-1}(\alpha)$. 
Se $a$ e $z_{0}$ são nulos, então $\hat{\theta}_{B C_{a}}[\alpha]=\hat{G}^{-1}(\alpha)$ é o centésimo pertencil "bootstrap". Assim, o intervalo de confiança fica determinado pelo $5^{\circ}$ e $95^{\circ}$ percentis "bootstrap". Se $\hat{G}$ for uma distribuição perfeitamente normal, então $\hat{\theta}_{B C_{a}}=\hat{\theta}+z^{\alpha} \hat{\sigma}$, ou seja, um intervalo de confiança padrão com estimativas "bootstrap" (Diciccio \& Efron, 1996).

No caso de $a$ e $z_{0}$ diferentes de zero, excelentes estimativas para $a$ e $z_{0}$ são dadas por:

$$
\hat{a}=\operatorname{Viés}_{\theta=\hat{\theta}} \frac{\left[\ell_{\theta}(\hat{\theta})\right]}{6}
$$

em que, $\ell_{\theta}(\hat{\theta})=\frac{\partial}{\partial \theta} \log \left\{g_{\theta}(\hat{\theta})\right\}$ e $g_{\theta}(\hat{\theta})$ é a densidade de $\frac{\partial G_{\theta}(\hat{\theta})}{\partial \hat{\theta}}$

$$
\hat{z}_{0}=\Phi^{-1}\left\{\frac{\#\left\{\hat{\theta}^{*}(b)<\hat{\theta}\right\}}{B}\right\} .
$$

Outro método bastante utilizado para determinar intervalos de confiança "bootstrap" é o método "bootstrap-t", baseado na distribuição $t$ - student. Os limites de confiança são dados por:

$$
\left[T_{n}^{*}-t_{n-1}^{1-\alpha} s^{*}, T_{n}^{*}-t_{n-1}^{\alpha} s^{*}\right]
$$

em que, $T_{n}^{*}$ definido na equação (30); $s^{*}$ definido na equação (31) e $t_{n-1}^{\alpha}$ é o valor de $t$, da tabela de $t-$ student, ao nível de $(1-\alpha) 100 \%$, com n-1 graus de liberdade.

Outras metodologias, para intervalos de confiança "bootstrap" foram desenvolvidas em função das distribuições de probabilidade, como o método ABC, apresentado por Diciccio \& Efron (1996). Vale ressaltar que o $B C_{a}$, "bootstrap-t" e o método $\mathrm{ABC}$ podem ser usados para a construção de intervalos de confiança não-paramétrico.

Finalmente, a grande vantagem dos procedimentos estatísticos "jackknife" e "bootstrap" é a estimação da precisão, de qualquer estatística com distribuição de probabilidade desconhecida. Esses métodos começaram a se tornar ferramentas bastante úteis e poderosas na construção de procedimentos inferenciais, evitando obtenção de fórmulas via argumentos analíticos. Dessa forma, vem tornando-se como alternativas eficientes para os métodos estatísticos tradicionais. 


\section{MATERIAL E MÉTODOS}

Em 1983, a Embrapa Florestas, através de um convênio estabelecido com a CSIRO (Commonwealth Scientific and Industrial Research Organization) e sob o patrocínio do Banco Mundial BIRD colheu, na Austrália, sementes de 200 árvores de Eucalyptus grandis, dentre outras espécies. Esse material englobou 10 procedências e um número de progênies que variou de 5 a 26. Desse material foram selecionadas, para efeito desse estudo, três procedências, que envolveram 70 árvores (Tabela 6).

Tabela 6. Localização das procedências de Eucalyptus grandis coletadas na Austrália

\begin{tabular}{|c|c|c|c|c|c|}
\hline $\begin{array}{l}N^{o} \text { do } \\
\text { Lote }\end{array}$ & Procedência & $\begin{array}{l}N^{o} \text { de } \\
\text { Progênies }\end{array}$ & $\begin{array}{l}\text { Lat. } \\
(\mathrm{S})\end{array}$ & $\begin{array}{l}\text { Long. } \\
\text { (E) }\end{array}$ & $\begin{array}{l}\text { Alt. } \\
(\mathrm{m})\end{array}$ \\
\hline 14.420 & 12 km S. of Ravenshoe-Mt Pandanus-QLD & 20 & $17^{\circ} 06^{\prime}$ & $145^{\circ} 38^{\prime}$ & 1020 \\
\hline 14.423 & Baldy State Forest 194-Atherton-QLD & 25 & $17^{\circ} 25^{\prime}$ & $145^{\circ} 27^{\prime}$ & 950 \\
\hline 14.431 & Bellthorpe St. Forest-QLD & 25 & $26^{\circ} 44^{\prime}$ & $152^{\circ} 39^{\prime}$ & 650 \\
\hline
\end{tabular}

Lat.: latitude; Long.: longitude e Alt.: altitude

Através de parcerias com empresas florestais privadas foram estabelecidos sete testes combinados de procedência e progênie nas regiões sul e sudeste do Brasil (Tabela 7). O delineamento utilizado foi o de blocos casualizados, com 6 plantas por parcelas e 10 repetições, no espaçamento de 3,0 m por 2,0 m. 
Tabela 7. Localização dos testes de procedências e progênies de Eucalyptus grandis implantados no Brasil

\begin{tabular}{llllll}
\hline Locais & Municípios/Estado & Regiões & $\begin{array}{l}\text { Latitude } \\
(\mathrm{S})\end{array}$ & $\begin{array}{l}\text { Longitude } \\
(\mathrm{W})\end{array}$ & $\begin{array}{l}\text { Altitude } \\
(\mathrm{m})\end{array}$ \\
\hline L1 & Barra Ribeiro - RS & Sul & $30^{\circ} 20^{\prime}$ & $51^{\circ} 14^{\prime}$ & 30 \\
L2 & Telêmaco Borba - PR & Sul & $24^{\circ} 15^{\prime}$ & $20^{\circ} 29^{\prime}$ & 850 \\
L3 & Boa Esperança de Sul - SP & Sudeste & $21^{\circ} 57^{\prime}$ & $48^{\circ} 32^{\prime}$ & 540 \\
L4 & Guanhães - MG & Sudeste & $18^{\circ} 40^{\prime}$ & $42^{\circ} 60^{\prime}$ & 900 \\
L5 & Ipatinga - MG & Sudeste & $19^{\circ} 15^{\prime}$ & $42^{\circ} 20^{\prime}$ & 250 \\
L6 & Aracruz - ES & Sudeste & $19^{\circ} 48^{\prime}$ & $40^{\circ} 17^{\prime}$ & 50 \\
L7 & Caçapava - SP & Sudeste & $23^{\circ} 03^{\prime}$ & $45^{\circ} 46^{\prime}$ & 650 \\
\hline
\end{tabular}

O dados de altura, em metros aos cinco anos de idade, foram submetidos à análise de variância para cada um dos locais, considerando o modelo estatístico:

$$
Y_{i k}=\mu+g_{i}+b_{k}+\epsilon_{i k}
$$

em que:

$Y_{i k}$ : é o valor observado na parcela experimental que recebeu o genótipo i, no bloco k;

$\mu$ : é o efeito fixo da média geral do experimento;

$g_{i} \quad$ : é o efeito fixo do genótipo i;

$b_{k} \quad$ : é o efeito aleatório do bloco $\mathrm{k}$;

$\epsilon_{i k}$ : é o efeito aleatório de erro experimental associado à observação $Y_{i k}$, sendo $\epsilon_{i k} \sim\left(0, \sigma^{2}\right)$

O esquema da análise de variância é mostrado na Tabela 8. 
Tabela 8. Esquema da análise de variânia para cada local

\begin{tabular}{lllll}
\hline FV & GL & QM & F & E(QM) \\
\hline Blocos & $\mathrm{b}-1$ & $\mathrm{Q}_{1}$ & & $\sigma_{e}^{2}+g \sigma_{b}^{2}$ \\
Genótipos & $\mathrm{g}-1$ & $\mathrm{Q}_{2}$ & $Q_{2} / Q_{3}$ & $\sigma_{e}^{2}+b \Phi_{g}$ \\
Resíduo & $(\mathrm{b}-1)(\mathrm{g}-1)$ & $\mathrm{Q}_{3}$ & & $\sigma_{e}^{2}$ \\
\hline
\end{tabular}

Após as análises de variâncias em cada um dos locais, foi realizada a análise conjunta de variância desses locais, obdecendo o modelo estatístico:

$$
Y_{i j k}=\mu+g_{i}+e_{j}+b_{k(j)}+(g e)_{i j}+\epsilon_{i j k}
$$

em que:

$Y_{i j k}$ : é o valor observado na parcela experimental que recebeu o genótipo i

do bloco k, , no local j;

$\mu$ : é o efeito fixo da média geral do experimento;

$g_{i} \quad$ : é o efeito fixo do genótipo i;

$e_{j}$ : é o efeito aleatório do local j;

$(g e)_{i j}$ : é o efeito aleatório da interação do genótipo i com o local j;

$b_{k(j)}$ : é o efeito aleatório do bloco $\mathrm{k}$ dentro do local $\mathrm{j}$;

$\epsilon_{i j k}$ : é o efeito aleatório de erro experimental associado à observação $Y_{i j k}$, sendo $\epsilon_{i j k} \sim N\left(0, \sigma^{2}\right)$.

O esquema da análise conjunta de variância desses locais é mostrado na Tabela 2 .

O clima das regiões experimentais, segundo a classificação de köppen, temperaturas e precipitação pluviométrica anual, são apresentadas na Tabela 9. 
Tabela 9. Condições climáticas das regiões experimentais

\begin{tabular}{|c|c|c|c|c|c|c|c|}
\hline \multirow[b]{3}{*}{ Locais } & \multirow[b]{3}{*}{ Clima } & \multicolumn{5}{|c|}{ Temperaturas $\left({ }^{\circ} C\right)$} & \multirow[b]{3}{*}{ Precipitação (mm } \\
\hline & & \multicolumn{2}{|c|}{ Mínima } & \multicolumn{2}{|c|}{ Máxima } & \multirow[b]{2}{*}{ Média Anual } & \\
\hline & & Mês & Média & Mês & Média & & \\
\hline L1 & $\mathrm{CFA}$ & Jul & 9 & Jan & 25 & 19 & 1400 \\
\hline L2 & $\mathrm{CFB}$ & Jul & 11 & Fev & 26 & 19 & 1480 \\
\hline L3 & CWA & Jun & 15 & Nov & 23 & 21 & 1300 \\
\hline L4 & CWA & Jun & 14 & Out & 24 & 19 & 1600 \\
\hline L5 & CWA & Jun & 15 & Out & 24 & 22 & 1250 \\
\hline L6 & CWA & Jun & 15 & Set & 26 & 24 & 1360 \\
\hline $\mathrm{L} 7$ & CWA & Jul & 14 & Jan & 24 & 20 & 1260 \\
\hline
\end{tabular}

Para efeito de adubação, as repetições foram subdivididas em dois grupos iguais. Os cinco primeiros blocos receberam adubação normal dos plantios comerciais realizados pela empresa (Tabela 10). Os blocos restantes receberam uma adubação padronizada de 200g de NPK 10:20:10, por planta aplicado numa coroa de 15 a 20cm distante do colo da muda e incorporado. As características do solo na área experimental são apresentadas na Tabela 10.

As análises de estabilidade e adaptabilidade fenotípica foram executadas pelos métodos:

a) AMMI (Additive Main Effects and Multiplicative Interaction Analysis), com base na análise multivariada por componentes principais (Zobel et al., 1988), equação (18) e teste $F_{R}$ equação (19); e

b) "bootstrap" AMMI, com base na reamostragem da matriz de resíduos, livres de ruídos, obtida dos valores estimados pelo método AMMI, proposto por Gollob (1968). 
Tabela 10. Condições ambientais dos locais de ensaios, preparos e adubações dos solos, pelas empresas

\begin{tabular}{llll}
\hline Locais & \multicolumn{1}{c}{ Caracterização } & Ocupação Anterior & Adubação da Empresa \\
\hline L1 & Neossolo Flúvico Tb distrófico, & Agricultura & 135g de NPK 10:20:10 \\
& $\begin{array}{l}\text { relevo suave. O preparo do solo foi } \\
\text { realizado com arado reformador. }\end{array}$ & por planta no plantio. \\
L2 & Latossolo amarelo distrófico típico, Eucalipto & 100g de NPK 6:14:3 por \\
& $\begin{array}{l}\text { relevo ondulado. O solo recebeu } \\
\text { duas gradagens antes do plantio. }\end{array}$ & planta no plantio. \\
Latossolo amarelo distrófico psa- & Eucalipto & 120g de NPK 6:30:6 por \\
& mítico, relevo suave. O preparo do & planta, no Plantio e 50g \\
solo foi realizado com arado refor- & de NPK 12:6:12 mais \\
mador (camalhão sobre a linha de & 10g de FTE BR 9, 90 \\
tocos). & dias após Plantio.
\end{tabular}

L4 Latossolo vermelho amarelo, dis- Mata secundária, 100g de NPK 8:28:6 por trófico, típico, relevo ondulado. O vegetação original planta no plantio. solo foi preparado com gradagem subperenifolia pesada e gradagem leve.

L5 Argissolo vermelho amarelo, dis- Pastagem 100g de NPK 8:28:6 por trófico típico, relevo ondulado. $\mathrm{O}$ planta no plantio. solo foi preparado com gradagem pesada e gradagem leve.

L6 Neossolo quartizarênico órtico típico, relevo suave ondulado. O Floresta Tropical 100g de NPK 10:20:10 Atlântica por planta no plantio. preparo do solo foi realizado com arado reformador e gradagem leve.

L7 Argissolo vermelho amarelo, dis- Pastagem 175g de NPK 10:20:10 trófico típico, relevo ondulado. O solo foi preparado com gradagem por planta no plantio. pesada e gradagem leve. 
Para ambos os métodos, foram esquematizadas as análises de variância pelo quadro completo da análise conjunta, a partir de médias (Duarte \& Vencovsky, 1999) (Tabela 11). Foram aplicados os testes $F_{\text {Gollob }}$ e $F_{R}$ propostos por Gollob (1968) e Cornelius et al. (1992), respectivamente.

Tabela 11. Análise completa de variância, a partir de médias, usando os procedimentos de Gollob (1968) e Cornelius et al.(1992)

\begin{tabular}{lllll}
\hline $\begin{array}{l}\text { Fonte de } \\
\text { variação }\end{array}$ & G.L. & $\begin{array}{l}\text { Soma de quadrados } \\
\text { Gollob }\end{array}$ & $\begin{array}{l}\text { G.L. } \\
\text { Cornelius }\end{array}$ & $\begin{array}{l}\text { Soma de quadrados } \\
\text { Cornelius }\end{array}$ \\
\hline Genótipos $(\mathrm{G})$ & $\mathrm{g}-1$ & $\mathrm{SQ}(\mathrm{G})$ & - & - \\
Ambientes $(\mathrm{E})$ & $\mathrm{e}-1$ & $\mathrm{SQ}(\mathrm{E})$ & - & - \\
Interação $(\mathrm{G} \times \mathrm{E})$ & $(\mathrm{g}-1)(\mathrm{e}-1)$ & $\mathrm{SQ}(\mathrm{G} \times \mathrm{E})$ & - & - \\
$\mathrm{IPCA}_{1}$ & $\mathrm{~g}+\mathrm{e}-1-(2 \times 1)$ & $\lambda_{1}^{2}$ & $(\mathrm{~g}-1-1)(\mathrm{e}-1-1)$ & $\sum_{k=2}^{n} \lambda_{k}^{2}$ \\
$\mathrm{IPCA}_{2}$ & $\mathrm{~g}+\mathrm{e}-1-(2 \times 2)$ & $\lambda_{2}^{2}$ & $(\mathrm{~g}-1-2)(\mathrm{e}-1-2)$ & $\sum_{k=3}^{n} \lambda_{k}^{2}$ \\
$\mathrm{IPCA}_{3}$ & $\mathrm{~g}+\mathrm{e}-1-(2 \times 3)$ & $\lambda_{3}^{2}$ & $(\mathrm{~g}-1-3)(\mathrm{e}-1-3)$ & $\sum_{k=4}^{n} \lambda_{k}^{2}$ \\
$\ldots$ & $\ldots$ & $\ldots$ & $\ldots$ \\
$\mathrm{IPCA}_{n}$ & $\mathrm{~g}+\mathrm{e}-1-(2 \times \mathrm{n})$ & $\lambda_{n}^{2}$ & $\ldots$ & \\
Error mean $/ \mathrm{r}$ & $\mathrm{ge}(\mathrm{n}-1)$ & $\mathrm{SQ}$ (Erro médio) & & \\
Total & ger -1 & $\mathrm{SQ}$ (total) & & \\
\hline
\end{tabular}

G.L.: graus de liberdade; g: número de genótipos; e: número de ambientes;

$\lambda$ : valor singular (escalar) da matriz de interação GE; n = mínimo(g-1, e-1);

IPCA: eixo da interação da análise de componentes principais.

Foram adotados os critérios de Gauch \& Zobel (1988), para a definição do número de eixos a serem retidos para explicar o padrão relacionado à interação, levando em consideração a proporção da soma de quadrados da interação $\left(S Q_{(G \times E)}\right)$ acumulada até o n-ésimo eixo $\sum_{k=1}^{n} \lambda_{k}^{2} / S Q_{(G \times E)}$. Os pontos de parada que determinaram a seleção dos modelos $\left(A M M I_{0}, A M M I_{1}, \cdots, A M M I_{6}\right)$ foram obtidos com base na significância dos testes $F_{\text {Gollob }}$ e $F_{R}$, para os sucessivos termos da interação. 


\subsection{Estabilidade e adaptabilidade fenotípica via método AMMI}

Uma vez selecionado o modelo AMMI, através do IPCA significativo ao nível de $1 \%$ de probabilidade, pelo teste $F_{R}$, foram processadas as inferências sobre as adaptabilidades e estabilidades fenotípicas dos genótipos e dos ambientes.

As adaptabilidades, em termos da capacidade que um genótipo tem em aproveitar vantajosamente os efeitos ambientais, de maneira a assegurar alto nível de produtividade, foram preditas em função das respostas para cada combinação de genótipos e ambientes, sobre o modelo AMMI, selecionado pelo IPCA, de acordo com os níveis de significância de $F_{R}$. As respostas esperadas dos genótipos i (i $=1$, $2, \cdots, \mathrm{g})$ nos ambientes $\mathrm{j}(\mathrm{j}=1,2, \cdots, \mathrm{e})\left(\hat{Y}_{i j}\right)$ foram determinadas por:

$$
\hat{Y}_{i j}=\bar{Y}_{i .}+\bar{Y}_{. j}-\bar{Y}_{. .}+\sum_{k=1}^{p} \lambda_{k} \gamma_{i k} \alpha_{j k},
$$

em que: p é o número de eixos significativos para a decomposição da interação

$(\mathrm{G} \times \mathrm{E})$, com $\mathrm{p} \leq 6 ; \bar{Y}_{i}$. é a média do genótipo i; $\bar{Y}_{. j}$ é a média do ambiente $\mathrm{j} ; \bar{Y}_{\text {.. }}$ é a média geral; $\lambda_{k}$ é o k-ésimo valor singular (escalar) da matriz de interação original (denotada por $\mathbf{G E}_{g \times e}=\left[(\widehat{g e})_{i j}\right]$, com, $\left.\widehat{g e}_{i j}=Y_{i j}-\bar{Y}_{i .}-\bar{Y}_{. j}+\bar{Y}_{. .}\right) ; \gamma_{i k}$ é o elemento correspondente ao i-ésimo genótipo no k-ésimo vetor singular coluna da matriz GE e $\alpha_{j k}$ é o elemento correspondente ao j-ésimo ambiente no k-ésimo vetor singular linha da matriz GE. Os termos $\lambda_{k}, \gamma_{i k}$ e $\alpha_{j k}$ foram obtidos pela decomposição por valores singulares (DVS) da matriz de interação GE.

Os escores de genótipos $(\mathbf{G})$ e de ambientes $\left(\mathbf{H}^{\prime}\right)$ foram obtidos pela decomposição aproximada por n componentes:

$$
\begin{aligned}
\mathbf{G E} & =\mathbf{U S V}^{\prime}=\mathbf{U S}^{\frac{1}{2}} \mathbf{S}^{\frac{1}{2}} \mathbf{V}^{\prime} \\
\mathbf{G} & =\mathbf{U S}^{\frac{1}{2}} \\
\mathbf{H}^{\prime} & =\mathbf{S}^{\frac{1}{2}} \mathbf{V}^{\prime}
\end{aligned}
$$

em que: 


$$
\begin{aligned}
\mathbf{U} & : \text { é a matriz com os vetores singulares-coluna } \gamma_{i k} ; \\
\mathbf{S} & : \text { é a matriz com os valores singulares } \lambda_{k} ; \\
\mathbf{V}^{\prime} & \text { : é a matriz com os vetores singulares-linha } \alpha_{j k}^{\prime} \text {. }
\end{aligned}
$$

A adaptabilidade, via estimativa do modelo AMMI, foi obtida através da exploração do efeito positivo da interação $\mathrm{G} \times \mathrm{E}$. Nesse sentido, foram observados os produtos entre os escores de genótipos e escores de ambiente, os quais fornecem as estimativas dos efeitos da interação. Os efeitos positivos desses produtos indicaram as situações favoráveis dos genótipos a aqueles ambientes. Essas relações adaptativas, também foram verificadas pelos biplots AMMI selecionados, através das observações dos sinais dos escores para cada par de genótipo e ambiente. As indicações das adaptabilidades foram associadas aos genótipos e ambientes com escores de mesmo sinal, evidenciando um sinergismo adaptativo. Por outro lado, genótipos e ambientes com escores de sinais opostos, indicaram um certo antagonismo, com uma combinação desfavorável de genótipo e ambiente (Duarte \& Vencovsky, 1999).

A estabilidade, que está relacionada com a manutenção da produtividade ou de suas previsibilidades com outros ambientes, foi avaliada através das análises das magnitudes e dos sinais dos escores biplots, correspondentes aos modelos AMMI selecionados, sendo considerados estáveis aqueles genótipos e/ou ambientes cujos escores foram considerados baixos (próximos de zero), que são próprios de genótipos e ambientes que contribuíram pouco ou quase nada para a interação (Duarte \& Vencovsky, 1999). Os resultados foram analisados pela representação gráfica em biplot (Gabriel, 1971).

Dada a dificuldade para que fossem estabelecidos critérios para a quantificação dos escores como baixos, foram realizados os testes de Shapiro-Wilk para verificar as normalidades dos escores, e construídas as regiões de confiança de $90 \%$ e 99\% para a média, para o modelo AMMI2 $\left(\mathrm{IPCA}_{1} \times \mathrm{IPCA}_{2}\right)$, pela expressão (Johnson 
\& Wichern, 1998):

$$
\left(\overline{\theta_{k}}-\theta_{k}\right)^{\prime} S_{\theta_{k}}^{-1}\left(\overline{\theta_{k}}-\theta_{k}\right) \leq \frac{2(n-1)}{n(n-2)} F_{2, n-2}(\alpha)
$$

em que: $\mathrm{k}=\mathrm{g}$ ou $\mathrm{k}=\mathrm{e}$, para genótipos ou ambientes, respectivamente; $\mathrm{n}$ é o número de escores envolvidos (20 para o lote 14.420; 25 para os lotes 14.423 e 14.431 e sete para os ambientes); $\overline{\theta_{k}}$ é o vetor de médias dos escores (vetor nulo); $\theta_{k}$ vetor de escores observados e $S_{\theta_{k}}^{-1}$ é a inversa da matriz de covariâncias dos escores.

Para saber se um dado genótipo ou ambiente pertence à região de confiança estabelecida, foram verificados os valores de $\left[n\left(\bar{\theta}_{k}-\theta_{k}\right)^{\prime} S_{\theta_{k}}^{-1}\left(\bar{\theta}_{k}-\theta_{k}\right)\right]$ menores que $\frac{2(n-1)}{n-2} F_{2, n-2}(\alpha)$. Nesses casos foram considerados estáveis. Os valores menores foram classificados como de alta estabilidade para aqueles associados ao $\alpha=0,10 \mathrm{e}$ estável para $\alpha=0,01$.

Para o modelo $\mathrm{AMMI}_{1}$, foram determinados os intervalos de confiança, aos níveis de $90 \%$ e $99 \%$ para a média do $\operatorname{IPCA}_{1}\left(\bar{X}_{I P C A_{1}}\right)$ de genótipos e ambientes, dados por:

$$
\bar{X}_{I P C A_{1}} \pm t_{n-1}(\alpha) \frac{s_{I P C A_{1}}}{\sqrt{n-1}}
$$

em que: $t_{n-1}(\alpha)$ são os valores da distribuição t de Student, com (n-1) graus de liberdade e $\alpha$ os níveis de significância; $s_{I P C A_{1}}$ é o desvio padrão do IPCA 1 .

Genótipos e ambientes inclusos dentro do intervalo de confiança de 90\%, foram considerados de alta estabilidade; para aqueles inclusos dentro do intervalo de confiança de 99\%, foram considerados estáveis; e, para aqueles externos a esses limites foram considerados como instáveis.

\subsection{Estabilidade e adaptabilidade fenotípica via método "bootstrap" AMMI}

O método AMMI faz a decomposição da soma de quadrados originais $\left(S Q_{G \times E}\right)$, em eixos singulares, ortogonais, que podem ser separados em duas partes, padrão e ruído. Os primeiros eixos associados ao modelo AMMI, detém praticamente 
todo o padrão devido à interação, e os eixos de mais alto grau captam, praticamente, somente os ruídos (Gauch, 1988).

O padrão possibilita a identificação de fatores genotípicos e ambientais mais associados à interação, e, o ruído, sem interesse agronômico é descartado, propiciando uma melhoria na capacidade preditiva das respostas fenotípicas.

Assim, a proposta metodológica para o "bootstrap" AMMI, consistiu em executar o método AMMI seguindo a proposta de Gollob (1968), o qual garante pelo menor rigor dos graus de liberdade, um número maior de fatores multiplicativos, e, conseqüentemente, absorve todo o padrão devido a interação $\mathrm{G} \times E$. A partir desse modelo, foram determinadas as estimativas dos genótipos i nos ambientes $\mathrm{j}\left(\hat{Y}_{i j}\right)$ livres de ruídos, conforme equação (34), e, a partir desse novo conjunto de dados, foram obtidas as matrizes de resíduos $\left[\widehat{\mathbf{G E}}_{G \times E}=\left(\widehat{g e}_{i j}\right)\right]$ representadas por:

$$
\widehat{\mathbf{G E}}_{G \times E}=\left[\begin{array}{cccc}
\widehat{g e}_{11} & \widehat{g e}_{12} & \cdots & \widehat{g e}_{1 e} \\
\widehat{g e}_{21} & \widehat{g e}_{22} & \cdots & \widehat{g e}_{2 e} \\
\vdots & \vdots & \cdots & \vdots \\
\widehat{g e}_{g 1} & \widehat{g e}_{g 2} & \cdots & \widehat{g e}_{g e}
\end{array}\right]
$$

com:

$$
\widehat{g e}_{i j}=\hat{Y}_{i j}-\hat{\bar{Y}}_{i .}-\hat{\bar{Y}}_{. j}+\hat{\bar{Y}}_{. .}
$$

em que:

$\hat{\bar{Y}}_{i \text {. }}$ : é a média dos valores estimados do genótipo i;

$\hat{\bar{Y}}_{. j}$ : é a média dos valores estimados do ambiente j;

$\hat{\bar{Y}}_{\text {.. }} \quad$ : é a média geral dos valores estimados. 
Das matrizes $\widehat{\mathbf{G E}}_{G \times E}$, foram reamostradas 200 matrizes "bootstrap" para genótipo $\left(\mathbf{G E}_{g}^{*}\right)$, com o sorteio com reposição executado nas linhas, e 200 matrizes "bootstrap" para ambiente $\left(\mathbf{G E}_{e}^{*}\right)$, com o sorteio com reposição executado nas colunas, para cada procedência estudada. Obtendo-se:

$$
\mathbf{G E}_{k \ell}^{*}=\left[\begin{array}{cccc}
g e_{11}^{*} & g e_{12}^{*} & \cdots & g e_{1 e}^{*} \\
g e_{21}^{*} & g e_{22}^{*} & \cdots & g e_{2 e}^{*} \\
\vdots & \vdots & \cdots & \vdots \\
g e_{g 1}^{*} & g e_{g 2}^{*} & \cdots & g e_{g e}^{*}
\end{array}\right]
$$

com: $\mathrm{k}=\mathrm{g}$ ou $\mathrm{k}=\mathrm{e}$, para genótipos ou ambientes, respectivamente $\mathrm{e}$ $\ell=(1,2, \cdots, 200)$.

As matrizes "bootstrap" de resíduos foram centradas em relação às médias de linhas, de coluna e geral, afim de atender às restrições de identificabilidade da matriz de resíduos (Krzanowski $\left.{ }^{3}, 2002\right)$.

Assim, de maneira esquemática, foram determinadas as matrizes $\widetilde{\mathbf{G E}}_{k \ell}^{*}$, denominadas de matrizes "bootstrap" de resíduos corrigidos:

$$
\widetilde{\mathbf{G E}}_{k \ell}^{*}=\left[\begin{array}{cccc}
\widetilde{g e}_{11}^{*} & \widetilde{g e}_{12}^{*} & \cdots & \widetilde{g e}_{1 e}^{*} \\
\widetilde{g e}_{21}^{*} & \widetilde{g e}_{22}^{*} & \cdots & \widetilde{g e}_{2 e}^{*} \\
\vdots & \vdots & \cdots & \vdots \\
\widetilde{g e}_{g 1}^{*} & \widetilde{g e}_{g 2}^{*} & \cdots & \widetilde{g e}_{g e}^{*}
\end{array}\right]
$$

em que:

$$
\begin{aligned}
\widetilde{g e}_{i j}^{*} & =\widehat{g e}_{i j}^{*}-\frac{1}{e} \sum_{j=1}^{e} \widehat{g e}_{i j}^{*}-\frac{1}{g} \sum_{i=1}^{g} \widehat{g e}_{i j}^{*}+\frac{1}{g e} \sum_{i=1}^{g} \sum_{j=1}^{e} \widehat{g e}_{i j}^{*} \\
& =\widehat{g e}_{i j}^{*}-\widehat{g e}_{i .}^{*}-\widehat{g e}_{. j}^{*}+\widehat{g e}_{. .}^{*}
\end{aligned}
$$

${ }^{3}$ - comunicação pessoal do Prof. Wojtek J. Krzanowski, School of Mathematical Sciences, Laver Building, EXETER, UK via Email, em 12/11/2002. 
A partir dessas matrizes foram determinados os efeitos "bootstrap" de genótipos $\left(\widetilde{\mathbf{G}}_{k \ell}^{*}\right)$ e efeitos "bootstrap" de ambientes $\left(\widetilde{\mathbf{H}}_{k \ell}^{*^{\prime}}\right)$, através da DVS. Nesse caso, a DVS foi aplicada em cada uma das 1.200 matrizes "bootstrap" de desvios corrigidos:

$$
\begin{aligned}
\widetilde{\mathbf{G E}}_{k \ell}^{*} & =\mathbf{U}_{k \ell} \mathbf{S}_{k \ell} \mathbf{V}_{k \ell}^{\prime}=\mathbf{U}_{k \ell} \mathbf{S}_{k \ell}^{\frac{1}{2}} \mathbf{S}_{k \ell}^{\frac{1}{2}} \mathbf{V}_{k \ell}^{\prime} \\
\widetilde{\mathbf{G}}_{k \ell}^{*} & =\mathbf{U}_{k \ell} \mathbf{S}_{k \ell}^{\frac{1}{2}} \\
\widetilde{\mathbf{H}}_{k \ell}^{*^{\prime}} & =\mathbf{S}_{k \ell}^{\frac{1}{2}} \mathbf{V}_{k \ell}^{\prime}
\end{aligned}
$$

em que:

$$
\begin{aligned}
& \mathbf{U}_{k \ell}: \text { é a matriz com os vetores "bootstrap" singulares-coluna } \gamma_{i k \ell} ; \\
& \mathbf{S}_{k \ell} \text { : é a matriz com os valores "bootstrap" singulares } \lambda_{k \ell} ; \\
& \mathbf{V}_{k \ell}^{\prime}: \text { é a matriz com os vetores "bootstrap" singulares-linha } \alpha_{j k \ell}^{\prime} \text {. }
\end{aligned}
$$

Dessa forma, foram obtidos para cada genótipo e ambiente, 200 escores associados a cada matriz "bootstrap", totalizando 18.200 respostas, por eixos da interação $\mathrm{G} \times \mathrm{E}\left(\mathrm{IPCA}_{1}^{*}, \mathrm{IPCA}_{2}^{*}\right)$. Esses resultados foram plotados seguindo o modelo $\mathrm{AMMI}_{2}$, isto é, em eixos cartesianos $\mathrm{IPCA}_{1} \times \mathrm{IPCA}_{2}$. A adoção dessa representação gráfica foi justificada pelo critério de avaliação "posdictiva" (Gauch \& Zobel, 1988) que visa um alto coeficiente de determinação.

A partir desses escores foram estabelecidas as regiões "bootstrap" de confiança, de $99 \%$ para $\bar{\theta}_{k}^{*}=\left[{\overline{I P C A_{1 k}}}^{*},{\overline{I P C A_{2 k}}}^{*}\right]$, ou seja para os escores médios de cada genótipo e de cada ambiente, separadamente. As regiões de confianças foram obtidas a partir da estimativa não viesada da matriz de covariâncias $S_{\theta_{k}}^{*}$, para o par de coordenadas $\theta_{k \ell}^{*}=\left[I P C A_{1 k \ell}^{*}, I P C A_{2 k \ell}^{*}\right]$, dada por Weinberg et al., (1984):

$$
\left(\bar{\theta}_{k}^{*}-\theta_{k \ell}^{*}\right)^{\prime}\left(S_{\theta_{k}}^{*}\right)^{-1}\left(\bar{\theta}_{k}^{*}-\theta_{k \ell}^{*}\right) \leq \frac{2(B-1)}{B(B-2)} F_{(2, B-2)} \alpha
$$

em que:

$$
S_{\theta_{k}}^{*}=\left[\begin{array}{cc}
S_{1 k}^{2 *} & r_{k}^{*} S_{1 k}^{*} S_{2 k}^{*} \\
r_{k}^{*} S_{1 k}^{*} S_{2 k}^{*} & S_{2 k}^{2 *}
\end{array}\right]
$$


$B$ : é o número de amostras "bootstrap" $(\mathrm{B}=200)$;

$S_{1 k}^{2 *} \quad$ : é a variância "bootstrap", para os escores associados ao IPCA

$S_{2 k}^{2 *} \quad$ : é a variância "bootstrap", para os escores associados ao IPCA ${ }_{2}^{*}$;

$r_{k}^{*}$ : é o coeficiente de correlação de Pearson para os escores "bootstrap" obtidos a partir de $I P C A_{1}^{*}$ e $I P C A_{2}^{*}$;

$k=(\mathrm{g}, \mathrm{e})$ para "g" genótipos e "e" ambientes; $i=1,2, \cdots, g ; j=1,2, \cdots, e$;

$\ell=1,2, \cdots, 200$

$g$ : é o número de genótipos;

e : é o número de ambientes.

Visando medir a precisão das estimativas de estabilidade, foram determinados os coeficientes "bootstrap" de estabilidade, denominado por "CBE". O CBE foi obtido através da razão entre o núméro de pontos $\left(\mathrm{IPCA}_{1}^{*}, \mathrm{IPCA}_{2}^{*}\right)$ inclusos na região de predição para $\widetilde{\theta}_{k}^{*}=[0,0]$, e o tamanho da amostra bootstrap (B):

$$
C B E=\#\left[\left(\widetilde{\theta}_{k}^{*}-\theta_{k \ell}^{*}\right)^{\prime}\left(S_{\theta_{k}}^{*}\right)^{-1}\left(\widetilde{\theta}_{k}^{*}-\theta_{k \ell}^{*}\right) \leq \frac{2(B-1)}{(B-2)} F_{(2, B-2)} \alpha\right] B^{-1}
$$

A justificativa teórica para a utilização dessa expressão, foi fundamentada na região de predição para uma única observação, nesse caso, o ponto nulo $(0,0)$. A distribuição $T^{2}$ de Hotelling foi baseada numa matriz $\mathbf{X}$ com distribuição normal p-variada, com vetor de médias zero e matriz de covariâncias $\mathbf{\Sigma}$ e $\mathbf{Z}$, com distribuição de Wishart com $\nu$ graus de liberdade e parâmetro $\boldsymbol{\Sigma}$. Então $\mathbf{X}^{\prime} \mathbf{Z}^{-\mathbf{1}} \mathbf{X}$ tem uma distribuição $\frac{p}{\nu-p+1} F_{p, \nu-p+1}$. No caso das regiões de predição "bootstrap" para a origem, X é uma única estimativa "bootstrap". A matriz de covariâncias $\mathbf{\Sigma}$ é calculada por S, obtida de B amostras "bootstrap", de forma que (B-1)S substitui Z com $\nu=\mathrm{B}-1$ e $\mathrm{p}=2$. Substituindo esses valores, obtemos o numerador da expressão $(35)$.

Segundo Duarte \& Vencovsky (1999) os genótipos e ambientes estáveis situam-se próximos à origem, isto é, com escores praticamente nulos para os dois eixos da interação $\mathrm{G} \times \mathrm{E}\left(\mathrm{IPCA}_{1}\right.$ e $\left.\mathrm{IPCA}_{2}\right)$. Assim, para as interpretações das esta- 
bilidades via análise gráfica (regiões "bootstrap" de confiança) e numérica (CBE), foram utilizados os seguintes critérios:

a) para os genótipos e ambientes cujas regiões de confiança "bootstrap" continham o ponto de coordenada nula $(0,0)$;

\begin{tabular}{lc}
\hline Precisão das estimativas de estabilidade & Classificação da estabilidade \\
\hline $\mathrm{CBE} \geq \mathrm{Q} 3$ (terceiro quartil) & Consistente \\
$\mathrm{Q} 2($ segundo quartil $) \leq \mathrm{CBE}<\mathrm{Q} 3$ & Alta \\
$\mathrm{Q} 1$ (primeiro quaril) $\leq \mathrm{CBE}<\mathrm{Q} 2$ & Média \\
$\mathrm{CBE}<\mathrm{Q} 1$ & Baixa \\
\hline
\end{tabular}

b) instáveis, para as regiões de confiança que não continham o ponto de coordenada nula.

A adoção dos quartis como medida de classificação da estabilidade, visou dividir a distribuição em quatro partes iguais, quanto ao número de elementos em cada uma. Os critérios de classificação foram baseados na amplitude do CBE, que pela equação (35) varia de zero a um $(0 \vdash \mathrm{CBE} \dashv 1)$. Assim, quanto mais próximo de um for o CBE, maior a classificação da estabilidade. A classificação como consistente, significa que os genótipos e/ou os ambientes, não sofrerão alterações significativas em seus postos, quando submetidos novamente a esses ambientes (genótipos) ou no conjunto desses genótipos (ambientes). Quanto à classificação como de alta estabilidade, espera-se não haver alterações significativas nos postos, porém se ocorrerem, que sejam de pequena magnitude, isto é, um e no máximo dois níveis. Embora, a estabilidade estatística dê a garantia de que os postos não sofrerão alterações significativas, a qualidade dessa informação cai, consideravelmente, quando o CBE aproxima-se de zero, assim, as classificações das estabilidades como média e baixa, requerem uma avaliação mais cuidadosa, para recomendação desses genótipos e desses locais. Nesses casos, deve-se ponderar os riscos de uma indicação mais produtiva em relação a de maior constância, nos resultados. 
As adaptabilidades, via "bootstrap" AMMI, foram observadas através dos produtos entre os escores "bootstrap" de genótipos $\left(\mathbf{G}^{*}\right)$ e escores "bootstrap" de ambiente $\left(\mathbf{H}^{*^{\prime}}\right)$, envolvendo apenas as duas primeiras colunas de $\mathbf{G}^{*}$ e as duas primeiras linhas de $\mathbf{H}^{*^{\prime}}$. Os resultados das somas desses produtos indicaram as situações favoráveis, para as respostas positivas e desfavoráveis para as respostas negativas.

Vale ressaltar que as estabilidades de genótipos indicam boa adaptação aos ambientes de estudo. Assim, os sinais negativos para os produtos dos escores devem ser estudados com cautela, antes de serem prontamentes descartados. O mesmo é válido para os genótipos instáveis que, apesar de sua adaptabilidade restrita, podem ser aproveitados vantajosamente na seleção e recomendação para um ambiente específico (Duarte \& Vencovsky, 1999).

Todas as análises e gráficos foram implementadas através do sistema estatístico SAS. 


\section{RESULTADOS E DISCUSSÃO}

Para o desenvolvimento dessa pesquisa, cujo objetivo principal foi apresentar uma nova metodologia para avaliar a estabilidade e adaptabilidade fenotípica de progênies de eucaliptos, por meio da análise AMMI - Additive Main effects and Multiplicative Interaction analysis, utilizou-se as medições das alturas médias de Eucalyptus grandis, por parcelas, aos cinco anos de idade, apresentadas nas Tabelas 12, 13 e 14, para os lotes 14.420, 14.423 e 14.431, respectivamente.

Para avaliar a estabilidade entre os vários locais, em um único ano, ou seja, estabilidade no sentido geográfico, foram processadas as análises de variância para os três experimentos envolvidos neste estudo (Tabelas 15, 16 e 17). A presença significativa da interação do tipo genótipo por ambiente, que é a princípio a condição necessária para se proceder esse estudo, foi disgnosticada pelo teste F (Cochran, 1954).

Em relação aos genótipos $(\mathrm{G})$, ambientes (E) e interação dos genótipos com os ambientes $(\mathrm{G} \times \mathrm{E})$ foram detectadas diferenças significativas, ao nível de $1 \%$ de probabilidade, para todos os lotes analisados. O efeito de ambientes foi responsável pela maior parte da variação dos tratamentos, seguida pelo efeito da interação $\mathrm{G} \times \mathrm{E}$ e por último o efeito de genótipos.

As interações $\mathrm{G} \times \mathrm{E}$ significativas indicaram que os genótipos sofreram influências diferenciadas dos ambientes, ou seja, responderam de forma diferente aos estímulos ambientais, dificultando assim a indicação regionalizada dos genótipos superiores. A presença de variabilidade entre genótipos indica que esses poderão ser selecionados pelos seus desempenhos médios nos vários locais de avaliação. 
Tabela 12. Médias de alturas, em metros, das progênies (Prog.) de E. grandis aos 5 anos. Procedência, 12 km S. of Ravenshoe-Mt Pandanus-QLD (14.420)

\begin{tabular}{|c|c|c|c|c|c|c|c|c|}
\hline \multirow[b]{2}{*}{ Prog. } & \multicolumn{7}{|c|}{ Locais } & \multirow[b]{2}{*}{ Médias } \\
\hline & L1 & L2 & L3 & L4 & L5 & L6 & L7 & \\
\hline 183 & 17,40 & 25,00 & 18,67 & 20,61 & 13,88 & 19,84 & 14,72 & 18,59 \\
\hline 184 & 17,58 & 24,00 & 17,69 & 20,44 & 13,10 & 17,77 & 14,44 & 17,86 \\
\hline 185 & 16,52 & 23,70 & 15,94 & 18,91 & 12,86 & 17,93 & 13,43 & 17,04 \\
\hline 186 & 16,78 & 22,68 & 16,28 & 16,55 & 11,92 & 17,70 & 13,03 & 16,42 \\
\hline 187 & 15,36 & 21,56 & 15,95 & 16,57 & 10,97 & 18,06 & 13,03 & 15,93 \\
\hline 188 & 15,76 & 22,34 & 16,61 & 19,08 & 11,91 & 19,22 & 13,17 & 16,87 \\
\hline 189 & 14,57 & 20,35 & 17,02 & 15,06 & 12,47 & 17,01 & 11,14 & 15,37 \\
\hline 190 & 18,46 & 24,52 & 17,87 & 18,16 & 13,66 & 19,72 & 14,37 & 18,11 \\
\hline 191 & 16,87 & 20,77 & 16,84 & 18,96 & 13,54 & 18,69 & 14,06 & 17,10 \\
\hline 192 & 16,92 & 22,48 & 17,16 & 18,94 & 13,71 & 19,38 & 14,98 & 17,65 \\
\hline 193 & 16,50 & 22,98 & 16,87 & 17,17 & 13,55 & 19,12 & 13,13 & 17,05 \\
\hline 194 & 17,71 & 23,61 & 16,88 & 18,19 & 12,62 & 18,17 & 13,52 & 17,24 \\
\hline 195 & 17,62 & 22,65 & 16,01 & 18,78 & 11,92 & 17,88 & 13,24 & 16,87 \\
\hline 196 & 16,29 & 23,59 & 18,79 & 20,20 & 13,29 & 19,31 & 13,60 & 17,87 \\
\hline 197 & 15,94 & 23,36 & 18,10 & 17,91 & 12,75 & 19,71 & 12,49 & 17,18 \\
\hline 198 & 16,46 & 22,59 & 17,80 & 19,08 & 12,80 & 19,44 & 13,78 & 17,42 \\
\hline 199 & 17,74 & 23,38 & 16,17 & 18,91 & 14,42 & 20,24 & 13,32 & 17,74 \\
\hline 200 & 16,90 & 21,71 & 16,95 & 18,56 & 12,50 & 18,82 & 14,33 & 17,11 \\
\hline 201 & 16,28 & 20,12 & 14,66 & 15,68 & 10,60 & 16,10 & 11,98 & 15,06 \\
\hline 202 & 15,78 & 22,15 & 15,36 & 16,46 & 12,51 & 16,89 & 12,07 & 15,89 \\
\hline Média & 16,67 & 22,68 & 16,88 & 18,21 & 12,75 & 18,55 & 13,39 & 17,02 \\
\hline C.V $(\%)$ & 5,60 & 5,77 & 6,32 & 8,43 & 7,55 & 6,04 & 7,25 & \\
\hline
\end{tabular}


Tabela 13. Médias de alturas, em metros, das progênies (Prog.) de E. grandis aos 5 anos. Procedência, Baldy State Forest 194-Atherton-QLD (14.423)

\begin{tabular}{|c|c|c|c|c|c|c|c|c|}
\hline \multirow[b]{2}{*}{ Prog. } & \multicolumn{6}{|c|}{ Locais } & \multirow[b]{2}{*}{ L7 } & \multirow[b]{2}{*}{ Médias } \\
\hline & L1 & L2 & L3 & L4 & L5 & L6 & & \\
\hline 269 & 15,54 & 23,42 & 16,10 & 19,08 & 12,83 & 17,32 & 13,71 & 16,86 \\
\hline 270 & 16,41 & 21,80 & 17,53 & 18,60 & 11,98 & 17,74 & 12,46 & 16,65 \\
\hline 271 & 16,51 & 22,96 & 16,77 & 19,15 & 11,57 & 18,07 & 13,63 & 16,95 \\
\hline 272 & 19,43 & 23,54 & 19,34 & 19,75 & 13,87 & 18,00 & 14,49 & 18,35 \\
\hline 273 & 15,03 & 19,75 & 16,66 & 16,31 & 11,95 & 17,26 & 12,22 & 15,60 \\
\hline 274 & 16,68 & 23,06 & 16,42 & 20,00 & 12,75 & 18,47 & 13,56 & 17,28 \\
\hline 275 & 16,90 & 22,53 & 16,49 & 18,68 & 11,37 & 18,88 & 13,92 & 16,97 \\
\hline 276 & 19,03 & 25,20 & 18,24 & 20,68 & 13,27 & 19,91 & 14,48 & 18,69 \\
\hline 277 & 14,83 & 23,35 & 16,13 & 18,54 & 11,95 & 17,88 & 12,98 & 16,52 \\
\hline 278 & 16,22 & 21,48 & 16,55 & 18,53 & 12,53 & 16,98 & 13,03 & 16,47 \\
\hline 292 & 18,07 & 23,30 & 16,20 & 19,54 & 12,99 & 19,62 & 14,01 & 17,68 \\
\hline 293 & 16,50 & 22,58 & 16,23 & 16,00 & 10,53 & 18,72 & 12,62 & 16,17 \\
\hline 294 & 16,39 & 22,98 & 16,03 & 18,64 & 12,73 & 17,80 & 13,51 & 16,87 \\
\hline 295 & 17,40 & 22,98 & 18,01 & 19,30 & 13,91 & 17,89 & 13,88 & 17,62 \\
\hline 296 & 14,49 & 21,31 & 16,08 & 17,74 & 13,53 & 18,09 & 13,44 & 16,38 \\
\hline 297 & 18,99 & 24,25 & 19,20 & 20,66 & 12,46 & 19,82 & 15,04 & 18,63 \\
\hline 298 & 14,40 & 21,75 & 15,00 & 16,65 & 10,75 & 18,27 & 11,81 & 15,52 \\
\hline 299 & 18,90 & 24,49 & 17,92 & 20,25 & 13,05 & 18,70 & 15,03 & 18,33 \\
\hline 300 & 16,87 & 24,81 & 17,35 & 20,60 & 12,21 & 18,31 & 14,62 & 17,82 \\
\hline 301 & 16,69 & 21,50 & 17,24 & 19,15 & 10,90 & 17,16 & 12,16 & 16,40 \\
\hline 302 & 14,87 & 20,97 & 17,00 & 14,48 & 10,61 & 16,95 & 10,93 & 15,12 \\
\hline 303 & 17,30 & 22,59 & 16,35 & 20,41 & 13,28 & 18,38 & 13,91 & 17,46 \\
\hline 304 & 14,63 & 21,99 & 17,21 & 18,15 & 11,85 & 17,87 & 12,76 & 16,35 \\
\hline 305 & 17,27 & 24,52 & 20,32 & 20,14 & 13,31 & 19,32 & 13,96 & 18,41 \\
\hline 306 & 17,90 & 23,18 & 18,88 & 18,21 & 13,87 & 20,47 & 13,76 & 18,04 \\
\hline Média & 16,57 & 22,81 & 16,97 & 18,77 & 12,40 & 18,32 & 13,44 & 17,09 \\
\hline C.V $(\%)$ & 8,94 & 5,71 & 7,33 & 8,40 & 8,36 & 5,14 & 7,55 & \\
\hline
\end{tabular}


Tabela 14. Médias de alturas, em metros, das progênies (Prog.) de E. grandis aos 5 anos. Procedência, Bellthorpe St. Forest-QLD (14.431)

\begin{tabular}{|c|c|c|c|c|c|c|c|c|}
\hline \multirow[b]{2}{*}{ Prog. } & \multicolumn{6}{|c|}{ Locais } & \multirow[b]{2}{*}{ L7 } & \multirow[b]{2}{*}{ Médias } \\
\hline & L1 & L2 & L3 & L4 & L5 & L6 & & \\
\hline 662 & 17,37 & 23,84 & 19,18 & 19,61 & 12,00 & 19,20 & 13,45 & 17,81 \\
\hline 663 & 15,23 & 17,79 & 15,43 & 17,46 & 10,42 & 16,76 & 15,10 & 15,46 \\
\hline 664 & 14,49 & 23,37 & 18,22 & 19,22 & 13,05 & 18,89 & 14,20 & 17,35 \\
\hline 665 & 16,51 & 23,17 & 18,62 & 19,78 & 12,08 & 17,59 & 14,52 & 17,47 \\
\hline 666 & 15,90 & 23,28 & 17,32 & 19,64 & 13,25 & 18,81 & 14,67 & 17,55 \\
\hline 667 & 18,69 & 24,15 & 17,55 & 21,41 & 13,71 & 19,23 & 14,67 & 18,49 \\
\hline 668 & 17,84 & 22,76 & 17,55 & 19,63 & 12,70 & 19,65 & 14,37 & 17,79 \\
\hline 669 & 18,21 & 23,51 & 17,26 & 19,65 & 11,85 & 18,12 & 13,80 & 17,49 \\
\hline 670 & 17,56 & 23,79 & 15,64 & 19,17 & 11,11 & 19,16 & 13,86 & 17,18 \\
\hline 671 & 17,87 & 23,65 & 18,09 & 20,93 & 13,98 & 19,56 & 14,50 & 18,37 \\
\hline 672 & 18,93 & 23,26 & 17,67 & 20,51 & 13,10 & 18,78 & 15,11 & 18,19 \\
\hline 673 & 18,83 & 23,78 & 17,80 & 20,31 & 12,88 & 19,64 & 14,92 & 18,31 \\
\hline 674 & 18,09 & 23,47 & 17,30 & 19,99 & 12,20 & 18,93 & 13,76 & 17,68 \\
\hline 675 & 17,31 & 22,97 & 17,79 & 18,62 & 12,65 & 19,05 & 13,71 & 17,44 \\
\hline 676 & 18,30 & 23,38 & 16,90 & 19,18 & 13,11 & 19,84 & 13,65 & 17,77 \\
\hline 677 & 17,06 & 23,62 & 17,11 & 18,29 & 14,00 & 18,77 & 13,44 & 17,47 \\
\hline 678 & 18,13 & 23,41 & 17,37 & 18,83 & 13,04 & 18,21 & 13,89 & 17,55 \\
\hline 679 & 17,18 & 22,98 & 18,14 & 19,85 & 13,96 & 19,18 & 14,31 & 17,94 \\
\hline 680 & 19,65 & 24,21 & 18,20 & 20,90 & 13,37 & 19,10 & 14,63 & 18,58 \\
\hline 681 & 17,79 & 24,44 & 16,62 & 19,62 & 12,76 & 18,54 & 14,62 & 17,77 \\
\hline 682 & 14,37 & 19,77 & 14,20 & 14,18 & 11,11 & 17,84 & 14,57 & 15,15 \\
\hline 683 & 16,77 & 20,45 & 16,49 & 18,03 & 12,05 & 18,85 & 12,48 & 16,45 \\
\hline 684 & 17,16 & 22,98 & 16,01 & 18,28 & 12,97 & 19,38 & 13,39 & 17,17 \\
\hline 685 & 15,57 & 20,36 & 15,36 & 15,10 & 10,59 & 18,09 & 12,75 & 15,40 \\
\hline 686 & 15,12 & 22,62 & 16,39 & 20,18 & 12,61 & 19,12 & 13,70 & 17,11 \\
\hline Média & 17,20 & 22,84 & 17,13 & 19,13 & 12,58 & 18,81 & 14,08 & 17,40 \\
\hline C.V $(\%)$ & 8,20 & 6,88 & 6,71 & 8,63 & 7,95 & 3,80 & 4,85 & \\
\hline
\end{tabular}


Tabela 15. Autovalor $\left(\lambda_{k}^{2}\right)$ e porcentagem da soma de quadrados acumulada (PA) por eixo singular . Análise conjunta da variância, incluíndo o desdobramento da interação $\mathrm{G} \times \mathrm{E}$ para dados de altura, em metros, de Eucalyptus grandis aos 5 anos. Procedência, 12 km S. of Ravenshoe-Mt PandanusQLD (14.420)

\begin{tabular}{|c|c|c|c|c|c|c|c|}
\hline \multirow{2}{*}{$\begin{array}{c}\text { Eixos } \\
\text { Singulares }\end{array}$} & \multirow[b]{2}{*}{$\lambda_{k}^{2}$} & \multirow[b]{2}{*}{ PA } & \multirow{2}{*}{$\begin{array}{l}\text { Fonte de } \\
\text { variação }\end{array}$} & \multicolumn{2}{|c|}{ Gollob } & \multicolumn{2}{|c|}{ Cornelius } \\
\hline & & & & $\mathrm{DF}$ & $\mathrm{F}$ & $\mathrm{DF}$ & $F_{R}$ \\
\hline & & & Genótipos (G) & 19 & $10,10^{* *}$ & & \\
\hline & & & Ambientes (E) & 6 & $392,77^{* *}$ & & \\
\hline & & & $\mathrm{G} \times \mathrm{E}$ & 114 & $66,06^{* *}$ & & \\
\hline 1 & 18,9016 & 29,03 & $I P C A_{1}$ & 24 & $2,53^{* *}$ & 90 & $1,65^{* *}$ \\
\hline 2 & 17,2607 & 55,53 & $I P C A_{2}$ & 22 & $2,52^{* *}$ & 68 & $1,37^{*}$ \\
\hline 3 & 13,3854 & 76,09 & $I P C A_{3}$ & 20 & $2,15^{* *}$ & 48 & $1,04 \mathrm{~ns}$ \\
\hline 4 & 7,3940 & 87,44 & $\mathrm{IPCA}_{4}$ & 18 & $1,32 \mathrm{~ns}$ & 30 & $0,88 \mathrm{~ns}$ \\
\hline 5 & 5,6935 & 96,18 & $I P C A_{5}$ & 16 & $1,14 \mathrm{~ns}$ & 14 & $0,57 \mathrm{~ns}$ \\
\hline 6 & 2,4844 & 100,00 & $I P C A_{6}$ & 14 & $0,57 \mathrm{~ns}$ & & \\
\hline & & & Error mean & 216 & & & \\
\hline
\end{tabular}

$F_{R}$ : teste $F_{R}$ de Cornelius et al., 1992 e Piepho (1995), equação (19);

** : significativo ao nível de probabilidade, $\mathrm{p}<0,01$;

* : significativo ao nível de probabilidade, $\mathrm{p}<0,05 \mathrm{e}$

ns : não significativo. 
Tabela 16. Autovalor $\left(\lambda_{k}^{2}\right)$ e porcentagem da soma de quadrados acumulada (PA) por eixo singular . Análise conjunta da variância, incluíndo o desdobramento da interação $\mathrm{G} \times \mathrm{E}$ para dados de altura, em metros, de Eucalyptus grandis aos 5 anos. Procedência, Baldy State Forest 194-Atherton-QLD (14.423)

\begin{tabular}{|c|c|c|c|c|c|c|c|}
\hline \multirow{2}{*}{$\begin{array}{c}\text { Eixos } \\
\text { Singulares }\end{array}$} & \multirow[b]{2}{*}{$\lambda_{k}^{2}$} & \multirow[b]{2}{*}{ PA } & \multirow{2}{*}{$\begin{array}{l}\text { Fonte de } \\
\text { variação }\end{array}$} & \multicolumn{2}{|c|}{ Gollob } & \multicolumn{2}{|c|}{ Cornelius } \\
\hline & & & & $\mathrm{DF}$ & $\mathrm{F}$ & $\mathrm{DF}$ & $F_{R}$ \\
\hline & & & Genótipos (G) & 14 & $10,57^{* *}$ & & \\
\hline & & & Ambientes (E) & 6 & $456,19^{* *}$ & & \\
\hline & & & $\mathrm{G} \times \mathrm{E}$ & 144 & $62,30^{* *}$ & & \\
\hline 1 & 32,6532 & 34,22 & $I P C A_{1}$ & 29 & $2,94^{* *}$ & 115 & $1,42^{*}$ \\
\hline 2 & 21,8369 & 57,11 & $I P C A_{2}$ & 27 & $2,11^{* *}$ & 88 & $1,21 \mathrm{~ns}$ \\
\hline 3 & 19,2019 & 77,23 & $I P C A_{3}$ & 25 & $2,00 * *$ & 63 & $0,90 \mathrm{~ns}$ \\
\hline 4 & 12,5947 & 90,43 & $\mathrm{IPCA}_{4}$ & 23 & $1,43 \mathrm{~ns}$ & 40 & $0,60 \mathrm{~ns}$ \\
\hline 5 & 6,3277 & 97,06 & $I P C A_{5}$ & 21 & $0,79 \mathrm{~ns}$ & 19 & $0,39 \mathrm{~ns}$ \\
\hline 6 & 2,8036 & 100,00 & $I P C A_{6}$ & 19 & $0,39 \mathrm{~ns}$ & & \\
\hline & & & Error mean & 256 & & & \\
\hline
\end{tabular}

$F_{R}$ : teste $F_{R}$ de Cornelius et al., 1992 e Piepho (1995), equação (19);

** : significativo ao nível de probabilidade, $\mathrm{p}<0,01$;

* : significativo ao nível de probabilidade, $\mathrm{p}<0,05 \mathrm{e}$

ns : não significativo. 
Tabela 17. Autovalor $\left(\lambda_{k}^{2}\right)$ e porcentagem da soma de quadrados acumulada (PA) por eixo singular . Análise conjunta da variância, incluíndo o desdobramento da interação $\mathrm{G} \times \mathrm{E}$ para dados de altura, em metros, de Eucalyptus grandis aos 5 anos. Procedência, Bellthorpe St. Forest-QLD (14.431)

\begin{tabular}{|c|c|c|c|c|c|c|c|}
\hline \multirow{2}{*}{$\begin{array}{c}\text { Eixos } \\
\text { Singulares }\end{array}$} & \multirow[b]{2}{*}{$\lambda_{k}^{2}$} & \multirow[b]{2}{*}{ PA } & \multirow{2}{*}{$\begin{array}{l}\text { Fonte de } \\
\text { variação }\end{array}$} & \multicolumn{2}{|c|}{ Gollob } & \multicolumn{2}{|c|}{ Cornelius } \\
\hline & & & & $\mathrm{DF}$ & $\mathrm{F}$ & $\mathrm{DF}$ & $F_{R}$ \\
\hline & & & Genotypes (G) & 24 & $7,46^{* *}$ & & \\
\hline & & & Environments (E) & 6 & $368,77^{* *}$ & & \\
\hline & & & $\mathrm{G} \times \mathrm{E}$ & 144 & $62,29^{* *}$ & & \\
\hline 1 & 40,5552 & 36,16 & $I P C A_{1}$ & 29 & $3,11^{* *}$ & 115 & $1,38^{*}$ \\
\hline 2 & 24,2231 & 57,76 & $I P C A_{2}$ & 27 & $1,99^{* *}$ & 88 & $1,20 \mathrm{~ns}$ \\
\hline 3 & 20,5236 & 76,06 & $I P C A_{3}$ & 25 & $1,82^{*}$ & 63 & $0,95 \mathrm{~ns}$ \\
\hline 4 & 11,0383 & 85,90 & $\mathrm{IPCA}_{4}$ & 23 & $1,07 \mathrm{~ns}$ & 40 & $0,88 \mathrm{~ns}$ \\
\hline 5 & 9,3648 & 94,25 & $I P C A_{5}$ & 21 & $0,99 \mathrm{~ns}$ & 19 & $0,75 \mathrm{~ns}$ \\
\hline \multirow[t]{2}{*}{6} & 6,4496 & 100,00 & $I P C A_{6}$ & 19 & $0,75 \mathrm{~ns}$ & & \\
\hline & & & Error mean & 256 & & & \\
\hline
\end{tabular}

$F_{R}$ : teste $F_{R}$ de Cornelius et al., 1992 e Piepho (1995), equação (19);

** : significativo ao nível de probabilidade, $\mathrm{p}<0,01$;

* : significativo ao nível de probabilidade, $\mathrm{p}<0,05$ e

$n s$ : não significativo. 
Observou-se que, as médias dos locais foram bastantes diferentes, variando de 12,75 metros em Ipatinga-MG (L5) a 22,68 metros em Telêmaco Borba-PR (L2), para o lote 14.420, mostrando uma amplitude de variação ambiental bastante elevada (9,93 metros), correspondendo aproximadamente a 58,34\% da média geral do ensaio (17,02 metros). Esse percentual aumentou para aproximadamente 59\% para o lote 14.431 e $61 \%$ para o lote 14.423 , quando envolvendo os mesmos locais. Essa diferença se deve provavelmente às condições edafoclimáticas inerentes de cada ambiente, o que leva a adaptação dos genótipos. Essa faixa de variação ambiental é um indicativo importante para se proceder o estudo de estabilidade fenotípica dos genótipos envolvidos no estudo.

Os coeficientes de variação que medem a precisão dos experimentos, foram baixos, variando de $5,60 \%$ a $8,43 \%$ para os locais Barra Ribeiro-RS (L1) e Guanhães-MG (L4), respectivamente, no lote 14.420. De 5,14\% em Aracruz-ES (L6) a $8,94 \%$ em L1, para o lote 14.423 e de $3,80 \%$ em (L6) a 8,63\% em (L4), para o lote 14.431. Esses valores encontram-se abaixo dos limites aceitáveis na literatura (entre $10 \%$ e $20 \%$ ) para dados de altura de eucaliptos, refletindo os cuidados que foram tomados para a condução desses experimentos.

Esses fatos levam à necessidade de um estudo mais minucioso dessa interação, visando identificar genótipos superiores específicos para um determinado ambiente, assim como, de comportamento geral, aptos a todos os ambientes envolvidos no estudo. Para se fazer essas indicações, são necessárias as análises de estabilidade e adaptabilidade fenotípica. Vale ressaltar que, por ser a estabilidade uma medida relativa, não permite que os resultados sejam extrapolados para outros grupos de genótipos e para outros ambientes não envolvidos no estudo.

A significância para genótipos indicou que eles são formados por grupos geneticamente distintos, mostrando uma suficiente disponibilidade de variabilidade para a seleção. Com relação à significância de ambientes, em princípio era de se esperar a sua existência, devido a grande diversidade de condições ambientais onde esses experimentos foram instalados (Tabelas 9 e 10). Como foi observada uma 
elevada amplitude de variação da altura dos locais, isso permitiu inferir que eles são bem contrastantes entre si.

Como já relatado, a condição primária para se estabelecer a análise de estabilidade é observar a significância da interação do tipo genótipos com ambientes, que é um indicativo do comportamento diferenciado dos genótipos frente aos ambientes. Essa significância sugeriu, ainda, que as variâncias dos genótipos são diferentes de um ambiente para outro, o que permitiu inferir que há genótipos ou grupos de genótipos com adaptação específica para determinados ambientes e outros com adaptação geral a todos os ambientes. Cruz \& Regazzi (1994) comentaram que, quando for observada a significância da interação $\mathrm{G} \times \mathrm{E}$, é necessário que a seleção de genótipos seja efetuada para locais específicos, ou grupos afins, podendo nesse processo identificar quais os genótipos que apresentaram menor variação.

Normalmente os ambientes são classificados como favoráveis quando apresentam médias superiores à média geral da experimentação (alta produtividade), ou desfavoráveis, quando suas médias são inferiores à média geral (baixa produtividade), sendo a forma mais comum para classificar esses ambientes, através do uso do índice ambiental, que é uma medida da qualidade do ambiente. Assim, muitos métodos que visam identificar a estabilidade e adaptabilidade dos genótipos via análise de regressão fazem o uso desse índice ambiental. Entretanto, como já mencionado, o índice ambiental atua como variável independente na regressão e tem recebido muitas críticas por estar associado à variável dependente. Dessa forma, o detalhamento dos efeitos da interação $\mathrm{G} \times \mathrm{E}$ foi realizado pelo modelo AMMI, visando a identificação de genótipos de desempenhos superiores, em altura, e largamente adaptados, assim como, na recomendação dirigida para um ambiente específico. O modelo AMMI, também foi utilizado para fins de seleção de ambiente de teste para estudos de segunda geração (Gauch \& Zobel, 1996). 


\subsection{Análises AMMI}

\subsubsection{Procedência, 12 km S. of Ravenshoe-Mt Pandanus-QLD}

A análise conjunta da variância, para o lote 14.420 (Tabela 15), apresentou diferenças significativas $(\mathrm{p}<0,01)$ para genótipos, ambientes e interação entre eles. Observou-se que, mesmo com um número reduzido de ambientes (sete) foi possível detectar diferenças entre eles, indicando condições bastante variadas para a avaliação dos genótipos. Verificou-se, em termos de F, que a magnitude da fonte de variação de ambientes foi muito superior às demais, sendo ela responsável pela maior parte da variação ocorrida. Pode-se, assim, inferir que os efeitos de locais contribuíram de modo mais acentuado para a variação na altura. O resultado da interação $\mathrm{G} \times \mathrm{E}$ indicou a necessidade de identificar e selecionar genótipos que consigam captalizar os ganhos genéticos em locais específicos ou que sejam menos influenciados pelas variações ambientais, podendo ser explorados em vários outros ambientes.

Com base nesses resultados, procedeu-se o estudo mais detalhado da interação significativa, através da análise da estabilidade fenotípica dos genótipos, via AMMI.

O efeito multiplicativo da interação $\mathrm{G} \times \mathrm{E}$ foi diagnosticado através da análise de componentes principais (ACP), pela decomposição da soma de quadrados da interação $\left(S Q_{G \times E}\right)$ em seis eixos ou componentes principais da interação (IPCA), sendo adotado o critério "posdictivo" (uso de testes de hipóteses), através do teste $F_{R}$ apresentado por Cornelius et al., 1992 e Piepho (1995), para a seleção de modelos AMMI mais preditivos (Tabela 15).

A análise da interação $\mathrm{G} \times \mathrm{E}$ pela $\mathrm{ACP}$, mostrou os dois primeiros eixos $\left(\mathrm{IPCA}_{1}\right.$ e IPCA $\left.\mathrm{IPC}_{2}\right)$ significativos, com $\mathrm{p}<0,01$ para o primeiro eixo e $\mathrm{p}<0,05$ para o segundo eixo. De acordo com Gauch (1988), o primeiro eixo singular da análise AMMI captura a maior porcentagem de "padrão" e, com acumulação subseqüente das dimensões dos eixos, há uma diminuição na porcentagem de "padrão" e um incremento de "ruídos". Com isso, apesar da porção pequena de $S Q_{G \times E}$ explicada 
pelos dois primeiros eixos (55,53\%), espera-se capturar todo o "padrão" devido a interação $\mathrm{G} \times \mathrm{E}$. Dessa forma, os escores de genótipos e de ambientes (Tabela 18) foram plotados, seguindo o modelo $\mathrm{AMMI}_{2}$ (Figura 3).

Num biplot $\mathrm{AMMI}_{2}$, genótipos e ambientes estáveis são aqueles cujos pontos situam-se próximos à origem, ou seja, com escores praticamente nulos para os dois eixos da interação (IPCA 1 e IPCA 2$)($ Duarte \& Vencovsky, 1999). Podese notar através de Figura 3, que os genótipos que atendem essa situação estão contidos dentro da região de confiança menor $(\alpha=0,10)$, ou seja, os genótipos 187, 192, 197 e 200. Esses, pelos critérios adotados, podem ser considerados com alta estabilidade. Um pouco distante da origem, incluso na região de confiança maior $(\alpha=0,01)$, está o genótipo 199, que pode ser considerado estável. Em uma análise mais completa, em que foram calculados os valores de predição para cada coordenada (IPCA $\left.1, \mathrm{IPCA}_{2}\right)$, foi possível identificar que os genótipos $187(1,68)$, $192(0,70), 197(3,29)$ e $200(2,91)$ tiveram respostas dos valores de predição (entre parênteses) inferiores ao $\mathrm{F}_{2,18}(0,10)$ corrigido $(5,54)$, portanto com alta estabilidade, $\mathrm{e}$ o genótipo $199(10,85)$ teve resposta inferior ao $\mathrm{F}_{2,18}(0,01)$ corrigido $(12,69)$, portanto estável. Todos os demais genótipos foram classificados como instáveis, por esse critério. Os genótipos que mais contribuíram para a interação $\mathrm{G} \times \mathrm{E}$, foram: 184 $(71,85), 189(134,76), 191(63,58), 195(51,43), 196(84,99)$ e $201(53,12)$, o que atesta suas instabilidades.

A construção das regiões de confiança para a estabilidade foram suportadas pela normalidade observadas para os dois eixos da interação. Os valores observados pelo teste de Shapiro-Wilk, foram: $\mathrm{W}=0,9355(\mathrm{p}=0,1970)$ e $\mathrm{W}=0,9710$ $(\mathrm{p}=0,7774)$, para os eixos $\mathrm{IPCA}_{1}$ e $\mathrm{IPCA}_{2}$, respectivamente, para genótipos, e $\mathrm{W}=0,8895(\mathrm{p}=0,2726)$ e $\mathrm{W}=0,9718(\mathrm{p}=0,9116)$, para os eixos $\mathrm{IPCA}_{1}$ e IPCA, respectivamente, para ambientes. 
Tabela 18. Médias e escores de genótipos e de ambientes para dados de altura, em metros, de E. grandis aos 5 anos. Procedência, $12 \mathrm{~km} \mathrm{S.} \mathrm{of} \mathrm{Ravenshoe-Mt}$ Pandanus-QLD (14.420)

\begin{tabular}{|c|c|c|c|}
\hline Genótipos / Ambientes & Médias & $\mathrm{IPCA}_{1}$ & $\mathrm{IPCA}_{2}$ \\
\hline 183 & 18,59 & 0,2353 & $-0,5342$ \\
\hline 184 & 17,86 & 0,8680 & $-0,2659$ \\
\hline 185 & 17,04 & 0,5556 & 0,0293 \\
\hline 186 & 16,42 & $-0,0663$ & 0,5934 \\
\hline 187 & 15,93 & $-0,1389$ & $-0,0059$ \\
\hline 188 & 16,87 & 0,1654 & $-0,6657$ \\
\hline 189 & 15,37 & $-1,2454$ & 0,0364 \\
\hline 190 & 18,11 & $-0,1719$ & 0,6032 \\
\hline 191 & 17,18 & $-0,7295$ & $-0,4360$ \\
\hline 192 & 17,65 & 0,0193 & $-0,0852$ \\
\hline 193 & 17,05 & $-0,5792$ & 0,2923 \\
\hline 194 & 17,24 & 0,2902 & 0,4286 \\
\hline 195 & 16,87 & 0,7265 & 0,2478 \\
\hline 196 & 17,87 & $-0,0531$ & $-0,9626$ \\
\hline 197 & 17,10 & 0,0455 & $-0,1845$ \\
\hline 198 & 17,42 & $-0,1200$ & $-0,5246$ \\
\hline 199 & 17,74 & $-0,0935$ & 0,3322 \\
\hline 200 & 17,11 & 0,1512 & $-0,1006$ \\
\hline 201 & 15,06 & 0,2405 & 0,7252 \\
\hline 202 & 15,89 & $-0,0997$ & 0,4767 \\
\hline L1 & 16,67 & 0,5399 & 1,3435 \\
\hline $\mathrm{L} 2$ & 22,68 & 0,2630 & 0,2852 \\
\hline L3 & 16,88 & $-0,9483$ & $-0,6956$ \\
\hline $\mathrm{L} 4$ & 18,21 & 1,2533 & $-1,2264$ \\
\hline L5 & 12,75 & $-0,7498$ & 0,3781 \\
\hline L6 & 18,55 & $-0,8464$ & $-0,3012$ \\
\hline $\mathrm{L} 7$ & 13,39 & 0,4884 & 0,2163 \\
\hline
\end{tabular}

IPCA: eixo da interação da análise de componentes principais. 

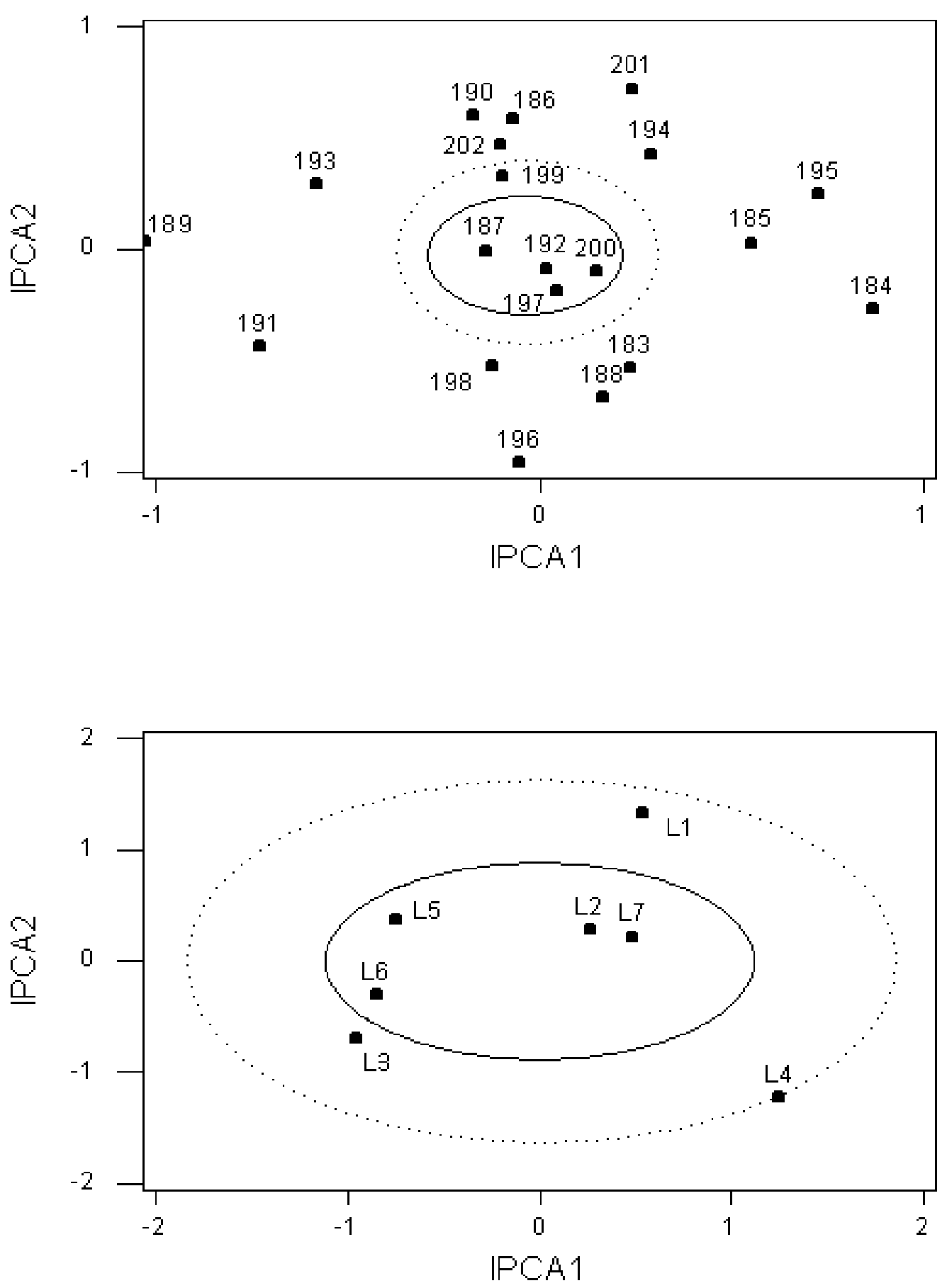

Figura 3 - Regiões de confiança de 90\% (linha cheia) e de 99\% (linha pontilhada) segundo os escores de genótipos (acima) e de ambientes (abaixo) sobre o modelo $\mathrm{AMMI}_{2}$, para dados de altura, em metros, de E. grandis aos 5 anos. Procedência, 12 km S. of Ravenshoe-Mt Pandanus-QLD (14.420) 
A Figura 3, mostrou que os ambientes apresentaram maior variabilidade do que os genótipos. Isso confirma os resultados para as magnitudes do teste F evidenciados pela análise de variância.

Em relação aos escores de ambientes foi observado que Telêmaco Borba-PR (L2), Ipatinga-MG (L5), Aracruz-ES (L6) e Caçapava-SP (L7) estão contidos dentro da região de confiança menor (90\%), então, foram considerados com alta estabilidade. Os demais locais, Barra Ribeiro-RS (L1), Boa Esperança do Sul-SP (L3) e Guanhães-MG (L4) foram inclusos na região de confiança maior (99\%), sendo então pelos critérios adotados, considerados estáveis. Essas respostas também foram verificadas em função das predições das coordenadas $\left(\mathrm{IPCA}_{1}, \mathrm{IPCA}_{2}\right)$, em que L2 $(1,28)$, L5 $(5,89)$, L6 $(6,72)$ e L7 $(2,38)$ tiveram respostas inferiores ao $\mathrm{F}_{2,6}(0,10)$ corrigido $(9,07)$, portanto, com alta estabilidade, e os ambientes L1 (18,05), L3 (11,64) e L4 $(26,04)$ tiveram respostas inferiores ao $\mathrm{F}_{2,6}(0,01)$ corrigido $(31,86)$, considerados portanto, estáveis. Os ambientes que mais contribuíram para a interação $\mathrm{G} \times \mathrm{E}$, foram: L1 e L4 o que atestam as baixas estabilidades, e os ambientes L2 e L7, com menores contribuições para a interação, apresentaram maiores estabilidades.

Pelo lado dos genótipos, as estabilidades verificadas indicaram suas respectivas amplitudes adaptativas, ou seja, os genótipos estáveis mostraram-se amplamente adaptados aos ambientes ensaiados. Assim, para fins de recomendação e seleção, à exceção do genótipo 187, que apresentou desempenho médio em altura, inferior à média geral dos genótipos, todos apresentaram médias superiores, e deverão compor o conjunto de genótipos, indicados por estabilidades, para serem testados em estudos de segunda geração.

A estabilidade ambiental informa sobre a confiabilidade das posições dos genótipos (postos) em cada ambiente, em relação à classificação para a média dos ambientes testados. Nesse contexto, as discrepâncias menores foram verificadas para os locais Telêmaco Borba-PR (L2) e Caçapava-SP (L7), em relação aos outros locais. Isso sugere que a classificação dos genótipo nesses ambientes deveriam apresentar discordâncias pequenas em relação à classificação média em todos os locais. Então, 
o teste de materiais genéticos em L2 e L7 devem produzir um grau mais consistente e fidedigno para recomendação de material genético. Como o ambiente L2 apresentou média maior e discrepância menor, deveria ser preferido para estudos de segunda geração.

As adaptabilidades dos genótipos instáveis foram verificadas em função das predições do modelo $\mathrm{AMMI}_{2}$ (Tabela 19), assim como, através da exploração do efeito positivo da interação $\mathrm{G} \times$ E. Foram observadas as melhores adaptabilidades para o local Barra Ribeiro-RS (L1), os genótipos: 198 (+3,09), 193 (+2,22), 195 $(+1,44), 186(+0,30), 190(+0,28), 196(+0,22)$ e $191(+0,11)$; para o local Telêmaco Borba-PR (L2), os genótipos: $183(+9,39), 188(+4,93), 201(+4,32), 184(+1,82)$, $185(+1,37), 189(+0,62)$ e $190(+0,38)$; para o local Boa Esperança do Sul-SP (L3), os genótipos: $190(+7,98), 198(+2,63), 183(+1,25)$ e $193(+0,98)$; para o local Guanhães-MG (L4), os genótipos: 186 (+1,51), 191 (+1,05), 195 (+0,58), 194 $(+0,45), 202(+0,44), 188(+0,32), 187(+0,16), 185(+0,16)$ e $196(+0,15) ;$ para o local Ipatinga-MG (L5), os genótipos: $194(+4,24), 196(+4,19), 191(+3,95), 201$ $(+2,64), 202(+2,38), 189(+1,93), 185(+1,88), 188(+1,52)$ e $195(+0,43)$; para o local Aracruz-ES (L6), os genótipos: $184(+5,53), 196(+5,46), 193(+2,78), 192$ $(+2,17), 202(+1,26), 195(+1,21), 198(+0,89), 186(+0,73)$ e $201(+0,43)$ e finalmente, para o local Caçapava-SP (L7), os genótipos: $190(+6,16), 194(+4,88)$, $189(+3,10), 192(+3,01), 202(+2,44), 193(+2,07), 198(+1,94), 195(+1,693), 191$ $(+1,11), 196(+1,11)$ e $184(+0,09)$. Todas as demais combinações foram desfavoráveis, devido ao fator negativo da interação $\mathrm{G} \times \mathrm{E}$.

Assim, os melhores desempenhos, em alturas, dos genótipos com sinergismo adaptativo deverão compor o conjunto de materiais genéticos indicados para estudos de segunda geração. Dessa forma, aumentam-se as probabilidades de sucesso de ganhos em altura, nos programas de melhoramento genético desse material. 
Tabela 19. Respostas médias esperadas para dados de altura, em metros, de $E$. grandis aos 5 anos. Procedência, 12 km S. of Ravenshoe-Mt PandanusQLD (14.420)

\begin{tabular}{cccccccc}
\hline & \multicolumn{7}{c}{ Ambientes } \\
\cline { 2 - 8 } Genótipos & 1 & 2 & 3 & 4 & 5 & 6 & 7 \\
\hline 183 & 17,65 & 24,16 & 18,60 & 20,73 & 13,94 & 20,08 & 14,96 \\
184 & 17,62 & 23,67 & 17,08 & 20,47 & 12,84 & 18,74 & 14,60 \\
185 & 17,03 & 22,85 & 16,36 & 18,89 & 12,37 & 18,09 & 13,69 \\
186 & 16,83 & 22,23 & 15,93 & 16,80 & 12,42 & 17,83 & 12,89 \\
187 & 15,50 & 21,55 & 15,93 & 16,95 & 11,76 & 17,58 & 12,23 \\
188 & 15,72 & 22,38 & 17,04 & 19,09 & 12,22 & 18,46 & 13,18 \\
189 & 14,40 & 20,72 & 16,39 & 14,96 & 12,05 & 17,95 & 11,15 \\
190 & 18,48 & 23,89 & 17,71 & 18,35 & 14,20 & 19,60 & 14,53 \\
191 & 15,85 & 22,52 & 18,04 & 17,99 & 13,29 & 19,46 & 13,10 \\
192 & 17,20 & 23,29 & 17,56 & 18,97 & 13,34 & 19,19 & 14,02 \\
193 & 16,78 & 22,63 & 17,25 & 17,15 & 13,32 & 18,98 & 13,20 \\
194 & 17,63 & 23,10 & 16,53 & 18,27 & 12,92 & 18,40 & 13,85 \\
195 & 17,25 & 22,79 & 15,87 & 18,67 & 12,15 & 17,71 & 13,65 \\
196 & 16,20 & 23,24 & 18,45 & 20,17 & 13,27 & 19,73 & 14,01 \\
197 & 16,53 & 22,72 & 17,05 & 18,58 & 12,73 & 18,65 & 13,46 \\
198 & 16,31 & 22,90 & 17,76 & 19,11 & 13,04 & 19,21 & 13,62 \\
199 & 17,79 & 23,47 & 17,46 & 18,41 & 13,67 & 19,25 & 14,14 \\
200 & 16,71 & 22,78 & 16,90 & 18,62 & 12,69 & 18,54 & 13,53 \\
201 & 15,82 & 20,99 & 14,19 & 15,66 & 10,88 & 16,17 & 11,71 \\
202 & 16,13 & 21,66 & 15,51 & 16,37 & 11,87 & 17,36 & 12,32 \\
\hline
\end{tabular}




\subsubsection{Procedência, Baldy State Forest 194-Atherton-QLD.}

A análise conjunta da variância, para o lote 14.423 (Tabela 16), indicou diferenças significativas $(\mathrm{p}<0,01)$ para todas as fontes de variação. Essa significância permitiu inferir que os locais foram bastante contrastante entre si e que os genótipos não constituem um conjunto geneticamente homogêneo. A significância da interação $\mathrm{G} \times \mathrm{E}$ mostrou a ocorrência de diferenças no padrão de resposta dos genótipos às variações edafoclimáticas dos ambiente.

De forma similar ao lote 14.420, a magnitude da fonte de variação de ambientes foi muito superior às demais, sendo ela responsável pela maior parte da variação ocorrida. As significâncias das interações demonstraram que os genótipos testados apresentaram padrões de respostas diferenciados frente às variações de ambientes. Dessa forma, verificou-se a necessidade de identificar e selecionar genótipos que respondam mais significativamente, em relação aos ganhos genéticos em alturas, em locais específicos, assim como, àqueles que apresentaram comportamento geral, aptos aos vários outros ambientes.

Com base no modelo AMMI e teste $\mathrm{F}_{R}$, para a seleção de modelos mais preditivos e parcimoniosos, o efeito multiplicativo da interação $\mathrm{G} \times \mathrm{E}$ mostrou significância $(\mathrm{p}<0,05)$ apenas para o primeiro eixo singular. Esse eixo explicou $34,22 \%$ da $S Q_{G \times E}$. Observou-se nesse caso que a maior parte da soma de quadrados da interação G $\times E$ foi devida aos "ruídos", sem interesse agronômico. Assim, apesar da porção pequena de $S Q_{G \times E}$ explicada pelo modelo, espera-se capturar todo o "padrão" devido a interação G×E, apenas no primeiro eixo. Dessa forma, os escores de genótipos e de ambientes (Tabela 20) foram plotados, seguindo o modelo $\mathrm{AMMI}_{1}$ (Figura 4). 
Tabela 20. Médias e escores de genótipos e de ambientes para dados de altura, em metros, de E. grandis aos 5 anos. Procedência, Baldy State Forest 194Atherton-QLD (14.423)

\begin{tabular}{|c|c|c|c|}
\hline Genótipos / Ambientes & Médias & $\mathrm{IPCA}_{1}$ & $\mathrm{IPCA}_{2}$ \\
\hline 269 & 16,86 & 0,5531 & $-0,4756$ \\
\hline 270 & 16,65 & $-0,2015$ & 0,2115 \\
\hline 271 & 16,95 & 0,3138 & 0,1627 \\
\hline 272 & 18,35 & $-0,2081$ & 0,6900 \\
\hline 273 & 15,60 & $-0,7627$ & $-0,3789$ \\
\hline 274 & 17,28 & 0,5283 & $-0,1828$ \\
\hline 275 & 16,97 & 0,1305 & 0,1334 \\
\hline 276 & 18,69 & 0,2888 & 0,4410 \\
\hline 277 & 16,52 & 0,3268 & $-0,4541$ \\
\hline 278 & 16,47 & 0,0987 & $-0,1083$ \\
\hline 292 & 17,68 & 0,3261 & $-0,0729$ \\
\hline 293 & 16,17 & $-0,5694$ & 0,2573 \\
\hline 294 & 16,87 & 0,3212 & $-0,2826$ \\
\hline 295 & 17,62 & $-0,0542$ & $-0,0674$ \\
\hline 296 & 16,38 & $-0,1631$ & $-1,1800$ \\
\hline 297 & 18,63 & 0,0439 & 0,7243 \\
\hline 298 & 15,52 & $-0,1357$ & $-0,4631$ \\
\hline 299 & 18,33 & 0,3812 & 0,4839 \\
\hline 300 & 17,82 & 0,7541 & 0,1626 \\
\hline 301 & 16,40 & 0,1043 & 0,6741 \\
\hline 302 & 15,12 & $-1,2149$ & 0,1322 \\
\hline 303 & 17,46 & 0,6110 & $-0,1836$ \\
\hline 304 & 16,35 & $-0,1906$ & $-0,3710$ \\
\hline 305 & 18,41 & $-0,3830$ & 0,2861 \\
\hline 306 & 18,04 & $-0,8986$ & $-0,1387$ \\
\hline L1 & 16,69 & $-0,0922$ & 1,3648 \\
\hline L2 & 22,81 & 0,5602 & 0,1544 \\
\hline L3 & 17,17 & $-1,4257$ & 0,6558 \\
\hline L4 & 18,77 & 1,6117 & 0,1811 \\
\hline $\mathrm{L} 5$ & 12,40 & $-0,3121$ & $-1,3390$ \\
\hline L6 & 18,32 & $-0,7215$ & $-0,5909$ \\
\hline $\mathrm{L} 7$ & 13,44 & 0,3796 & $-0,4261$ \\
\hline
\end{tabular}

IPCA: eixo da interação da análise de componentes principais. 

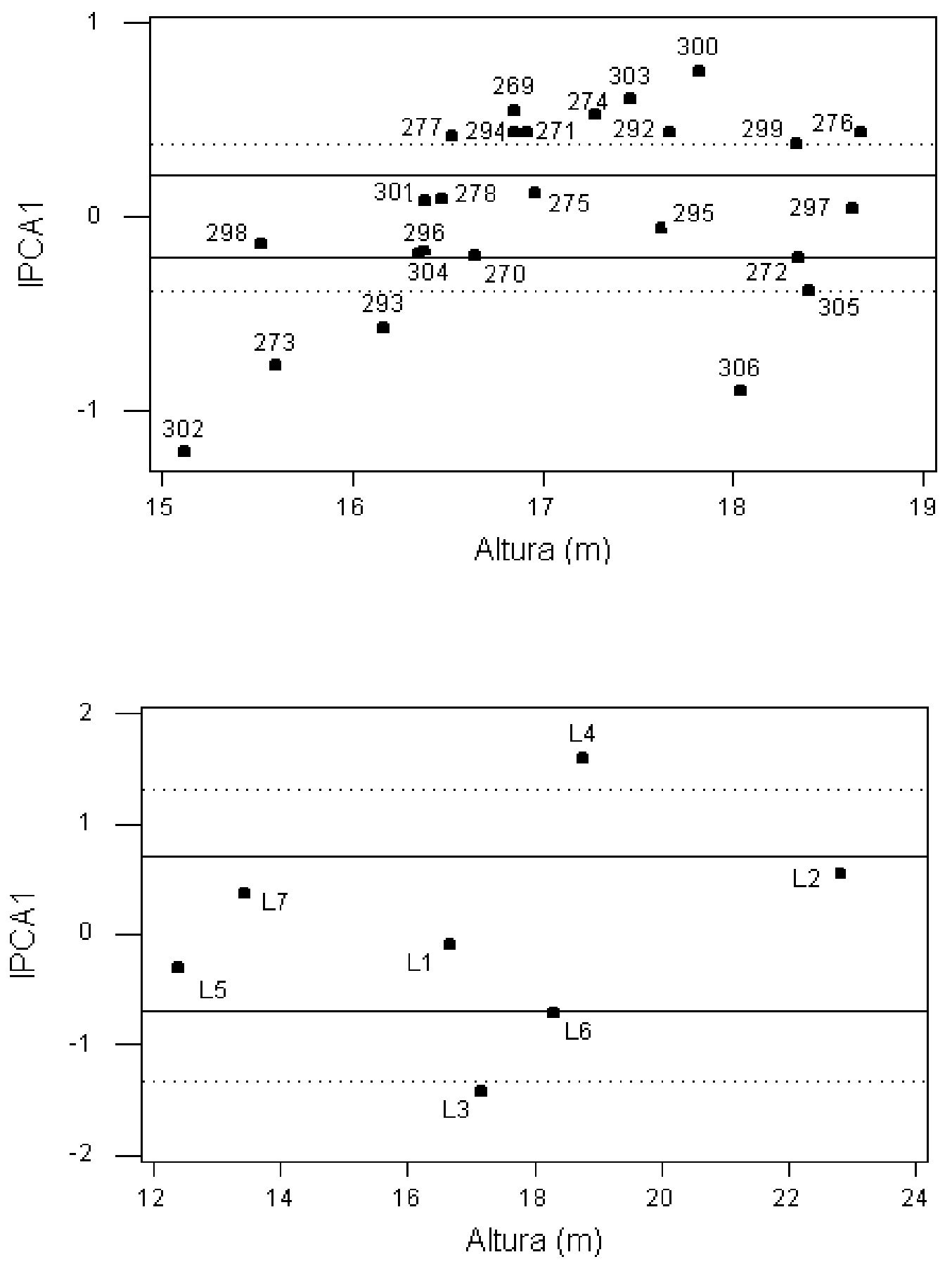

Figura 4 - Intervalos de confiança de 90\% (linha cheia) e de 99\% (linha pontilhada) segundo os escores de genótipos (acima) e de ambientes (abaixo) sobre o modelo $\mathrm{AMMI}_{1}$, para dados de altura, em metros, de E. grandis aos 5 anos. Procedência, Baldy State Forest 194-Atherton-QLD (14.423) 
Num biplot $\mathrm{AMMI}_{1}$, genótipos e ambientes estáveis são aqueles cujos pontos situam-se próximos de zero, em relação ao eixo IPCA 1 (Duarte \& Vencovsky, 1999). Verificou-se através da Figura 4, que os genótipos que atendem essa situação estão contidos dentro da faixa menor, que corresponde ao intervalo de confiança de 90\% (-0,167, +0,167), ou seja, os genótipos 275, 278, 295, 296, 297, 298 e 301. Esses foram considerados, pelos critérios adotados, com alta estabilidade. Um pouco mais afastados de zero, inclusos no intervalo de confiança de $99 \%(-0,273,+0,273)$ estão os genótipos 270, 272 e 304, que foram considerados estáveis. Os demais genótipos, por estarem fora dos limites de confiança estabelecidos, foram classificados como instáveis.

A construção dos intervalos de confiança para a estabilidade foi garantida pelas normalidades observadas para os dois eixos da interação. Os valores observados pelo teste de Shapiro-Wilk, foram: $\mathrm{W}=0,9479(\mathrm{p}=0,2256)$ e $\mathrm{W}=0,9710$ $(\mathrm{p}=0,7774)$, para os eixos $\mathrm{IPCA}_{1}$ e $\mathrm{IPCA}_{2}$, respectivamente, para genótipos, e $\mathrm{W}$ $=0,9593(\mathrm{p}=0,4021)$ e $\mathrm{W}=0,9718(\mathrm{p}=0,9116)$, para os eixos $\mathrm{IPCA}_{1}$ e IPCA 2 , respectivamente, para ambientes.

Em relação aos escores de ambientes observou-se que os locais Barra Ribeiro-RS (L1), Telêmaco Borba-PR (L2), Ipatinga-MG (L5) e Caçapava-SP (L7) estavam contidos dentro do intervalo de confiança de $90 \%(-0,717,+0,717)$. Assim, foram considerados com alta estabilidade. O local Aracruz-ES (L6) contido no intervalo de confiança de $99 \%(-1,368,+1,368)$ foi considerado estável. E os locais, Boa Esperança do Sul-SP (L3) e Guanhães-MG (L4), estavam fora dos limites de confiança aceitáveis. Então pelos critérios adotados foram considerados instáveis. Os ambientes que mais contribuíram para a interação $\mathrm{G} \times \mathrm{E}$, foram L3 e L4, o que atestam suas instabilidades.

As adaptabilidades dos genótipos instáveis foram verificadas em função das predições do modelo $\mathrm{AMMI}_{1}$ (Tabela 21), assim como através da exploração do efeito positivo da interação $\mathrm{G} \times \mathrm{E}$. 
Tabela 21. Respostas médias esperadas para dados de altura, em metros, de $E$. grandis aos 5 anos. Procedência, Baldy State Forest 194-Atherton-QLD $(14.423)$

\begin{tabular}{|c|c|c|c|c|c|c|c|}
\hline \multirow[b]{2}{*}{ Genótipos } & \multicolumn{7}{|c|}{ Ambientes } \\
\hline & 1 & 2 & 3 & 4 & 5 & 6 & 7 \\
\hline 269 & 16,41 & 22,89 & 16,15 & 19,43 & 12,00 & 17,69 & 13,42 \\
\hline 270 & 16,27 & 22,26 & 17,02 & 18,01 & 12,03 & 18,02 & 12,92 \\
\hline 271 & 16,53 & 22,85 & 16,59 & 19,14 & 12,17 & 17,96 & 13,42 \\
\hline 272 & 17,97 & 23,96 & 18,73 & 19,69 & 13,73 & 19,73 & 14,62 \\
\hline 273 & 15,27 & 20,90 & 16,77 & 16,05 & 11,15 & 17,38 & 11,66 \\
\hline 274 & 16,83 & 23,30 & 16,61 & 19,81 & 12,43 & 18,13 & 13,83 \\
\hline 275 & 16,56 & 22,77 & 16,87 & 18,86 & 12,24 & 18,10 & 13,37 \\
\hline 276 & 18,27 & 24,58 & 18,36 & 20,84 & 13,91 & 19,71 & 15,15 \\
\hline 277 & 16,10 & 22,43 & 16,14 & 18,73 & 11,74 & 17,52 & 13,00 \\
\hline 278 & 16,07 & 22,26 & 16,42 & 18,32 & 11,76 & 17,63 & 12,86 \\
\hline 292 & 17,25 & 23,58 & 17,30 & 19,89 & 12,89 & 18,67 & 14,15 \\
\hline 293 & 15,83 & 21,58 & 17,07 & 16,94 & 11,66 & 17,81 & 12,30 \\
\hline 294 & 16,44 & 22,78 & 16,50 & 19,07 & 12,09 & 17,87 & 13,34 \\
\hline 295 & 17,23 & 23,32 & 17,79 & 19,22 & 12,96 & 18,89 & 13,96 \\
\hline 296 & 16,00 & 22,02 & 16,70 & 17,80 & 11,75 & 17,73 & 12,67 \\
\hline 297 & 18,23 & 24,38 & 18,65 & 20,39 & 13,93 & 19,83 & 15,00 \\
\hline 298 & 15,14 & 21,17 & 15,80 & 16,98 & 10,88 & 16,85 & 11,82 \\
\hline 299 & 17,90 & 24,27 & 17,88 & 20,63 & 13,53 & 19,29 & 14,83 \\
\hline 300 & 17,36 & 23,97 & 16,83 & 20,72 & 12,91 & 18,51 & 14,46 \\
\hline 301 & 16,00 & 22,19 & 16,34 & 18,25 & 11,68 & 17,55 & 12,79 \\
\hline 302 & 14,83 & 20,16 & 16,93 & 14,84 & 10,81 & 17,22 & 11,01 \\
\hline 303 & 17,01 & 23,53 & 16,67 & 20,13 & 12,59 & 18,25 & 14,04 \\
\hline 304 & 15,97 & 21,97 & 16,71 & 17,73 & 11,73 & 17,72 & 12,63 \\
\hline 305 & 18,05 & 23,92 & 19,04 & 19,47 & 13,84 & 19,91 & 14,61 \\
\hline 306 & 17,73 & 23,26 & 19,40 & 18,27 & 13,64 & 19,92 & 14,05 \\
\hline
\end{tabular}


Foram observadas as melhores adaptabilidades para o local Barra Ribeiro-RS (L1), os genótipos: $269(+0,87), 300(+0,49), 273(+0,24)$ e $274(+0,15)$; para o local Telêmaco Borba-PR (L2), os genótipos: $273(+1,15), 303(+0,94), 274$ $(+0,24)$ e $306(+0,08)$; para o local Boa Esperança do Sul-SP (L3), os genótipos: 293 $(+0,84), 306(+0,52), 303(+0,32), 274(+0,19), 273(+0,11)$ e $269(+0,05)$; para o local Guanhães-MG (L4), os genótipos: 293 (+0,84), $302(+0,36), 269(+0,35), 300$ $(+0,12)$ e $306(+0,06)$; para o local Ipatinga-MG (L5), os genótipos: $293(+1,13), 300$ $(+0,70)$ e $302(+0,20)$; para o local Aracruz-ES (L6), os genótipos: $269(+0,37), 302$ $(+0,27), 300(+0,20)$ e $273(+0,12)$ e para o local Caçapava-SP $(L 7)$, os genótipos: $301(+0,63), 306(+0,29), 274(+0,27), 303(+0,13)$ e $302(+0,08)$. Todas as demais combinações foram desfavoráveis, devido ao fator negativo da interação $\mathrm{G} \times \mathrm{E}$.

\subsubsection{Procedência, Bellthorpe St. Forest-QLD.}

A análise conjunta da variância para o lote 14.431 (Tabela 16), indicou diferenças significativas $(\mathrm{p}<0,01)$ para todas as fontes de variação. O efeito de ambiente foi mais importante do que o efeito da interação $\mathrm{G} \times \mathrm{E}$, e esse mais importante do que o efeito de genótipos.

A análise da interação $\mathrm{G} \times \mathrm{E}$, pela análise de componentes principais, mostrou que somente o primeiro IPCA foi significativo $(\mathrm{p}<0,05)$. Esse eixo explicou $36,16 \%$ da $S Q_{G \times E}$. Os demais eixos representam variações da $S Q_{G \times E}$ mais predominantemente ricas em ruído. Assim, pelo critério de Cornelius et al. (1992) o modelo $\mathrm{AMMI}_{1}$ foi selecionado como aquele que melhor descreve o padrão inerente à interação $\mathrm{G} \times \mathrm{E}$. Dessa forma, os escores de genótipos e de ambientes (Tabela 22) foram plotados, seguindo o modelo $\mathrm{AMMI}_{1}$ (Figura 5).

Observou-se no biplot $\mathrm{AMMI}_{1}$, que os ambientes apresentaram maior variabilidade do que os genótipos, tanto em efeitos principais quanto multiplicativo (variação para efeitos principais e multiplicativos são visualizados nos sentidos horizontal e vertical do gráfico, respectivamente). Isso confirma os resultados observados para as magnitudes das somas de quadrados evidenciados pela análise de variância. 
Tabela 22. Médias e escores de genótipos e de ambientes para dados de altura, em metros, de E. grandis aos 5 anos. Procedência, Bellthorpe St. Forest-

\begin{tabular}{|c|c|c|c|}
\hline Genótipos / Ambientes & Médias & $\mathrm{IPCA}_{1}$ & $\mathrm{IPCA}_{2}$ \\
\hline 662 & 17,81 & $-0,4449$ & $-0,3329$ \\
\hline 663 & 15,46 & 1,2365 & 0,0307 \\
\hline 664 & 17,35 & 0,1772 & $-1,2842$ \\
\hline 665 & 17,47 & $-0,2073$ & $-0,6450$ \\
\hline 666 & 17,55 & 0,1286 & $-0,6623$ \\
\hline 667 & 18,49 & $-0,4915$ & 0,0714 \\
\hline 668 & 17,79 & 0,0568 & 0,1373 \\
\hline 669 & 17,49 & $-0,5127$ & 0,2932 \\
\hline 670 & 17,18 & $-0,3369$ & 0,5036 \\
\hline 671 & 18,37 & $-0,2268$ & $-0,2600$ \\
\hline 672 & 18,19 & $-0,1762$ & 0,3177 \\
\hline 673 & 18,31 & $-0,1873$ & 0,3259 \\
\hline 674 & 17,68 & $-0,4398$ & 0,2092 \\
\hline 675 & 17,44 & 0,0008 & $-0,0057$ \\
\hline 676 & 17,77 & $-0,1364$ & 0,4423 \\
\hline 677 & 17,47 & $-0,0352$ & $-0,0813$ \\
\hline 678 & 17,55 & $-0,2130$ & 0,2627 \\
\hline 679 & 17,94 & 0,0534 & $-0,3811$ \\
\hline 680 & 18,58 & $-0,5415$ & 0,4047 \\
\hline 681 & 17,77 & $-0,3189$ & 0,1668 \\
\hline 682 & 15,15 & 1,5889 & 0,2884 \\
\hline 683 & 16,45 & 0,2463 & 0,2289 \\
\hline 684 & 17,17 & 0,0624 & 0,2919 \\
\hline 685 & 15,40 & 0,7517 & 0,4484 \\
\hline 686 & 17,11 & $-0,0342$ & $-0,7707$ \\
\hline L1 & 17,20 & $-0,5131$ & 1,8625 \\
\hline L2 & 22,84 & $-1,1865$ & $-0,1724$ \\
\hline L3 & 17,13 & $-0,0126$ & $-0,8822$ \\
\hline L4 & 19,13 & $-1,1532$ & $-0,6508$ \\
\hline L5 & 12,58 & 0,4974 & $-0,4006$ \\
\hline L6 & 18,81 & 0,7864 & 0,2468 \\
\hline L7 & 14,08 & 1,5816 & $-0,0034$ \\
\hline
\end{tabular}

IPCA: eixo da interação da análise de componentes principais. 

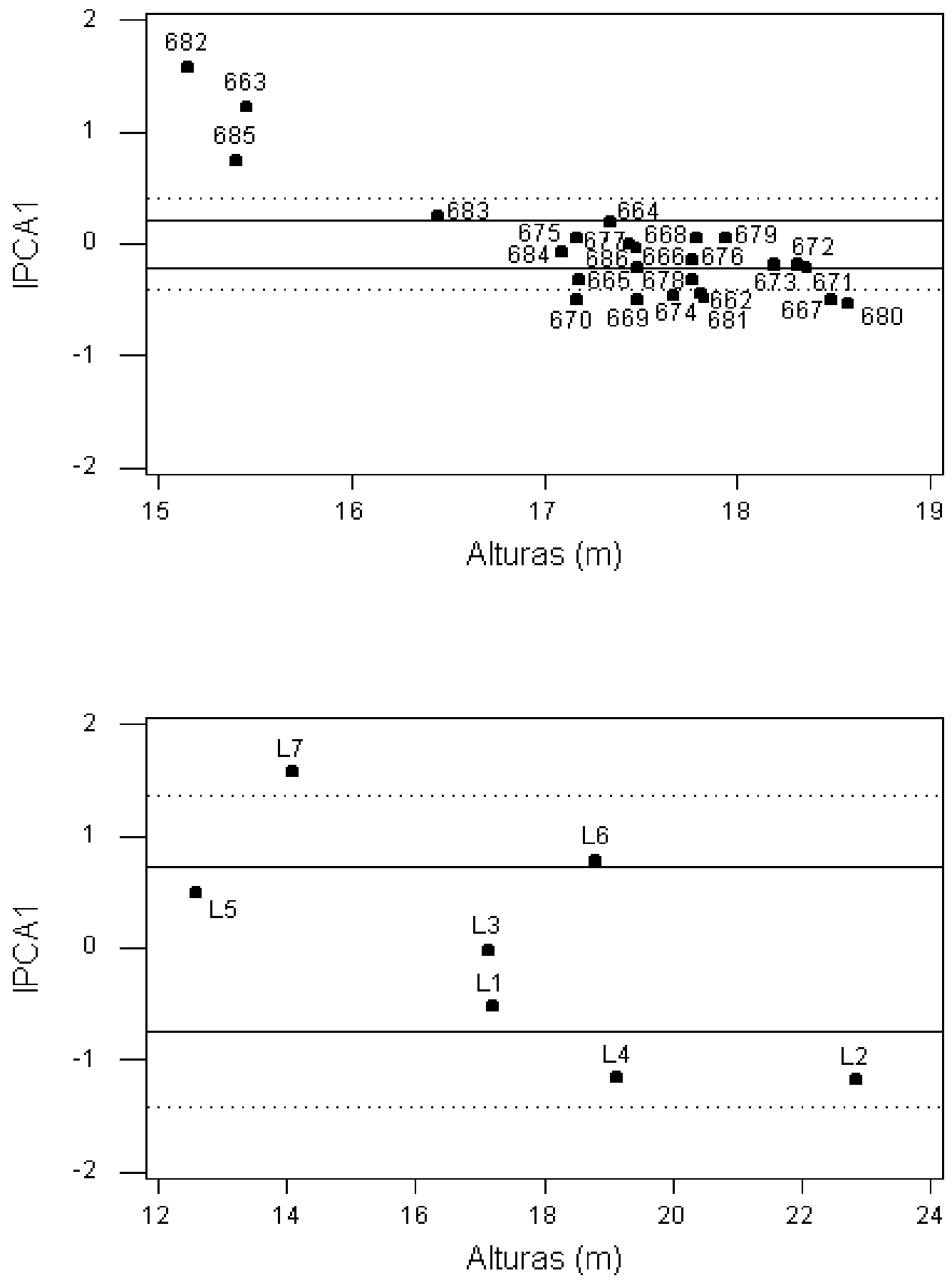

Figura 5 - Intervalos de confiança de 90\% (linha cheia) e de 99\% (linha pontilhada) segundo os escores de genótipos (acima) e de ambientes (abaixo) sobre o modelo $\mathrm{AMMI}_{1}$, para dados de altura, em metros, de E. grandis aos 5 anos. Procedência, Bellthorpe St. Forest-QLD (14.431) 
Os genótipos que mais contribuíram para a interação $\mathrm{G} \times \mathrm{E}$ foram: 682 , 663 e 685, pois apresentaram as maiores magnitudes de escores no eixo da interação (Figura 5). Entretanto, os genótipos 662, 663, 667, 669, 670, 674, 680, 681, 682 e 685 foram considerados instáveis, por apresentarem escores fora dos limites estabelecidos. Os genótipos contidos dentro da faixa menor: 666, 668, 672, 675, 676, 677, 679, 684 e 686, que corresponde ao intervalo de confiança de $90 \%(-0,176,+0,176)$, foram os que menos contribuíram para a interação. Assim foram considerados com alta estabilidade, pela metodologia adotada. Inclusos no intervalo de confiança de $99 \%$ $(-0,288,+0,288)$, faixa maior, estão os genótipos: 664, 665, 671, 673, 678 e 683, que foram considerados estáveis.

Em relação aos escores de ambientes foi observado que os locais Barra Ribeiro-RS (L1), Boa Esperança do Sul-SP (L3), e Ipatinga-MG (L5) estão contidos dentro do intervalo de confiança de $90 \%(-0,757,+0,757)$. Assim, foram considerados com alta estabilidade. E os locais Telêmaco Borba-PR (L2), Guanhães-MG (L4) e Aracruz-ES (L6) estão contidos no intervalo de confiança de $99 \%(-1,444,+1,444)$. Então, pelos critérios adotados, foram considerados estáveis. O ambiente que mais contribuíu para a interação $\mathrm{G} \times \mathrm{E}$, foi o local Caçapava-SP (L7). O valor de seu escore está fora dos limites estabelecidos, o que atestou sua instabilidade.

Os valores observados pelo teste de Shapiro-Wilk, foram: $\mathrm{W}=0,7998$ $(\mathrm{p}=0,0002)$ e $\mathrm{W}=0,8635(\mathrm{p}=0,0032)$, para os eixos $\mathrm{IPCA}_{1}$ e $\mathrm{IPCA}_{2}$, respectivamente, para genótipos, e $\mathrm{W}=0,9465(\mathrm{p}=0,6981)$ e $\mathrm{W}=0,8441(\mathrm{p}=0,1085)$, para os eixos IPCA $\mathrm{IPCA}_{2}$, respectivamente, para ambientes. Observou-se nesse caso, a não normalidade para os escores de genótipos. Assim, as inferências feitas para esse fator devem ser vistas com ressalvas.

As adaptabilidades dos genótipos instáveis foram verificadas em função das predições do modelo $\mathrm{AMMI}_{1}$ (Tabela 23), assim como através da exploração do efeito positivo da interação $\mathrm{G} \times \mathrm{E}$. 
Tabela 23. Respostas médias esperadas para dados de altura, em metros, de $E$. grandis aos 5 anos. Procedência, Bellthorpe St. Forest-QLD (14.431)

\begin{tabular}{cccccccc}
\hline & \multicolumn{7}{c}{ Ambientes } \\
\cline { 2 - 8 } Genótipos & 1 & 2 & 3 & 4 & 5 & 6 & 7 \\
\hline 662 & 17,84 & 23,78 & 17,54 & 20,06 & 12,77 & 18,87 & 13,79 \\
663 & 14,62 & 19,43 & 15,17 & 15,77 & 11,26 & 17,84 & 14,10 \\
664 & 17,06 & 22,58 & 17,08 & 18,88 & 12,62 & 18,90 & 14,31 \\
665 & 17,37 & 23,16 & 17,20 & 19,44 & 12,55 & 18,72 & 13,83 \\
666 & 17,29 & 22,84 & 17,28 & 19,14 & 12,80 & 19,07 & 14,44 \\
667 & 18,54 & 24,51 & 18,23 & 20,79 & 13,43 & 19,52 & 14,40 \\
668 & 17,56 & 23,16 & 17,52 & 19,46 & 13,00 & 19,25 & 14,56 \\
669 & 17,55 & 23,54 & 17,22 & 19,82 & 12,42 & 18,50 & 13,36 \\
670 & 17,16 & 23,03 & 16,92 & 19,31 & 12,20 & 18,33 & 13,34 \\
671 & 18,29 & 24,08 & 18,10 & 20,37 & 13,44 & 19,61 & 14,70 \\
672 & 18,09 & 23,85 & 17,93 & 20,14 & 13,29 & 19,47 & 14,60 \\
673 & 18,21 & 23,97 & 18,04 & 20,26 & 13,40 & 19,58 & 14,70 \\
674 & 17,70 & 23,64 & 17,41 & 19,92 & 12,64 & 18,75 & 13,67 \\
675 & 17,24 & 22,89 & 17,17 & 19,18 & 12,63 & 18,86 & 14,13 \\
676 & 17,64 & 23,37 & 17,50 & 19,66 & 12,88 & 19,07 & 14,24 \\
677 & 17,29 & 22,96 & 17,20 & 19,25 & 12,64 & 18,86 & 14,10 \\
678 & 17,46 & 23,25 & 17,29 & 19,54 & 12,63 & 18,80 & 13,90 \\
679 & 17,72 & 23,32 & 17,67 & 19,62 & 13,15 & 19,40 & 14,71 \\
680 & 18,66 & 24,67 & 18,32 & 20,94 & 13,50 & 19,57 & 14,41 \\
681 & 17,73 & 23,59 & 17,51 & 19,88 & 12,80 & 18,93 & 13,95 \\
682 & 14,13 & 18,71 & 14,86 & 15,05 & 11,12 & 17,81 & 14,35 \\
683 & 16,12 & 21,60 & 16,17 & 17,90 & 11,75 & 18,05 & 13,52 \\
684 & 16,94 & 22,54 & 16,90 & 18,83 & 12,38 & 18,63 & 13,95 \\
685 & 14,82 & 19,95 & 15,13 & 16,27 & 10,96 & 17,41 & 13,28 \\
686 & 16,92 & 22,59 & 16,84 & 18,88 & 12,27 & 18,49 & 13,74 \\
\hline & & & & & & &
\end{tabular}


Foram observadas as melhores adaptabilidades para o ambiente Barra Ribeiro-RS (L1) o genótipo, $662(+0,47)$; para o ambiente Telêmaco Borba-PR (L2), os genótipos, $663(+1,64), 680(+0,46), 667(+0,36), 674(+0,17)$ e $669(+0,03)$; para o ambiente Boa Esperança do Sul-SP (L3), os genótipos, $670(+1,28), 681(+0,89)$, $667(+0,68), 682(+0,66), 680(+0,12)$ e $674(+0,11)$; para o ambiente GuanhãesMG (L4), os genótipos, $685(+1,17), 682(+0,87), 662(+0,45), 681(+0,26), 669$ $(+0,17), 670(+0,14)$ e $680(+0,04)$; para o ambiente Ipatinga-MG (L5), os genótipos, $670(+1,09), 663(+0,84), 662(+0,77), 669(+0,57), 674(+0,44), 685(+0,37), 680$ $(+0,13), 681(+0,04)$ e $682(+0,01)$; para o ambiente Aracruz-ES (L6), os genótipos, $663(+1,08), 680(+0,47), 681(+0,39), 669(+0,38)$ e $667(+0,29)$ e para o ambiente Caçapava-SP (L7), os genótipos, $685(+0,53)$ e $662(+0,34)$. Todas as demais combinações foram desfavoráveis, devido ao fator negativo da interação $\mathrm{G} \times \mathrm{E}$.

\subsubsection{Considerações sobre as análises AMMI}

Uma preocupação constante dos estatísticos é a escolha do nível de significância do teste adotado. Nesse sentido, vale salientar que, com a utilização de $1 \%$ em vez de 5\%, reduz-se a probabilidade de ocorrer o erro tipo I, isto é, de aceitar um modelo AMMI com maior número de eixos, quando na verdade o modelo é menos parametrizado. Porém aumenta-se a probabilidade de ocorrer o erro tipo II, isto é, de aceitar um modelo AMMI com menor número de eixos, mas cujo modelo correto seja de fato mais parametrizado (Oliveira et al. 2003).

A adoção do nível de 1\% para este trabalho, deu-se em função da escolha do teste $F_{R}$ de Cornelius et al. (1992), que, segundo Piepho (1995), é um teste robusto para a escolha do modelo AMMI. Segundo Cornelius et al. (1992), a adoção de testes de seleção de modelos AMMI com mais acurácia, minimiza as possibilidades de ocorrência do erro tipo I. Nesse mesmo sentido, Mandel (1971), já alertava para essa preocupação, e considerou que testes mais liberais, como proposto por Gollob (1968), podiam selecionar um número maior de eixos, aumentando assim, a ocorrência do erro tipo I. 
Vale ressaltar que, a escolha de um teste mais rigoroso para a seleção do modelo AMMI, implica, consequentemente, na diminuição do número de eixos utilizados para explicar as somas de quadrados dos efeitos multiplicativos, e isto pode levar a uma menor porcentagem da soma de quadrados explicada por esses eixos. Entretanto, diferentemente da maneira convencional, em que se busca uma explicação máxima dessa soma de quadrados, no modelo AMMI, busca-se absorver apenas o "padrão" devido a interção, nesse caso $S Q_{G \times E}$. Uma das premissas da análise AMMI é a de que nos primeiros eixos concentram-se as maiores porcentagens de "padrão", mesmo que esses eixos expliquem a menor porcentagem das somas de quadrados da interação $\mathrm{G} \times \mathrm{E}$.

Por outro lado, as baixas proporções das somas de quadrados explicadas pelos primeiros eixos, indicam uma contaminação da matriz de interações por "ruídos", que não foram controlados pela experimentação, muito provavelmente, devido a fatores imprevisíveis ou previsíveis, porém não controlados. Esses "ruídos" inflacionam a matriz de interações originais depreciando a qualidade de suas estimativas. Dessa forma, todos os métodos que se utiliza dessas estimativas para fazer as inferências sobre o material, sem eliminar esses "ruídos", fornecem informações de baixa qualidade. Nessa mesma direção, Gauch (1988), enfatiza que os primeiros eixos AMMI captam maior porcentagem de "padrão" e, com subseqüente acumulação de eixos, ocorre diminuição na porcentagem de "padrão" e um acréscimo de "ruídos". Assim, a inclusão excessiva de termos multiplicativos no modelo AMMI pode reduzir seriamente a qualidade e a acurácia da análise (Gauch \& Zobel, 1996).

A análise AMMI, por eliminar o "ruído" da matriz de interações, tornou-se uma ferramenta essencial na identificação de relações importantes no discernimento das verdadeiras causas da interação $\mathrm{G} \times \mathrm{E}$ (Duarte \& Vencovsky, 1999). A análise de estabilidade e adaptabilidade via modelo AMMI é particularmente importante quando não se têm medidas sobre variáveis ambientais externas que contribuem para as interações $\mathrm{G} \times \mathrm{E}$ (Vargas et al. 2001), assim como, quando o número de genótipos é baixo (Ariyo, 1998). Entretanto, como em qualquer metodologia, o 
uso inadequado da técnica pode fornecer informações imprecisas sobre a estabilidade e adaptabilidade fenotípica dos materiais, principalmente se forem observadas apenas as análises gráficas dos resultados.

Neste estudo, observou-se pela análise gráfica do lote 14.431 (Figura 5), uma enganosa estabilidade para os genótipos 662, 667, 669, 670, 674, 680 e 681, pois, a análise $\mathrm{AMMI}_{1}$, identifica a estabilidade através dos valores de $\mathrm{IPCA}_{1}$, próximos de zero, e esses, demonstram estabilidade a todos os ambientes testados. $\mathrm{Ou}$, ainda, as combinações de genótipos e ambientes com escores de mesmo sinal, têm interações específicas positivas, e as combinações de sinais opostos, apresentam interações específicas negativas. Essas análises não foram confirmadas na íntegra para esses genótipos.

Fato semelhante foi observado pela análise gráfica do lote 14.420 (Figura 3), em que, para o modelo $\mathrm{AMMI}_{2}$, genótipos e ambientes estáveis são aqueles cujos pontos situam-se próximos à origem, ou seja, com escores praticamente nulos para os dois eixos da interação (IPCA 1 e IPCA 2$)($ Duarte \& Vencovsky, 1999). Observou-se que apenas quatro genótipos atenderiam esses critérios. Por outro lado, os ambientes que apresentaram uma maior variabilidade, consequentemente, ampliaram suas regiões de confiança para o vetor nulo, e assim todos estiveram contidos dentro dos limites de estabilidade.

Diante desses fatos, ficou clara a necessidade de um trabalho mais detalhado para os processos de inferência, para estabilidade e adaptabilidade fenotípica, via modelo AMMI. Dessa forma, visando uma melhoria nesse processo, para este estudo utilizou-se técnicas de reamostragem "bootstrap", para melhor predizer as estabilidades e adaptabilidades fenotípicas de Eucalyptus grandis.

\subsection{Análises "bootstrap" AMMI}

Conforme já exposto, a interção dos genótipos com os ambientes mostrou-se significativa. Dessa forma, foi necessário o desenvolvimento de um estudo mais detalhado dessa interação $\mathrm{G} \times \mathrm{E}$. Pelos procedimentos AMMI's, ficou ca- 
racterizada a falta de precisão nas análises gráficas dos biplots para as estabilidades. Assim, foi necessário o desenvolvimento de uma metodologia complementar para avaliar a precisão dos escores de genótipos e de ambientes, permitindo uma melhoria na qualidade das inferências para as estabilidades fenotípicas.

Como os escores AMMI têm distribuição de probabilidade desconhecida, isso dificultou a obtenção de fórmulas via argumentos analíticos, para medir a precisão desses escores. Dessa forma, procurou-se utilizar sistemas interativos para medir a precisão desses escores.

Os recentes avanços da ciência da computação, permitiram o desenvolvimento de sistemas interativos de processamento de dados, com algoritmos rápidos e precisos. Dentro desse enfoque, buscou-se ferramentas estatísticas como o "jackknife" e o "bootstrap", que permitissem uma análise criteriosa da precisão dos escores AMMI. Optou-se, neste estudo, pelo uso da reamostragem "bootstrap".

Como os coeficientes dos escores de genótipos e de ambientes são obtidos a partir da matriz de resíduos, procurou-se enquadrar a ferramenta estatística "bootstrap" à necessidade da análise AMMI. Em concordância com o modelo AMMI, que permite a estimação dos genótipos associados aos ambientes livres de "ruídos", optou-se pela reamostragem na matriz de resíduos, obtida dos valores estimados. Dessa forma, foram desenvolvidos procedimentos estatísticos que possibilitaram as análises gráficas e numéricas das estabilidades, e adaptabilidade fenotípica dos genótipos e dos ambientes envolvidos neste estudo.

\subsubsection{Procedência, $12 \mathrm{~km}$ S. of Ravenshoe-Mt Pandanus-QLD}

A análise da interação G×E pela ACP e Gollob (1968), mostrou que os três primeiros eixos $\left(\mathrm{IPCA}_{1}, \mathrm{IPCA}_{2}\right.$ e IPCA $\left.{ }_{3}\right)$ foram significativos, com $\mathrm{p}<0,01$ (Tabela 15). Esses eixos explicaram 76,09\% da $S Q_{G \times E}$. Dessa forma, os valores estimados seguiram o modelo $\mathrm{AMMI}_{3}$ (Tabela 24). 
Tabela 24. Alturas médias, em metros, de E. grandis aos 5 anos, estimadas pelo modelo $\mathrm{AMMI}_{3}$. Procedência, $12 \mathrm{~km}$ S. of Ravenshoe-Mt PandanusQLD (14.420)

\begin{tabular}{|c|c|c|c|c|c|c|c|}
\hline \multirow[b]{2}{*}{ Genótipos } & \multicolumn{7}{|c|}{ Ambientes } \\
\hline & 1 & 2 & 3 & 4 & 5 & 6 & 7 \\
\hline 183 & 17,52 & 24,95 & 18,68 & 20,65 & 13,79 & 19,94 & 14,58 \\
\hline 184 & 17,55 & 24,12 & 17,13 & 20,42 & 12,76 & 18,66 & 14,38 \\
\hline 185 & 16,92 & 23,56 & 16,43 & 18,82 & 12,24 & 17,97 & 13,35 \\
\hline 186 & 16,77 & 22,65 & 15,98 & 16,76 & 12,35 & 17,75 & 12,68 \\
\hline 187 & 15,53 & 21,36 & 15,91 & 16,97 & 11,79 & 17,61 & 12,32 \\
\hline 188 & 15,74 & 22,26 & 17,03 & 19,10 & 12,25 & 18,48 & 13,24 \\
\hline 189 & 14,43 & 20,53 & 16,37 & 14,98 & 12,09 & 17,98 & 11,23 \\
\hline 190 & 18,38 & 24,50 & 17,78 & 18,28 & 14,08 & 19,50 & 14,23 \\
\hline 191 & 15,71 & 23,41 & 18,13 & 17,90 & 13,13 & 19,30 & 12,67 \\
\hline 192 & 17,37 & 22,27 & 17,45 & 19,08 & 13,52 & 19,37 & 14,51 \\
\hline 193 & 16,74 & 22,87 & 17,28 & 17,13 & 13,28 & 18,94 & 13,09 \\
\hline 194 & 17,53 & 23,69 & 16,59 & 18,21 & 12,81 & 18,30 & 13,56 \\
\hline 195 & 17,25 & 22,80 & 15,87 & 18,67 & 12,15 & 17,71 & 13,65 \\
\hline 196 & 16,12 & 23,71 & 18,50 & 20,12 & 13,19 & 19,65 & 13,78 \\
\hline 197 & 16,83 & 20,85 & 16,85 & 18,77 & 13,08 & 18,98 & 14,36 \\
\hline 198 & 16,35 & 22,60 & 17,73 & 19,14 & 13,10 & 19,26 & 13,76 \\
\hline 199 & 17,81 & 23,33 & 17,45 & 18,42 & 13,69 & 19,27 & 14,21 \\
\hline 200 & 16,89 & 21,67 & 16,78 & 18,73 & 12,89 & 18,74 & 14,07 \\
\hline 201 & 15,93 & 20,27 & 14,11 & 15,74 & 11,02 & 16,29 & 12,05 \\
\hline 202 & 16,06 & 22,11 & 15,56 & 16,33 & 11,79 & 17,28 & 12,10 \\
\hline
\end{tabular}


A partir do conjunto de dados apresentados na Tabela 24, determinouse a matriz de resíduos $\left(\widehat{G E}_{14.420}\right)$, a qual foi denominada de matriz de resíduo livre de "ruídos:

$$
\widehat{G E}_{14.420}=\left[\begin{array}{rrrrrrr}
-0,7203 & 0,7057 & 0,2307 & 0,8702 & -0,5288 & -0,1778 & -0,3798 \\
0,0369 & 0,6029 & -0,5921 & 1,3674 & -0,8316 & -0,7306 & 0,1474 \\
0,2254 & 0,8614 & -0,4736 & 0,5859 & -0,5331 & -0,6021 & -0,0641 \\
0,6969 & 0,5729 & -0,3021 & -0,8526 & 0,1984 & -0,2006 & -0,1126 \\
-0,0503 & -0,2243 & 0,1207 & -0,1498 & 0,1312 & 0,1522 & 0,0202 \\
-0,7846 & -0,2686 & 0,2964 & 1,0359 & -0,3531 & 0,0779 & -0,0041 \\
-0,5960 & -0,5000 & 1,1350 & -1,5855 & 0,9855 & 1,0765 & -0,5155 \\
0,6197 & 0,7357 & -0,1893 & -1,0198 & 0,2412 & -0,1378 & -0,2498 \\
-1,1217 & 0,5743 & 1,0893 & -0,4712 & 0,2198 & 0,5908 & -0,8812 \\
0,0640 & -1,0400 & -0,0650 & 0,2345 & 0,1355 & 0,1865 & 0,4845 \\
0,0397 & 0,1657 & 0,3707 & -1,1098 & 0,5012 & 0,3622 & -0,3298 \\
0,6354 & 0,7914 & -0,5136 & -0,2241 & -0,1631 & -0,4721 & -0,0541 \\
0,7254 & 0,2714 & -0,8636 & 0,6059 & -0,4531 & -0,6921 & 0,4059 \\
-1,4003 & 0,1857 & 0,7707 & 1,0602 & -0,4088 & 0,2522 & -0,4598 \\
0,0740 & -1,9100 & -0,1150 & 0,4745 & 0,2455 & 0,3465 & 0,8845 \\
-0,7231 & -0,4771 & 0,4479 & 0,5274 & -0,0516 & 0,3094 & -0,0326 \\
0,4169 & -0,0671 & -0,1521 & -0,5126 & 0,2184 & -0,0006 & 0,0974 \\
0,1269 & -1,0971 & -0,1921 & 0,4274 & 0,0484 & 0,0994 & 0,5874 \\
1,2183 & -0,4457 & -0,8107 & -0,5112 & 0,2298 & -0,2992 & 0,6188 \\
0,5169 & 0,5629 & -0,1921 & -0,7526 & 0,1684 & -0,1406 & -0,1626
\end{array}\right]
$$

Sobre a matriz $\widehat{G E}_{14.420}$ foram processadas as reamostragens "bootstrap".

De acordo com a metodologia "bootstrap" AMMI proposta, a análise da estabilidade de genótipos (Figura 6) e de ambiente (Figura 7), permitiram identificar como estáveis os genótipos: 183, 185, 186, 187, 188, 190, 192, 194, 197, 198, 199, 200, 201 e 202; assim como, aos ambientes: Barra Ribeiro-RS (L1), Telêmaco Borba- 
PR (L2) e Caçapava-SP (L7). Todos esses, continham o ponto de coordenadas nulas $(0,0)$ incluídas na região de confiança para o vetor "bootstrap" de médias. Enquanto que os genótipos: 184, 189, 191, 193 e 195 e os ambientes: Boa Esperança do Sul-SP (L3), Guanhães-MG (L4), Ipatinga-MG (L5) e Aracruz-ES (L6), por não conterem o vetor nulo em suas regiões de confiança, foram classificados como instáveis.
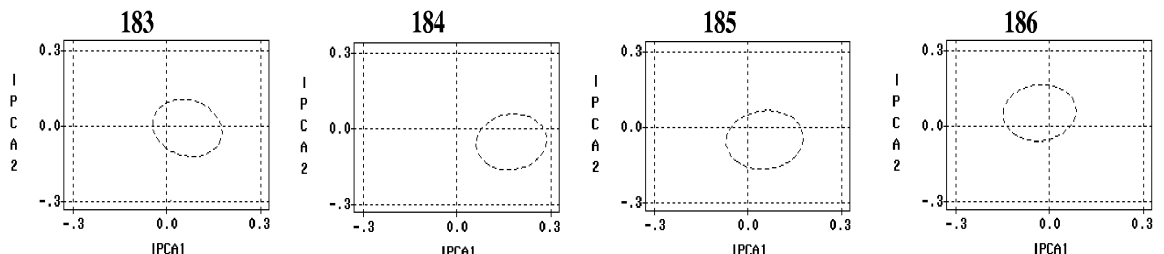

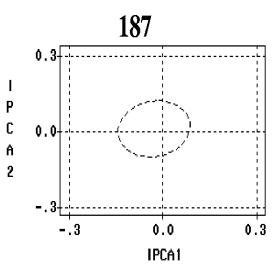

188

189
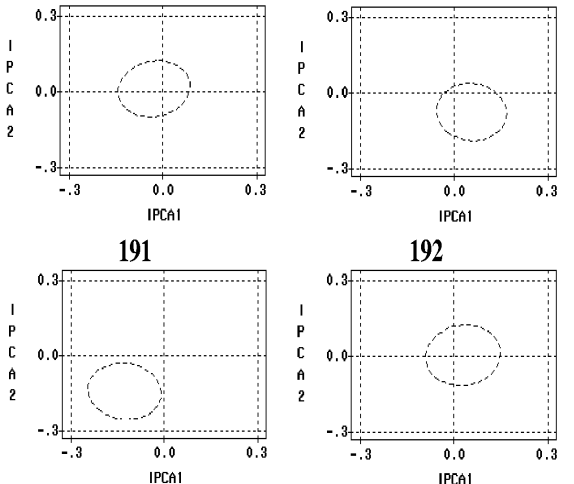

195

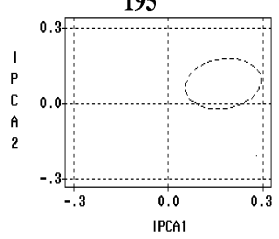

199

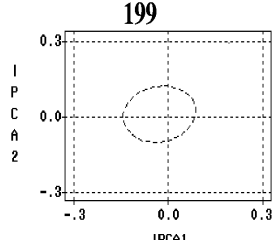

192

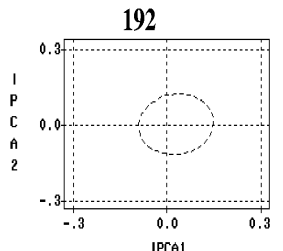

196

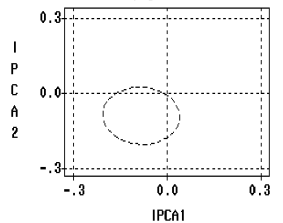

200

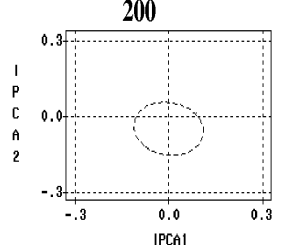

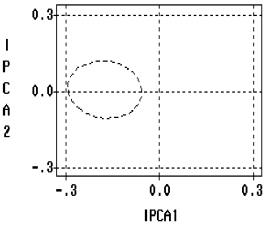

193

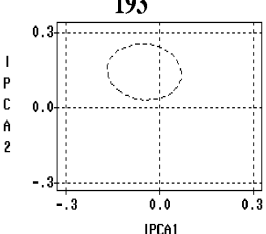

197

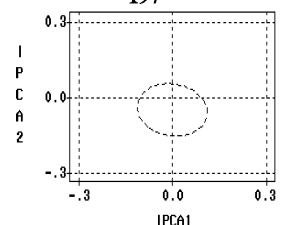

201

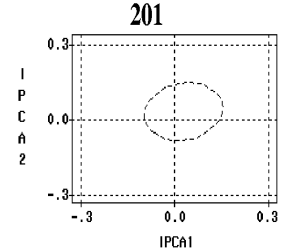

190

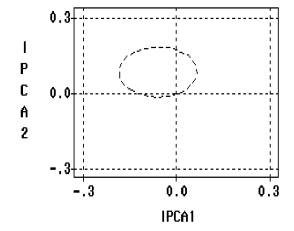

194

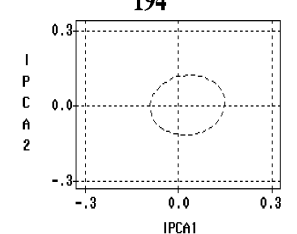

198

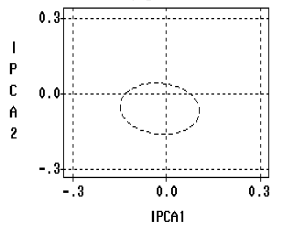

202

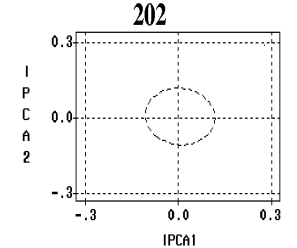

Figura 6 - Regiões de confiança de $99 \%$ para os escores de genótipos, para dados de altura, em metros, de E. grandis aos 5 anos. Procedência, $12 \mathrm{~km} \mathrm{S.} \mathrm{of}$ Ravenshoe-Mt Pandanus-QLD (14.420) 

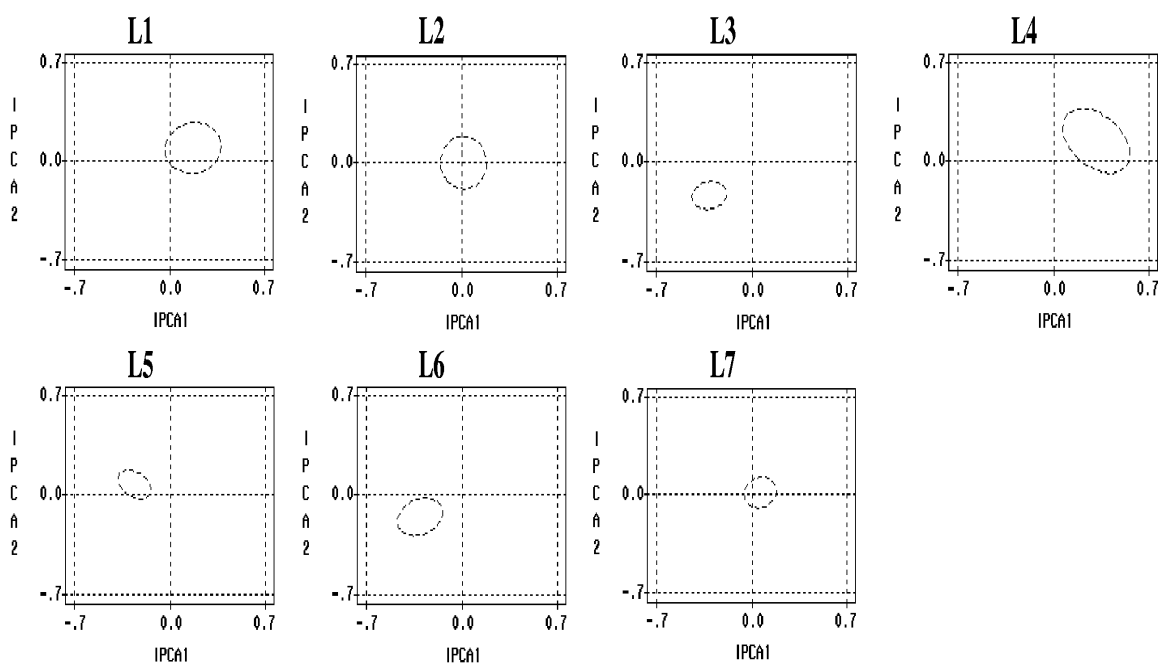

Figura 7 - Regiões de confiança de $99 \%$ para os escores de ambientes, para dados de altura, em metros, de E. grandis aos 5 anos. Procedência, $12 \mathrm{~km} \mathrm{S.} \mathrm{of}$ Ravenshoe-Mt Pandanus-QLD (14.420)

No que diz respeito à avaliação da estabilidade, a análise "bootstrap" AMMI apresentou seus resultados com maior clareza e facilidade, o que permitiu uma interpretação da estabilidade sem margens de suposições, isto é, foi mais eficiente do que a interpretação gráfica feita pelo modelo tradicional, para o biplot $\mathrm{AMMI}_{2}$.

Os resultados apresentados pela análise "bootstrap" AMMI estiveram mais coerentes com aqueles verificados pelos testes de Eberhart \& Russel (1966) e de Wricke (1962), apresentados para esse mesmo conjunto de dados, e onde, os genótipos 184, 189 e 191 apresentaram-se como instáveis (Lavoranti et al., 2001a).

Ficou evidenciado, pelas Figuras 6 e 7, que a análise de estabilidade pela metodologia AMMI com representação gráfica em biplot, apenas apresentaram falta de estabilidade àqueles genótipos ou ambientes que tiveram suas coordenadas $\left(\mathrm{IPCA}_{1}, \mathrm{IPCA}_{2}\right)$ ambas distanciadas de zero ou muito distante do IPCA 1 . Casos fáceis para verificar isso, foram para os genótipos 196 e 201 e ambiente L1 (Figura 
3), que apresentaram $\mathrm{IPCA}_{1}$ próximo de zero e $\mathrm{IPCA}_{2}$ o mais distante de zero, mesmo assim, apresentaram-se estáveis. Por outro lado, os genótipos 191, 193 e 195 e os ambientes L3 e L4 (Figura 3), por apresentarem escores (IPCA 1 e IPCA 2$)$ distantes de zero, foram aqueles que se apresentaram instáveis. Verificou-se também que as estabilidades são mais influenciadas pelo eixo $\mathrm{IPCA}_{1}$, isto é, quanto mais afastados de zero em relação ao eixo $\mathrm{IPCA}_{1}$, mais instáveis são os genótipos e os ambientes. Pode-se verificar isso pelas Figuras 3 e 6, nas quais, os genótipos 184 e 189 e os ambientes L5 e L6, apresentaram maiores distâncias em relação ao IPCA 1 e, praticamente nula em relação ao eixo $\mathrm{IPCA}_{2}$ e apresentaram-se como instáveis.

Diante dessas observações, suspeita-se que as regiões de maiores instabilidades têm as coordenadas $\left(\mathrm{IPCA}_{1}, \mathrm{IPCA}_{2}\right)$, localizadas na reta que passa pela origem, com inclinação de $45^{\circ}$. Trata-se portanto, das bissetrizes aos quadrantes um e três e dois e quatro, do gráfico cartesiano $\mathrm{IPCA}_{1} \times \mathrm{IPCA}_{2}$. Embora sendo muito difícil a definição de quem são os eixos $\mathrm{IPCA}_{1}$ e IPCA $\mathrm{IP}_{2}$, suspeita-se, por essas observações, que sejam ambientes $\left(\mathrm{IPCA}_{1}\right) \times$ genótipos $\left(\mathrm{IPCA}_{2}\right)$. Se assim o forem, existe uma forte concordância com as metodologias de Finlay \& Wilkinson (1963) e Eberhart \& Russel (1966), e implica que as curvas de regressão para cada genótipo tenham um ponto de concorrência comum (Mandel, 1961). Assim, mais pesquisas devem ser conduzidas visando dar uma luz a esse fenômeno. Em relação a maior influência do $\mathrm{IPCA}_{1}$, isso pode ser explicado em função da análise multivariada por componentes principais reter a maior porcentagem da variância explicada no primeiro eixo principal (Johnson \& Wichern, 1998). Assim como a maior concentração do "padrão" de variação, devido a interação, está concentrada no IPCA (Gauch, 1988).

Observou-se através das Figuras 6 e 7, que as regiões de confiança, para a estabilidade tiveram níveis diferentes de inclusão do vetor nulo. Então, foram determinadas as regiões "bootstrap" de predição para o vetor nulo, e, a partir dos valores ordenados dos coeficientes "bootstrap" para a estabilidade (Tabela 25), foi possível proceder as classificações das estabilidades. 
Table 25. Classificações das estabilidades, para dados de altura, em metros, de $E$. grandis aos 5 anos. Procedência, 12 km S. of Ravenshoe-Mt PandanusQLD (14.420)

\begin{tabular}{|c|c|c|c|c|c|c|c|c|c|c|c|}
\hline \multirow[b]{2}{*}{ Gen } & \multicolumn{3}{|c|}{ Consistente } & \multirow[b]{2}{*}{ Gen } & \multicolumn{3}{|c|}{ Alta } & \multirow[b]{2}{*}{ Gen } & \multicolumn{3}{|c|}{ Média } \\
\hline & Média & $\mathrm{DP}$ & $\mathrm{CBE}$ & & Média & $\mathrm{DP}$ & $\mathrm{CBE}$ & & Média & $\mathrm{DP}$ & $\mathrm{CBE}$ \\
\hline 185 & 17,04 & 6,67 & 0,140 & 186 & 16,42 & 3,48 & 0,075 & 194 & 17,24 & 3,60 & 0,065 \\
\hline \multirow[t]{5}{*}{199} & 17,74 & 3,47 & 0,090 & 188 & 16,87 & 3,65 & 0,075 & 198 & 17,42 & 3,40 & 0,065 \\
\hline & & & & 202 & 15,89 & 3,34 & 0,075 & 201 & 15,06 & 3,11 & 0,060 \\
\hline & & & & 192 & 17,65 & 2,93 & 0,070 & & & & \\
\hline & & & & 197 & 17,10 & 2,63 & 0,070 & & & & \\
\hline & \multicolumn{3}{|c|}{ Baixa } & & \multicolumn{3}{|c|}{ Instável } & & & & \\
\hline Gen & Média & DP & $\mathrm{CBE}$ & Gen & Média & $\mathrm{DP}$ & $\mathrm{CBE}$ & & & & \\
\hline 183 & 18,59 & 3,77 & 0,050 & 184 & 17,86 & 3,62 & 0,065 & & & & \\
\hline 187 & 15,93 & 3,42 & 0,050 & 193 & 17,05 & 3,35 & 0,065 & & & & \\
\hline 200 & 17,11 & 3,03 & 0,050 & 195 & 16,87 & 3,58 & 0,055 & & & & \\
\hline 190 & 18,11 & 3,60 & 0,045 & 191 & 17,18 & 3,85 & 0,035 & & & & \\
\hline \multirow[t]{2}{*}{196} & 17,87 & 3,71 & 0,045 & 189 & 15,37 & 3,09 & 0,015 & & & & \\
\hline & \multicolumn{3}{|c|}{ Alta } & & \multicolumn{3}{|c|}{ Baixa } & & \multicolumn{3}{|c|}{ Instável } \\
\hline Amb & Média & DP & $\mathrm{CBE}$ & $\mathrm{Amb}$ & Média & $\mathrm{DP}$ & $\mathrm{CBE}$ & Amb & Média & $\mathrm{DP}$ & $\mathrm{CBE}$ \\
\hline L2 & 22,68 & 1,31 & 0,110 & L7 & 13,39 & 0,97 & 0,025 & L5 & 12,75 & 0,96 & 0,045 \\
\hline \multirow[t]{3}{*}{ L1 } & 16,67 & 0,93 & 0,095 & & & & & L6 & 18,55 & 1,12 & 0,020 \\
\hline & & & & & & & & L3 & 16,88 & 1,07 & 0,010 \\
\hline & & & & & & & & L4 & 18,21 & 1,53 & 0,000 \\
\hline
\end{tabular}

Gen: genótipos; Amb: ambientes; DP: desvio padrão e CBE: coeficiente "bootstrap" de estabilidade. 
Conforme já discutido, os genótipos estáveis mostraram-se amplamentes adaptados aos ambientes ensaiados. Assim, para fins de recomendação e seleção, a exceção dos genótipos 186, 187, 188, 201 e 202 que apresentaram desempenho médio, em altura, inferior à média geral dos genótipos, todos deverão compor o conjunto de genótipos de comportamento geral, indicados por estabilidade, para estudos de segunda geração. Merece um destaque especial o genótipo 199 que apresenta altura média superior a média geral e estabilidade consistente, o que caracteriza um forte candidato a seleção para fins de melhoramento genético. Observou-se pelas classificações que as maiores alturas médias (genótipos 183, 190 e 196) tiveram as menores classificações em termos de estabilidade. Isso exige do melhorista alguns cuidados na seleção de árvores superiores altamente produtivas, porém com baixa estabilidade. Para os genótipos instáveis, os dados confirmam as adaptações específicas, ou seja, para o local Barra Ribeiro-RS (L1), os genótipos: 193, 195 e 191; para o local Telêmaco Borba-PR (L2), os genótipos: 184 e 189; para o local Boa Esperança do Sul-SP (L3), o genótipo: 193; para o local Guanhães-MG (L4), os genótipos: 191 e 195; para o local Ipatinga-MG (L5), os genótipos: 191, 189 e 195; para o local Aracruz-ES (L6), os genótipos: 184, 193 e 195 e, finalmente, para o local Caçapava-SP (L7), os genótipos: 189, 193, 195, 191, e 184. Todas as demais combinações foram desfavoráveis, devido ao fator negativo da interação $\mathrm{G} \times \mathrm{E}$.

Para efeito de estudos de segunda geração os ambientes, Telêmaco Borba-PR (L2) e Barra Ribeiro-RS (L1) devem promover as maiores confiabilidades das posições dos genótipo (postos) em cada ambiente, em relação à classificação para a média dos ambientes testados. Então, o teste de materiais genéticos em L1 e L2 deve produzir um grau mais consistente e fidedigno para recomendação de material genético. Como o ambiente L2 apresentou média maior, em altura, deveria ser preferido para estudos de segunda geração. 


\subsubsection{Procedência, Baldy State Forest 194-Atherton-QLD}

A análise da interação $\mathrm{G} \times \mathrm{E}$ pela ACP e Gollob (1968), mostrou que os três primeiros eixos ( $\mathrm{IPCA}_{1}, \mathrm{IPCA}_{2}$ e IPCA $\mathrm{IPC}_{3}$ ) foram significativos, com $\mathrm{p}<0,01$ (Tabela 16). Esses eixos explicaram $77,23 \%$ da $S Q_{G \times E}$. Dessa forma, os valores estimados seguiram o modelo $\mathrm{AMMI}_{3}$ (Tabela 26).

Tabela 26. Alturas médias, em metros, de E. grandis aos 5 anos, estimadas pelo modelo $\mathrm{AMMI}_{3}$. Procedência, Baldy State Forest 194-Atherton-QLD $(14.423)$

\begin{tabular}{cccccccc}
\hline & \multicolumn{7}{c}{ Ambientes } \\
\cline { 2 - 7 } Genótipos & 1 & 2 & 3 & 4 & 5 & 6 & 7 \\
\hline 269 & 15,76 & 22,73 & 15,91 & 19,41 & 12,73 & 17,85 & 13,61 \\
270 & 16,57 & 21,94 & 17,42 & 18,27 & 12,08 & 17,45 & 12,80 \\
271 & 16,75 & 23,04 & 16,58 & 19,07 & 11,80 & 18,06 & 13,37 \\
272 & 18,93 & 23,33 & 19,72 & 20,29 & 13,50 & 18,39 & 14,26 \\
273 & 14,77 & 20,38 & 16,86 & 16,28 & 12,10 & 17,01 & 11,78 \\
274 & 16,58 & 23,25 & 16,51 & 19,80 & 12,70 & 18,20 & 13,91 \\
275 & 16,73 & 23,24 & 16,62 & 18,60 & 11,63 & 18,60 & 13,35 \\
276 & 18,86 & 25,00 & 18,39 & 20,69 & 12,98 & 19,90 & 14,99 \\
277 & 15,47 & 22,66 & 15,62 & 18,46 & 12,06 & 18,16 & 13,22 \\
278 & 15,94 & 21,67 & 16,77 & 18,66 & 12,45 & 16,97 & 12,86 \\
292 & 17,14 & 23,98 & 16,95 & 19,61 & 12,60 & 19,23 & 14,22 \\
293 & 16,15 & 22,61 & 16,50 & 16,35 & 10,37 & 18,92 & 12,29 \\
294 & 16,06 & 22,76 & 16,29 & 19,00 & 12,43 & 18,07 & 13,47 \\
295 & 17,16 & 22,70 & 18,20 & 19,60 & 13,63 & 18,15 & 13,93 \\
296 & 14,40 & 21,54 & 16,15 & 17,78 & 13,61 & 18,05 & 13,15 \\
297 & 19,22 & 24,64 & 19,02 & 20,42 & 12,82 & 19,59 & 14,71 \\
298 & 14,48 & 21,84 & 14,94 & 16,43 & 10,79 & 18,07 & 12,09 \\
299 & 18,56 & 24,38 & 18,17 & 20,70 & 12,86 & 19,04 & 14,63 \\
300 & 17,58 & 24,21 & 16,78 & 20,62 & 12,48 & 18,69 & 14,41 \\
301 & 16,93 & 21,90 & 17,07 & 18,63 & 11,16 & 16,66 & 12,47 \\
302 & 15,01 & 20,36 & 16,88 & 14,75 & 10,46 & 17,38 & 10,97 \\
303 & 16,77 & 23,19 & 16,78 & 20,29 & 13,13 & 17,96 & 14,09 \\
304 & 15,47 & 21,80 & 16,55 & 17,73 & 12,33 & 17,80 & 12,78 \\
305 & 18,44 & 23,73 & 19,40 & 19,68 & 13,69 & 19,44 & 14,47 \\
306 & 17,53 & 23,42 & 19,18 & 18,14 & 13,65 & 20,23 & 14,13 \\
\hline
\end{tabular}


A partir do conjunto de dados apresentados na Tabela 26, determinouse a matriz de resíduos $\left(\widehat{G E}_{14.423}\right)$, a qual foi denominada de matriz de resíduo livre de "ruídos":

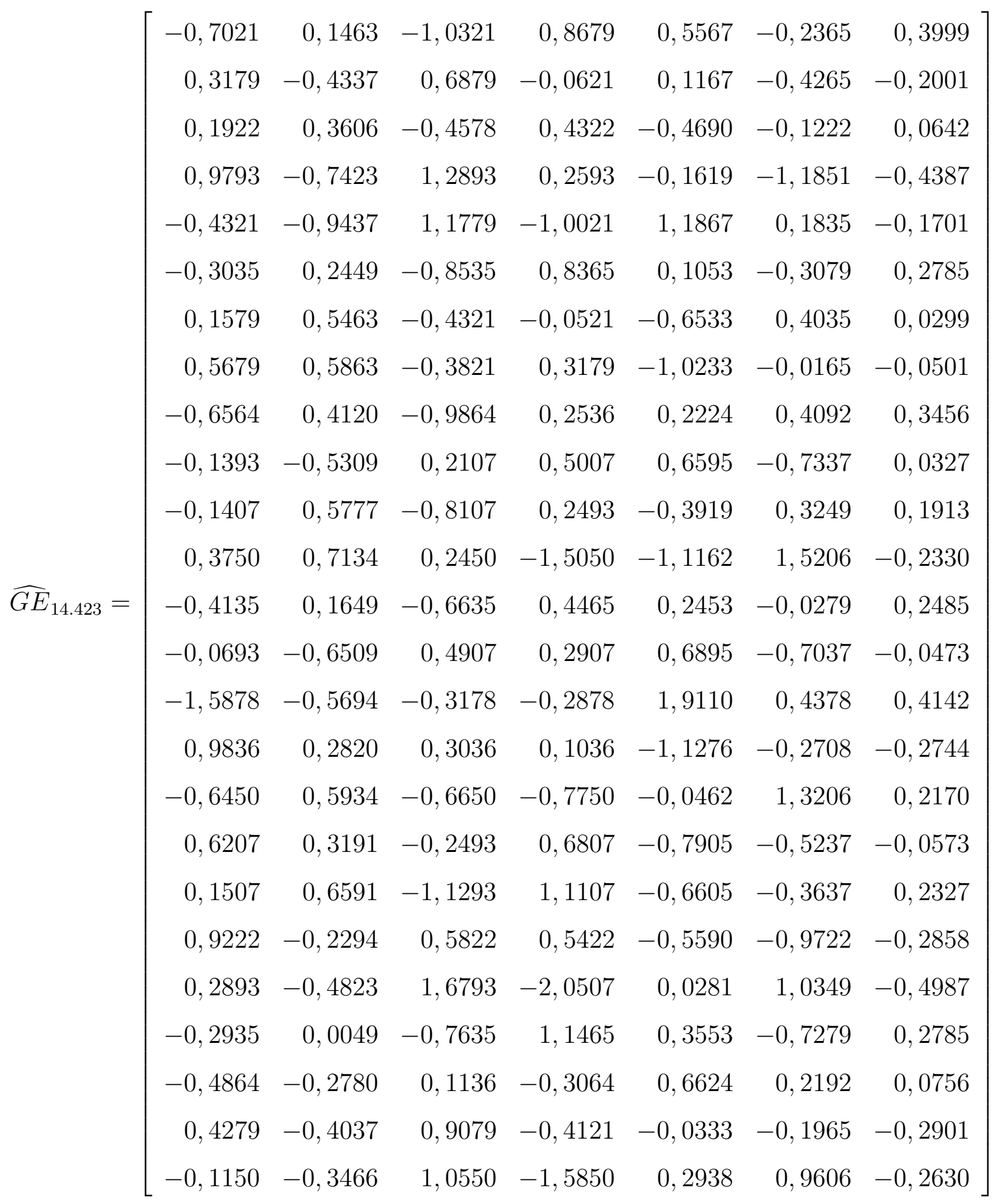


Sobre a matriz $\widehat{G E}_{14.423}$ foram processadas as reamostragens "bootstrap".

De acordo com a metodologia "bootstrap" AMMI proposta, a análise da estabilidade de genótipos (Figura 8) e de ambiente (Figura 9), permitiram identificar como instáveis os genótipos: 300, 302 e 306; assim como, os ambientes: Telêmaco Borba-PR (L2), Boa Esperança do Sul-SP (L3), Guanhães-MG (L4), e Aracruz-ES (L6). Todos esses, não continham o ponto de coordenadas nulas $(0,0)$ incluídas na região de confiança, para o vetor "bootstrap" de médias.

Os resultados apresentados pela análise "bootstrap" AMMI reduziram, consideravelmente, o número de genótipos instáveis quando comparados com a metodologia AMMI tradicional (de 14 para 4). A análise "bootstrap" AMMI, também apresentou comportamento diferenciado daquele observado pelos testes de Eberhart \& Russel (1966) e de Wricke (1962), apresentados para esse mesmo conjunto de dados, em que, os genótipos 272, 273, 293, 296, 302, 305 e 306 apresentaram-se como instáveis (Lavoranti et al., 2001a).

A análise da estabilidade via "bootstrap" AMMI, foi mais rigorosa para a indicação de instabilidade, quando comparadas com a metodologia AMMI tradicional. Pode-se acreditar que a metodologia "bootstrap" AMMI apresenta maior confiança nas informações fornecidas, uma vez que, essa técnica trabalhou com um conjunto da amostras "bootstrap" muito superior (200 vezes maior) aos utilizados para a tradicional análise AMMI.

Confirmando as observações feitas, aqui, para a procedência anterior, ficou evidenciado, pelas Figuras 8 e 9, que a estabilidade pela metodologia tradicional AMMI, com representação gráfica em biplot $\left(\mathrm{AMMI}_{2}\right)$, apenas apresentam falta de estabilidade para aqueles genótipos ou ambientes que têm coordenadas $\left(\mathrm{IPCA}_{1}\right.$, $\mathrm{IPCA}_{2}$ ) distantes de zero, localizadas próximos às retas que passam pela origem, com inclinação de $45^{\circ}$ ou muito distantes de zero, em relação ao eixo $\mathrm{IPCA}_{1}$. Isso pode ser verificado pela Figura 10, na qual, os ambientes L2, L3, L5 e L6, assim como o genótipo 300, estão próximos a essas retas, e o ambiente L4, e os genótipos 302 e 
306 estão mais afastados de zero em relação ao $\mathrm{IPCA}_{1}$.
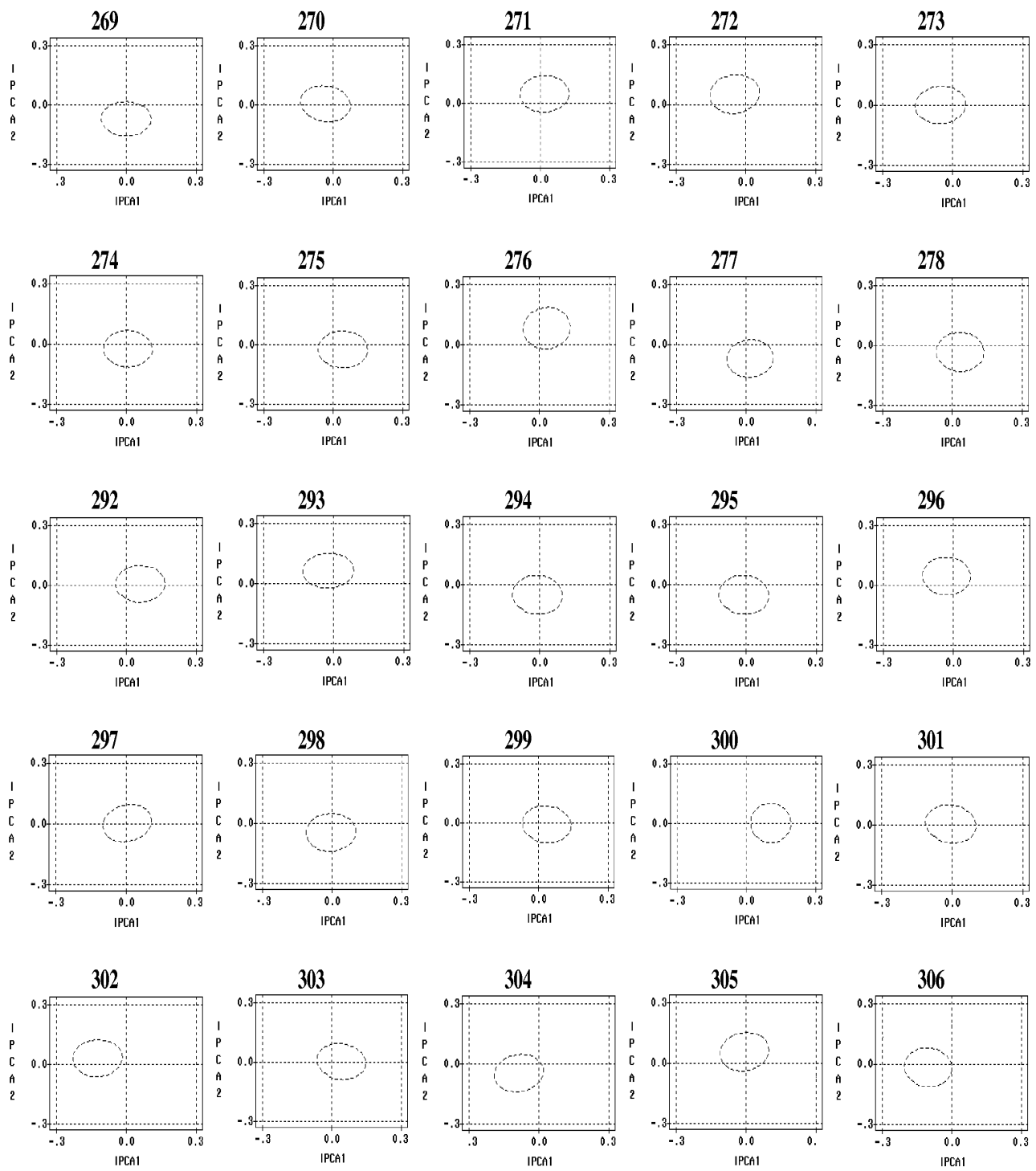

Figura 8 - Regiões de confiança de $99 \%$ para os escores de genótipos, para dados de altura, em metros, de E. grandis aos 5 anos. Procedência, Baldy State Forest 194-Atherton-QLD (14.423) 

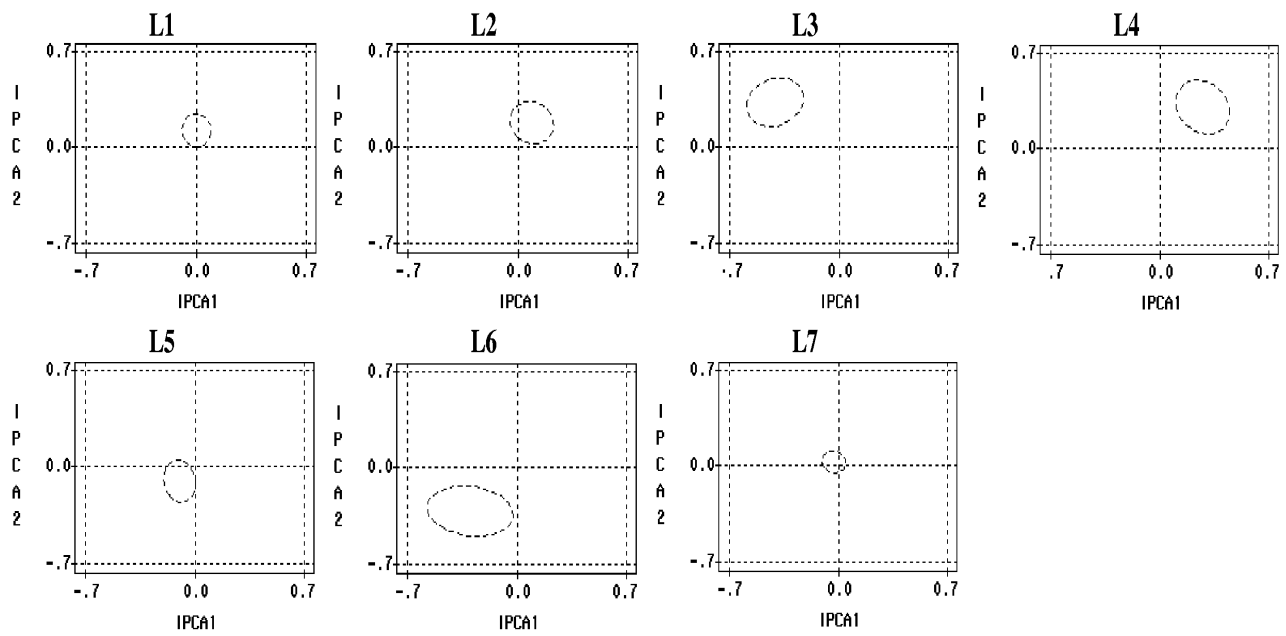

Figura 9 - Regiões de confiança de $99 \%$ para os escores de ambientes, para dados de altura, em metros, de E. grandis aos 5 anos. Procedência, Baldy State Forest 194-Atherton-QLD (14.423)

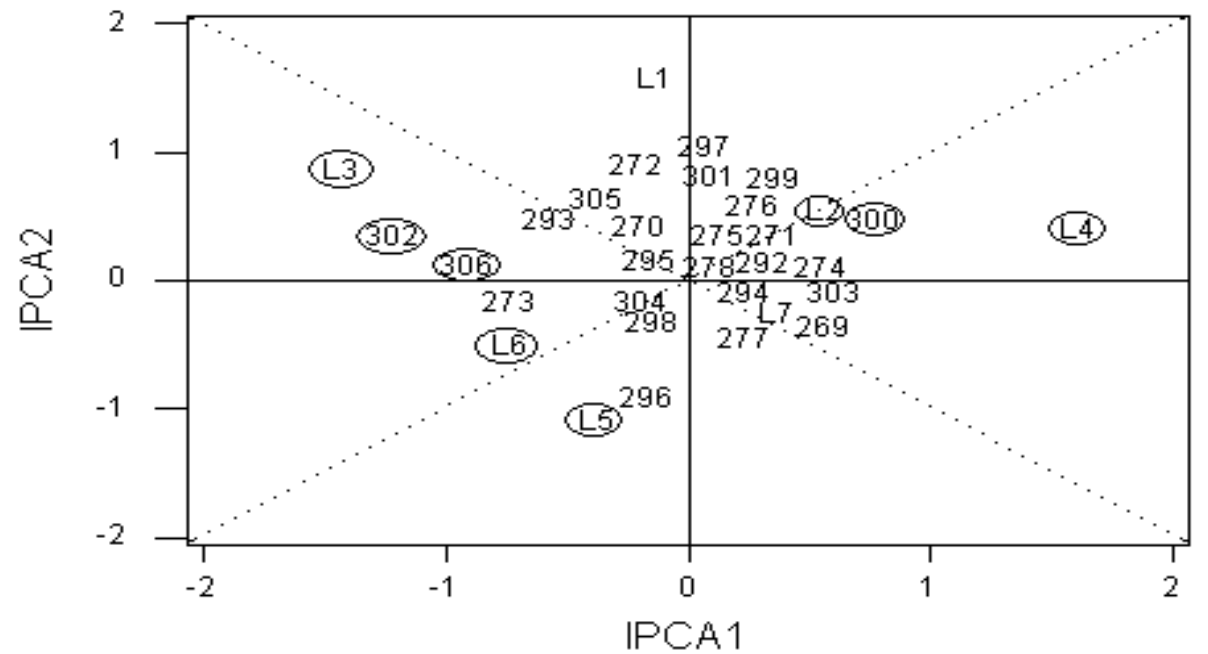

Figura 10 - Biplot $\mathrm{AMMI}_{2}$, para genótipos e ambientes, dos dados de altura, em metros, de E. grandis aos 5 anos. Procedência, Baldy State Forest 194Atherton-QLD (14.423) 
Observou-se através das Figuras 8 e 9, que as regiões de confiança para a estabilidade tiveram níveis diferentes de inclusão do vetor nulo. E, principalmente em relação aos escores de ambientes, foi verificada uma dispersão maior para os locais Boa Esperança do Sul-SP (L3), Guanhães-MG (L4) e Aracruz-ES (L6) em relação aos demais ambientes, sendo que, o local Caçapava-SP (L7) foi o que apresentou menor variância. Esses resultados confirmam o alto valor de F (Tabela 16) observado para o fator ambiente dessa procedência, o que permitiu inferir que os ambientes têm maior influência para a variabilidade, em altura, do que os genótipos, e provavelmente, o efeito da interação $\mathrm{G} \times \mathrm{E}$, foi mais influenciado por esse fator.

A partir dos valores ordenados dos coeficientes "bootstrap" para a estabilidade (Tabela 27), obtidos a partir das regiões "bootstrap" de predição para o vetor nulo, foi possível proceder as classificações das estabilidades.

Os genótipos estáveis mostraram-se amplamentes adaptados aos ambientes ensaiados. Assim, para fins de recomendação e seleção, os genótipos 276 e 297 apresentaram os maiores desempenhos médio, em altura, e estabilidade consisteste. Assim, estão entre os fortes candidatos à seleção para fins de melhoramento genético. Entretanto, todos os genótipos com desempenhos superiores a média geral (17,09 metros) e estabilidades alta e média, deverão compor o conjunto de genótipos de comportamento geral, indicados por estabilidades, para estudos de segunda geração.

Em relação à adaptabilidade dos genótipos instáveis, foram verificadas as melhores combinações para o genótipo 300, os ambientes Barra Ribeiro-RS (L1), Guanhães-MG (L4), Ipatinga-MG (L5) e Aracruz-ES (L6); para o genótipo 302, os ambientes L4, L5, L6 e Caçapava-SP (L7); e para o genótipo 306, os ambientes L2, L3, L4 e L7. Todas as demais combinações foram desfavoráveis devido ao fator negativo da interação $\mathrm{G} \times \mathrm{E}$. 
Table 27. Classificações das estabilidades, para dados de altura, em metros, de $E$. grandis aos 5 anos. Procedência, Baldy State Forest 194-Atherton-QLD $(14.423)$

\begin{tabular}{|c|c|c|c|c|c|c|c|c|c|c|c|}
\hline \multirow[b]{2}{*}{ Gen } & \multicolumn{3}{|c|}{ Consistente } & \multicolumn{5}{|c|}{ Alta } & \multicolumn{3}{|c|}{ Média } \\
\hline & Média & $\mathrm{DP}$ & $\mathrm{CBE}$ & Gen & Média & $\mathrm{DP}$ & $\mathrm{CBE}$ & Gen & Média & $\mathrm{DP}$ & $\mathrm{CBE}$ \\
\hline 276 & 18,69 & 3,98 & 0,085 & 269 & 16,86 & 3,57 & 0,065 & 293 & 16,17 & 3,92 & 0,050 \\
\hline 297 & 18,63 & 3,84 & 0,085 & 272 & 18,35 & 3,32 & 0,065 & 305 & 18,41 & 3,91 & 0,050 \\
\hline \multirow[t]{6}{*}{301} & 16,40 & 3,72 & 0,075 & 278 & 16,47 & 3,08 & 0,065 & 271 & 16,95 & 3,71 & 0,045 \\
\hline & & & & 295 & 17,62 & 3,15 & 0,060 & 294 & 16,87 & 3,43 & 0,045 \\
\hline & & & & 273 & 15,60 & 2,79 & 0,055 & 299 & 18,33 & 3,67 & 0,045 \\
\hline & & & & 275 & 16,97 & 3,61 & 0,055 & & & & \\
\hline & & & & 292 & 17,68 & 3,57 & 0,055 & & & & \\
\hline & \multicolumn{3}{|c|}{ Baixa } & & \multicolumn{3}{|c|}{ Instável } & & & & \\
\hline Gen & Média & $\mathrm{DP}$ & $\mathrm{CBE}$ & Gen & Média & $\mathrm{DP}$ & $\mathrm{CBE}$ & & & & \\
\hline 270 & 16,65 & 3,46 & 0,040 & 306 & 18,04 & 3,39 & 0,050 & & & & \\
\hline 274 & 17,28 & 3,60 & 0,040 & 302 & 15,12 & 3,64 & 0,045 & & & & \\
\hline 296 & 16,38 & 2,87 & 0,040 & 300 & 17,82 & 4,08 & 0,035 & & & & \\
\hline 303 & 17,46 & 3,35 & 0,040 & & & & & & & & \\
\hline 304 & 16,35 & 3,52 & 0,040 & & & & & & & & \\
\hline 277 & 16,52 & 3,85 & 0,025 & & & & & & & & \\
\hline \multirow[t]{2}{*}{298} & 15,52 & 3,78 & 0,025 & & & & & & & & \\
\hline & \multicolumn{3}{|c|}{ Alta } & & \multicolumn{3}{|c|}{ Média } & & \multicolumn{3}{|c|}{ Baixa } \\
\hline Amb & Média & $\mathrm{DP}$ & $\mathrm{CBE}$ & Amb & Média & $\mathrm{DP}$ & $\mathrm{CBE}$ & $\mathrm{Amb}$ & Média & $\mathrm{DP}$ & $\mathrm{CBE}$ \\
\hline \multirow[t]{2}{*}{$\mathrm{L} 7$} & 13,44 & 7,55 & 0,145 & L1 & 16,69 & 8,94 & 0,080 & L5 & 12,40 & 8,36 & 0,045 \\
\hline & \multicolumn{3}{|c|}{ Instável } & & & & & & & & \\
\hline Amb & Média & $\mathrm{DP}$ & $\mathrm{CBE}$ & & & & & & & & \\
\hline L3 & 17,17 & 7,33 & 0,100 & & & & & & & & \\
\hline L2 & 22,81 & 5,71 & 0,065 & & & & & & & & \\
\hline L4 & 18,77 & 8,40 & 0,030 & & & & & & & & \\
\hline L6 & 18,32 & 5,14 & 0,025 & & & & & & & & \\
\hline
\end{tabular}

Gen: genótipos; Amb: ambientes; DP: desvio padrão e CBE: coeficiente "bootstrap" de estabilidade. 
Em função da estabilidade, os ambientes, Barra Ribeiro-RS (L1) e Caçapava-SP (L7), com estabilidade alta e média, devem promover as maiores confiabilidades das posições dos genótipo (postos) em cada ambiente, em relação à classificação para a média dos ambientes testados. Então, o teste de materiais genéticos em L1 e L7 devem produzir um grau mais consistente e fidedigno para recomendação de material genético. Entretanto, foi observado para esses ambientes, baixas alturas médias, o que de certo modo, é um fator desmotivante para estudos de segunda geração nesses locais. Pela Figura 9, foi observado que o local Telêmaco Borba-PR (L2) tem coeficiente "bootratap" de estabilidade (CBE) de classificação média, pela análise dos quartis, e sua região de confiança está com boa aproximação do ponto de coordenadas nulas. Assim, pode ser vantajosa a realização de estudos de segunda geração nesse ambiente. Porém, o mesmo não pode ser dito do local Aracruz-ES (L6), que, embora tenha apresentado altura média superior a média geral, sua região de confiança está longe do vetor nulo e apresenta CBE baixo.

\subsubsection{Procedência, Bellthorpe St. Forest-QLD.}

A análise da interação G×E pela ACP e Gollob (1968), mostrou que os três primeiros eixos ( $\mathrm{IPCA}_{1}, \mathrm{IPCA}_{2}$ e IPCA $\mathrm{IPC}_{3}$ ) foram significativos, com $\mathrm{p}<0,05$ (Tabela 17). Em relação ao nível de significância, vale ressaltar que, com a utilização de $1 \%$ em vez de 5\%, reduz-se a probabilidade de ocorrer o erro tipo I, isto é, de aceitar um modelo AMMI com mais número de eixos, quando na verdade o modelo correto é menos parametrizado. Ademais, um modelo preditivo, geralmente tem menor número de termos do que o número julgado significativo por um teste. Assim, uma estratégia no sentido de selecionar um modelo preditivo é aumentar o rigor dos testes, reduzindo o seu nível de significância (Oliverira et al., 2003). Então, em virtude da utilização do modelo de Gollob (1968), conhecidamente menos rigoroso na seleção de modelos AMMI, foi utilizado o nível de $1 \%$ de probabilidade, o que implicou na utilização do modelo $\mathrm{AMMI}_{2}$. Esse modelo explicou 57,76\% da $S Q_{G \times E}$ e foi utilizado para estimar as alturas médias (Tabela 28). 
Tabela 28. Alturas médias, em metros, de E. grandis aos 5 anos, estimadas pelo modelo $\mathrm{AMMI}_{2}$. Procedência, Bellthorpe St. Forest-QLD (14.431)

\begin{tabular}{cccccccc}
\hline & \multicolumn{6}{c}{ Ambientes } \\
\cline { 2 - 8 } Genótipos & 1 & 2 & 3 & 4 & 5 & 6 & 7 \\
\hline 662 & 17,22 & 23,84 & 17,84 & 20,27 & 12,90 & 18,79 & 13,79 \\
663 & 14,68 & 19,43 & 15,14 & 15,75 & 11,24 & 17,85 & 14,10 \\
664 & 14,67 & 22,80 & 18,21 & 19,72 & 13,14 & 18,59 & 14,32 \\
665 & 16,17 & 23,27 & 17,77 & 19,86 & 12,81 & 18,56 & 13,83 \\
666 & 16,05 & 22,96 & 17,87 & 19,57 & 13,07 & 18,91 & 14,44 \\
667 & 18,67 & 24,50 & 18,16 & 20,75 & 13,40 & 19,53 & 14,40 \\
668 & 17,81 & 23,14 & 17,40 & 19,37 & 12,94 & 19,28 & 14,56 \\
669 & 18,10 & 23,49 & 16,97 & 19,62 & 12,30 & 18,57 & 13,36 \\
670 & 18,10 & 22,94 & 16,48 & 18,98 & 12,00 & 18,46 & 13,34 \\
671 & 17,80 & 24,13 & 18,33 & 20,54 & 13,55 & 19,54 & 14,70 \\
672 & 18,68 & 23,79 & 17,65 & 19,93 & 13,16 & 19,55 & 14,60 \\
673 & 18,81 & 23,92 & 17,76 & 20,05 & 13,27 & 19,66 & 14,70 \\
674 & 18,09 & 23,61 & 17,23 & 19,79 & 12,56 & 18,80 & 13,67 \\
675 & 17,23 & 22,89 & 17,18 & 19,18 & 12,63 & 18,86 & 14,13 \\
676 & 18,46 & 23,29 & 17,11 & 19,37 & 12,71 & 19,18 & 14,23 \\
677 & 17,14 & 22,97 & 17,27 & 19,30 & 12,67 & 18,84 & 14,10 \\
678 & 17,95 & 23,21 & 17,06 & 19,37 & 12,53 & 18,87 & 13,90 \\
679 & 17,01 & 23,39 & 18,01 & 19,87 & 13,31 & 19,31 & 14,71 \\
680 & 19,41 & 24,60 & 17,96 & 20,68 & 13,33 & 19,67 & 14,41 \\
681 & 18,04 & 23,56 & 17,36 & 19,77 & 12,73 & 18,98 & 13,95 \\
682 & 14,67 & 18,66 & 14,61 & 14,87 & 11,01 & 17,88 & 14,35 \\
683 & 16,55 & 21,56 & 15,97 & 17,75 & 11,66 & 18,11 & 13,52 \\
684 & 17,48 & 22,49 & 16,64 & 18,64 & 12,27 & 18,70 & 13,95 \\
685 & 15,65 & 19,88 & 14,73 & 15,98 & 10,78 & 17,52 & 13,28 \\
686 & 15,49 & 22,72 & 17,52 & 19,38 & 12,58 & 18,30 & 13,74 \\
\hline & & & & & & &
\end{tabular}

A partir do conjunto de dados apresentados na Tabela 28, determinouse a matriz de resíduos $\left(\widehat{G E}_{14.431}\right)$, a qual foi denominada de matriz de resíduos livre de "ruídos": 


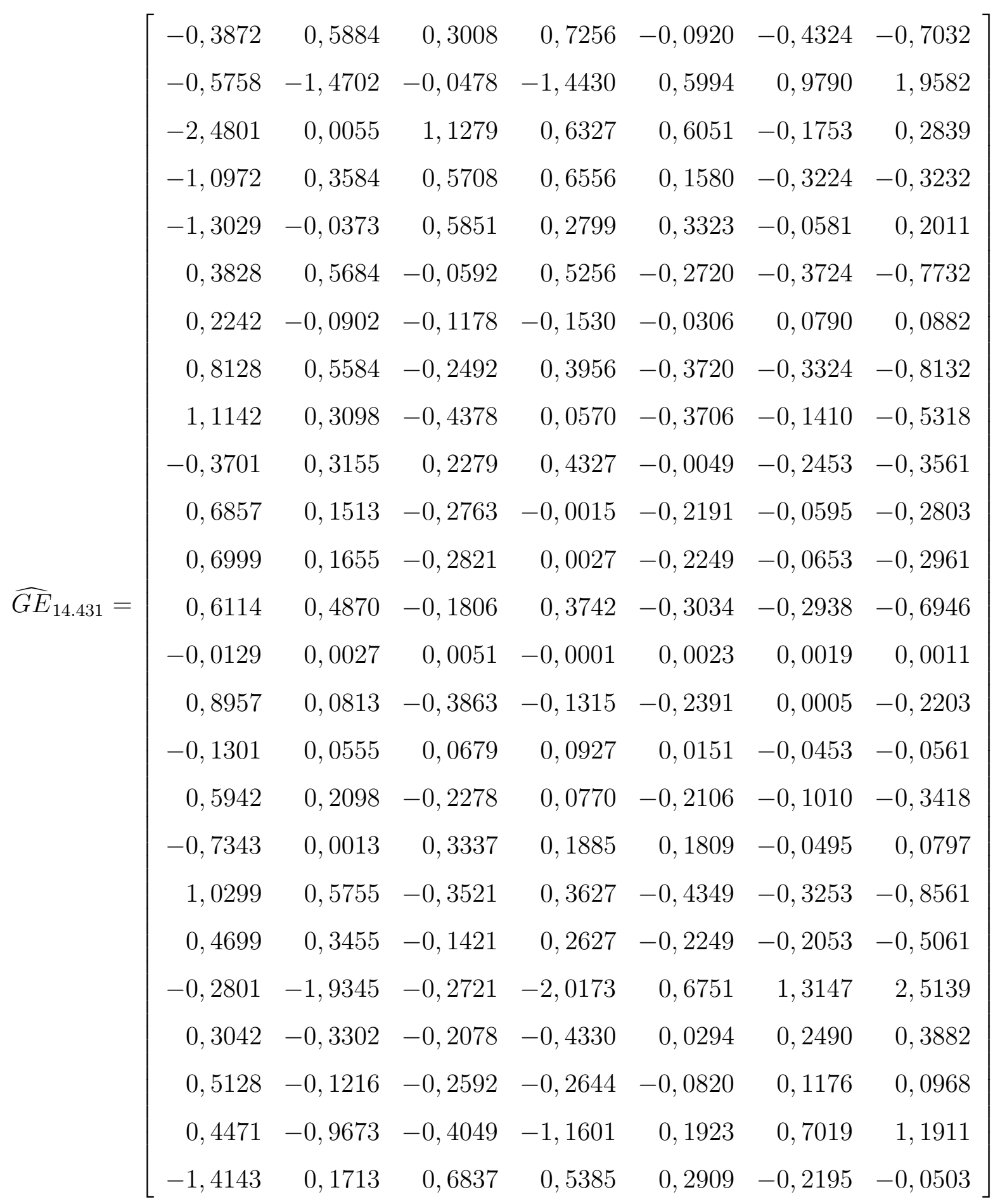

Sobre a matriz $\widehat{G E}_{14.431}$ foram processadas as reamostragens "bootstrap". 
De acordo com a metodologia "bootstrap" AMMI proposta, as análises da estabilidade de genótipos (Figura 11), permitiram identificar como instáveis os genótipos: 663, 664, 682 e 685. Esses resultados corroboraram com aqueles verificados pelos testes de Eberhart \& Russel (1966), e de Wricke (1962), apresentados para esse mesmo conjunto de dados (Lavoranti et al., 2001a). Em relação à estabilidade de ambientes (Figura 12), verificou-se que, à exceção do local Boa Esperança do SulSP (L3), todos apresentaram-se como instáveis, isto é, não continham o ponto de coordenadas nulas $(0,0)$ incluídas na região de confiança para o vetor "bootstrap" de médias. Semelhante às procedências anteriores, os escores "bootstrap" de ambientes apresentaram maior divergência em termos de variância para as regiões de confiança.

Confirmando as observações feitas para as procedências anteriores, ficou evidenciado, pelas Figuras 11 e 12, que a região de estabilidade via representação gráfica em biplot $\left(\mathrm{AMMI}_{2}\right)$, apenas apresentaram-se como instáveis para aqueles genótipos ou ambientes que tinham coordenadas $\left(\mathrm{IPCA}_{1}, \mathrm{IPCA}_{2}\right)$ distantes de zero, localizadas próximas as retas que passam pela origem, com inclinação de $45^{\circ}$, ou muito distantes de zero em relação ao eixo $\operatorname{IPCA}_{1}$ (Figura 13).

A partir dos valores ordenados dos coeficientes "bootstrap" para a estabilidade (Tabela 29), obtidos a partir das regiões "bootstrap" de predição para o vetor nulo, foi possível proceder as classificações das estabilidades.

Dentre os genótipos melhores classificados, com estabilidades consitente e alta, destacaram-se com melhores desempenhos, em altura, os genótipos: 678, 667, 680, 668, 672, 662, 665 e 677. Assim, na seleção de árvores superiores com alta estabilidade e produtividade (altura), esses genótipos estão entre os fortes candidatos à seleção.

Em relação à estabilidade de ambientes, somente o local Boa Esperança do Sul-SP (L3) apresentou estabilidade, e foi classificado como consistente. Observou-se, também que o local Ipatinga-MG (L5), foi o que apresentou o maior coeficiente "bootstrap" de estabilidade, e sua região de confiança esta próximo das coordenadas nulas. Entretanto, apresenta uma altura média muito baixa, o que 
torna inviável sua recomendação para efeito de testes de segunda geração. Assim, embora com média inferior à média geral, o ambiente L3, deve promover as maiores confiabilidades das posições dos genótipo (postos) em cada ambiente, em relação à classificação para a média dos ambientes testados.
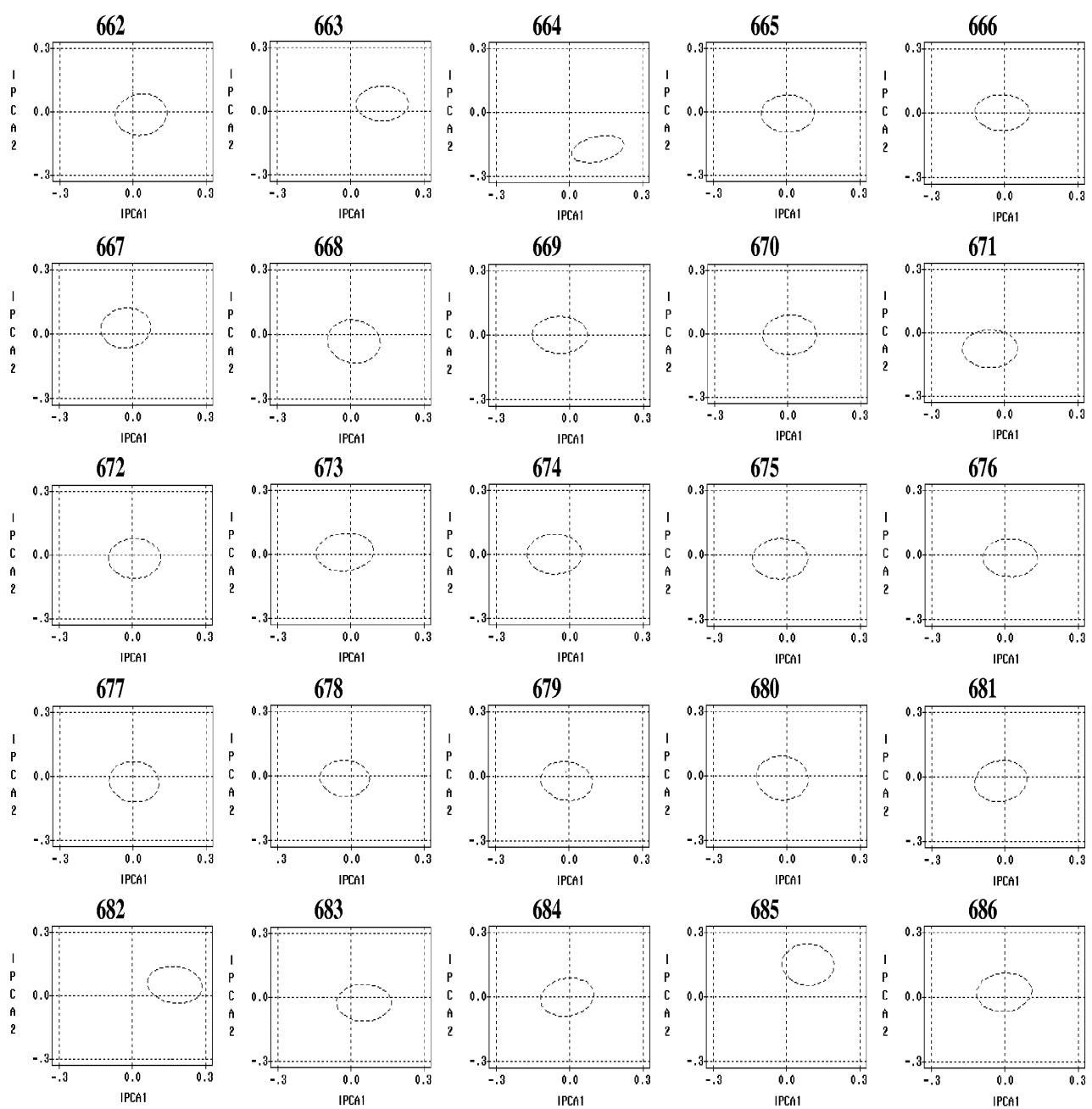

Figura 11 - Regiões de confiança de 99\% para os escores de genótipos, para dados de altura, em metros, de E. grandis aos 5 anos. Procedência, Bellthorpe St. Forest-QLD (14.431) 

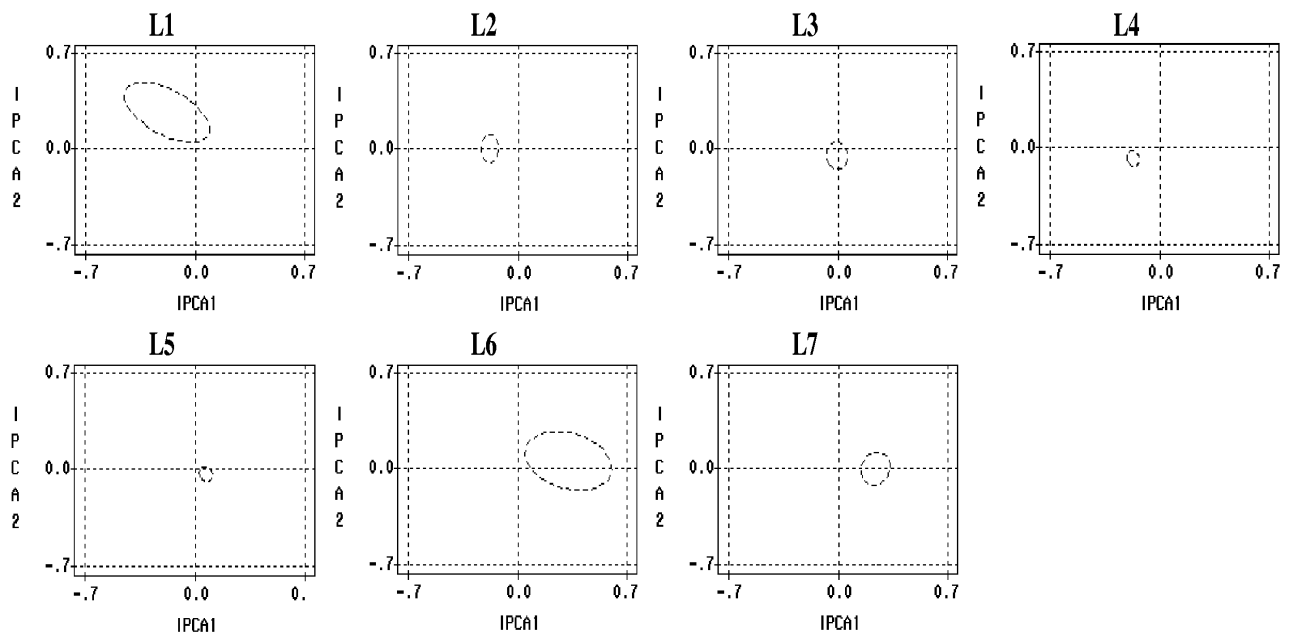

Figura 12 - Regiões de confiança de $99 \%$ para os escores de ambientes, para dados de altura, em metros, de E. grandis aos 5 anos. Procedência, Bellthorpe St. Forest-QLD (14.431)

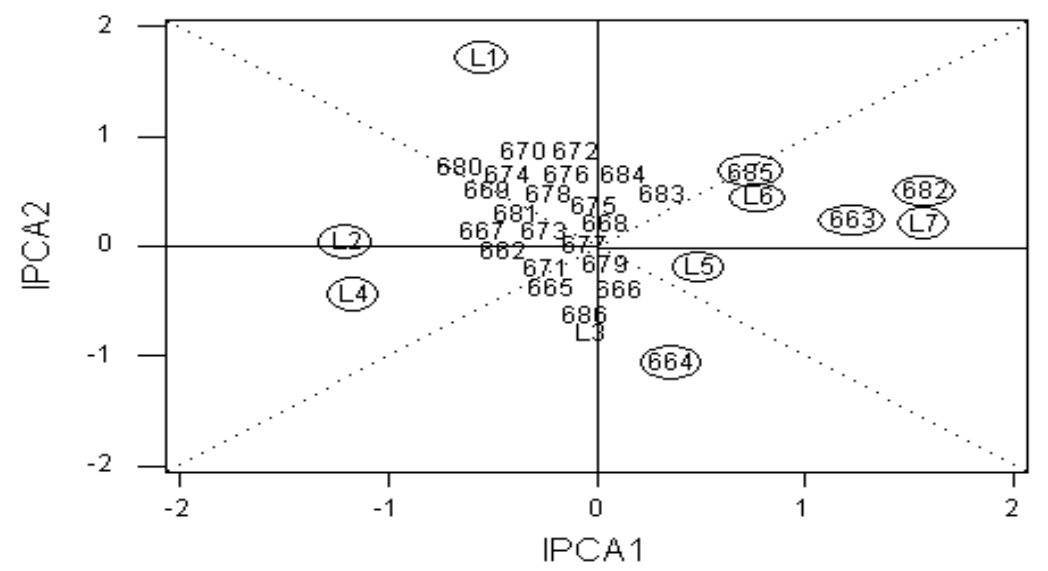

Figura 13 - Biplot $\mathrm{AMMI}_{2}$, para genótipos e ambientes, dos dados de altura, em metros, de E. grandis aos 5 anos. Procedência, Bellthorpe St. ForestQLD (14.431) 
Table 29. Classificações das estabilidades, para dados de altura, em metros, de $E$. grandis aos 5 anos. Procedência, Bellthorpe St. Forest-QLD (14.431)

\begin{tabular}{|c|c|c|c|c|c|c|c|c|c|c|c|}
\hline \multirow[b]{2}{*}{ Gen } & \multicolumn{3}{|c|}{ Consistente } & \multirow[b]{2}{*}{ Gen } & \multicolumn{3}{|c|}{ Alta } & \multirow[b]{2}{*}{ Gen } & \multicolumn{3}{|c|}{ Média } \\
\hline & Média & $\mathrm{DP}$ & CBE & & Média & $\mathrm{DP}$ & $\mathrm{CBE}$ & & Média & $\mathrm{DP}$ & $\mathrm{CBE}$ \\
\hline 678 & 17,55 & 3,43 & 0,150 & 668 & 17,79 & 3,40 & 0,120 & 673 & 18,31 & 3,59 & 0,105 \\
\hline 667 & 18,49 & 3,64 & 0,135 & 683 & 16,45 & 3,15 & 0,120 & 674 & 17,68 & 3,79 & 0,105 \\
\hline 670 & 17,18 & 4,12 & 0,130 & 672 & 18,19 & 3,36 & 0,115 & 681 & 17,77 & 3,76 & 0,105 \\
\hline 686 & 17,11 & 3,66 & 0,130 & 662 & 17,81 & 4,01 & 0,110 & 666 & 17,55 & 3,38 & 0,100 \\
\hline \multirow[t]{3}{*}{680} & 18,58 & 3,68 & 0,125 & 665 & 17,47 & 3,60 & 0,110 & 669 & 17,49 & 3,81 & 0,100 \\
\hline & & & & 677 & 17,47 & 3,38 & 0,110 & & & & \\
\hline & \multicolumn{3}{|c|}{ Baixa } & & \multicolumn{3}{|c|}{ Instável } & & & & \\
\hline Gen & Média & $\mathrm{DP}$ & $\mathrm{CBE}$ & Gen & Média & $\mathrm{DP}$ & $\mathrm{CBE}$ & & & & \\
\hline 675 & 17,44 & 3,45 & 0,095 & 663 & 15,46 & 2,47 & 0,165 & & & & \\
\hline 676 & 17,77 & 3,59 & 0,095 & 664 & 17,35 & 3,64 & 0,125 & & & & \\
\hline 679 & 17,94 & 3,17 & 0,075 & 682 & 15,15 & 2,82 & 0,105 & & & & \\
\hline 671 & 18,37 & 3,43 & 0,070 & 685 & 15,40 & 3,22 & 0,085 & & & & \\
\hline \multirow[t]{2}{*}{684} & 17,17 & 3,49 & 0,065 & & & & & & & & \\
\hline & \multicolumn{3}{|c|}{ Consistente } & & \multicolumn{3}{|c|}{ Instável } & & & & \\
\hline Amb & Média & $\mathrm{DP}$ & $\mathrm{CBE}$ & Amb & Média & $\mathrm{DP}$ & $\mathrm{CBE}$ & & & & \\
\hline \multirow[t]{6}{*}{ L3 } & 17,13 & 1,15 & 0,125 & L5 & 12,58 & 1,00 & 0,140 & & & & \\
\hline & & & & L7 & 14,08 & 0,68 & 0,085 & & & & \\
\hline & & & & L2 & 22,84 & 1,57 & 0,060 & & & & \\
\hline & & & & L4 & 19,13 & 1,65 & 0,050 & & & & \\
\hline & & & & L6 & 18,81 & 0,71 & 0,010 & & & & \\
\hline & & & & L1 & 17,20 & 1,41 & 0,000 & & & & \\
\hline
\end{tabular}

Gen: genótipos; Amb: ambientes; DP: desvio padrão e CBE: coeficiente "bootstrap" de estabilidade. 
Em relação às adaptabilidade dos genótipos instáveis, foram verificadas as melhores combinações para o genótipo 663, os ambientes Telêmaco Borba-PR (L2), Ipatinga-MG (L5) e Aracruz-ES (L6); para o genótipo 664, os ambientes Barra Ribeiro-RS (L1), (L6) e Caçapava-SP (L7); para o genótipo 682, os ambientes Boa Esperança do Sul-SP (L3), Guanhães-MG (L4) e L5; e para o genótipo 685, os ambientes L4, L5 e L7. Todas as demais combinações foram desfavoráveis, devido ao fator negativo da interação $\mathrm{G} \times \mathrm{E}$.

\subsubsection{Considerações sobre as análises "bootstrap" AMMI}

Apesar da versatilidade do modelo "bootstrap" AMMI, mais pesquisas devem ser conduzidas visando o pleno entendimento desse fenômeno, tão intrigante nos programas de melhoramento, que é a interação de genótipos com ambientes. Um dos pontos que merecem estudos mais detalhados é a definição dos níveis de estabilidade, via região de predição para o vetor nulo. Pode-se pensar em outros fatores de correção para a distribuição de Wishart, que sejam menos exigentes e permitam um aumento no coeficiente "bootstrap" de estabilidade (maior proximidade de um), o que caracteriza a estabilidade consistente. Ou ainda, analisar os gráficos de dispersão dos escores "bootstrap".

Nesse sentido, foi realizada uma avaliação mais criteriosa da metodologia "bootstrap" AMMI, envolvendo também, a análise gráfica da dispersão dos escores "bootstrap" de genótipos (Figuras 14, 15 e 16) e de ambientes (Figuras 17, 18 e 19), para os lotes 14.420, 14.423, e 14.431, respectivamente. Nessa avaliação, observou-se que os genótipos apresentaram menor oscilação do que os ambientes, confirmando as magnitudes dos testes $\mathrm{F}$ para esse efeito.

Notou-se que, apesar da região de confiança para a média dos escores, não ter envolvido o vetor nulo para os genótipos 184, 189, 191, 193, 195, 300, 302, 306, 664, 682 e 685, esses não devem ser imediatamente descartados por falta de estabilidade, visto que, apresentaram nuvens de pontos nas proximidades do vetor nulo, e, em muitos casos, com coeficiente "bootstrap" de estabilidade (CBE) maiores 
que aqueles com estabilidade verificadas, pelas regiões de confiança, como é o caso dos genótipos 663 e 664, que teriam classificações de estabilidade consistente, assim como, os genótipos, 184, 193, 302, 306 e 682, que teriam classificações de estabilidade média. Entretanto, o mesmo não pode ser dito para os ambientes onde ficou evidenciada a instabilidade dos locais, Boa Esperança do Sul-SP (L3), Guanhães-MG (L4) e Aracruz-ES (L6) para a lote 14.420; dos locais L4 e L6, para o lote 14.423 e dos locais Barra Ribeiro-RS (L1) e L6 para o lote 14.431.

Dessa forma, reforçam-se as indicações dos locais Telêmaco Borba-PR (L2) e Caçapava-SP (L7), ambientes de alta e baixa produtividade (em altura), respectivamente, como os mais recomendados para os estudos de segunda geração.

Outro fato que deve ser melhor explorado, é o número de eixos que definem o padrão de interação, pela análise AMMI. Foi observado nesse estudo, que o padrão explicado pelos eixos singulares da análise AMMI, via Cornellius et al. (1992), não foi suficiente para captar toda a estrutura da interação $\mathrm{G} \times \mathrm{E}$, pois, ao utilizar-se do processo "bootstrap", contendo, supostamente, todo o padrão (Gollob, 1968), as interpretações das estabilidades foram diferentes.

Vale ressaltar que, a soma de quadrados da interação $\mathrm{G} \times E\left(\mathrm{SQ}_{G \times E}\right)$ é importante para explicar o padrão adjacente à interação $\mathrm{G} \times \mathrm{E}$. Assim, quando se comete o erro tipo II, isto é, de aceitar um modelo AMMI com menor número de eixos, mas cujo modelo correto, seja de fato mais parametrizado, ficam excluídos partes da $\mathrm{SQ}_{G \times E}$, que contêm variações devida aos padrões de interação $\mathrm{G} \times \mathrm{E}$, que são de interesse agronômico. Dessa forma as interpretações de estabilidade ficam comprometidas. Para evitar os riscos desse tipo de erro, recomenda-se utilizar outras técnicas mais precisas para a definição do modelo, como as apresentadas por Dias \& Krzanowski (2003). Assim, combinando-se essas técnicas (seleção de modelos "exatos" e "bootstrap" AMMI) pode-se diagnosticar, com alta qualidade, as estruturas dos efeitos da interação $\mathrm{G} \times \mathrm{E}$ e inferir, seguramente, suas estabilidades e adaptabilidades fenotípicas. 


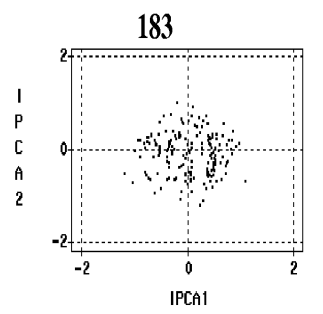

187

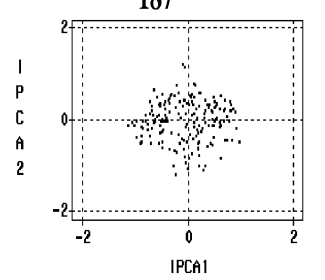

191

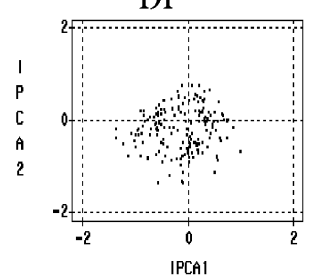

195

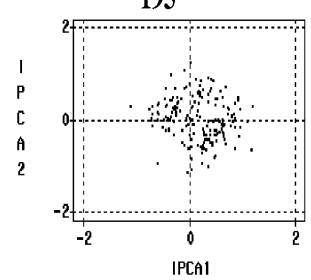

199

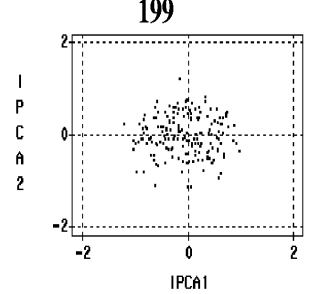

184

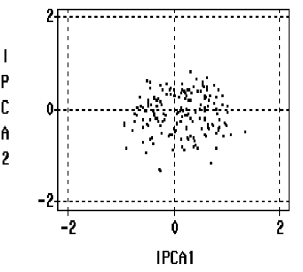

188

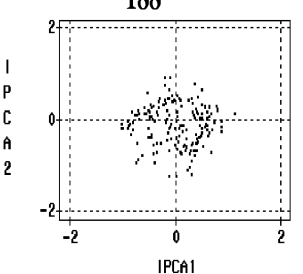

192

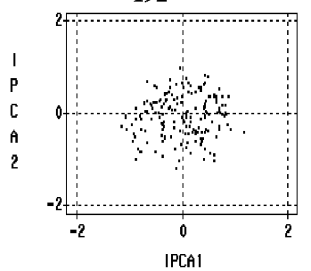

196

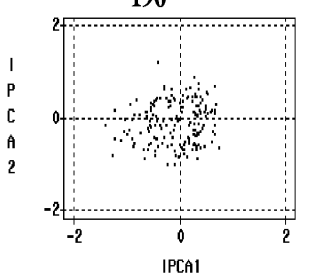

200

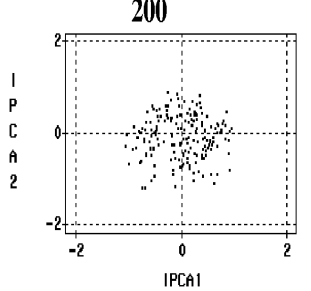

185

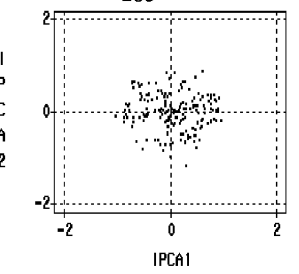

189

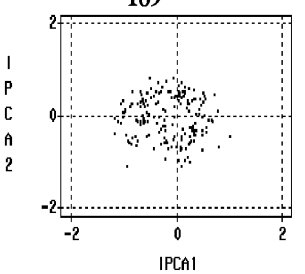

193

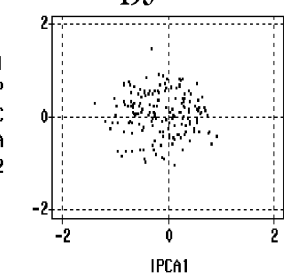

197

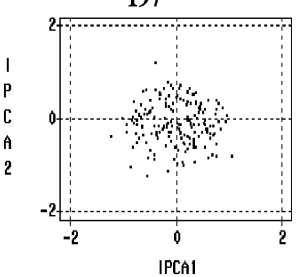

201

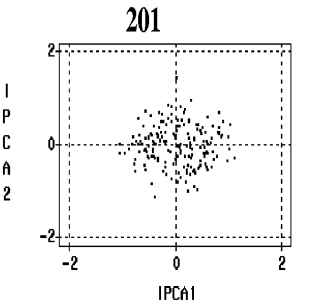

186

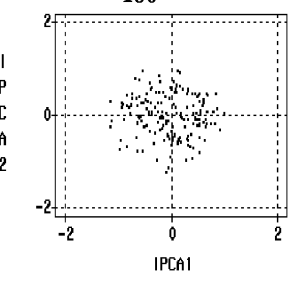

190

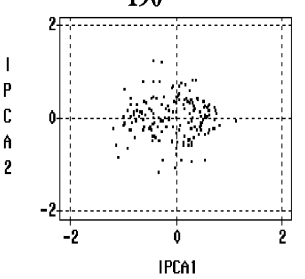

194

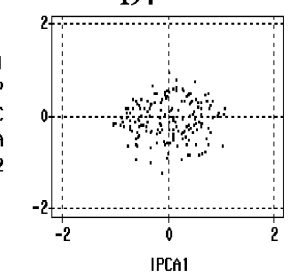

198

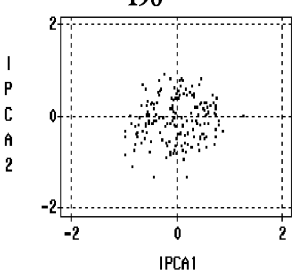

202

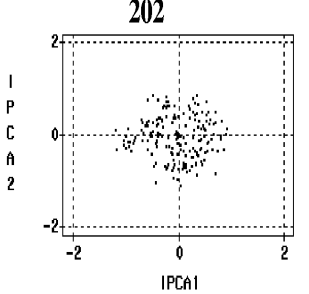

Figura 14 - Gráficos de dispersão dos escores "bootstrap" de genótipos, para dados de altura, em metros, de E. grandis aos 5 anos. Procedência, $12 \mathrm{~km} \mathrm{S.}$ of Ravenshoe-Mt Pandanus-QLD (14.420) 

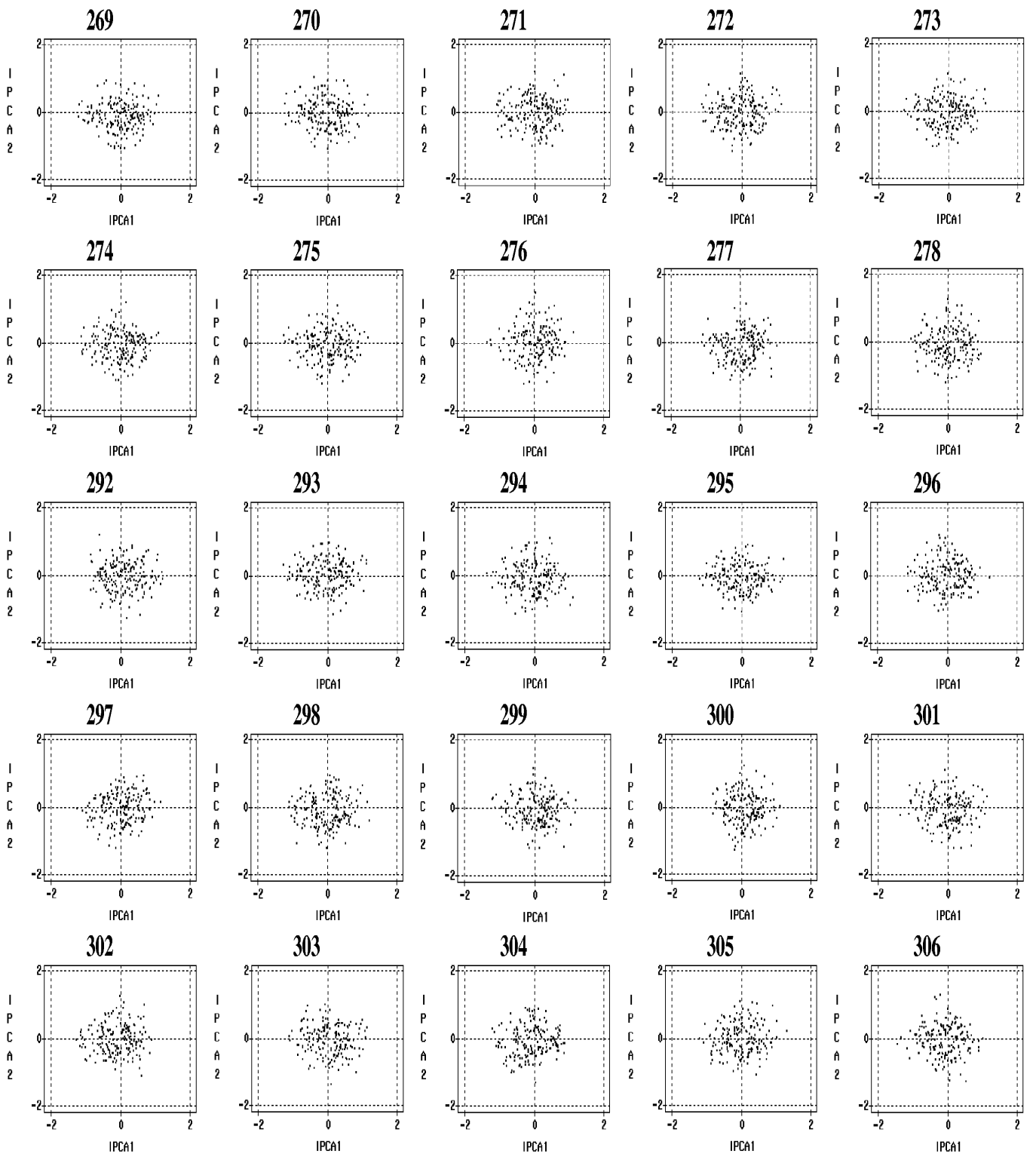

Figura 15 - Gráficos de dispersão dos escores "bootstrap" de genótipos, para dados de altura, em metros, de E. grandis aos 5 anos. Procedência, Baldy State Forest 194-Atherton-QLD (14.423) 

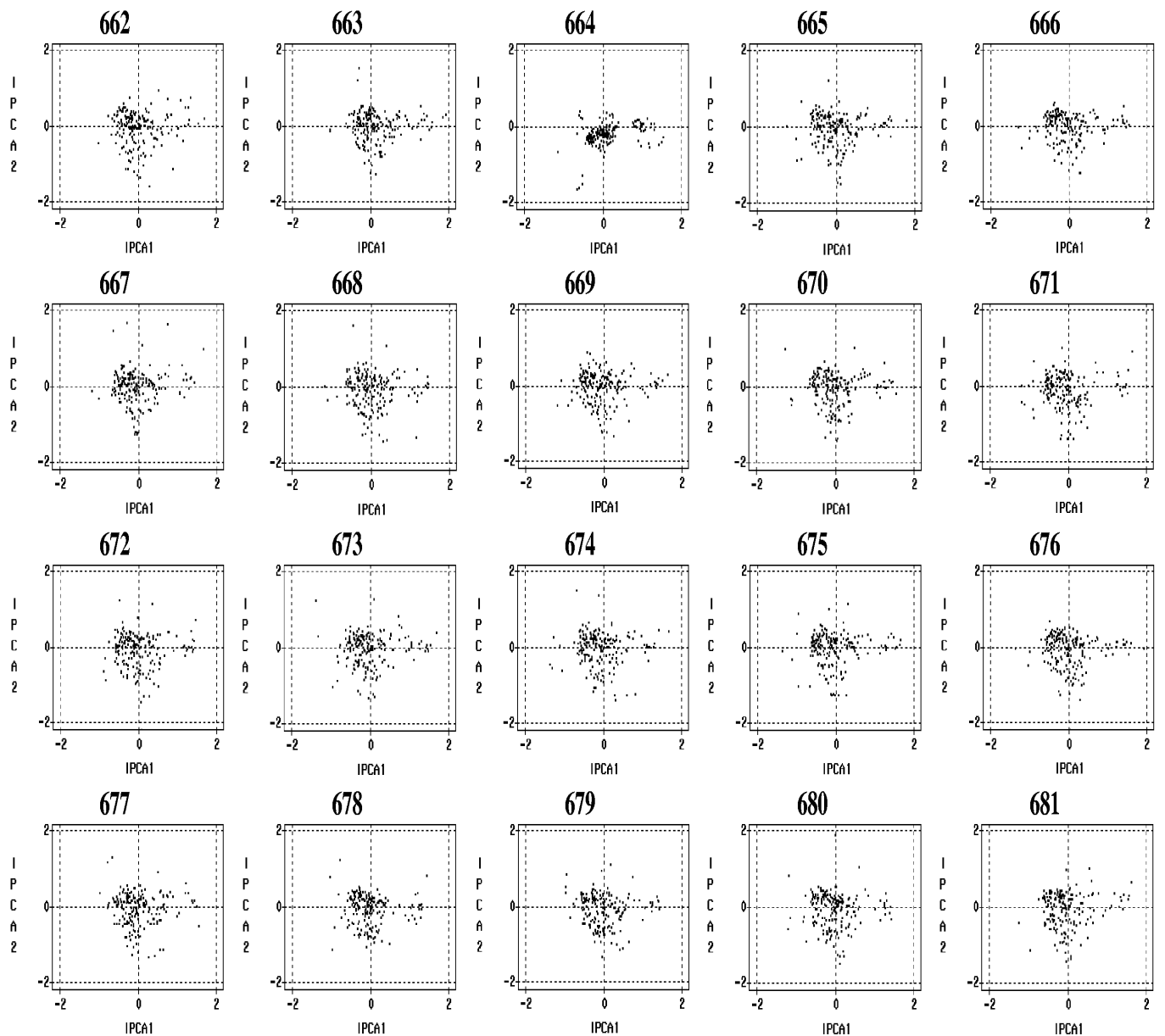

681

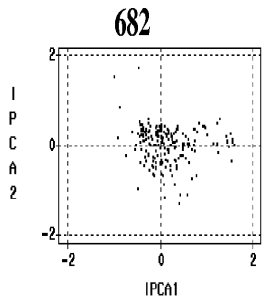

683

684

685
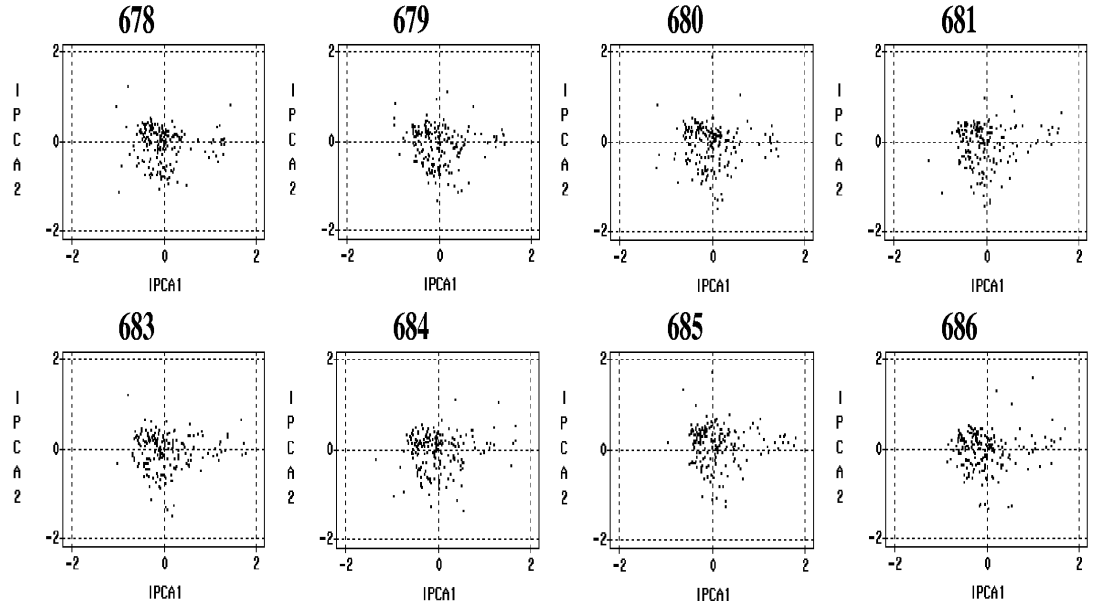

Figura 16 - Gráficos de dispersão dos escores "bootstrap" de genótipos, para dados de altura, em metros, de E. grandis aos 5 anos. Procedência, Bellthorpe St. Forest-QLD (14.431) 

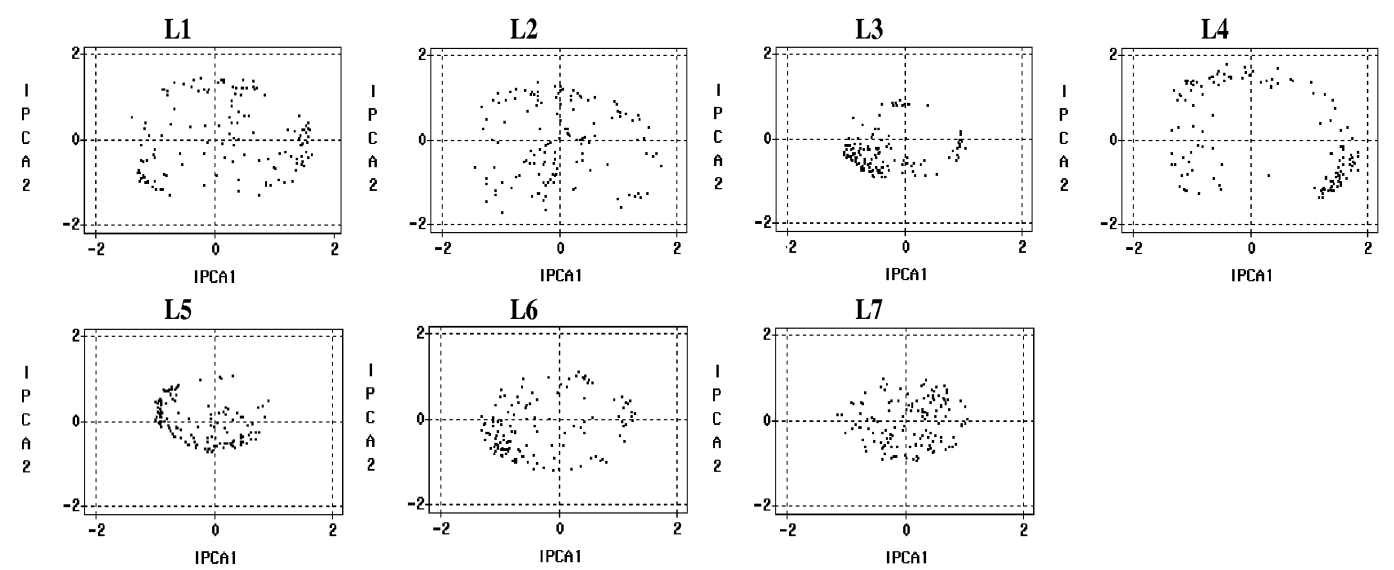

Figura 17 - Gráficos de dispersão dos escores "bootstrap" de ambientes, para dados de altura, em metros, de E. grandis aos 5 anos. Procedência, $12 \mathrm{~km} \mathrm{~S}$. of Ravenshoe-Mt Pandanus-QLD (14.420)
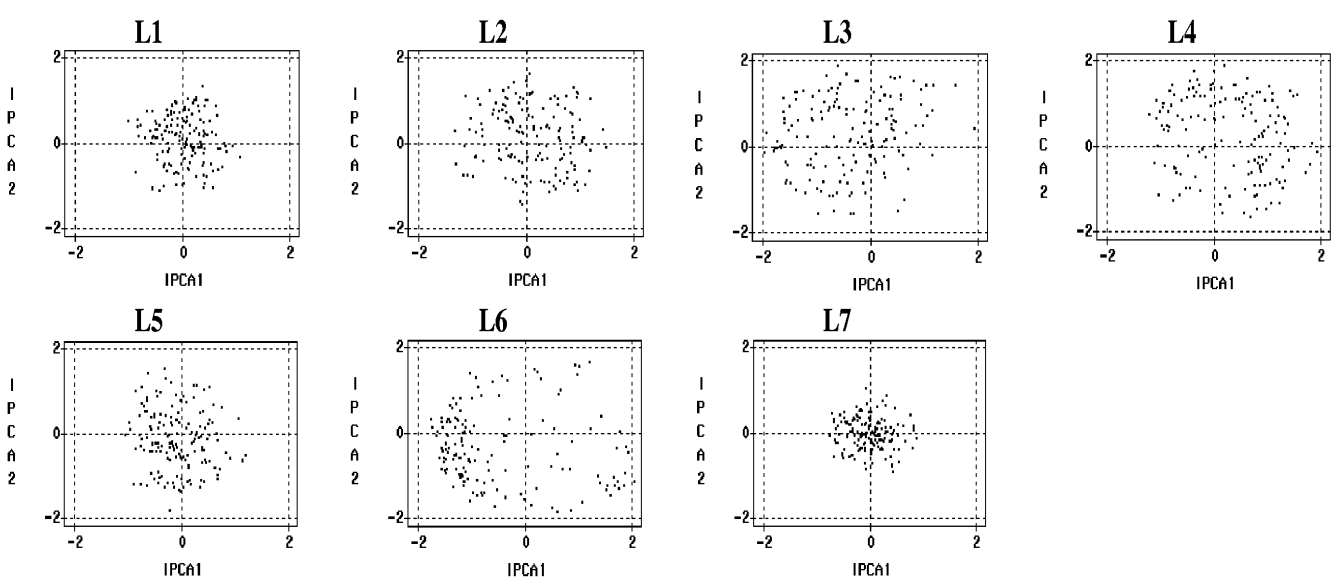

Figura 18 - Gráficos de dispersão dos escores "bootstrap" de ambientes, para dados de altura, em metros, de E. grandis aos 5 anos. Procedência, Baldy State Forest 194-Atherton-QLD (14.423) 

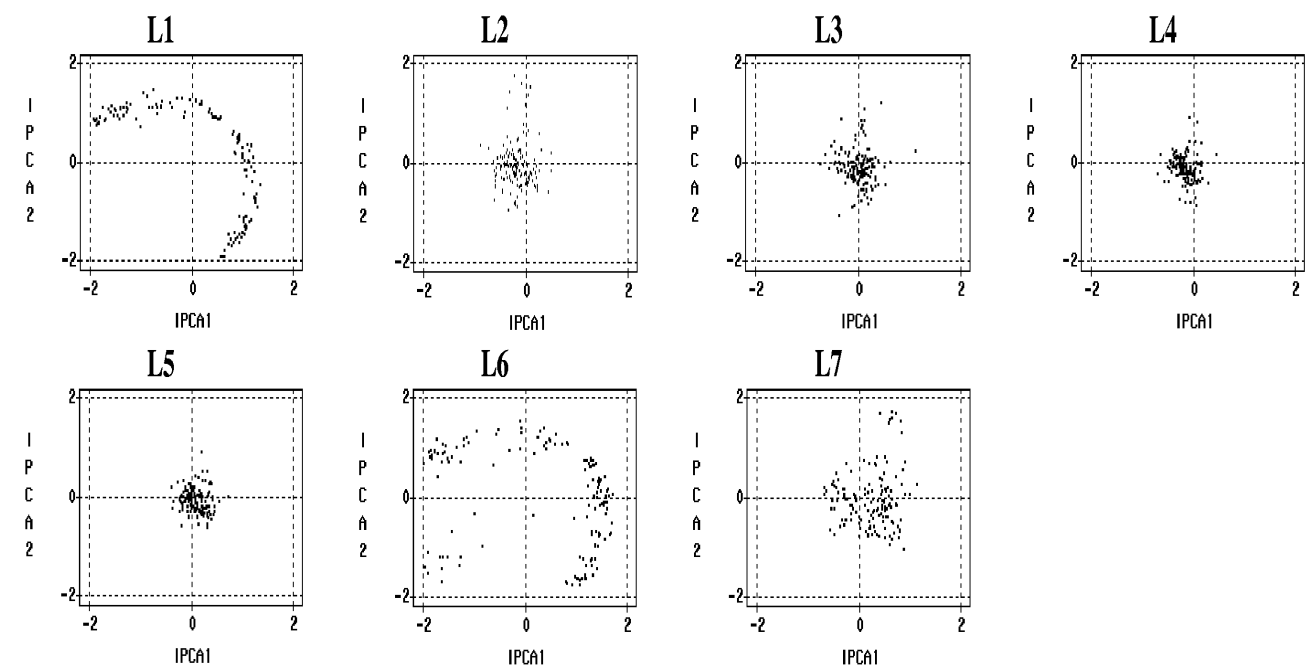

Figura 19 - Gráficos de dispersão dos escores "bootstrap" de ambientes, para dados de altura, em metros, de E. grandis aos 5 anos. Procedência, Bellthorpe St. Forest-QLD (14.431)

De modo geral, observou-se que a metodologia "bootstrap" AMMI, mostrou-se útil para classificar os genótipos e ambientes segundo a suas estabilidades, permitindo que houvesse um maior discernimento entre eles, o que facilita o processo de seleção e recomendação aos produtores de eucalipto.

A interpretação pelos biplots dos escores "bootstrap" AMMI foi suficiente para descrever o comportamento da interação padrão para esse grupo de genótipos e ambientes, sendo que suas relações adaptativas foram melhores interpretadas com o auxílio das médias e interações preditas pelos modelos AMMI selecionados. 
Finalmente, é preciso mensionar que a técnica "bootstrap" AMMI proposta, exige muito esforço computacional. Entretanto, pode ser vantajosa sua utilização quando se deseja alta qualidade na informação sobre a estabilidade fenotípica de genótipos e de ambientes.

Merece um destaque especial, a possibilidade de se estimarem, via técnica "bootstrap", as esperanças dos quadrados médios dos eixos singulares. Dessa forma, os parâmetros genéticos de herdabilidades poderão ser determinados com maior precisão, e assim, as estimativas dos ganhos genéticos devidos à seleção, também terão maior precisão. 


\section{CONCLUSÕES}

Os resultados obtidos nesta pesquisa possibilitaram concluir que:

a) As análises gráficas das regiões "bootstrap" de confiança, juntamente com os coeficientes "bootstrap" de estabilidade e os gráficos de dispersão, permitiram uma interpretação precisa das estabilidades fenotípicas dos genótipos e dos ambientes, envolvidos nesse estudo;

b) A metodologia "bootstrap" AMMI, elimina as dúvidas relacionadas à quantificação dos escores como baixos, tornando a metodologia AMMI mais precisa e confiável, na predição da estabilidade fenotípica de genótipos e de ambientes;

c) O coeficiente "bootstrap" de estabilidade (CBE), baseado na distância quadrada de Mahalanobis, sobre o modelo $\mathrm{AMMI}_{2}$, isto é, envolvendo os escores "bootstrap" ( $\operatorname{IPCA}_{1}$ e IPCA 2 ), obtidos através da região de predição para o vetor nulo, permitiu classificar os genótipos e ambientes em cinco escalas de estabilidade: consistente, alta, média, baixa e instável;

d) Os genótipos 272, 276, 297, 667, 672 e 680 apresentaram estabilidade fenotípica consistente ou alta, e incremento médio anual superior a 3,6 metros por ano, sendo, portanto, os mais indicados para uma recomendação geral, e para estudos de clonagem para plantios comerciais;

e) O local Telêmaco Borba-PR é mais indicado para o teste de linhagens dos genótipos instáveis de alta produtividade, em altura. 


\section{REFERÊNCIAS BIBLIOGRÁFICAS}

ALLARD, R.W.; BRADSHAW, A.D. Implications of genotype environmental interactions in applied plant breeding. Crop Science, v.4, n.5, p.503-508, 1964.

ANDRADE, E.N. de. O eucalypto. 2.ed. Jundiaí: Cia Paulista de Estradas de Ferro, 1961. 665p.

ANNICCHIARICO, P. Additive main effects and multiplicative interaction (AMMI) analysis of genotype-location interaction in variety trials repeated over years. Theoretical and Applied Genetics, v.94, n.8, p.1072-1077, 1997a.

ANNICCHIARICO, P. Joint regression vs AMMI analysis of genotype-environment interactions for cereals in Italy. Euphytica, v.94, n.1, p.53-62, 1997b.

ARAIYO, O.J. use of additive main effects and multiplicative interaction model to analyse multilocation soybean varietal trials. Journal of Genetics \& Breeding, v.53, n.2, p.129-134, 1998.

ATLIN, G.N.; BAKER, R.J.; McRAE, K.B.; LU, X. Selection response in subdividid target regions. Crop Science, v.40, n.1, p.7-13, 2000.

BARNES, R.D. The breeding seedling orchard in a multiple population breeding strategy for tropical trees. In: SIMPÓSIO SOBRE SILVICULTURA E MELHORAMENTO GENÉTICO DE ESPÉCIES FLORETALES, Buenos Aires, 1987. Buenos Aires: Centro de Investigaciones Forestales, 1987. p.81-88.

BECKER, H.C.; LÉON, L. Stability analysis in plant breeding. Plant Breeding, v.101, n.1, p.1-23, 1988. 
BICKEL, P.; FREEDMAN, D. Some asymptotic theory for the bootstrap. Annals of Statistics, v.1, n.9, p.1196-1197, 1981.

BILBRO, J.D.; RAY, L.L. Environmental stability and adaptation of cotton cultivars. Crop Science, v.16, p.821-824, 1976.

BOLAND, D.J.; BROOKER, M.I.H.; CHIPPENDALE, G.M.; HALL, N.; TURNER J.D.; HYLAND, B.P.M.; KLEINING, D.A. Forest trees of Australia. Melborne: CSIRO, 1993. 686p.

BRAKKE, J.P., FRANCIS, C.A, NELSON, L.A, GARDNER, C.O Genotype by cropping sister interactions in maize grow in short season environment. Crop Science, v.23, n.5, p.868-70, 1983.

BRASIL, E.M. Comparação de métodos de controle da interação genótipo $\times$ ambiente em milho (Zea mays L.). Goiânia, 1990. 181p. Dissertação (Mestrado) - Universidade Federal de Goiás.

BRASIL, E.M.; CHAVES, L.J. Utilizacion de un modelo cuadratico para el estudio de la respuesta de cultivares a la variacion ambiental. In: CONGRESSO LATINOAMERICANO DE GENÉTICA, 11., Monterrey, 1994. Memorias. Monterrey: Asociation Latinoamericana de Genetica, 1994. p.616.

BRENNAN, P.S., BYTH, D.E. Genotype x evironmental interactions for wheat yields and selection for wiely adapted wheat genotypes. Australian Journal of Agricultural Research, v.30, n.2, p.221-21, 1979.

BURTON, J.W. Soyabean (Glycine max (L.) Merrill). Field Crops Research, v.53, n.1/3, p.171-186, 1997.

CAMPBELL. L.G., LAFEVER, H.N. cultivar x evironment interactions in soft red wrinter wheat yield test. Crop Science, v.17, n.4, p.604-608, 1977. 
CARNEIRO, P.C.S. Novas metodologias de análise da adaptabilidade e estabilidade de comportamento. Viçosa, 1998. 182p. Tese (Doutorado)- Universidade Federal de Viçosa.

CHAVES, L.J. Interação de genótipos com ambientes. In: NASS, L.L.; VALOIS, A.C.C.; MELO, I.S.; VALADARES-INGLIS, M.C. (Ed.). Recursos genéticos \& melhoramento: plantas. Rondonópolis: Fundação MT, 2001. p.816-858.

CHAVES, L.J.; VENCOVSKY, L; GERALDI, I.O. Modelo não linear aplicado ao estudo da interação genótipo x ambiente em milho. Pesquisa Agropecuária Brasileira, v.24, n.2, p.259-269, 1989.

COCRHRAN, W.G. The combination of estimates from different experiments. Biometrics, v.10, p.101-129, 1954.

COMSTOCK R.E.; MOLL, R. H. Genotype $\times$ environment interactions. Statistical and plant breeding. Bulletin. National Academy of Sciences, v.82, n.2, p.164-196, 1963.

CORNELIUS, P.L. Statistical tests and retention of terms in the additive main effects and multiplicative interaction model for cultivar trials. Crop Science, v.33, n.6, p.1186-1193, 1993.

CORNELIUS, P.L.; CROSSA, J. Prediction assessment of shrinkage estimators of multiplicative model for multi-environment cultivar trials. Crop Science, v.39, n.3, p.998-1009, 1999.

CORNELIUS, P.L.; SEYEDSADR, M.; CROSSA, J. Using the shifted multiplicative model to search for "separability" in crop cultivar trials. Theoretical and Applied Genetics, v.84, n.1-2, p.161-172, 1992. 
CRESSWELL, R.D.; BOURLAY, M.; FLANCLET, A. Vegetative propagation of Eucalyptus. In: BONGA, J.M.; DURZAN, D.J. (Ed.). Tissue culture in forestry. Dordrecht: Martinus Nüyhoff, 1985. cap.6, p.45-72.

CROSSA, J. Statistical analysis of multilocation trials. Advance in Agronomy, v.44, p.55-85, 1990.

CROSSA, J.; FOX, P.N.; PFEIFFER, W.H.; RAJARAM, S.; GAUCH, H.G. AMMI adjustment for statistical analysis of an international wheat yield trial. Theoretical and Applied Genetics, v.81, n.1, p.27-37, 1991.

CRUZ, C.D. Aplicação de algumas técnicas multivariadas no melhoramento de plantas. Piracicaba, 1990. 188p. Tese (Doutorado) - Escola Superior de Agricultura "Luiz de Queiroz", Universidade de São Paulo.

CRUZ, C.D., REGAZZI, A.J. Modelos biométricos aplicados ao melhoramento genético. Viçosa: UFV, 1994. 390p.

CRUZ, C.D.; TORRES, R.A.; VENCOVSKY, R. Na alternative approach to the stability analysis proposed by Silva and Barreto. Revista Brasileira de Genética, v.12, p.567-580, 1989.

DAVIDE, A.C. Avaliação da adaptabilidade e da estabilidade fenotípica de progênies de Eucalyptus pellita F. Murell, indroduzidas da Austrália. Curitiba, 1992. 114p. Tese (Doutorado) - Universidade Federal do Paraná.

DE CAUWER, I.; ORTIZ, R. Analysis of the genotype $\times$ environment interaction in Musa trials. Experimental Agriculture, v.34, p.177-188, 1998.

DIAS, C.T.S.; KRZANOWSKI, W.J. Model selection and cross-validation in additive main effect and multiplicative interaction (AMMI) models. Crop Science, v.43, n.3, p.865-873, 2003.

DICICCIO, T.J.; EFRON, B. Bootstrap confidence interval. Statistical Science, v.11, n.11, p.189-228, 1996. 
DIGBY, P.G.N. Modified joint regression analysis for incomplete variety x environment data. Journal of Agricultural Science, v.93, p.81-86, 1979.

DUARTE, J.B. Aspectos gerais da interação genótipos $\times$ ambientes com ênfase na formação de redes de avaliação (compact disc). In: CONGRESSO BRASILEIRO DE MELHORAMENTO DE PLANTAS, 1., Goiânia, 2001. Resumos. Goiânia: SBPM, 2001.

DUARTE, J.B.; VENCOVSKY, R. Interação genótipo $\times$ ambiente: uma introdução à análise "AMMI". Ribeirão Preto: Sociedade Brasileira de Genética, 1999. 60p. (Série Monografias, 9).

DUARTE, J.B.; ZIMMERMANN, M.J.O. Correlation among yield stability parameters in commom bean. Crop Science, v.35, n.3, p.905-912, 1995.

EBERHART, S.A.; RUSSELL, W.A. Stability parameters for comparing varieties. Crop Science,v.6, n.1, p.36-40, 1966.

EFRON, B. Bootstrap methods: another look at jakknife. Annals of Statistics, v.7, n.1, p.1-26, 1979.

EFRON, B.; STEIN, C. The jackknife estimate of variance. Annals of Statistics, v.9, n.3, p.586-596, 1981.

EFRON, B.; TIBSHIRANI, R.J. Bootstrap methods for standard errors, confidence intervals and other measures of statistical accuracy. Statistical Science, v.1, n.1, p.54-76, 1986.

EFRON, B.; TIBSHIRANI, R.J. An introduction to the bootstrap. London: Chapman \& Hall, 1993. 579p.

ELDRIDGE, K; DAVIDSON,J; HARWOOD, C.; VAN WYK, G. Domestication and breeding. Oxford: Clarendon Press, 1993. p.228-246: Eucalypt domestication and breeding. 
EMPRESA BRASILEIRA DE PESQUISA AGROPECUÁRIA. Pesquisas florestais em andamento no Brasil: terceiro levantamento. Colombo: EMBRAPA, CNPF, 1987. 587p.

FERREIRA, C.A. Nutritional aspects of the management of Eucalyptus plantation on poor sandy soils of the brazilian cerrado region. Oxford, 1989. 193p. Thesis(Ph.D) - Green College, University of Oxford.

FERREIRA, M.; SANTOS, P.E.T. dos. Melhoramento genético florestal dos Eucalyptus no Brasil. Breve histórico e perspectivas. In: IUFRO CONFERENCE ON SULVICULTURE AND IMPROVEMENT OF EUCALYPTUS, Salvador, 1997. Proceedings. Colombo: EMBRAPA, Centro Nacional de Pesquisa de Florestas, 1997. v.1, p.14-34.

FINLAY, K.W.; WILKINSON, G.N. The analysis of adaptation in a Plant-Breeding Programme. Australian Journal of Agricultural Research, v.14,n.5, p.742-754, 1963.

FLORES, F.; MORENO, M.T.; CUBERO, J.I. Genotype-enviromment interaction in faba bean: comparison of AMMI and principal coordinate models. Field Crops Research, v.47, p.117-127, 1996.

FOX. P.N.; CROSSA, J.; ROMAGOSA, I. Multi-environment testing and genotype $\times$ environment interaction. In: KEMPTON, R.A.; FOX, P.N. (Ed.). Statistical methods for plant variety evaluation. New York: Chapman and Hall, 1997. cap.8, p.117-138.

FRANCIS, T.R., KANNENBERG, L.W. Yield stability studies in short-seaso maize. I.A descriptive method for grouping genotypes. Canadian Journal of Plant Science, v.58, n.6, p.1029-34, 1978.

FREEMAN, G.H. Statistical methods for the analysis of genotype-environment interactions. Heredity, v.31, n.3, p.339-54, 1973. 
FURTAdO, M.R.; CARDOSO, A .A .; CRUZ, C.D.; GALVÃO.J.D.; VIEIRA,C. Competição entre linhas de feijoeiros selecionadas em populações segregantes no monucultivo e no consórcio com milho, nos dois sistemas de cultivo. Parte I - Avaliação de linhas selecionadas no monocultivo. In: SIMPÓSIO DA PESQUISA NA UFV, 2., Viçosa, 1990. Resumos. Viçosa: UFV, 1990. p.6869.

GABRIEL, K.R. Le biplot - outil d'exploration de données multidimensionelles. Journal de la Societe Francaise de Statistique, v.143, n.1, p.1-12, 2002.

GABRIEL, K. R. The biplot graphic display of matices with application to principal component analysis. Biometrika, v.58, n.3, p.453-467, 1971.

GALLANT, A.R. Nonlinear statistical models. New York: John Wiley, 1987. $610 \mathrm{p}$.

GAUCH, H.G. Model selection anf validation for yield trails with interaction. Biometrics, v.44, p.705-715, 1988.

GAUCH, H.G. Full and reduced model for yield trials. Theoretical and Applied Genetics, v.80, n.1, p.153-160, 1990.

GAUCH, H.G. Statistical analysis of regiononal yield trials: AMMI analysis of factorial designs. New York: Elsevier Science, 1992. 278p.

GAUCH, H.G.; ZOBEL, R.W. AMMI analysis of yield trails. In: KANG, M.S.; GAUCH, H.G. (Ed.).Genotype by environment interaction. New York: CRC Press, 1996. p.416-428.

GAUCH, H.G.; ZOBEL, R.W. Identifying mega-environments and targeting genotypes. Crop Science, v.37, n.2, p.311-326, 1997.

GOLLOB, H.F. A statistical model which combines features of factor analytic and analysis of variance techniques. Psychometrika, v.33, n.1, p.73-115, 1968. 
GONÇALVES, J.L.M. Interação genótipo - ambiente e relação entre produtividade de sítios florestais de Eucalyptus grandis e Eucalyptus saligna com as propriedades de alguns solos de textura arenosa e média no Estado de São Paulo. Piracicaba, 1990. 135p. Tese (Doutorado) - Escola Superior de Agricultura "Luiz de Queiroz", Universidade de São Paulo.

HANSON, W.D. Distance statistics and interpretation of Southern states regional soybean tests. Crop Science, v.34, n.6, p.1498-1504, 1994.

HARDWICK, R.C. The analysis of genotype-environment interactions: What does it means if varietal stability is linearly related to varietal preformance? Euphytica, v.30, n.1, p.217-221, 1981.

HEINRICH, G.M.; FRANCIS, C.A.; EASTIN, J.D. Stability of grain sorghum yield components across diverse environments. Crop Science, v.23, n.2, p.209-212, 1983.

HERNANDES, C.M.; CROSSA, J.; CASTILlO, A. The area under the function: an index for selecting desirable genotypes. Theoretical and Applied Genetics, v.87, n.4, p.409-15, 1993.

HIGA, A.R.; RESENDE, M.D.V. de; KODAMA, A.S.; LAVORANTI, O.J. Programa de melhoramento de eucalipto na Embrapa. In: IUFRO CONFERENCE ON SULVICULTURE AND IMPROVEMENT OF EUCALYPTUS, Salvador, 1997. Proceedings. Colombo: EMBRAPA, Centro Nacional de Pesquisa de Florestas, 1997. v.1, p.377-385.

HILL, M.O. Correspondence analysis: a neglected multivariate method. Apllied Statistics, v.23, n.2, p.340-354, 1974.

HINSON, K.; HANSON, W.D. Competition studies in soybeans. Crop Science, v.2, n.2, p.117-23, 1962. 
HO, C.K.; CHANG, S.H.; TSAY, J.Y.; CHIANG, V.L.; CHEN, Z.Z. Agrobacterium tumefaciens mediated transformation of Eucalyptus camaldulensis and production of transgenic plants. Plants Cell Reports, v.17, n.9, p.675-680, 1998.

HUEHN, M. Nonparametric measures of phenotypic statbilit. Part 1: Theory. Euphytica, v.47, n.3, p.189-194, 1990.

HUEHN, M. Nonparametric analysis of genotype $\mathrm{x}$ environment interactions by ranks. In: KANG, M.S.; GAUCH, H.G. Genotype-by-environment interaction. Boca Raton: CRC Press, 1996. cap.9, p.235-270.

IKEMORI, Y.K. Genetic variation in characteristics of Eucalyptus grandis raised from micro-propagation and seed. Oxford, 1990. 123p. Thesis(Ph.D) - Green College, University of Oxford.

JOHNSON, R.A.; WICHERN, D.W. Applied multivariate statistical analysis. Madison: Prentice Hall International, 1998, 816p.

KANG, M.S., MILLER, J.D. genotype-environment interactions for cane and sugar yield and their implications in sugarcane breeding. Crop Science, v.24, n.3, p.435-40, 1984 .

KEMPTHORNE, O. An introduction to genetic statistics. New York: John Wiley, 1957. 545p.

KRUG, C.A.; ALVES, A.S. Eucalyptus improvement. Journal of Hereditary, v.40, n.5/6, p.133-139, p.143-149, 1949.

LAVORANTI, O.J.; DIAS, C.T.S.; VENCOVSKY, R. Estudo comparativo: AMMI $\times$ EBERHART E RUSSELL. In: REUNIÃO ANUAL DA REGIÃO BRASILEIRA DA SOCIEDADE INTERNACIONAL DE BIOMETRIA, 46.; SIMPÓSIO DE ESTATÍSTICA APLICADA A EXPERIMENTAÇÃO AGRONÔMiCA, 9., Piracicaba, 2001. Anais. Piracicaba: ESALQ, 2001a. p.114-117. 
LAVORANTI, O.J.; DIAS, C.T.S.; VENCOVSKY, R. Estudo da adaptabilidade e estabilidade genética de progênies de Eucalyptus grandis, através da metodologia AMMI. In: REUNIÃO ANUAL DA REGIÃO BRASILEIRA DA SOCIEDADE INTERNACIONAL DE BIOMETRIA, 46.; SIMPÓSIO DE ESTATÍSTICA APLICADA A EXPERIMENTAÇÃO AGRONÔMICA, 9., Piracicaba, 2001. Anais. Piracicaba: ESALQ, 2001b. p.118-121.

LAVORANTI, O.J.; DIAS, C.T.S.; VENCOVSKY, R. Estudo da estabilidade e adaptabilidade fenotípica de progênies de Eucalyptus grandis, via metodologia AMMI. Boletin de Pesquisa Florestal, v.44, n.1, p.107-124,jan./jun. 2002.

LEWIS, D. Gene-environment interaction. A relationship between dominance heterosis phenotype stability and variability. Heredity, v.8, n.3, p.333-356, 1954.

LIANG, G.H.L., HEYNE, E.G., WALTER, T.L. Estimates of variety x environment interactions in yield tests of three small grains and their significance on the breeding programs. Crop Science, v.6, n.2, p.135-39, 1966.

LIN, C.S. Grouping genptypes by cluster method directly related to genotypeenvironment interaction mean square. Theoretical and Applied Genetics, v.62, p.277-280, 1982.

LIN, C.S.; BINNS, M.R. A method of analysing cultivar x location x years experiments: a new stability parameter. Theoretical and Applied Genetics, v.76, n.3, p.425-430, 1988.

LIN, C.S.; BINNS, M.R.; LEFKOVICTH, L.P. Stability analysis: Where do we stand? Crop Science, v.26, n.5, p.894-900, 1986.

LIN, F.H., WU, Y.L. Analysis of the adaptability of strains of hybrid progenies of indica rice under diverse cultural environment. Journal of Agricultural Associates of China, v.86, n.1, p.9-18, 1974. 
LOEFGREN, A. Notas sobre plantas exóticas introduzidas no Estado de São Paulo. São Paulo: Revista Agrícola, 1906. 220p.

LÓPEZ, C.R.; FORNÉS, L.F. Estabilidade genética em progênies de Eucalyptus grandis (Hill) ex Maiden. In: IUFRO CONFERENCE ON SULVICULTURE AND IMPROVEMENT OF EUCALYPTUS, Salvador, 1997. Proceedings. Colombo: EMBRAPA, Centro Nacional de Pesquisa de Florestas, 1997. v.1, p.163-168.

MAGARI, R.; KANG, M.S. SAS STABLE: stability analysis of balanced and unbalanced data. Agronomy Journal, v.89, n.5, p.929-932, 1997.

MANDEL, J. Non-additivity in two-way analysis of variance. Journal of the American Statistical Association, v.56, p.878-888, 1961.

MANDEL, J. A new analysis of variance model for non-additive data. Technometrics, v.13, n.l, p.1-18, 1971.

MARIOTTI, J.A.; OYARZABAL, E.S.; OSA, J.M.; BULACIO, A.N.R.; ALMADA, G.H. Analisis de estabilidade y adaptabilidade de genótipos de cana de azúcar. Interacciones dentro de um localidad experimental. Revista Agronômica Argentina, v.13, p.105-127, 1976.

MAURO, A .O. Adaptabilidade, estabilidade e ganho genético com o processo seletivo em soja (Glycine max L.) em Ponta Porã, Mato Grosso do Sul. Viçosa, 1991. 192p. Tese (Doutorado)- Universidade Federal de Viçosa.

MATHERSON, A.C.; RAYMOND, C.A. a review of provenance x evironment interaction: its pratical importance and use with particular reference to the tropics. The Commonwealth Review, v.65, n.4, p.283-302, 1986.

MONELLI, V.L. Distância de cultivares em relação ao melhor genótipo na análise de grupos de experimentos. Piracicaba, 1996. 178p. Dissertação (Mestrado) Escola Superior de Agricultura "Luiz de Queiroz", Universidade de São Paulo. 
MORAES, M.L.T. Variação genética da densidade básica da madeira em progênies de Eucalyptus grandis Hill ex. Maiden e suas relações com as características de crescimento. Piracicaba, 1987. 129p. Dissertação (Mestrado)- Escola Superior de Agricultura "Luiz de Queiroz", Universidade de São Paulo.

MORI, E.S.; LELLO, L.R.B.; KAGEYAMA, P.Y. Efeito da interação genótipo $\times$ ambiente em progênies de Eucalyptus saligna Smith. IPEF, n.33, p.19-25, 1986.

MUNGOMERY, V.E., SHORTER, R., BYTH, D.E. Genotype x environment adaptation. I pattern analysis - application to soya bean population. Australian Journal of Agricultural Research, v.25, n.1, p.59-72, 1974.

OLIVEIRA, A.B.; DUARTE, J.B.; PINHEIRO, J.B. Emprego da análise AMMI na avaliação da estabilidade produtiva em soja. Pesquisa Agropecuária Brasileira, v.26, n.1, p.357-364, mar. 2003.

ORTIZ, R.; MADSEN, S.; WAGOIRE, W.W.; HILL, J.; CHANDRA, S.; STOLEN, O. Additive main effect and multiplicative interaction model for a diallel-cross analysis. Theoretical and Applied Genetics, v.102, n.6-7, p.1103-1106, 2001.

OWINO, F. Genotype x environment interaction and genotypic stability in Iobolly pine. Silvae Genetica, v.26, n.1, p.21-26, 1977.

PLAISTED, R.L., PETERSON, L.C. A technique for evaluating the ability ot selection the yield consistently in different locations or seasons. American Potato Journal, v.36, n.6, p.381-5, 1959.

PEREGO, A.E.G.; GARLIPP, R.C.D. A evolução da pesquisa florestal na Cia. Suzano de Papel e Celulose. In: SIMPÓSIO: AS PERSPECTIVAS DA PESQUISA FLORESTAL NO BRASIL, Piracicaba, 1983. Anais. Piracicaba: IPEF, 1983. p.60-65. 
PERKINS, J.M.; JINKS, J.L. Environmental and genotype-environmental components of variability. III. Multiple lines and crosses. Heredity, v.23, n.3, p.339-356, 1968.

PIEPHO, H.P. Best linear unbiased prediction (BLUP) for regional yield trials: a comparison to additive main effects and multiplicative interaction (AMMI) analysis. Theoretical Applied of Genetics, v.89, p.647-654, 1994.

PIEPHO, H.P. Robustness of statistical test for multiplicative terms in the additive main effects and multiplicative interaction model for cultivar trial. Theoretical Applied of Genetics, V.90, p.438-443, 1995.

PIMENTEL GOMES, F. Curso de estatística experimental. 13.ed. Piracicaba: Nobel, 1990. 467p.

QUENOUILLE, M.H. The joint distribuition of serial correlation coefficients. Annual Mathematics and Statistics, v.1. n.20, p.561-571, 1949.

QUENOUILLE, M.H. Notes on bias in estimation. Biometrika, v.1. n.43, p.353360, 1956.

RAO, C.R. Linear statistical inference and its applications. New York: Wiley, 1965. 468p.

RAMALHO, M.A.P.; SANTOS, J.B.; ZIMMERMANN, M.J.O. Genética quantitativa em plantas autógamas: aplicações ao melhoramento do feijoeiro. Goiânia: UFG, 1993. 271p.

ROBERTSON, A. Experimental design on the mesurement of herdabilities and genetic correlations. Biometrical genetics. New York: Pergamon, 1959. $186 \mathrm{p}$.

ROCHA, M.M. Seleção de linhagens experimentais de soja para adaptabilidade e estabilidade fenotípica. Piracicaba, 2002. 173p. Tese (Doutorado) - Escola Superior de Agricultura "Luiz de Queiroz", Universidade de São Paulo. 
ROCHA, M.M.; VELLO, N.A. Interação genótipos e locais para rendimento de grãos de linhagens de soja com diferentes ciclos de maturação. Bragantia, v.58, n.1, p.69-81, 1999.

ROMAGOSA, I.; FOX, P.N. Genotype x environment interaction and adaptation. In: HAYWARD, M.D.; BOSEMARK, N.O.; ROMAGOSA, I. Plant breeding: principles and prospects. Londom: Chapman \& Hall, 1993. cap. 20, p.375-390.

ROSSE, L.N. Modelo de regressão não-linear aplicado na avaliação da estabilidade fenotípica em plantas. Piracicaba, 1999. 179p. Tese (Doutorado) - Escola Superior de Agricultura "Luiz de Queiroz", Universidade de São Paulo.

ROSSE, L.N.; VENCOVSKY, R. Modelo de regressão não-linear aplicado ao estudo da estabilidade fenotípica de genótipos de feijão no Estado do Paraná. Bragantia, v.59, n.1, p.99-107, 2000.

SHAFII, B.;PRICE, W.J. Analysis of genotype-by-environment interaction using the additive main effects and multiplicative interaction model and stability estimates. Jornal of Agricultural, Biological, and Environmental Statistics, v.3, n.3, p335-345, 1998.

SHUKLA, G.K. Some statistical aspects of partitioning genotype-environmental components of variability. Heredity, v.29, n.2, p.237-245, 1972.

SILVA, J.G.C. Análise da adaptabdidade por regressão segmentada com estimação da junção dos segmentos. Pesquisa Agropecuária Brasileira, v.33, n.7, p.1013-1029, 1998.

SILVA, J.G.; BARRETO, J.N. Aplicação da regressão linear segmentada em estudos da interação genótipo x ambiente. In: SIMPÓSIO DE ESTATÍSTICA APliCADA A EXPERIMENTAÇÃO AGRONÔMICA, 1., Campinas, 1985. Resumos. Campinas: Fundação Cargill, 1985. p.49-50. 
SILVA, J.G.C.; BARRETO, J.N. An application of segmented linear regression to the study of genotypes environment interaction. Biometrics, v.41, n.4, p.1093, 1986.

SNEE, R.D. Nonadditivity in a two classification: Is it interaction or nonhomogeneous variance? Jornal of the Americam Statistical Association, v.77, n.379, p.515-519, 1982.

SOARES, P.C. Correlações, coeficientes de trilha e resposta indireta à seleção em genótipos de arroz (Oryza sativa L.) cultivados em condições de irrigação por inundação contínua e em várzea úmida. Viçosa, 1987, 72p. Dissertação (Mestrado)- Universidade Federal de Viçosa.

SOCIEDADE BRASILEIRA DE SILVICULTURA. Eucalipto no Brasil e no mundo. htt//www.floresta.ipef.br. (20 jan. 2002).

STELL, R.G.D.; TORRIE, J.H. Principles and procedures of statistics, a biometrical approach. New York: MacGraw-Hill, 1980. 633p.

STORK, L. Modelo de regressão bi-segmentado descontínuo com erros de medida aplicado na análise de estabilidade de cultivares. Piracicaba, 1989. 217p. Tese (Doutorado) - Escola Superior de Agricultura "Luiz de Queiroz", Universidade de São Paulo.

STORCK, L.; VENCOVSKY, R. Stability analysis on a bi-segmented discontinuous model with measurement errors in the variables. Revista Brasileira de Genética, v.17, n.1, p.75-81, 1994.

TAI, G.C.C. Genotypic stability analysis and its application to potato regional trials. Crop Science., v.11, n.2, p,184-90, 1971.

THALLAINATHAN, M.; FERNANDEZ, G.C.J. SAS applications for Tai's stability analysis and AMMI model in genotype $\times$ environmental interaction (GEI) effects. Journal of Heredity, v.92, n.4, p.367-377, 2001. 
TOLEDO, J.F.F.; ARIAS, C.A.A.; OLIVEIRA, M.F.; TRILlER, C.; MIRANDA, Z.F.S. Genetical and environment analyses of yield in six biparental soybean cosses. Pesquisa Agropecuária Brasileira, v.35, n.9, p.1783-1796, 2000.

TOLER, J.E. Patterns of genotypic performance over enviromental arrays. Clemson, 1990. 154p. Thesis(Ph.D) - Clemson University.

TOLER, J.E.; BURROWS, P.M. Genotypic performance over environmental arrays: a non-linear grouping protocol. Jornal of Applied Statistics, v.25, n.1, p.131-143, 1998.

TUKEY, J.W. One degree of freedom for non-adsitivity. Biometrics, v.5, p.232$242,1949$.

TUKEY, J.W. Bias and confidence in not quite large sample, abstract. Annals of Mathematics and Statistics, v.1, n.29, p.614-623, 1958.

VARGAS, M.; CROSSA, J.; VAN EEUWIJK, F.; SAYRE, K.D.; REYNOLDS, M.P. Interpreting treatment $\mathrm{x}$ environment in agronomy trials. Agronomy Journal, v.93, n.4, p.949-960, 2001.

VENCOVSKY, R. Melhoramento genético em vegetais. Ciência e Cultura, v.38, p.1155-1160, 1986.

VENCOVSKY, R.; BARRIGA, P. Genética biomética no fitomelhoramento. Ribeirão Preto: Revista Brasileira de Genética, 1992. 496p.

VENCOVSKY, R.; TORRES, R.A.A. Estabilidade geográfica e temporal de algumas cultivares de milho. In: CONGRESSO NACIONAL DE MILHO E SORGO, 16., Belo Horizonte, 1988. Anais. Belo Horizonte: EMBRAPA, CNPMS, 1988. p.294-300.

VENCOVSKY, R.; CRUZ, CD.; SILVA, A.C. Uma avaliação do potencial de diferentes locais para a discriminação genotípica entre cultivares de milho. Revista Brasileira de Genética, v.13, n.2. p.323-34, 1990. 
VERMA, M.M.; CHAHAL, G.S.; MURTY, B.R. Limitations of conventional regression on analysis a proposed modification. Theoretical and Applied Genetics, V.53, p.89-91, 1978.

WESTCOTT, B. A method of assessing the yield stability of crop genotypes. Journal of Agricultural Sciences, v.108, n.2, p.267-274, 1987.

WRICKE, G. Uber eine nethode zur erfassung der Okologischen streubreite in feldversuchen. Zeitschrift fur Pflanzenzüchtung, v.47, n.l, p.92-96, 1962.

WRICKE, G.; WEBER, E.W. Quantitative genetics and selection in plant breeding. Berlin: Walter de Druyter, 1986. 406p.

YAN, W.; CORNELIUS, P.L.; CROSSA, J.; HUNT, L.A. Two types of GGE biplots for analyzing multi-environment trial data. Crop Science, v.41, n.3, p.656663, 2001.

YATES, F. A Monte-Carlo trial on the behaviour of the non-additivity test with non-normal data. Biometrics, v.59, p.253-262, 1972.

YATES, F.; COCHRAN, W.G. The analysis of groups of experiments. The Journal of Agricultural Science, v.28, n.4, p.556-580, 1938.

YUE, G.L.; ROOZEBOOM, K.L.; SCHAPAUGH Jr.,W.T.; LIANG, G.H. Evaluation of soybean cultivars using parametric and nonparamétric stability estimates. Plant Breeding,v.116, n.3, p.271-275, 1997.

ZOBEL, R.W.; WRIGHT, M.J.; GAUCH, H.G. Statistical analysis of a yield trial. Agronomy Jornal, v.80, p.388-393, 1988. 